\title{
A STUDY OF TECHNOLOGICAL INNOVATION IN NEW ZEALAND
}

\author{
by \\ Peter Harry Winsley
}

A thesis

submitted to the Victoria University of Wellington in fulfilment of the requirements for the $\mathrm{PhD}$ in Management

Victoria University of Wellington 


\title{
A STUDY OF TECHNOLOGICAL INNOVATION IN NEW ZEALAND
}

\begin{abstract}
This thesis addresses the research problem of "what are the key underpinning assets or drivers of technological innovation, and how can they be harnessed to create competitive advantage?"
\end{abstract}

Technological change is an evolutionary process. Research and technological innovation creates knowledge and technology that is irreversible in the sense that inventions can be superseded but not "uninvented". Technological innovation creates knowledge and technology that is cumulative because it lays a platform for further knowledge creation, or sets in place another rung in an ascending ladder of new performance characteristics or properties which are demonstrably superior to their antecedents. In turn, the asset specificity and irreversibility of technology and its cumulativeness create barriers to competitive entry. This allows a firm to earn the premiums that create market power and allow further innovation to be financed.

The model of technological innovation advanced in this thesis has at its core the strategic governance framework of a firm, within which the dynamics of significant new technology, human capital and social processes are catalysed and made productive by differentiated technological learning processes. No one type of technological learning applies universally, but rather learning is differentiated by variables such as firm size and structure, the past experience and core competencies of the firm, its human capital stocks, social processes, interactions with the external environment, and a host of market, institutional and technological factors.

It is argued that the dynamics of significant new technology, human capital and social processes are fundamental and necessary conditions of technological innovation. Technological learning processes underly and provide a connecting thread that 
integrates these necessary conditions into a model of technological innovation that can be applied by managers to create and sustain competitive advantage.

Technological learning both shapes and is shaped by the human capital stocks and social processes of a firm. Learning processes give rise to significant new technology, and the dynamics of that technology in turn helps catalyse and gives rise to further learning. The rate and direction of learning and of technological innovation is also driven by the firm's interaction with external sources of ideas and technology.

To create competitive advantage through technological innovation business managers must address a firm's strategy, human capital-related assets, social processes and technological learning abilities. Policy managers must ensure that the public technostructure is in place to foster human capital creation within an economy and to facilitate access to new ideas and sources of stimulus. 


\section{STATEMENT OF ORIGINAL AUTHORSHIP}

This thesis is the sole and original work of the author, with the exception of the sectoral classification of data in Table A1 of Annex 1 .

\section{ACKNOWLEDGMENTS}

The author very gratefully acknowledges the supervision, and above all the wisdom, insights and personal encouragement of Dr Paul Couchman, Wollongong University, and Dr Dai Gilbertson, Victoria University. He also acknowledges the assistance of Prue Hyman at Victoria University in navigating through the $\mathrm{PhD}$ enrolment process. 


\section{TABLE OF CONTENTS}

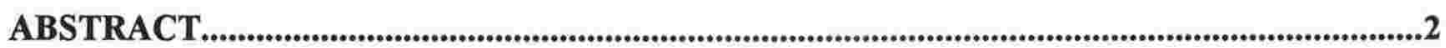

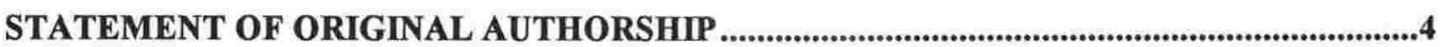

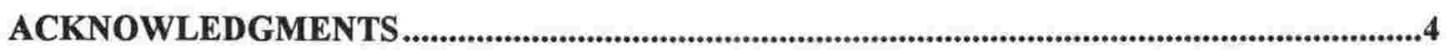

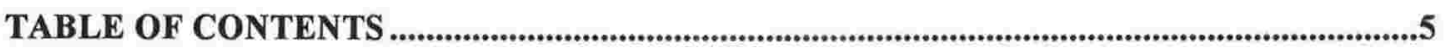

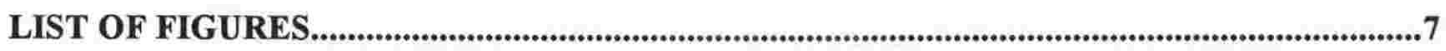

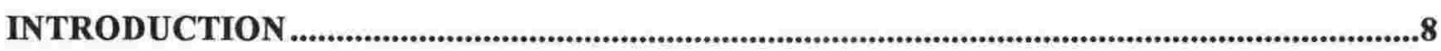

TECHNOLOGICAL INNOVATION: AN OVERVIEW OF THE LITERATURE....................18

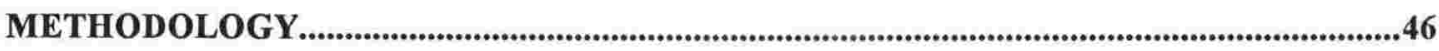

CASE STUDIES OF TECHNOLOGICAL INNOVATION IN NEW ZEALAND: 1981-1993...65

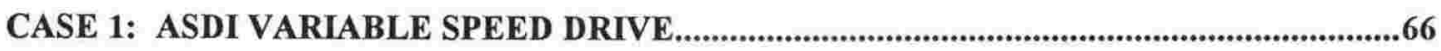

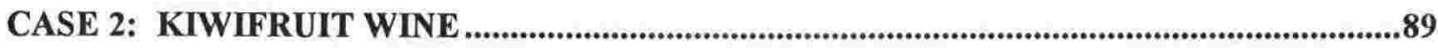

CASE 3: RUAKURA MILK HARVESTER ........................................................................107

CASE 4: FP4000 INTELLIGENT FIRE ALARM INNOVATION.........................................138

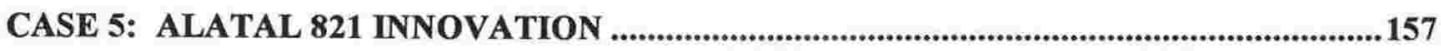

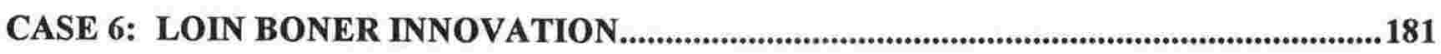

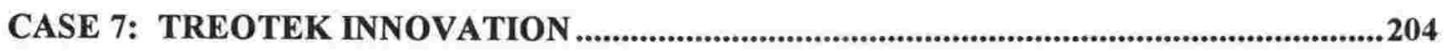

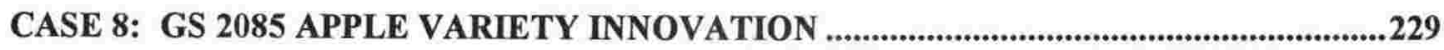

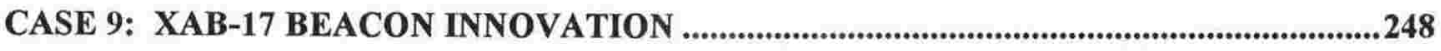

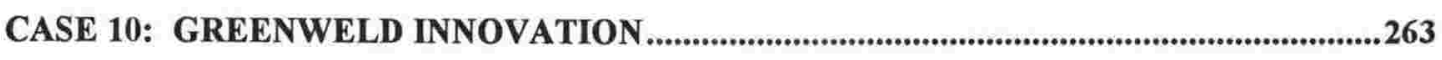

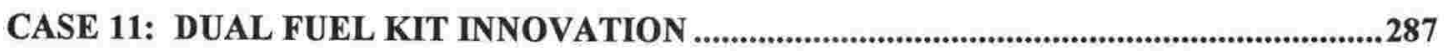

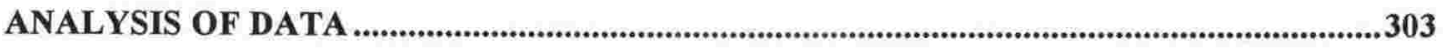

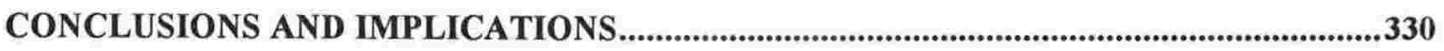

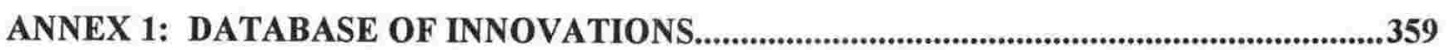

ANNEX 1.1: LITERATURE AND SOURCES TO IDENTIFY POPULATION OF

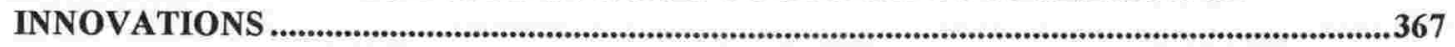

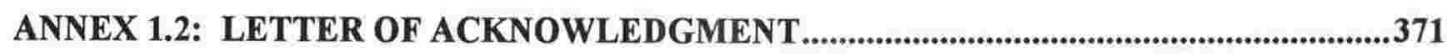

ANNEX 2: SAMPLES OF DOCUMENTS RELATING TO CASE RESEARCH.....................372 
ANNEX 2.1: FORMAT FOR CASE STUDY INTERVIEWS ..................................................373

ANNEX 2.2: CONFIDENTIALITY AGREEMENT.................................................................374

ANNEX 2.3: LIST OF PEOPLE INTERVIEWED IN CASE STUDIES ...................................375

ANNEX 3: OPEN CODED VARIABLES BY BROAD AREA AND AXIAL CATEGORY...378 ANNEX 3.1: AN EXAMPLE OF THE INFORMATION RECORDED ON AN OPEN CODED CARD

ANNEX 3.2: AN EXAMPLE OF THE INFORMATION RECORDED ON AN AXIAL

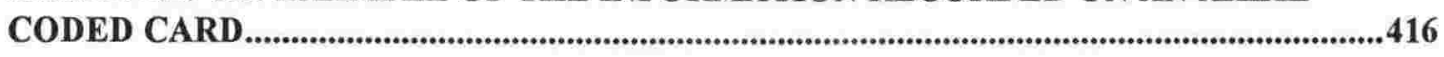

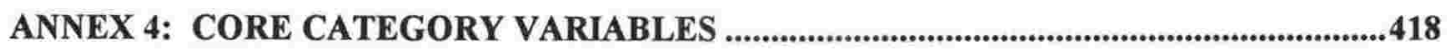

ANNEX 4.1: AN EXAMPLE OF THE INFORMATION RECORDED ON A CORE

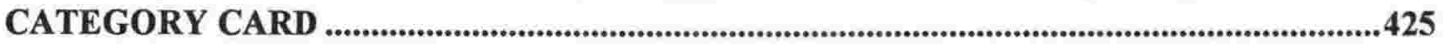

ANNEX 5: VARIABLES RELATING TO TECHNOLOGICAL LEARNING........................427

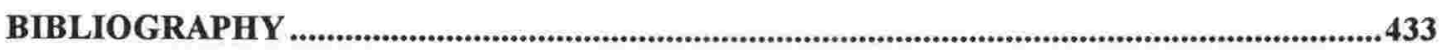




\section{LIST OF FIGURES}

Page

Figure 1: Relationship between Core Categories and

Differentiated Technological Learning

335

Figure 2: A Model of Technological Innovation 


\section{INTRODUCTION}

It is increasingly accepted that technological innovation is at the heart of the competitive performance of both the business enterprise and the national economy. In his ten-nation study Michael Porter found that firms gain and sustain competitive advantage in international competition through improvement, innovation and upgrading (Porter, 1990). A major study of New Zealand's industry competitiveness concluded that:

Innovation, in the broadest sense of the term, has become vital to success in international competition...the essential character and source of competitive advantage is innovation and change.

(Crocombe et al, 1991, p. 27)

However, very little is known in New Zealand about how technological innovation can be used by managers to create competitive advantage, and about how learning processes underpin and catalyse technological innovation. This thesis therefore seeks to increase understanding of the technological innovation process, to assist managers, and to help them make technological innovation a core part of business strategy.

The thesis focuses on technological innovation in New Zealand over the period 19811993. Technological innovation is seen as a dynamic process undertaken within the strategic governance framework of a firm. It is argued that human capital, the dynamics of significant new technology, and social processes are fundamental and necessary conditions of technological innovation. Technological learning processes underly and provide a connecting thread that integrates these necessary conditions into a model of technological innovation that can be applied by managers to create competitive advantage.

Technological innovation is catalysed by learning processes through which firms search for, select or create the intangible assets of human capital and knowledge and 
apply them to economic opportunities. No one type of technological learning applies universally, but rather it is differentiated by variables such as firm size and structure, the past experience and core competencies of the firm, its human capital stocks and social processes, its interactions with the external environment, and a host of market, institutional and technological factors.

Technological learning both shapes and is shaped by the human capital stocks and social and organisational processes of a firm. Learning processes give rise to significant new technology, and the dynamics of that technology in turn help catalyse and give rise to further learning.

\section{Background and Justification for Research}

Technological change and innovation is at the heart of economic growth (see Romer, $1986 ; 1990)$ and can also be a key strategy that allows managers to create a long-term and sustainable competitive advantage. However, Johnston (1991) and Frater et al (1995) highlight the lack of understanding and commitment by New Zealand managers to the role of technology strategy and technological innovation to their business enterprises. A great deal of the research that has been undertaken on technological innovation internationally is of little relevance or is difficult to apply to New Zealand firms. Research to date has generally focused on larger economies, and technological innovation has not been extensively studied in New Zealand, or indeed in many other smaller economies.

Very small economies such as New Zealand's are not "little big countries", but have economic and market structures different in key respects to larger economies. While New Zealand is now an independent and open economy, its industry structure, technological level and patterns of innovative activity reflect its history as a semiperipheral "Dominion capitalist" (see Ehrensaft \& Armstrong, 1978), which later evolved into a highly protectionist economy (see Crocombe et al, 1991). From the 19th century New Zealand developed as a supplier of agricultural commodities to 
Britain. Up to 1940 Britain bought around $80 \%$ of New Zealand's exports, over $50 \%$ to the 1960 s, and as much as a third by the early 1970s (Frater et al, 1995). Only from 1980 did other countries overtake Britain as the top export market.

New Zealand had a highly regulated and protectionist economy until the economic reforms of the 1980s (see Frater et al, 1995). Many firms had been established under a regime of import substitution, and lacked the scale economies and markets to compete internationally. Much of the manufacturing industry that has developed in New Zealand focuses on the processing of meat, wool, dairy and forestry products rather than on competing directly in the export market. Most industry sectors are dominated by small firms. In the non-farm enterprise sector, $92 \%$ of firms employ fewer than 10 staff. Enterprises employing fewer than 50 staff account for about twothirds of total non-farm employment. In New Zealand as a whole, only 340 enterprises employ more than 100 people. In the manufacturing sector, enterprises employing fewer than 50 people account for $96 \%$ of enterprises and $42 \%$ of employment (Frater et al, 1995).

\section{New Zealand Studies of Technological Innovation}

New Zealand studies relating to technological innovation and technical change include technology or sector-specific studies, studies of the business or industry environment, of firm management and behaviour, of social aspects of innovation, and studies of the technological innovation process itself. Most of these studies do not adequately accommodate the role of intangible assets such as knowledge or human capital, or conceive of innovation as a dynamic learning process.

Research aimed at elucidating the contribution of technology to industry performance has tended to focus at the level of an industry sector or technology, eg. Cullwick \& Thirkell (1977), the New Zealand Communications Advisory Council (1985), Bowie \& Bollard (1987), Dordick (1987), and Slade (1994). None of these studies looked at the social, organisational, motivational and dynamic aspects of the technological innovation process itself. 
The most influential recent study of the broader industry environment in New Zealand was Upgrading New Zealand's Competitive Advantage (Crocombe et al, 1991) which applied Michael Porter's analytical framework (Porter, 1990) to the New Zealand economy and its competitive performance. This study emphasised the importance to firms of innovation, and of investment in human resource development, but it did not look at the more dynamic aspects of human capital creation and technological learning. Nor did it address organisational and social aspects of innovation.

The Ministry of Research, Science and Technology (MoRST) has supported research on firm management and behaviour and the innovation environment in New Zealand, for example the Technology Strategy in New Zealand Industry study (Johnston, 1991) and a joint study with BERL on the New Zealand Innovation Environment (Frater et al, 1995). Johnston (1991), inter alia, concluded that New Zealand R\&D-spending firms had a limited understanding of the role of technology and learning strategies in their businesses, and suggested that public research institutes were poorly rated by firms as sources of new technology. The study did not however analyse the origins of innovation, the social and organisational processes involved, or the dynamic and learning aspects of technological innovation.

The "BERL Report" (Frater et al, 1995) has been the major study of New Zealand's innovation environment. It sought to identify the important sources of information and ideas for new innovations over a wide spectrum of industry. It rated sources such as senior managers, customers, marketing and internal R\&D personnel highly, and external research institutes and consultants at the bottom as sources of new ideas. However, the Report did not look at the dynamic, interactive and differentiated nature of technological learning. The BERL Report's major limitations included its emphasis on the environment for innovation rather than the technological innovation process itself. It did not address the origins, nature and dynamics of significant new technology. It placed little emphasis on the social and institutional side of innovation, 
and it lacked a rigorous framework through which the data could be analysed and the insights and conclusions generalised.

Although technological innovation is a social process, few New Zealand studies have focused primarily on the social, organisational and managerial aspects of innovation. Some studies have looked at the interaction between government and social change (Couchman, 1984; 1989), while Couchman et al (1988) looked at the implications of technological change on social policy. The work of Inkson \& Cammock (1984) and some of Couchman's work has been informed by such work as Braverman (1974), and a plethora of associated research that addresses the relationships between technical change and social control.

Hill \& Gidlow (1988), in their study of technical change in the printing industry, addressed social choices and processes of negotiation, conflict and compromise that influence the pace and pervasiveness of technical change, and elucidated how people's perceptions of technical change influence their social, political and economic strategies. While Hill \& Gidlow confine themselves to the adoption of existing technology in one sector rather than looking at technological innovation per se, the importance of the interaction of individuals with their institutional environment is an important theme in this and other social sciences research undertaken in the DSIR.

Most New Zealand studies of the technological innovation process itself have been "grey" or "popular" literature, in-house reports, or masterate-level academic projects (eg. Hamilton, 1991). Such studies tend to be based on overseas theoretical frameworks and methodologies which are then adapted and applied to or tested in the New Zealand scene. They are often based on limited survey data, designed as inhouse discussion papers to build awareness on issues related to technological innovation (see for example Stuart, 1980; Stuart \& McCulloch, 1980), or are popular summaries of interesting local inventions or innovations (see Harman, 1978; Riley, 1995). 
Winsley (1991) analysed the process of technological innovation, drawing on evolutionary perspectives on technical change and addressing social and management processes associated with technological innovation. Gilbertson \& Knight (1992) and Gilbertson \& Gilbertson (1995) published a series of case studies in innovation and management. Key strengths of these studies included the elucidation of the "people side" of the innovation process. The cases were mainly based on firms or entrepreneurs rather than technological innovations. However, the cases included technology-based firms such as Trigon, Cadac Holdings, Gough Technology, Interlock and Power Beat international.

However, these cases did not all draw on the multiple sources of data and levels of analysis needed to provide the rich insight into technological innovation that is achievable in a more focused study. Nor did the cases explore innovation as a learning process. The cases used a very wide definition of innovation, emphasising that innovation does not have to involve technology, and that many innovation skills or variables are generic and as applicable to starting a fashion business as they are to the management of complex technological innovations. However, as is shown in this thesis, there are aspects of technological innovation that involve quite specific management challenges, and which have never been closely examined in New Zealand. These include the nature and dynamics of significant new technology, technological learning, and the role of human capital.

This thesis focuses on innovations that have been commercialised and uses them as "windows" or entry points through which the technological innovation process can be understood in its wider complexity. Other New Zealand studies have tended to look more narrowly at technological inventions. Bray \& Perry (1994) briefly summarised 104 recent DSIR inventions, looking in depth at 20 of them. As with Leary (1992), the Bray \& Perry study was imbued with a linear view of scientific research leading in a serial way to invention and innovation. Its major limitations included its dependence on superficial interviews, rather than exploiting multiple sources of information and levels of analysis. It lacked a conceptual or theoretical framework to give focus to the research and an adequate framework for analysis of the data. 
The above studies come from different perspectives and address different issues, and generally do not explore the process of technological innovation per se. We are therefore left with some major "knowledge gaps" in our understanding of technological innovation in New Zealand. These gaps include the nature and dynamics of significant new technology, the sources of key ideas and stimulus and the external influences impacting on technological innovation, human and social aspects of innovation, human capital creation and learning processes.

\section{Research Problem and Thesis Proposition}

This thesis addresses the research problem of "what are the key underpinning assets or drivers of technological innovation, and how are they harnessed to create competitive advantage?" The central proposition underlying this thesis is that technological innovation is a learning process whereby firms search for, create or acquire the intangible assets of knowledge and human capital, and make them economically productive.

It is argued that learning is shaped by knowledge and competencies in a firm that are built up cumulatively over time. Learning occurs at many levels, and a firm's external interactions and search and selection processes are a key element in its learning strategy. These external interactions include networking and interactions with customers, suppliers, users, and with other sources of new ideas and technology. Learning requires people to interact together in trusting social relationships, both internally within a firm and externally. These social relationships are important in enhancing learning and the absorption of new ideas and technologies.

The thesis proposition is that differentiated technological learning and social processes catalyse and make productive human capital-related assets within the strategic governance framework of a firm. The dynamics associated with significant new technological innovations can then be managed to create a sustainable competitive 
advantage, with the dynamics of technical change over time providing further sources of technological learning for the firm.

\section{Methodology}

This thesis is case study-based qualitative research that uses inductive, grounded research techniques to gather and analyse data. It is explicitly interdisciplinary research. The methodology involves participants in technological innovation in the process of creating the data for the research, data that is then analysed. The aim is to create theory from data, and to develop more focused research questions which are then examined in detail, rather than to begin with a very specific hypothesis which is then tested against data.

Essentially, the research began with the scoping of the field and a literature review, together with the preparation of a database of every identifiable technological innovation within New Zealand over the period 1981-1993. Written material such as trade and technical literature was the major source of this database. The database, together with the criteria used in its preparation and other relevant material, is summarised in Annex 1.

Eleven innovations were then selected for case study, with details of the selection criteria and of the case research procedures being set out in the Methodology chapter. Five broad areas of research enquiry were used to give focus to the case research. The primary data generated by the case study research, together with secondary data arising from such sources as the literature review, was then analysed through open, axial and selective coding, to derive core categories of related variables that appeared to lie at the heart of an understanding of technological innovation in New Zealand's small, open economy. The core categories were the Dynamics of Significant New Technology, Human Capital, and Social Processes. 
Further data analysis then led to the key proposition emerging of technological innovation as being underpinned by technological learning processes that catalyse the other core categories of variables. This key proposition began to appear in embryonic form early in the case study data collection process, but only began to crystallise during the data coding process, essentially from axial coding stage on.

The proposition of technological innovation catalysed by learning processes was then further tested by reference to the literature, to the case study results, and through further analysis at more selective and advanced coding stages that elucidated the relationships, causations and dependencies between the core categories of variables. Progressively, learning processes emerged as the unifying thread across all core categories of variables. The literature review was then revisited, to help test the key proposition in the thesis against the theoretical work and empirical evidence of others. This helped verify that the picture generated by the case study and grounded research procedures approximated to reality.

The core categories generated through axial and selective coding and the differentiated learning thesis were then integrated into a unified model of technological innovation. This hinged around innovation as a differentiated learning process that catalysed other core variables, with the links between learning and other variables and categories of variables being elucidated. The results of this methodology and set of procedures was then given expression to in the conclusions.

A detailed outline of the methodology is set out in the Methodology chapter.

\section{Outline of the Thesis}

The "Technological Innovation: An Overview of the Literature" chapter provides an overview of the theoretical and empirical literature on technological innovation that relates to the research problem and thesis proposition. The Methodology chapter explains and justifies the methodology to be used, sets out the units of analysis and the 
sources of data, the methods of data collection, and the detailed data analysis procedures that were used in the research.

The Case Study chapter encompasses the eleven completed case studies, all of which have been verified by those involved in the innovations. Further details of the case

study research and copies of relevant documentation are in Annex 2. The Analysis of Data chapter summarises the data generated by the research and gives expression to the results in the form of core categories of variables. The Conclusions and Implications chapter then weaves the core categories of variables into a model of technological innovation that has at its core a view of technological innovation as a process that is catalysed by technological learning. The implications of the research to the theory relating to technological innovation are then set out. Finally, the practical implications for business and policy managers are summarised and suggestions are made for further research.

\section{Definitions and Delimitations of Scope}

For the purposes of this thesis, technological innovations are defined as "new products, processes or services that embody significant new functional properties or technical performance characteristics or inventive features that are substantive and objectively measurable." The research is concerned only with innovations that are substantially New Zealand in origin. The detailed criteria, exclusions and protocols governing what is defined as a technological innovation are listed in the Methodology chapter. 


\section{TECHNOLOGICAL INNOVATION: AN OVERVIEW OF THE LITERATURE}

\section{Introduction}

This chapter outlines the major schools of thought on technological innovation as they relate to the research problem and thesis proposition, and identifies gaps in the understanding of key aspects of the technological innovation process. A range of multidisciplinary and theoretical perspectives are canvassed to shed light on technological innovation as a dynamic and social process, and as a process through which learning creates value from the intangible assets of human capital, technological knowledge and information.

The "domain of enquiry" for the thesis is then identified, and within this domain the "broad areas" that encompass the major knowledge gaps this thesis addresses are identified.

\section{Early Writers on Technology, Economics and Innovation}

While early writers such as Adam Smith and David Ricardo understood technology as a factor of production, Karl Marx was the first major theorist to provide rich insights into the relationships between technological change as a dynamic process and social and economic behaviour.

According to Marx and his colleague Engels:

The bourgeois cannot exist without constantly revolutionising the instruments of production and thereby the relationships of production, and with them the whole relations of society.

(Marx \& Engels, 1963) 
Enduring contributions by Marx include the recognition that "artefacts have politics", and that technological change is inextricably bound up with workplace organisation, social dynamics and social control. Marxist thinking both drew from and contributed to evolutionary theory. Shortly after Darwin published the Origin of the Species, Marx called for a critical history of technology to be written along evolutionary lines (see Basalla, 1988, p. 21). Technological innovation as a social and an evolutionary process provides an important backdrop to the issues this thesis addresses.

\section{Neoclassical Economics}

Neoclassical literature acknowledges the importance of and the high returns from R\&D and technological innovation (eg. Mansfield et al, 1977; Mansfield, 1981; Dempster, 1994). At a macroeconomic level the growth theory of Abramowitz (1956), Solow (1957) and Denison (1967) demonstrates that a great part of economic growth comes from factors other than labour and capital inputs. This "residual" underlying growth encompasses R\&D, human capital, knowledge and technology. These intangible assets are seen in this thesis as central to innovation and economic growth. However, the social and learning processes that generate "the growth residual" have not been addressed in the traditional neoclassical literature.

Traditional neoclassical economics tends to see technology as codified and exogenous knowledge that is easily transferable, often without cost (see McKelvey, 1991). It takes little account of the "unteachable" (Penrose, 1959) or tacit (Polanyi, 1967) nature of much knowledge, the fact that knowledge is often embedded in firm routines, and that only information that is easily codified is well suited to market trading (Boisot, 1995). Traditional neoclassical theory has tended towards a mechanistic view of the firm, with managers making rational decisions based on perfect knowledge, rather than seeing firms as learning organisations that are bounded by their core competencies, routines, tacit knowledge, and by the technology embedded in their social relations. 
Most neoclassical economics is based around static rather than dynamic models. These models have little explanatory power in a world of shifting technological frontiers, irreversible and cumulative technical change, and interactive technological learning. Hayek and others in the Austrian school argue that the market is the most efficient mechanism of discovering and acquiring dispersed information and that public interventions cannot improve on this (Hayek, 1975). However, the Austrian school treats learning as a subset of market allocation processes rather than as encompassing the creative, social and dynamic processes of technological innovation.

Some branches of neoclassical theory have however tried to gain insight into "real world" innovation processes at a firm behavioural level. Transaction cost economics (see Coase, 1937; Williamson, 1975) includes some concepts that provide insights into the technological innovation process. These include asset specificity, bounded rationality (see March \& Simon, 1958) and information asymmetry. Asset specificity refers to specialised assets whose value is higher in their dedicated use than in alternative uses. These assets can be human capital, skills, methods or embodied technology. Because specialised assets are of very low value in other markets and applications, investment in them constitutes a sunk cost and is subject to "fire sale" prices when investment is withdrawn from these specialised uses. Asset specificity is an important concept when we later grapple with the nature and dynamics of significant new technology, and with the irreversibility and cumulativeness of technological change.

Bounded rationality refers to the imperfect ability of individuals to process and interpret vast amounts of information (see Mokyr, 1990, pp. 158-9). Bounded rationality acts as a major constraint on decisions to invest in and manage technological change (see Dosi et al, 1990). Information asymmetry is also helpful in explaining differences in the rate and direction of technological learning. Because information, and the ability to interpret it, is not distributed evenly among firms, the ability to embody new information in significant new technology differs substantially (see Silbertson ed., 1989, p. 62). Bounded rationality and information asymmetry 
help account for radical divergencies in technological trajectories, and in the rate and direction of technological accumulation among firms.

However, there are real limits on the insight transaction cost theory provides into the learning aspects of technological innovation. Transaction cost theory sees organisational structure and external interactions as being primarily shaped by the need to reduce transaction costs. However, firms often network together to access external ideas and technologies rather than to reduce transaction costs. This networking depends on trust and cooperative action, while transaction cost theory sees economic relationships as partly driven by opportunism, deceit and guile (Johanson \& Mattsson, 1987). Transaction cost economics is inherently static in its view of institutions, it fails to take adequate account of people's nature, motivations and working relationships, and does not address interactive and externally-driven learning processes.

\section{Research, Science and Technology-Push and Demand-Pull Innovation Models}

The immediate post-World War 11 period was a time of enormous confidence in science, finding expression in such polemics as Vannevar Bush's Science the Endless Frontier (1945). However, researchers progressively began to question the assumption that basic research and science were the key drivers of technological learning, change and innovation.

\section{$\underline{\text { Relationships Between Scientific Research and Technological Innovation }}$}

Schmookler (1966) challenged the linear model of basic research leading inevitably to innovation, seeing invention/innovation instead as a needs or demand-driven phenomenon. The Hindsight study (see Isenson, 1969), and Langrish et al (1972) found that basic scientific research was responsible for very few of the key events leading to the technological innovations studied. However, these studies were partly 
countered by the 1968 TRACES (Technology in Retrospect and Critical Events in Science) analysis and by Freeman (1982), both of which placed rather more weighting on the role of scientific research in leading to or underpinning innovation.

A limitation of many studies in the management of technological innovation is that they focus excessively on the role of $R \& D$, or examine specific aspects of innovation in a narrow and segmented way, without looking at the overall process. Many studies treat the management of R\&D as quite separate from the wider process of innovation management. Key features of technological learning explored later in this thesis are its systemic and holistic nature, and its dependence on integrating R\&D with the wider learning processes associated with innovation.

Linear models of research leading to innovation have now largely been superseded by models based on interactive processes where formal scientific research is simply one of many different forms and sources of technological learning (see Kline, 1985; Rothwell, 1992). Technological innovation tends now to be likened to a continuous fermentation process in which old ideas endlessly seed new developments, and "learning by doing" effects feed into new ideas for the production and the innovation processes. However, even literature that treats the relationship between scientific research and innovation as a non-linear, interactive and cumulative process still does not adequately address the social and differentiated learning processes that catalyse and make productive the human capital assets of a firm.

\section{Technology-Push Versus Demand-Pull Theories of Innovation}

Associated with research on the role of science and basic research in stimulating technological change, many studies have addressed technology-push versus demandpull as sources of stimulus for innovation (eg. Myers \& Marquis, 1969; Freeman, 1974; Rothwell et al, 1974; Parker, 1978; Stern ed., 1982). These studies have some methodological limitations (see Chidamber \& Kon, 1994). However, they do highlight the importance in innovation of new information inputs and of external communication, and they confirm the importance of external sources of scientific 
expertise and advice. Some of these studies also look at the differentiation in the sources of new ideas and learning processes (eg. von Hippel, 1988), but this differentiation is not explored in any depth.

Research has progressively moved beyond simplistic demand-pull studies and sought deeper insights into the effects of the external and internal environment on innovation in firms. Ackerman \& Harrop (1985) concluded that the most significant sources of stimuli for innovation were competition, customer requirements, internal R\&D and technological trends, profit incentives, and public grants. Rothwell \& Zegveld (1985) listed as key success factors for technological innovation the understanding of user needs, effective coupling with the marketplace and with external sources of scientific and technological expertise, and internal coupling. However, this research failed to rigorously address sources of new ideas, human capital issues, social processes, or the dynamic nature of external interactions and of technological learning.

Overall, a limitation of research relating to the demand-pull stimulus for innovation is its overly narrow focus on market influences and one-way communication flows. The results of such research are often ambiguous, or too "coarse grained" to be useful. Chidamber \& Kon (1994) point out that firm or project-level studies judge market stimulus as more important to innovation than technology-push factors, but research using high-level units of analysis produces mixed results. Much of the research cited above addresses the motivational stimulus to innovate, but does not examine this external stimulus as part of a more interactive and differentiated search, selection and learning process. Nor does it adequately address the role of human capital, of social processes, or of the dynamics of technical change.

\section{Schumpeter}

Joseph Schumpeter shared with Karl Marx a view of economic change as a dynamic process rather than as an adjustment towards an equilibrium (see Schumpeter, 1942; MacLeod ed., 1986). While great neoclassical economists such as Keynes addressed 
the failure of macroeconomic policy to use existing assets, Schumpeter focused on the creation over time of new technological assets through an innovation process that he termed "the carrying out of new combinations".

Schumpeter saw innovations emerging in waves, associated with investment booms and gales of "creative destruction" (Schumpeter, 1942). This thinking is aligned to that of the "long wave" theorists (see Mensch, 1979; Graham \& Senge, 1980). Long wave theories of technical change lack rigorous support in the empirical literature, but are broadly consistent with the observation that innovations do stimulate other innovations and form clusters (see Haustein \& Maier, 1980; Marchetti,1980).

Schumpeterianism and associated long wave theory contain strands of evolutionary thinking. Biological evolution is characterised by long periods of stasis, with incremental adaptation punctuated by disequilibriums and sudden bursts of rapid change ("punctuated equilibrium"). This is analogous to Schumpeterian thinking about creative waves of innovation, and parallels the economic phenomenon of bursts of technological innovation, for example as exemplified in the "information technology revolution".

There are "fuzzy boundaries" between neo-Schumpeterian literature and work associated with the Science Policy Research Unit (SPRU) at Sussex University, work that includes researchers such as Freeman and Dosi. Very broadly, the works of Jewkes et al (1969), Langrish et al (1972), Freeman (1982), Rosenberg (1982, 1994), Scherer (1984) and Dosi et al (1988) can be labelled "neo-Schumpeterian". These researchers have addressed the dynamic and the "big picture" aspects of technological innovation, as well as some of the commoner research questions referred to above.

Neo-Schumpeterian literature increasingly emphasises firm-specific technological knowledge accumulation (see Granstrand, 1982; Dosi, 1984; Stiglitz, 1987a; Amendola \& Gaffard, 1988; Swan ed., 1992). As we shall see later, this work is closely intertwined with that of evolutionary economics, and more obliquely to "information theoretics" and new growth theory. 


\section{Social, Managerial and Organisational Aspects of Technological Innovation}

Research on the social, managerial and organisational aspects of technological innovation encompasses a range of major themes and problems. These have included:

\section{Sociology of Technology}

Social theory relating to technological innovation ranges from Veblen and institutional economics, social constructionism (see Bijker et al eds., 1987, Bijker \& Law eds., 1992; Mackenzie \& Wajcman eds., 1985) through to works such as Shapin (1994) which have an ethical and moral dimension. Mackenzie \& Wajcman eds. (1985), Bijker et al eds. (1987), Hodgson (1988), Bijker \& Law eds. (1992) and Mackenzie (1990) provide insights into how information and technology is socially and culturally processed and shaped within organisations, and also into how technology shapes organisations. There is now a wide acceptance that innovation is a social process that is shaped by interest groups within organisations and society, and by the interplay between individuals and institutions. This thesis sees social processes as being integral to a view of technological innovation as a team-based and interactive learning process.

Neo-Marxist and some "sociology of technology" views of technology as a manipulative tool of social control have in recent times been largely superseded by a recognition of the performance gains that flow from staff empowerment, team-based workplace reform and cross-functional management. Modern management thinking increasingly focuses on unlocking the performance gains that come from harnessing the innovation and the new ideas of workers at all levels in an organisation. The literature on the sociology of technology encompasses social processes in innovation, but does not integrate this with an understanding of human capital, or adequately address the catalytic role of differentiated learning in technological innovation. Nor does it effectively accommodate some of the economic aspects of technological 
dynamics such as irreversibility, cumulativeness and technical platform effects, and the related management implications.

\section{Organisational Strategy and Structure}

There are important relationships between organisational strategy and structure and the performance of firms in innovation.

Significant research effort has focused on the influence of a firm's strategy on the management of technological innovation (see Rothberg ed., 1981; Steele, 1989; Burgelman \& Sayles, 1986). Much of this work highlights the need for research and technological innovation to form an integral part of strategic corporate management, rather than being an activity that is divorced from wider corporate goals (see Gobeli \& Rudelius, 1985). Richardson (1985) identifies among key "failure factors" in innovation the poor linkage between R\&D and corporate strategy. Jelinek \& Schoonhoven (1990) stress the need for an innovative firm to articulate and diffuse its corporate strategy internally. Dodgson ed. (1989) and Johnston (1991) highlight the complex and quite specialised strategic demands of managing technology, and focus on the use of technology strategies as an integral part of the strategic management of firms. Such work acknowledges that the strategic management of technological change involves its own specialised challenges, and is not simply a subset of other business management practices.

Much early management literature (eg. Taylor, 1947) conceived of the firm in a mechanistic rather than a more organic and dynamic context, and focused on organising work to achieve the maximum efficiency within a fixed state of technology and set of production processes. However, mechanistic views of innovation fail to take account of social processes in the firm, and of the relationships between innovation as a learning process and the organisational structures that are suited to learning. Mechanistic models do not acknowledge the importance in innovation of such factors highlighted by Gobeli \& Brown (1993) as continuous process improvement and total employee involvement. 
The organisational structure required for technological innovation must facilitate its management as a systemic, non-linear and dynamic process (Rickards, 1985). Innovation is fostered by organic and flexible organisational forms rather than by formal and mechanistic structures (see Greson, 1984; Shane, 1990). Organisations that focus on dynamic innovation rather than static efficiency gains have to vest trust in people to perform in conditions of uncertainty, and where the performance of people is difficult to monitor and measure, rather than to rely on Taylorist management techniques (Blandy et al, 1985, p. 112). The Japanese kaisen (continuous improvement) work method, and the concept of reinnovation based on robust design configurations (Rothwell \& Gardiner, 1988; 1989), are all consistent with the view in this thesis that innovation is a process of dynamic, ongoing and evolutionary change rather than a process that tends towards a market equilibrium.

Some studies highlight the relationships between a firm's organisational structure and its communication flows and learning processes (see Hage \& Aiken, 1970; Maidique, 1980; Cohn, 1980; Jelinek \& Schoonhoven, 1990; Rothwell, 1992). Authoritarian and hierarchal structures stifle innovation because they hamper organisational learning by impeding flows of communication. They also fail to access and exploit tacit and uncodified information generated at all levels in an organisation (see Child \& Bate, 1987, pp. 60-61).

\section{Organisational Culture and Social Processes}

Organisational culture has significant impacts on productivity, creativity, idea generation and learning processes (see Akin \& Hopelain, 1986; Horwitch ed., 1986; Twiss \& Goodridge, 1989; Senge, 1990, p. 249). The culture of a firm can be defined as that part of its knowledge stock which is shared by the firm's staff but not by the general population (Cremer, 1993, p. 354). It therefore has a localised and a tacit dimension, and includes shared meanings and communication modes. Firm culture is therefore likely to influence organisational communication and learning. 
The willingness of organisations to allow incumbent interests and the accepted wisdom to be challenged is often crucial in technological learning (see Maidique, 1980; Twiss \& Goodridge, 1989; Senge, 1990). Myers \& Marquis (1969) identified among key barriers to innovation such cultural factors as a resistance to new ideas, and poor cooperation or communication. Twiss (1980) reported that learning and innovation processes are enhanced by an organisational culture that fosters a receptivity to new ideas, porous organisational boundaries, and openness and allowance of conflict. These studies identified but did not explore in depth some aspects of learning, such as the benefits from immediate feedback, and from crossfertilisation of ideas resulting from a mix of specialisations.

It is important to understand how people work together and complement each other in both a formally structured and an informal sense in the technological innovation process. There is an extensive literature on the key formal roles played by people in innovation (see Maidique, 1980; Smith et al, 1984; Knight, 1987; Freedman, 1988; Tushman \& Moore, 1988; Steele, 1989; Twiss \& Goodridge, 1989; Jelinek \& Schoonhoven, 1990). However, in many cases technological innovation will be far more dependent on the informal relationships in a firm and on the role of the team (see White et al, 1988; Kash, 1989).

Case studies later in this thesis show that the cultural foundations must be in place before firms can develop the "social architecture" and informal social processes needed in innovation. In many cases, innovation in social processes, teamwork or workplace organisation is necessary to catalyse technological innovation (see Boddy \& Buchanan, 1986; Tushman \& Moore, 1988). For example, Takeuchi \& Nonaka (1986), Johne \& Snelson (1988) and Florida \& Kenney (1990) promote the Japanese "rugby approach" to innovation that involves a marshalling and interweaving of complementary skills and ideas in an integrated and team-based way. 


\section{National Systems of Innovation}

Many studies of national innovation systems (see Dertouzos et al, 1989; Lundvall ed., 1992; Nelson ed., 1993) tend to be policy summaries or descriptive papers, rather than empirical studies. However, there is significant empirical evidence relating to the varying influence national systems of innovation have on different countries. The social and cultural environment of a country influences innovation (see Wallace, 1970; Dore, 1983; Shane, 1990; Mokyr, 1990). Historical contingencies and natural resource endowments have also shaped different national innovation systems (see Pavitt ed.; 1980; Florida \& Kenney, 1990). For example Japan, as a resource-poor country, is very strong in resource-saving or augmenting technologies, ranging from time-saving techniques to energy-efficient automobiles.

The national systems of innovation literature emphasises that strategic management is a key element in innovation. Studies of national innovation systems suggest that strong and innovative technology-based firms can be based in small countries. Such firms don't have to be major investors in formally-organised R\&D, but direct links between firms and public research institutes are important. Nelson ed. (1993) stresses that public policy, including Government funding of basic research and education and the legal and regulatory framework, exercises a major influence on innovation. Public scientific and technical institutions within a country are fundamental to the search and selection process, since they affect the bridging mechanisms between pure science and technological development, and the capabilities that firms can bring to bear on the search process (Dosi et al, 1990, p. 244).

Research on national systems of innovation takes an holistic view, and has links with the management of innovation literature and with research relating to innovation as a learning process. The importance of users as a source of learning in innovation is, for example, a strong feature of the national systems of innovation as well as of the management literature (see Slaughter, 1993; Nelson ed., 1993). Fagerberg (1995) places learning processes in a national systems of innovation framework, and argues 
that a country's long-run comparative advantage will be in areas where its rate of learning is higher than that of competing countries.

The national systems of innovation construct forms a backdrop to rather than a central focus for this thesis, though the thesis results will create a body of knowledge that includes some unique New Zealand elements, and will provide insight into specific features of the national system of innovation in New Zealand.

\section{Evolutionary Economics}

While neoclassical economics treats technology as exogenous "manna from heaven", evolutionary economics accepts that technological evolution is not an isolated event but depends on past research and the foundation provided by earlier innovators (Scotchmer, 1991). It argues that technological developments are shaped by innate characteristics that are transmitted through time, by social forces, and by interaction with and adaptation to the external environment (see Nelson \& Winter, 1982; Nelson, 1987). While the rate of evolutionary biological change is related to biological diversity and to possible mutations, the rate of technological change is linked to the diversity and vitality of new ideas that a firm is subject to.

Key concepts in evolutionary economics include:

Irreversibility, Technological Trajectories and Cumulativeness

Technical change is irreversible in the sense that inventions cannot be "uninvented". Richard Dawkins coined the term 'meme' to describe those ideas that propagate themselves through time like self-replicating viruses. The idea of the wheel, DNA, or the basic principles of software engineering are immortal, flowing like a river through a series of disposable vessels, whether those vessels be minds, bodies, or microchips. Ideas and technologies, like genes, compete and are subject to natural selection. New technological products must offer a customer a tangible (rather than cosmetic) benefit 
to survive (O'Hare, 1988, p. 13), so that the long-term survival of a technology, as of a gene, depends on its "fitness for purpose".

As foreshadowed in the earlier discussion of transaction cost theory, asset specificity is a key mechanism in the irreversibility of technical change. The irreversibility of specialised technological investments can discourage competitive entry, allowing an innovative firm to earn premiums from a quasi-monopoly position in the market that is based on its cumulative, specialised assets. This position in the market is reinforced by increasing returns from specialisation (see Romer, 1987).

The directions taken by a technology over time constitute its technological trajectory. These trajectories are linked with the development of specific infrastructures, systemscale economies, complementary technologies, cumulative learning processes, standardisation requirements and network externalities (Dosi, 1988, p. 1146; Dosi et al, 1994, p. 26). The emergence of major new technological developments is often characterised by widespread experimentation and "learning from diversity". This leads to the range of possible variants being narrowed down to limited trajectories of development, until one technological variant becomes a standard (see Cowan \& Foray, 1995). However, technological trajectories can involve a narrowing of focus, and "Wolf's Law" holds that there will be diminishing returns to technical advances along existing trajectories.

While Schumpeter saw innovation as a process of "creative destruction", evolutionary economics also focuses on the process of incremental technological accumulation. Small advantages can accumulate, as small events become locked in and determine long-run outcomes. The cumulativeness of technical know-how can also encourage economies of scope through the transferability of learning, which enables generic technology to underpin a wide range of new products (see Dodgson \& Rothwell eds., 1994). 


\section{Genotypes of Firms, Organisational Routines and Technological Regimes}

The internal skill base, core competencies and culture of a firm can be likened to a genotype, and their embodiment in the firm, and the firm's behaviour, performance and strategy, to the resulting phenotype.

Evolutionary economics sees a firm's organisational procedures, decision rules, and way of doing things as making up its "organisational routine" (see Nelson \& Winter, 1982). Routines embody firm-specific competencies and tacit knowledge, and they adapt and change in accord with learning experiences. Routines can help focus the efforts of individuals on the higher purpose of the group or the value system that the group embodies (see Postrel \& Rumelt, 1992). However, routines can also imply rote-learned behaviour, and can stifle creativity and the rate of learning. Significantly, Lundvall ed. (1992) argues that "organisational forgetting" can be an important form of learning in firms.

A firm's technological competencies and knowledge base and its operating procedures collectively make up a "technological regime". The technological regime embodied in a firm sets boundaries around its productive activities (Rosenbloom \& Burgelman eds., 1989). A technological regime reflects what is scientifically feasible, while the actual trajectory followed by a technology reflects how social and environmental factors impact on it, that is, what is socially possible (see Slade, 1994, p. 65). Where a firm lacks the internal competencies required to diversify into a new technological regime, it will rely on external sources of knowledge and technology for the learning needed to do so (Senker \& Faulkner, 1992, p. 158).

\section{$\underline{\text { Phenotypes of Firms and Search and Selection Processes }}$}

While a firm's genotype embodies its core technologies and organisational routines, a firm's phenotype reflects how it has interacted with, shaped and been shaped by external sources of technology and of learning. 
Firms scan the external environment and make search and selection decisions. This search and selection is focused within "neighbourhoods" of technological opportunity that are bounded by the firm's technological regimes and its external interactions, and which are also shaped by cultural, social and economic factors. Some of this technological learning is generic, but much is localised and specific to firms (Pavitt, 1984).

A firm's search and selection activities are interactive, with selection also driving search activities, and with the condition of a firm at any time laying the seeds for its future development. Search and selection encompasses active learning strategies, networking, and exploiting external sources of ideas to foster technological learning in a firm. The greater the pluralism and ferment of new ideas, and the more outwardlooking and global the firm or country, the wider the base from which mutations and new selections may flow.

Economic evolution is therefore to a substantial extent dependent on learning processes. At the level of a firm, learning is driven by informal processes of technological accumulation, for example, through learning by doing and learning by using, as well as by formal R\&D. At the level of an industry, learning processes occur through the development of intra and inter-industry relationships, which include diffusion of information and expertise, inter-firm mobility of personpower, and the growth of specialised services (Silverberg et al, 1988).

\section{Conclusion}

Evolutionary perspectives on economic and technical change have much explanatory but rather less obvious predictive power. Evolutionary theory explains much about the "how and why" of things that happen without active human volition, but is rather less helpful in explaining the decision making and social behaviour of people. In evolutionary biology the environment selects those fittest to survive, while in economics firms can influence and shape the external environment, or actively search for niches within it. Evolutionary concepts can therefore be used to gain insight into 
technological innovation, but cannot be used as exact metaphors of the technological innovation process.

\section{New Growth Theory}

New growth theory explicitly incorporates knowledge accumulation, human capital creation and technological change at the heart of economic growth (see Romer, 1990). This leads to powerful arguments for the pre-eminent role of research, technological innovation and human capital creation in the economy.

New growth theory has challenged more traditional neoclassical theory that predicts diminishing returns to investment and the convergence of economies and of growth rates (see Lucas, 1990). Basic propositions in new growth theory are that human capital and technological change are at the heart of economic growth, and that knowledge is the basic form of productive capital and is associated with an increasing rather than decreasing marginal product (see Romer, 1986, 1987, 1990). These increasing returns can be partly attributed to specialisation, but are primarily driven by the creation of non-rival goods.

Non-rival goods are those goods or ideas, such as the fundamental principles of physics or of software engineering, where the costs of dissemination and utilisation are very low in relation to their initial cost of production. For example, major technological innovations such as the semiconductor created a building block for revolutionary economic advances far beyond the returns directly attributable to the original innovation. A semiconductor itself is a rival good in that only one person can use it at a time. But the idea or technological knowledge embodied in the semiconductor is widely useable by many economic agents, and forms a building block for future technological innovations. A technology that is a "technical platform" for later innovations survives over time not in an unchanged and autonomous form, but through informing, underpinning and being conveyed by other and future technologies. 
This technical platform effect is associated with the evolutionary concept of irreversibility, and can be represented as a "quality ladder", where R\&D embodies in new products improved functional properties, quality or performance characteristics. Innovations build on those that came before, so the quality or functionality of a new product is higher than its antecedents (see Grossman \& Helpman, 1991b). While it is not explicit in the new growth literature, it can be argued that the irreversibility of technology and of fundamental technological breakthroughs, and the low marginal costs of each additional application of non-rival goods, combine to form an ascending "escalator" of technical platforms driving economic performance beyond the fixed limits of capital and labour inputs. It could be argued that these non-rival goods and associated technical platforms will be processes and systemic and networking technologies, rather than products or consumer goods.

Coe \& Helpman (1993) and other new growth theorists argue that there is a positive correlation between an open trade policy, links with foreign R\&D and human capital, the extent of a country's engagement in outward-looking international trade, and a country's rate of technical advance and growth in domestic total factor productivity. Open trade policies effectively improve access to international technologies and can therefore accelerate the rate of technological learning. There is therefore some convergence in thinking between researchers in new growth theory, national systems of innovation, and in technological learning theory.

While new growth theory accommodates the non-rival nature of significant new technology, it does not encompass the role of social processes and organisational behaviour in technical change, nor does it address sources of learning. New growth theory has not yet fully broken with some of the more limiting assumptions of neoclassical economics, such as the achievement of a market-clearing equilibrium.

This thesis encompasses new growth theory, especially as it relates to specific features of technical change and growth, but moves beyond it by applying some of its concepts to explore learning processes, human capital, and the dynamics of technical change in the context of the management of technological innovation. 


\section{Technological and Organisational Learning}

Arrow (1962b, p. 155) said:

I do not think that the picture of technical change as a vast and prolonged process of learning about the environment in which we operate is in any way a far-fetched analogy...

A view of technological innovation as a learning process is linked with work on the economics of information, human capital, intangible assets and technology strategy (see Arrow 1962b; 1984; Lamberton, 1986; Stiglitz, 1987a; Dodgson, 1990). Lamberton (1986) notes that the cost of producing information is independent of the scale on which it is used and argues that information is a form of capital that is differentiated in terms of its possession and in the capacity to use it. The uncertainty and indivisibility of information means that it behaves differently to other economic goods, and that it does not fit easily into a traditional production function mode of analysis. Significantly, learning only occurs when information is absorbed and understood. Cohen \& Levinthal (1990) argue that the ability to understand and apply new ideas is a function of the firm's level of prior related knowledge, that learning is cumulative, and that learning performance is greatest when the object of learning is related to what is already known.

Learning has both tactical and strategic elements. At a tactical level within an existing technological regime it may encompass short-term, event-driven, adaptive or survival learning, as well as maintenance learning and transitional learning (see Bowonder \& Miyake, 1993). However, major new innovations and the exploitation of new technological paradigms requires strategic, systems-based thinking and learning. Senge (1990) emphasises that it is generative learning that underpins the ability to create, and that generative learning requires strategic and systems-based thinking. Rickards (1985) sees innovation as "whole systems" in nature, encompassing social processes and participation by various communities of interest. It is also a matching process, where 'fit' must be achieved between technology, organisation and market needs. 
This thesis argues that technological learning, rather than being confined to one model, is a highly differentiated process, depending on variables such as firm size, industry structure, nature of the technology and of the market, and a host of internal and external relationships. To better understand the differentiated nature of learning, it is necessary to examine the information stocks and flows involved in a firm's operations, encompassing the generation and acquisition of information, and the learning processes through which information is processed and utilised (see Malerba, 1992). The capability or likelihood of productively using information is very differentiated, encompassing perceptions of its value, the effect of channels of communication, and the relationship between human capital and the absorptive capacity in a firm. Learning occurs both internally and externally. While the precise pattern of internal and external learning varies with such factors as firm size and industry sector, all firms make use of external sources (see Foray, 1991; Kleinknecht \& Reijnen, 1992).

It is useful to distinguish between major forms of learning, such as from systematic $\mathrm{R} \& \mathrm{D}$, organisational and team learning, learning by doing, and learning from interacting and networking.

\section{Learning from R\&D}

Traditional models of technological innovation see it as the result of systematic scientific research and development. Systematically-organised R\&D encompasses "learning from searching" or technological scanning. R\&D is best seen as a process of both creating information and enhancing the ability to assimilate and exploit existing information (Cohen \& Levinthal, 1989). Lamberton (1992) replaces a narrow view of R\&D as a formalised and separately-structured learning activity with a wider view of R\&D as part of the exploratory behaviour of firms. More importantly, R\&D should be seen as only one of many forms of learning. 


\section{Organisational and Team Learning}

Generally, learning must happen at both an individual and a team level if organisational learning is to occur. Learning tends to be context-dependent, and bound up with wider organisational processes. Dodgson (1990) argues that strategies for technological learning are inseparable from considerations of organisational structure and human resource management. Senge (1990) sees organisational learning revolving around long-term, systems and team-based learning. Team learning requires thinking insightfully about complex issues, with the team's collective learning being more than the sum of the individual learning of team members. A team also fosters the learning of other teams it interacts with.

Team learning and technology transfer depends on effective relationships between people, and on operational trust (see Polanyi, 1958; Senge, 1990). Trust is a key element in learning, since people are more likely to accept information from people they have contact with and trust than from strangers (see Arrow, 1971). The dependence on personal communication and relationships in the building of trust has significant implications for small economies such as New Zealand. Personal contacts across national boundaries are less frequent than within, while international communication channels are more expensive and have fewer purposes to serve. Coupled with translation problems, these factors slow down and increase the costs of technological adoption for small countries which depend on overseas technology proportionately to a higher degree than is the case for larger countries.

\section{Learning by Doing}

Arrow (1962b) argues that learning is the product of experience, and can only take place through attempting to solve problems, and therefore only takes place during activity. Senge (1990) also stresses that learning must be grounded in reality. Learning associated with repetition of essentially the same problem is subject to sharply diminishing returns. To have steadily increasing performance in learning 
therefore implies that the stimulus situations must themselves be steadily evolving rather than merely repeating (Arrow, 1962b, pp. 155-6).

Arrow cites as empirical support a study of the Horndal iron works in Sweden that had no new investment or significant changes in its methods of production for a period of 15 years, yet productivity (output per person-hour) rose on the average at close to $2 \%$ per annum. Learning by doing is lent further support by the extensive literature on "learning curve" effects (see Maidique \& Zirger, 1985, p. 305). Later work on learning by doing has associated it with production and information-intensive industries (see Dodgson \& Rothwell eds., 1994).

A limit to learning by doing is that it is most effective when there is rapid and unambiguous feedback from actions. It is less effective when the consequences of actions are not immediately obvious, where they are dependent on the unpredictable responses of others, or where they have long-term systemic impacts. Learning by doing is most effective in production processes undergoing incremental technical change. It is less appropriate for systems-based innovation, or in technological paradigms where the knowledge base is rapidly changing due to external scientific and technological dynamics, and where the knowledge base depends for its development on external and more interactive learning processes.

Other forms of learning are associated with learning by doing. Nathan Rosenberg (see Maidique \& Zirger, 1985, pp. 305-6) highlights learning from using. Dodgson \& Rothwell (1994) associate learning by using with specialised suppliers of capital and intermediate goods. While learning by doing is internal to a production process, learning by using is external and results from users gaining experience with a new product or process. This external learning by using creates two types of useful knowledge. Firstly, learning is embodied in design modifications that improve performance, useability or reliability. Secondly, disembodied learning results in improved operation of the modified product. Maidique \& Zirger (1985) and Freeman ed. (1990) also highlight learning from failing, citing IBM's Stretch computer as the 
"failure" that formed part of the learning leading to the successful 360 series. This form of learning is often associated with new product launches.

\section{Learning by Interacting and Networking}

Numerous studies lend support to a view of innovation in firms as a process of continuous, interactive learning (Stiglitz, 1987a; Freeman \& Lundvall ed., 1988; Lundvall ed., 1992, Freeman, 1994). Interactive learning includes learning resulting from external interactions with customers and suppliers. Dodgson \& Rothwell (1994) highlight interactive learning from competitors. Freeman (1994) explores the cumulativeness of interactive learning, while Lundvall ed. (1992) argues that innovation and growth in firms is a process of continuous, interactive learning that also draws on routine activities.

Interactive learning has strong external systemic and networking elements, as firms build external relationships as part of the information search and selection processes. Networking technologies, as well as being subject to declining marginal costs, share some of the economic traits of non-rival goods. Network technologies may form technical platforms for other innovative advances, characterised by high indivisibility and social benefits that may vastly exceed private returns. Associated with this, increasing returns sometimes arise from coordination externalities, an example being standardisation of the (allegedly sub-optimal) QWERTY keyboard (see Arthur, 1989, p. 126).

While transaction cost theory argues that organisational form is driven by a need to reduce transaction costs, networking aims not to reduce costs but to access new ideas and sources of external technology and complementarities. Sako (1992) and Sabel (1993) emphasise the importance of trust in networking relationships, and therefore in learning through networking. The growth of networking as a firm strategy is starting to supersede market/hierarchic forms of organisation. Some of this networking may take the form of intra and inter-firm learning, clusters of related industries and interlinked firms (see Debresson, 1989; Porter, 1990). Networking also has strategic 
policy implications. The work of Van den Ven et al eds. (1989), Rothwell (1991; 1992) and Dodgson $(1991 ; 1993)$ illustrates the importance of corporate strategy and government policy in developing networking relationships with external sources of information, knowledge and advice.

The specific nature of networking varies across industries, technologies and firm sizes (see Foray, 1991; Foray \& Freeman eds., 1993). Freeman (1994) argues that external networks are growing in importance for such new technologies as materials, biotechnology and information technology that are increasingly dependent on science. Related to this, the discontinuity associated with rapid technical change in information technology and biotechnology is leading to new sources of learning, such as learning by recruiting new staff, and learning by networking with other firms and with universities.

\section{$\underline{\text { Conclusion }}$}

Recent theoretical work on technological learning and innovation draws on evolutionary economics, neo-Schumpeterianism, and related work such as that of Christopher Freeman and colleagues at the Science Policy Research Unit (SPRU) at Sussex University. The learning at the heart of technological innovation reflects accumulations of past experiences, where technology and knowledge is weeded out or selected in terms of its fitness for purpose (or fitness to survive). Technological knowledge that survives over time creates robust technical platforms and improved functional properties or performance characteristics which feed into future technological advances and learning dynamics.

Learning processes seem to be at the core of many innovation-related phenomena. However, the studies cited above lack sufficient breadth to examine learning over a broad range of industry sectors and firm types, and they do not fully integrate learning with examination of human capital, social processes, and with the dynamic aspects of technological change. However, the holistic nature of learning, and its relationships with so many wider aspects of technical change, suggests that further understanding 
of learning processes will provide considerable insight into the management of technological innovation.

\section{Domain of Enquiry and Broad Areas for Research}

This thesis endeavours to define the key underpinning assets or drivers of technological innovation, and the processes through which they can be harnessed to create competitive advantage. In studies of technological innovation organisational researchers have tended to focus on the firm-level management and organisational aspects of innovation without linking them to external economic stimuli, while economists have focused on technology mainly as part of the market behaviour of firms, and have stopped short of exploring the organisational context of change (Freeman \& Soete eds., 1990, p. 62). In contrast, this thesis is explicitly interdisciplinary and aims to integrate varying schools of thought relating to the technological innovation process.

Some schools of thought relating to technological innovation have developed in isolation, but connecting threads between them allow more integrated research approaches. For example, while explicit links between evolutionary economics and new growth theory do not appear to have emerged in the literature, the two fields are likely to be intertwined in future. The irreversibility and cumulativeness of technical change, the tacit and generic nature of much knowledge, and its non-rival nature, must surely be major explanatory factors in understanding the increasing returns to knowledge and human capital proposed in the new growth literature.

The schools of thought reviewed in this chapter have set the scene for defining broad areas for empirical research to focus on. The broad areas aim to cast a wide net in the search for grounded insights into the technological innovation process. The broad areas have to be open ended enough to allow grounded research to generate theory and insights from data, without overly restricting the focus of the research too early in the research process. At the same time, the broad areas must provide sufficient focus 
to allow the major knowledge gaps relating to technological learning processes, the role of human capital, social processes, and the evolutionary and dynamic aspects of technological innovation and change to be explored in depth.

The broad areas are:

\section{The Origins of Technological Innovation}

While evolutionary theory places emphasis on "where things have come from" and how they got there, evolutionary perspectives on technological innovation have not been widely subjected to rigorous empirical analysis. The Origins of Technological Innovation broad area encompasses the initial idea, "trigger event" or stimulus, as well as the sources of the key knowledge and technologies leading up to an innovation. It encompasses aspects of learning processes and seeks to draw on evolutionary and other perspectives.

\section{Background, Experience and Education of Key Players}

This broad area encompasses all those past and historical factors, learning and personal experiences that have created human capital in firms, especially that embodied in the key innovators. It is informed by the management of innovation literature and, to a lesser extent, by evolutionary theory.

\section{External Influences}

Evolutionary economics and the work of neo-Schumpeterian writers such as Freeman and Dosi addresses how firms operate within, respond to, and seek to influence a dynamic external selection environment. Change and innovation is substantially driven by the ability to look externally and adopt new ideas, insights or sources of technology. The External Influences broad area encompasses all aspects of the external learning environment, including links 
with research institutes, market influences, changes in economic conditions or government policy, external joint ventures and networking.

\section{Motivations of Key Players}

Theoretical and empirical work on the management of technological innovation leaves many unanswered questions about innovation as a peopleoriented and social process. While many studies identify the key roles played by people in innovation, very few look at the motivations of those involved, or seek to understand why people acted in a certain way. The interrelationships between people are not conceptualised or explored as social and as learning processes.

Neoclassical economics and transaction cost theory sees a world populated by self-seeking, profit-motivated individuals, whose innate guile, opportunism and self-centeredness is constrained only by the legal framework and by rigorous monitoring and accountability structures. An alternative view could be that technological innovation harnesses motivations and social relationships that are different in significant respects to those driving a narrowly neoclassical paradigm, and which need to be better understood. Related to this, the way people relate together and are motivated provides insights into team-based and interactive learning processes.

\section{Dynamic Processes Over Time}

Theoretical work on the management of technological innovation and the dynamic processes associated with it lacks a rigorous empirical underpinning in New Zealand. It is important to address major knowledge gaps in our understanding of dynamic innovation processes over time. The Dynamic Processes over Time broad area includes, inter alia, the roles and interrelationships between the key players in innovation as they relate to organisational behaviour and learning processes. 


\section{Conclusion}

This chapter has canvassed the major schools of thought relating to technological innovation, and related them to the research problems identified in the Introduction chapter. The five broad research areas outlined above form the "focusing devices" for the case study research undertaken. The next chapter outlines the methodology used in addressing the above broad areas for research. 


\section{METHODOLOGY}

\section{Introduction}

This chapter sets out the justification for and limitations of the grounded, case-based methodology used in this thesis, the units of analysis and sources of data, and the methods and procedures used in the collection and analysis of data.

\section{Justification for the Methodology and Limitations}

Innovation is a complex, dynamic and multi-dimensional process. This thesis uses qualitative and inductive case study research methods and draws on grounded theory methodology and multiple levels of analysis to better understand the innovation process. This methodology allows deeper insights into the processes and critical events in innovation, and as far as possible minimises prior biases and value-driven assumptions. By developing theory and propositions from structured observation and analysis, the methodology avoids tendencies in much deductive research to impose theory on reality, thereby excluding relevant and often unexpected variables and patterns of variables. By using grounded theory data analysis methods, the thesis uses a structured and systematic means of analysing data to derive insight and meaning from it.

It is helpful to review case study research and grounded theory methodologies in some detail.

\section{Case Study Research}

Case study research has been defined as "an empirical enquiry that investigates a contemporary phenomenon within its real-life context, when the boundaries between phenomenon and context are not clearly evident, and in which multiple sources of evidence are used" (Yin, 1989, p. 23). Case study analysis is most appropriate for 
"how and why" questions relating to dynamic processes, where the researcher has no control over events, organisational context is important, and where no one data source, by itself, is likely to be sufficient. It allows the holistic and meaningful characterisation of real-life phenomena.

Case study analysis is sometimes criticised for being unsystematic and non-scientific. Concerns have focused on its alleged lack of rigour, the danger of biased views or equivocal evidence, and the inadequate base it provides for generalisable results.

These concerns are addressed in this thesis through several methodological safeguards, viz:

1. The use of multiple case studies and of multiple sources of data and levels of analysis (though Yin (1989) argues that analytical generalisation is theoretically possible from a single case if the data are rich enough);

2. A qualitative rather than quantitative research methodology that aims for richness of insight and analytical generalisation rather than the enumeration of frequencies and statistical generalisation, and;

3. Use of grounded theory techniques as part of a carefully constructed and executed methodology for data collection and analysis.

\section{Grounded Theory}

Grounded theory depends on a qualitative research method that uses a systematic set of procedures to develop an inductively derived grounded theory about a phenomenon (Stewart, 1991, p. 79). It involves multiple levels of analysis and interactive comparison. The processes and analytical procedures used in grounded theory are designed to build theory from data, rather than to construct a theory and test it through deductive hypothesising against data. 
Grounded theory research procedures aim to ensure that the research process has the rigour needed to make the theory well grounded in reality, and to avoid biases, artefacts and poorly framed assumptions. Grounded theory research aims to use data to build explanatory theory that is sensitive and integrated enough to closely approximate the reality it seeks to represent (see Strauss and Corbin, 1990, p. 57).

In more detail, grounded theory is developed through the following process:

1. The general field of enquiry or topic is selected for study.

2. A very tentative framework consisting of a few potential concepts and processes may guide the initial collection of data.

3. All through the research process the researcher undertakes continuous memoing of notes relating to the variables and categories of variables that are generated, and to the processes associated with them. This may include theoretical memos and operational memos recording details of the research process, as well as diagramming that allows the visual representation of qualitative data.

4. As much data as possible are assembled, using multiple sources. This initial data collection begins with a small sample, and as many variables as possible are recorded. After data collection has begun on a small sample, the next step is to progressively widen the data collection, and to begin to classify it.

5. Data are classified through "open coding", asking questions and making comparisons. Open coding is essentially the naming and basic description of variables through close examination of the data. A variable can be a phenomenon, a central idea, event, motivation or process that is observed.

6. The observed open coded data are then organised into categories of related variables through "axial coding". It is important that the research process can 
alternate flexibly between open and axial coding, though the two are distinct analytical procedures. Axial coding starts by making connections between variables. It then organises related variables into categories. Axial coding then aims to achieve focus by identifying and validating relationships between variables within a category. It elucidates the causal conditions that give rise to the category, the specific properties of the category, the context, and associated dynamic processes and relationships.

In detail, causal conditions are the events/incidents etc. that lead to the occurrence or development of a category of variables or set of phenomena. Properties are the attributes or characteristics of a category of variables. The context is the specific set of properties, locations of events or incidents pertaining to a category of variables or phenomena. Dynamic processes and relationships may relate to process over time, or interactions between phenomena.

7. The axial coding process continues with the elucidation of links and relationships within categories, including conditions under which the links or relationships hold. The discovery and specification of differences and similarities within, and to an extent between categories, allows patterns of variables to emerge at axial coding stage and be further developed.

8. Tentative links and connections with the existing theory and body of knowledge may begin to emerge by steps 6 and 7 above, and can be used to make comparisons with or provide insights into categorised data.

9. "Selective coding" is then undertaken. Selective coding is the process of selecting the core category or categories (central phenomena), systematically relating it or them to other categories, validating these relationships, and filling in or refining categories that need further development. 
10. Selective coding includes elucidating the "story-line" - that is, conceptualising the nature, key features and processes associated with the core categories at the heart of the study. It is at selective coding stage that existing theory and knowledge about the subject of the research starts to be explicitly woven in and used as a basis of comparison, but not in a way that biases the construction of a model or theory based on the grounded data. Selective coding identifies core categories of variables and then relates subsidiary categories around the core category(ries). These relationships between categories are elucidated and then validated against the data. Any further categories that need refinement or further development are then "filled in".

11. Towards the end of the process, "data saturation" has occurred and this allows "thick description". The data has been organised into categories and the conditions and relationships within and between categories will have been clearly elucidated. It is at this point that the framework for a model or theory will be in place, based on the results of the open, axial and selective coding processes, and where appropriate on the "weaving in" of existing knowledge and theory.

\section{Units of Analysis and Sources of Data}

The units of analysis in this thesis are those of technological innovations. Technological innovations selected for case study are used as "windows" into a wider understanding of the technological innovation process.

The case studies draw on multiple sources of data and analysis, including a marshalling of available literature relating to the innovation, interviews, corroborating interviews, in-house firm documentation, publicly-available information including firm reports, intellectual property documentation and technical literature. The use of multiple sources of data and methods of data collection allows more perspectives to be brought to bear on the phenomena being studied (see Easterby-Smith et al, 1991, 
p. 31). Multiple sources of data also assist in the verification of findings by allowing "triangulation" and the convergence of lines of enquiry.

Multiple sources of data also help to counter potential biases in, for example, too much reliance on one specific source of information. For example, in interviews individual biases can take the form of egocentrism, selective remembering of favourable events, a premium placed on recent experience, over-confidence by individuals in their own judgement, and a tendency to ignore new evidence. Biases that can emerge from group interviews include the unconscious convergence of views, deference to higher, authority figures, and defensive or territorial behaviour.

The key sources of primary data in this thesis are a comprehensive database that the author developed of New Zealand technological innovations that were successfully commercialised from 1981 to 1993, and far more importantly, case study research. The database of innovations is summarised in Annex 1, while the case studies are in the body of the thesis text. The secondary sources of data woven into this thesis consists of the wider body of theory and knowledge on the technological innovation process, much of which is summarised in the Technological Innovation: An Overview of the Literature chapter.

\section{Procedures Used to Collect Data}

The database of New Zealand innovations from 1981-1993 was prepared by scanning technical literature, journals and periodicals covering the 1981-1993 period. The key publications scanned are listed in Annex 1. The libraries and repositories used were those of Victoria, Canterbury and Massey Universities, the Wellington Public Library, the National Library, the Alexander Turnbull Library, the Patents Office and the Companies Office.

The innovations database includes both products and processes, and producer and consumer goods. A significant methodological question was whether published 
literature records all, or at least most significant innovations. It was initially unclear whether commercially confidential innovations and process and producer good innovations were likely to be covered in the publicly-available literature. Commercial confidentiality in consumer good and product innovations was found not to be a major issue, because firms have to advertise their innovations in order to market them. Specific technical details may be kept confidential, but not the existence of the innovation. Technical literature such as Demm, Automation and Control, and Industrial Equipment News recorded producer good and process innovations. There was, for example, wide coverage of very specialised innovations such as serpentine coil benders, programmable state controllers etc. that may not rate a mention in more mainstream trade and business literature.

\section{$\underline{\text { Criteria to Define Technological Innovations for Database }}$}

The innovations included in the database had to meet the following criteria:

1. They must involve significant new technology, defined as significant new functional properties or technical performance characteristics or inventive features that are substantive and objectively measurable.

2. The innovations must be substantially New Zealand in origin.

3. The innovations must have been successfully launched on the market, or in the case of process innovations in firms, they must have been successfully adopted and applied in productive activity in the firm.

4. They must have been launched on the market in the period 1981-1993.

It is important that the above criteria exclude inventions that have never been fully commercialised. However, study of the dynamic processes underlying technological innovations does provide insight within firms on inventions or technical approaches to a problem that have failed. No attempt was made to appraise the long-term 
commercial impact of the innovations. This is because the thesis addresses the key drivers and dynamic processes of technological innovation, not the size or the magnitude of the outcomes or commercial returns from specific innovations.

The focus of this thesis is technological innovation, but it is fully acknowledged that many of the most important advances for society result from organisational and social innovation. Many technological innovations require complementary social or organisational innovation, for example through workplace reform. The study of the social or organisational processes associated with technological innovation is an integral part of this thesis.

\section{Exclusions, Protocols and Limitations}

A number of exclusions and protocols were applied while developing the database:

1. "Reinnovations", new marks of a product, and design variations were excluded, except where they involved significant new technology.

2. Basic scientific discoveries were excluded.

3. The discovery or exploration of natural resources, eg. a new fishing ground or a geological deposit was excluded.

4. Scientific instrumentation inventions used for research but not sold commercially were excluded.

5. New machinery that was ancillary to or an input into an innovation was generally excluded, except where it involved significant new technology, or was sold separately as an innovation in its own right.

6. Most software development was excluded, since it was generally seen as a technical task involving existing technology, rather than being significant new 
technology in its own right. However, where significant new software technology was identified, for example generic applications platforms, it was included.

7. Systemic innovations where the individual elements are established technology, but where the system itself is a new innovation, were treated on a case by case basis. Generally, systemic innovations had to involve a significant new creative step, or deliver a level of technical performance that was more than the sum of its component parts in order to be included.

8. Plant breeding presented some difficulties in relation to whether it involved "significant new technology", and also whether a plant breeding innovation was judged to be of New Zealand origin. Breeding that simply selected from existing cultivars and trialed them in New Zealand conditions was excluded. However, plant breeding that created a new plant variety embodying significant new characteristics as a result of New Zealand breeding was included in the database.

9. Organisational and managerial innovations per se were excluded from the database. However, the technological innovation case studies provided an entry point to understand wider organisational and social processes.

\section{Selecting Innovations for Case Study}

From the database summarised in Annex 1 an initial sample of 14 innovations was selected for detailed case study analysis. This selection was made on the following basis:

1. Innovations that seemed most significant in technological performance and commercial impact were favoured. The selection of such innovations was a matter of judgement, based largely on data in published literature and on preliminary research. 
2. Innovations were selected from a wide range of industry sectors to ensure the maximum breadth and to increase the likely generalisability of the research findings.

3. Innovations were selected from firms of a range of different sizes and corporate forms, to provide the richest contrasts and insights, and to facilitate the grounded research technique of "extreme comparison". These included public and private firms, and ranged from a firm with 6 staff to a multi-billion dollar business.

4. The selection was weighted towards innovations where the key players were still available to be interviewed. In practice, this meant a slight bias towards innovations that were developed from the mid-late 1980 s on.

5. A number of innovations that the author had studied as part of MBA work were excluded. These were the Hennessey Grading Probe, the Phoebe noninvasive fat measurement innovation, and innovations from Tait Electronics, Fisher and Paykel, and Marine-Air-Systems.

6. The samples covered both product and process innovations.

7. The samples covered a range of technologies.

It is stressed that the technological innovations chosen for case study research were selected not for their own sake but as "windows" through which a wider understanding of the technological innovation process could be gained. 


\section{Application of Data Collection Procedures}

After innovations had been selected for case study, senior figures in the innovating firms or organisations were approached by phone and/or letter and asked to participate in the research. An outline of the research method was given, the provisions governing confidentiality were explained, as was a willingness on the part of the researcher to offer a workshop/seminar or written critique of the innovation environment in the firm as an act of reciprocity for participation. Permission was sought for "first round" in-depth, taped interviews with the key innovator(s), and detailed interviews with other key players associated with the innovation. Samples of relevant documentation are included in Annex 2.

Of the 14 innovations initially selected, 11 firms agreed to participate in the research. The 3 firms that did not respond to the request for their participation in case studies of their innovations were Pulse Data International (the Viewpoint visual aid system), Tru-Test Ltd (the MP400 printer) and Switchtec Ltd (a switch mode power supplies innovation).

Work on the case studies began with the marshalling of all available written material, including technical and business literature, patent documentation, and all other available information. In-house documentation was requested from and provided by the firms involved throughout the research process.

The field research proceeded with a consistently structured but open ended interview with the key people involved in the innovation. The format of the interview was determined by the conceptual focus and broad areas derived from the preparatory, literature-based work outlined in the Technology Innovation: An Overview of the Literature chapter. In accord with grounded theory methodology, the broad areas to explore were used only as a set of headings and as prompts; essentially to "get people talking". The intent of this was to avoid distorting or biasing the data collection process. 
In most cases people were interviewed individually. However, for the convenience of participants, group interviews were held with key people involved in the Alatal 821 and the Greenweld innovations. In no case was interview data entirely dependent on a group interview. In only one case did the interview-based data depend largely on one major interview source. However, in this case details were corroborated by phone with one other senior figure in the firm, and also by reference to extensive written documentation. All interviews were openly taped and the tapes transcribed verbatim. Interview durations varied, but almost invariably exceeded the planned time. Two hour duration interviews were typical. Interviewees were thanked in writing.

Case studies were written up drawing on all sources of data and the first drafts were returned to the interviewees for their verification. Minor details were discussed by phone, but in most cases participants responded to case studies in writing. The draft case studies were finalised based on the comments of interviewees, and in all cases were verified by participants as full and accurate accounts.

\section{Analysis of Data}

After the case studies had been verified by the participants in the research, analysis of data was undertaken through a process of open, axial and selective coding as explained above. Identifying phenomena, categorising them, establishing their similarities and differences, and critical questioning from different angles was critical to the data analysis process.

It is stressed that the research and data analysis process used was not rigidly sequential, and that the research moved flexibly between, for example, interviewing and study of written case material, coding, and critical questioning. Throughout the research process, operational and theoretical memos were separately written up with dated headings within a research diary. Operational memos recorded the overall 
process of the research undertaken; essentially the mechanics of the research. Theoretical memos recorded detailed aspects of specific variables and categories of variables, as well as wider insights and theoretical approaches emerging from the research as a whole.

The practical analysis of the data took place as follows:

\section{Open Coding}

The primary data generated by case studies was scanned and variables identified. An open coded card was prepared for each variable. Each card listed the title of the variable, where it occurred, a brief description ("taxonomic description"), and a comment which covered issues such as its relationship with other variables.

After the primary data had been open coded, secondary data generated through the literature review was also open coded. By the time open coding was completed a total of 797 open coded variables had been identified. These variables, most of them primary data, are listed in Annex 3. Annex 3.1 provides an example of the information recorded on an open coded card.

Open coded cards were then grouped initially under the five broad areas. This was done for convenience, to organise a mass of variables, and to facilitate axial coding. Variables that did not fit neatly within a specific broad area were assigned to the broad area that seemed most appropriate. For example, variables relating to the innate nature of people and people-related variables were loosely grouped within the Motivations broad area, and variables relating to market dynamics and competitive behaviour were grouped in the External Influences area. All dynamic aspects of innovation, and technology management variables, were grouped in the Dynamic Processes over Time broad area, as were organisational, structural and social variables, including those relating to the key roles played by people and how people relate and work together in the innovation process. 


\section{$\underline{\text { Axial Coding }}$}

Axial coding was then undertaken. Since axial coding is complex, operational memos recorded the detailed research process and procedures followed. Axial coding aimed at grouping all open coded variables into axial categories made up of linked or associated variables. To begin with, open coded cards were organised in an interim way into named categories within the broad areas. These categories were given an overarching name that was broad enough to encompass all the variables, with these categories still being loosely grouped for convenience into the broad areas. It is stressed that the categories of open coded variables were preliminary at this stage, and axial categories in a true sense only emerged during the next stage of the data analysis process.

Axial coding then proceeded with a more detailed study of the variables within each interim category. Determining relationships between variables was done at this stage by contents analysis, by observation of variables that were linked, by identification of variables that occurred across a range of case studies, and by observations of causations between variables.

In some cases, interim categories were later revised, merged with other categories, or abandoned as more detailed analysis better crystallised the relationships between variables. The axial categories that finally emerged essentially replaced the broad areas and the interim categories as the framework within which open coded variables were organised. A total of 50 axial categories were developed, covering all 797 open coded variables. These categories each covered a discrete grouping of variables that were related by their nature, purpose or interrelationships. The axial categories are listed in Annex 3. Annex 3.2 provides an example of the information recorded on an axial category card.

It was during axial coding, (and less intensively at open coding stage), that more detailed theoretical memos began to be made recording possible conceptual and theoretical insights and approaches. These memos interacted with or reflected back 
on the "conceptual focus" or broad areas for the research explained above. Memo taking on all pertinent aspects of the data was important all through the axial coding process. With the axial categories in place, the make up, characteristics and relationships between variables in each axial category were then elucidated, as set out below:

For each axial category a large card was labelled with the name of the axial category, and the cards listing open coded variables that were associated with it were grouped with this card. The large card recorded for each axial category the following:

\section{Causal Conditions}

These set out the nature of an axial category in relation to the circumstances, events, incidents that gave rise to the category.

\section{Properties}

These properties were the attributes/characteristics etc. of a category of variables, including any weighting given to the property.

\section{Context}

The context encompassed the specific set of properties, locations of events or incidents pertaining to a category.

\section{Dynamic Processes}

The dynamic processes included processes over time and dynamic interactions between variables within a category. 


\section{Links and Relationships within Categories}

This involved the discovery and specification of differences and similarities within categories, and to a lesser extent between categories.

\section{Tentative Links with Existing Theory, Other Knowledge or Data}

This noted any tentative links made at axial coding stage with existing theory and other knowledge and data. At axial coding stage, existing theory and knowledge about technological innovation was tentatively beginning to be "woven in".

The process continued with more advanced axial coding that essentially aimed to further elucidate the nature of the variables and their relationships within and to an extent between categories (more advanced analysis of the relationships between categories was undertaken through selective coding).

\section{Selective Coding}

The axial categories became the building blocks for selective coding. Selective coding compared axial categories in depth and elucidated relationships between categories. Core categories of variables were then identified by testing each axial category against the following criteria:

1. Is the category specifically or largely to do with technological innovation?

2. Is the category a major and key driver of variables?

3. Is the category a necessary (rather than just a desirable) condition of technological innovation?

These criteria were applied by closely examining all the axial coding cards and noting the nature of the axial coded data, and the relationships between axial categories of 
variables. Criterion (ii) above turned out in some respects to be the most important, since it required careful examination of the relationships between categories and variables, including the nature and direction of the causations. Large selective coding cards were used to record the application of the 3 criteria above to each of the axial coded categories.

After this initial selective coding, the axial categories that seemed to fulfil, or partly to fulfil the criteria were examined in more depth against the above criteria. This process allowed core categories to be progressively created, in some cases involving the merging of several axial categories, or extending an axial category by including variables from other categories.

A separate series of large core category cards was then used to record details of the core categories, to allow more advanced selective coding to be undertaken. The information recorded on these core category cards consisted of the:

1. Name and brief description of the core category.

2. Detailed listing of the variables and/or categories of variables that made up each core category.

3. Observations/Descriptions/Discussion of the nature of the data within the core category. This included comparisons, relationships, discussion of the nature of the data and how it fits together.

4. Observations/Descriptions/Discussion of nature of the data and relationships between the core category and other categories (core or otherwise).

In parallel with the above systematic and formalised selective coding the traits of reflective thinking and theoretical sensitivity were exercised. This took the form of observations on the holistic and meta-framework aspects of innovation, "thoughts about facts", conceptual thinking, and theoretical memoing of the "story line". 
Theoretical memoing included the researcher, immersed in the data, sketching out what was felt tacitly and conceptually as being the phenomena at the heart of the technological innovation process. These theoretical memos were written up in parallel with, and at the same time as more mechanical aspects of selective coding. These theoretical memos provided a parallel, more conceptual and imaginative counterpoint to, and basis for, comparison with the theory and model development undertaken through the more rule-based and formal selective coding procedures.

The theoretical memos and the results of formalised selective coding were then compared, and it was found that the parallel memoing process produced similar results and insights as the selective coding.

Core categories that were initially developed through formalised selective coding were the Nature and Dynamics of Significant New Technology, People Interacting with and Relating to each Other, the Nature of People, and Human Capital. The title of the first of these categories was changed to Dynamics of Significant New Technology, since the unique nature of significant new technology was heavily bound up with its dynamic behaviour. The title of the second of these core categories was paraphrased to Social Processes. Closer examination of the variables within the core categories showed that the Nature of Innovators category was really a subset of Social Processes, because even the most outstandingly creative or charismatic person is normally only successful in technological innovation when he forms part of a team, and operates in an organisational and social rather than an individualistic context. The Nature of Innovators category was therefore absorbed into Social Processes. Annex 4 lists the core categories and the variables included within them. Annex 4.1 provides an example of the information recorded on a core category card resulting from the selective coding process.

\section{Advanced Analysis}

After the core categories had been generated and refined by selective coding, advanced analysis sought to identify the key thread or common theme across all core 
categories. This theme had to be an enabling condition that would make productive the variables in all the core categories.

The advanced analysis involved careful examination of variables within each core category and conceptual representation of the relationships between core categories. Frequent reference was made to theoretical memos. Links with the conceptual focus background to the research started to crystallise at this point, and existing theory and knowledge was more explicitly integrated, or used as a basis for comparison. As differentiated learning emerged as a catalytic variable across the core categories, the research results were further compared and integrated with existing knowledge and theory. Where major anomalies, inconsistencies or unexpected discoveries occurred, further comparison, analysis and validation of conclusions against the data was undertaken. This continued until the explanatory power and richness of insights from the research came to be convincing.

The results of selective coding and advanced analysis were then drawn together and written up as the model set out in the Conclusions and Implications chapter. This model embodied the results of open, axial and selective coding and advanced analysis, existing theory and knowledge, insights resulting from reflective thinking, "thoughts about facts", theoretical sensitivity and discovering process through data.

\section{Ethical Issues}

The only ethical issue encountered was commercial confidentiality, which was carefully observed by the signing of and adherence to confidentiality agreements.

\section{Conclusion}

This chapter set out and justified the choice of the methodology used in this thesis. It then outlined the units of analysis and sources of data, the procedures used to collect data, the application of data collection procedures, and the procedures followed in the practical analysis of the data. The next chapter sets out the case studies. 


\section{CASE STUDIES OF TECHNOLOGICAL INNOVATION IN NEW ZEALAND: 1981-1993}

\section{Introduction}

This chapter contains the case studies of technological innovations. The case research was undertaken in accord with the methodological approach set out in the Methodology chapter. The cases all follow the same general format and major sections, with variations within sections tailored to accommodate the different nature of the various cases. For example, a postscript has been added where significant new events relating to the case occurred after the case research was completed. The major standard sections in the cases are the Introduction, Background, The Innovation, Background of Key People, and Conclusions. All the broad research areas are addressed pervasively within the case study accounts, except for the Background Experience and Education of Key Players (paraphrased as "Background of Key People") broad area which is written as a stand-alone section. The Conclusions section serves as an overview and discussion of the key themes, as well as being a summary of the conclusions.

The cases are the completed versions that have been verified by the research participants, with the exception of minor editing and formatting. References within the cases are included in the Bibliography at the end of the thesis rather than at the end of the case studies. 


\section{CASE 1: ASDi VARIABLE SPEED DRIVE}

\section{Introduction}

The ASDi is a variable speed drive developed by PDL Electronics in association with the Auckland University's Department of Electrical and Electronic Engineering.

\section{The ASDi Variable Speed Drive}

The ASDi was launched in 1988, won the 1989 National Electronics Development Association (NEDA) award, and created a world-class competitive edge for PDL Electronics in variable speed controllers.

The ASDi was PDL's first drive that combined digital electronics and microprocessor control. This gave it a major competitive advantage. The ASDi has a dedicated computer linked to a sophisticated high power waveform generator supplying a customised electrical supply to the motor. The ASDi allows the controller to set performance parameters for the motor. It can interface with existing standard voltage and current control systems. A major advantage of the ASDi is its communication capabilities. The computer and drive system communicate through an RS 485 serial interface, making it easy to link the drive to a central plant computer or to other digital devices.

The ASDi incorporates "Dynaflux" control. Dynaflux control (from dynamic flux control) is an active flux optimisation process that obeys a clear mathematical strategy. The Dynaflux control allows measurement of the load on the motor and adjustment of the voltage to whatever is required by maintaining constant flux in the motor air gap. Dynaflux control leads to some technical advantages, including maintaining constant shaft speed over a wide load range, allowing the ASDi to be operated with torque control, torque limiting or shearpin action. Because motor flux 
is reduced, noise is reduced. However, the major advantage of Dynaflux control was probably as a differentiating feature in the marketing of the ASDi.

The ASDi includes a full diagnostic capability to display the source of any fault which may cause the system to shut down, advance warning capability which can be used to predict the onset of downstream problems in the driven plant before they reach serious proportions, and thermal modelling of motor behaviour for real-time close protection of the motor. This latter feature eliminates the "just in case" factor in motor sizing, thereby often allowing the selection of smaller motors for a particular service.

Later versions of the ASDi incorporated a software development known as space vector modulation.

\section{Background}

PDL Electronics is a Napier-based company specialising in industrial motor control technology. Although owned by PDL Holdings it has a high degree of business autonomy over its commercial operation, $R \& D$ investment and business strategy. The company in 1994 had over 100 staff, with about a third having technical qualifications. It spends between 5-7\% of its turnover on R\&D. As at 1993 it had around $70 \%$ of the New Zealand market in industrial drives.

\section{Origins and History of PDL Electronics}

In 1973, two Napier electricians established Industrial Electronics and Automation (IEA) to make and service electrical and electronic equipment. The company began marketing inverters in the early 1970 s.

In 1974 IEA was bought by the cigarette giant Rothmans, which wanted a company to manufacture cigarette vending machines. A very entrepreneurial and visionary 
managing director, Bruce Lindermann, took a long-term view of company strategy, and also struck up a relationship with David Byers, a senior lecturer at Canterbury University.

While owned by Rothmans IEA had developed a "technology culture" which positioned R\&D as a core part of business strategy. This corporate culture was established very early in the company's history, survived changes of ownership, and was crucial to the later success with the ASDi.

In the late 1970s Keith Valentine, IEA's General Manager, reached agreement with Canterbury University for the development of AC motor controllers. At this time David Byers, a senior lecturer at Canterbury University, was working with a series of very able students in fields related to motor control. Byers provided the inspiration and ideas to students and also worked closely with companies on the application of the technology.

In 1976 IEA introduced one of the first production Pulse Width Modulated (PWM) solid state variable frequency drives in the world and the first in New Zealand. This was a three phase variable speed AC motor controller using new solid state switching devices and patented waveform generation techniques.

Between the earlier boom in vending machines and the growth in the motor control business, IEA suffered a slump in sales and staff halved to 20. However, in 1978 IEA introduced the DJB series (named after David John Byers) based on "inverter grade" Silicon Controlled Rectifiers (SCRs). Things improved further with the 1979 NEDA award for the DJB Series, and with the establishment of an agency in Australia in 1982.

By 1980, IEA had established an AC motor speed control market in Australia and New Zealand based on two types of inverters using SCRs as the basic switching element. Keith Valentine in the early 1980s made contact during a US conference with semiconductor manufacturers who were leading in the fields of power transistor 
and waveform generation technologies. In 1982 IEA launched the Microdrive, a low cost range of drives that incorporated the latest commercially available transistors from Fuji Electric. This amounted to a significant technical step forward. Since then, the company has maintained its relationship with Fuji Electric, and this link with a component supplier proved invaluable in later years.

In 1983 an IEA engineer, Murray Porteous, won the NEDA award for the Microdrive controller, and in the following year the Microdrive received the Design Mark award. Experience gained with the Microdrive series was then employed in the successful application of power transistor blocks in the ASD series.

The ASD series launched in 1984 incorporated the control features offered in the DJB series, as well as offering new features such as industrial reliability protection circuits for operation in a harsh industrial environment. The ASD series developed by Porteous was runner-up in the 1984 NEDA award. With this range of drives as a building block, PDL was able to capture the major share of the New Zealand market and a significant share of the Australian one.

As motor controllers began to set the company's future direction, Rothmans accepted the lack of affinity with the multinational's core business, and in 1984 it sold the company to PDL Holdings. Throughout the late 1970s and early 1980s, PDL maintained its links with the university sector. From about 1980, the focus of external influence began to switch from Canterbury to Auckland University. This was partly because IEA had developed its technology to the point where it was ahead of Canterbury University, and also because John Boys' work at Auckland University placed it on the leading edge of AC motor control in New Zealand. Boys had a good feel for the commercial side of innovation and was able to achieve an excellent working relationship with PDL. By 1985 a well-developed working relationship had been forged between PDL and Auckland University, and this laid the basis for the ASDi. 
For sources of ideas and stimulus the company also drew heavily on conferences, including those with a strong academic presence, and on technical journals to keep up to date with external sources of technology. Participation in trade fairs was also an important stimulus, and technical links with New Zealand companies in noncompeting industries and with key component suppliers were valuable to the company. There was little substantive contact with the DSIR or other parts of the publicly funded technical infrastructure, but the Development Finance Corporation (DFC) and its predecessor the Inventions Development Authority (IDA) provided some financial support for PDL in its earlier years. In fact, in the judgement of its former General Manager, Keith Valentine, the company may not have survived its early growth stages without the support of the DFC and the IDA.

\section{Technical Background of the Innovation}

Technological innovations do not exist in isolation but rather build on what has gone before.

\section{Technical Origins and Antecedent Technologies}

The advent of the thyristor in 1957 meant that for the first time variable speed drives controlled by power electronic devices could compete with the traditional WardLeonard mechanical systems. DC motors were initially the first choice for controlled drive systems but they then faced competition from Cage Induction Motors (CIMs) because of the low cost and weight, ruggedness and low maintenance requirements of CIMs.

The CIM provides a near constant-speed source of power directly from a conventional three-phase supply at high efficiency with no special starting arrangements. Conventional DC machines are easily controlled by varying either the armature voltage (or current) and/or the field current. However, CIM speed is fixed by the supply frequency while torque is a complex function of the input voltage, 
currents and the shaft speed. As a result, optimal CIM performance was only achievable through complex electronics.

PWM inverters were first applied by PDL (then IEA) in its DJB series of drives. In the 1970s, the PWM inverter used forced commutated SCRs. The SCR represented the first generation of power switching devices. SCRs cannot switch themselves off, and therefore require additional expensive power circuitry to switch off.

$\mathrm{AC}$ speed control was constrained by a number of factors, including the unreliability of inverters. Inverters were "black boxes" that enabled variable speeds to be achieved in the shaft rotation, but little sophistication could be achieved in the control of the motor's torque/speed characteristics. Most design effort by inverter manufacturers went into newer commutation circuits to reduce costs, rather than into control options.

Technical constraints on AC control only started to be overcome with the development of power Darlington transistors and Gate Turn Off (GTO) thyristors in the late 1970s and early 1980s. The Darlington transistor and GTO technology transformed AC motor control since they allowed turning on and off by gate control, no commutation circuit was needed, and there was a potential $30 \%$ reduction in manufacturing cost. Almost overnight, the high voltage PWM switches became simple and reliable, with manufacturers competing to reduce costs and add improved features.

From the late 1970 s, the switching capacity of transistors roughly doubled each year. Early in 1981 Fuji Electric of Japan introduced the power Darlington transistor commercially and PDL introduced them into the Microdrive series of motor controllers. The ASD series of drives introduced by PDL in 1984 used improved waveform generation in concert with fast, efficient switching power transistor blocks, allowing an average $50 \%$ reduction in volume, reduced complexity, greater efficiency and lower cost. 


\section{The Innovation}

In the mid-1980s PDL was planning a complete redesign of its ASD converters to make them smaller, lighter and cheaper. Murray Porteous forecast some of the technical goals in 1986 , noting that:

The key to the successful application of AC motor variable speed control is a clear understanding of the load, motor and drive characteristics...the future trend is toward more sophisticated drives...offering more intelligent control functions, including computer interface and load analysis...

(Automation and Control, 1986a, p. 54)

PDL understood that a small company in the specialised field of industrial control could not grow substantially in New Zealand and Australia but needed to move farther afield to bigger markets, thereby building turnover to the size where it could support the level of R\&D needed to compete internationally. In effect, the company had to get turnover up to justify the minimum critical mass of R\&D needed. At the same time, economic deregulation from the mid-1980s slowed the economy down, providing even more of an incentive for an export focus.

\section{The University Research}

PDL was aware of the work of Professor John Boys in the Department of Electrical and Electronics engineering at Auckland University and saw the opportunity to use control algorithms to achieve intelligent control over a motor's operating conditions, rather than simply attempting to maintain constant or set frequency. An agreement between Auckland University and PDL was negotiated through the Applied Research Office (later Uniservices Ltd), Auckland University's office that manages external client research. PDL purchased an exclusive licence to use the technology and a proportion of the royalties it paid was channelled back to the university department to fund new projects. 
The early links with John Boys focused on two major technological goals: moving from analogue to digital electronics, and improving the control technology to allow control over such variables as torque and speed.

One research possibility available was vector or angle controlled drive where a variety of external sensors (for flux, angle speed etc.) are added to a drive and sophisticated signal processing methods are then used to control the motor and give it performance superior even to DC drives. However, the New Zealand and Australian market for such drives is extremely small and John Boys focused instead on using a simple PWM inverter with no external sensors to control the motor, and to make such control interactive through a low cost personal computer. The technical approach was a microprocessor-controlled drive with a serial interface, with the PWM waveforms generated in real-time to control the transistor switching instant.

Boys' work at Auckland University integrated the new transistors with low cost microprocessors and newly developed motor control algorithms to implement a new form of intelligent $\mathrm{AC}$ drive control. A major objective was to avoid the need for complex customisation when interfacing with other equipment in a plant, focusing instead on the development of techniques for torque and speed control and/or monitoring which would be simpler to interface and would allow user-friendly information flows for the user.

Simon Walton, a student of John Boys, was undertaking masterate research in 1982 on SCR inverters, which by the early 1980 s were rapidly becoming dated technology. Walton then converted his masterate into a $\mathrm{PhD}$. Walton's $\mathrm{PhD}$ work was initially sponsored by Plessey, with part of the $\mathrm{PhD}$ focused on developing an inverter and part on developing control methodologies.

Boys encouraged Simon Walton to focus his $\mathrm{PhD}$ on the development of what became the Dynaflux algorithm technology. Walton also at this time became interested in a precise control of induction motors known as vector control, which 
was commercialised in the early 1990s in later PDL products, such as the Microvector. In parallel with Simon Walton's work, Graham Taylor at Auckland University was undertaking his masterate research in software engineering. Boys focused this research on microprocessor developments in a motor controller, to underpin Walton's work. By the time Taylor had completed his masterate research a working system was in place. Boys improved the software further to improve the control aspects and computer interfacing.

The technology then essentially "stayed on the shelf" at Auckland University for some time, until Boys organised a seminar for interested companies, including PDL, to demonstrate the technology. This led to the negotiation of an agreement for the transfer to and further development of the technology in PDL.

\section{The Innovation Process}

The first major technology transfer task in developing the ASDi was the "breadboarding" of the Auckland University control algorithms onto a PDL drive to demonstrate compatibility, and subjecting this drive to a series of tests. The University and PDL freely exchanged data and documents and then entered into the most crucial stage, which was the employment of Simon Walton at PDL. Walton was able to finish his $\mathrm{PhD}$ in the company while still under the supervision of Boys. Critical to the success of the university-company relationship was the open exchange of information, the existence of trust, and the desire of John Boys to ensure that things worked, rather than simply to achieve an academic understanding of why they worked. Significantly, Boys also provided some follow-up support and innovation, including a new waveform technology.

At the time, PDL Electronics was a small company with a high degree of interaction between development, applications and marketing people. PDL provided an environment that fostered creativity and in fact some significant innovations, such as a parallel drive technique, were generated as a result of informal discussions and "brainstorming" sessions among engineers. Walton emphasised the importance in 
innovation of that interaction, of the need to avoid the channelled thinking that comes from "compartmentalising" staff, and also that innovative ideas can only really be generated as off-shoots from addressing real problems, rather than resulting from desk-bound research in isolation from other parts of the industrial innovation process.

The ASDi was developed on a team basis, with a lot of interaction between the R\&D and the marketing side. At this time, engineering staff were involved in servicing and related work for customers in the field, and this enhanced the customer focus for the innovation. However, in the later stages of the development of the ASDi, PDL was starting to segment the R\&D group, essentially to accommodate the growth of the R\&D group, and as a means of accelerating the development of advanced new technology. This created some difficulties in maintaining an adequate, interactive dialogue between the R\&D staff and those more involved in the applications and marketing side of it. However, the link between the R\&D and the production staff worked well, very much on the basis of the R\&D effort creating the specifications for and driving production.

PDL, in supporting Simon Walton's work, adopted the ideas and control algorithms developed under Boys' supervision, but more significantly obtained the skills and human capital embodied in Walton. Simon Walton essentially came as part of a package made up of his skills, the software and the hardware. Walton injected new ideas into a company eager to pick them up, while at the same time rapidly making the adjustment from an academic to a customer-driven commercial environment.

Murray Porteous and Simon Walton significantly redesigned and rebuilt the Auckland University system. The software was completely redeveloped, greatly increasing the programme length. A single overworked 8 bit microprocessor was replaced with two microprocessors, and a customer interface was added. Porteous and others provided most of the know-how in the power electronic hardware development. Two microprocessors were used in the drive - one acting as an intelligent user interface, with the other controlling the motor and generating the PWM waveform. PDL also 
added a "personality module" - essentially a plug-in, battery backed-up RAM in which all the drive presets were memorised.

In retrospect, the decision to move to two 8-bit rather than a single 16-bit microprocessor reflected a desire to get as much value as possible out of the available but inadequate hardware, rather than starting from scratch and developing more appropriate technology.

Shortly after the earlier work on the ASDi was completed, John Boys became aware of an improved switching strategy development called space vector modulation. This was developed and transferred to PDL and it proved a major success, adding extra processing capacity to the ASDi's microprocessors. Boys' team also developed the original thermal modelling for the ASDi, while Walton at PDL refined this considerably for use in the ASDi.

The ASDi took the equivalent of about 10 person years of PDL time to develop, with the university contribution (including that of Simon Walton) not only being the key ideas but the advanced technical input that would probably have been impossible for PDL to obtain elsewhere.

Against a backdrop of great mutual respect and professional admiration, the key PDL and Auckland University staff had different perspectives over the value attributable to the Dynaflux feature itself. Uniservices Ltd sought to extract a substantial royalty for the incorporation of the Dynaflux into the later Microdrive 3 (UD 3) innovation. This royalty seemed excessive in relation to the lean margins PDL could earn from the product. After Uniservices declined a lower royalty offer, PDL modified the algorithm to avoid paying the royalty. This disagreement left no lasting ill feeling and may well have reflected the difficulties Uniservices Ltd experienced in understanding and placing a value on the technology in a commercial setting. 


\section{Marketing and Commercial Aspects}

PDL has always maintained a close relationship with the users of drives so that their needs can be embodied in product development, and the company backs this up with comprehensive product support services.

Marketing of the ASDi focused on its technical capabilities relating to torque, speed measurement and regulation, and communication capabilities. PDL was also aware of the need for at least one major differentiating feature or selling point, and this turned out to be the Dynaflux algorithm.

The ASDi was launched by PDL at the School of Engineering in Auckland in November 1988. In the subsequent 12 months, an extensive series of seminars and service training schools promoted the drive to customers locally and internationally. Major New Zealand users of the ASDi included the dairy and the pulp and paper sectors. During this period, the product range was extended from $7.5 \mathrm{~kW}$ to $250 \mathrm{~kW}$, and 200 units with a value of \$NZ3M were sold.

In a very competitive industry with product life cycles of about 5 years, PDL did not patent the innovation, preferring to get superior products to the market ahead of competitors and earn a premium by staying ahead of the competition. Part of this strategy involved upgrades and product improvement. The ASDi was uprated to 355 kW, and in March 1991 to 500kW. By 1989440 amp controllers were achieved, followed by 1040 amp controllers in 1991.

PDL's marketing effort had to overcome distance from markets, language requirements, different standards, and a lack of recognition of New Zealand as a source of high technology equipment. The ASDi was technologically advanced by world standards, and this gave PDL the confidence to move aggressively into the export market. Already by 1989 about $40 \%$ of PDL Electronics products were exported. 
In April 1989, the ASDi was launched into the European market at the Hanover Industrial Fair, generating over 100 enquiries over the 8 day period. The launch included extensive displays and demonstrations of practical applications. This rapidly led to a base of distributors and customers being established in Germany, Italy and the UK. Subsequent visits to Hanover led to the appointment of distributors in Spain and Denmark.

The ASDi was used in applications ranging from air conditioning fans in buildings in London, Singapore and Auckland, town water supply pumps in Scotland, Queensland and Whangarei, food processing in Korea, Victoria and Hastings, cement plants in Israel and Australia, gantry crane control in New Zealand, ceramic ball mills in Italy, mining in Australia, and conveying mine ore at an altitude of over 3,000 metres in Chile.

The ASDi by itself substantially expanded PDL's turnover and exports and allowed it to expand into new markets against intense competition from Japanese, American and European companies. By mid-1991 the ASDi represented about $40 \%$ of PDL Electronics turnover. Building on the profile achieved through the Hanover trade fair, a further breakthrough into the German and European market occurred when PDL won a major fan motor drive tender for a Leipzig power station in 1992. Based on its solution to a similar technical challenge with the installation of a $1040 \mathrm{amp}$ drive at a powdered milk plant in New Zealand, PDL won the contract with its ASDi $1040 \mathrm{amp}$ drive. Germany is now PDL's largest single export market.

The innovation and its later variants therefore provided a launching pad for significant PDL inroads into international markets and laid a basis for the company's growth.

\section{Technical Platform for Later Innovations}

The ASDi was not only a major new product but represented a transition in technologies, which in turn laid a technical platform for other products. In particular, the ASDi allowed the company to build on its strengths in analogue-type circuitry and 
in power electronics hardware by adding advanced microprocessor control algorithms. Microprocessor control also allowed more technical features to be built in.

Especially through Simon Walton, the work associated with the ASDi gave PDL advanced new competencies in motor control theory and capability and control algorithms. The ASDi combined these new technologies and skills with the power electronic strengths of PDL engineers such as Murray Porteous. Since the ASDi, all of PDL's subsequent ranges of drives have built on its technical advances and been microprocessor based.

Specific technical features in the ASDi laid the basis for, or were incorporated into future innovative products developed by the company. Dynaflux was incorporated with some software modifications into the third generation of the Microdrive, the UD3, launched in May 1991. The Microvector introduced in 1993 embodied ideas developed as spin-offs from the work of Walton and Boys in the mid-1980s.

\section{Background of the Key People}

Murray Porteous received his BE (Hons) degree in 1979 and his ME in electrical engineering at Canterbury University under David Byers. After a period working with Byers and the Canterbury University Electric Vehicle group developing high speed transistor inverters, he joined IEA in 1981. In developing controllers in IEA Porteous drew actively on the applications experience of other IEA engineers, the production techniques of manufacturing staff, and the feeding in to product development of customer requirements from the IEA sales team.

Keith Valentine was PDL Electronics' General Manager at the time the ASDi was developed. Valentine did a BE in electrical engineering at Canterbury University, worked in broadcasting, and then joined BP. Later he completed a Diploma in Business Administration. In his five years at BP he worked in marketing of non- 
electrical products such as fuels and lubricants, before moving to Cable Price and moving back into the importing and selling of electrical products. During this time, Valentine worked primarily in the administration and marketing side of the business, and developed an intimate understanding of the connection between the product and the application.

Valentine set up the agreements with Canterbury University and later with the Applied Research Office (later Uniservices) at Auckland university leading up to the development of the ASDi innovation. On acquiring IEA from Rothmans Industries, PDL Holdings appointed him General Manager of the restructured company. Keith Valentine has since left PDL and now runs a company that imports drives from overseas.

PDL's involvement in variable speed drives really had its genesis in the work and stimulus of David Byers, a senior lecturer and "larger than life" character at Canterbury University. Byers joined the Department of Electrical Engineering at Canterbury in 1964 after a varied and eventful career in the RNZAF as a technical signals officer. After study leave in the UK in 1972, Byers moved into research relating to $\mathrm{AC}$ motor control, especially focusing on variable frequencies and variable voltage power supplies. Byers' main contribution was ideas and the development of the "human capital" embodied in his students.

David Byers' early work at Canterbury University, including in waveform generation techniques, provided both the technological base and the research supervisory focus that led to the development of motor control drive technology in IEA and GEC (NZ).

David Byers essentially introduced the concept of AC motor control to New Zealand and his students transferred his ideas and technology to companies they joined. These externally generated sources of ideas, technology and trained people from Canterbury were effectively exploited by IEA. IEA's link with Canterbury University was initially made through the Inventions Development Authority (IDA), and only later did IEA work directly with Canterbury rather than through agencies such as the IDA. IEA 
sponsored students at Canterbury University to finish off their masterates. One ME graduate at IEA, Alan Cooper, was funded to transfer back to Canterbury University for a year, adapt technology and transfer it back to the company. IEA paid for research work at Canterbury University, for the use of university facilities, and for David Byers' input as a consultant to the company and as a project supervisor.

An inspirational supervisor, Byers did not however attain the level of familiarity with the realities of the commercial world that was later achieved by Boys. This was primarily because, while Byers fostered the ideas and the development of research skills in his students, he also sought to move beyond that and exert a high degree of influence and direction over the applied engineering and product development work within companies.

As a visionary with a strong personality, Byers attracted some of the most able students around him, including Murray Porteous and John Penny. John Penny's masterate laid the basis for the Ranger drive commercialised by GEC. While widely acclaimed as an outstanding innovative and technical achievement, the Ranger was not a commercial success on the scale of the ASDi. After a period in GEC, Penny moved to PDL Electronics and became a key member of its R\&D and engineering team from 1990.

Byers retired in 1987, and with Boys is remembered as one of the two academics who laid the intellectual and the research supervisory base for New Zealand's exceptional competencies in variable speed drive technology.

The driving force in motor controller development at Auckland University was John Boys, a strong personality at Auckland University as David Byers had been at Canterbury. Boys' reputation meant he was able to attract able students and provide research leadership and links with applications, as well as the supervisory focus needed to ensure $\mathrm{PhDs}$ didn't stray too far from their achievable goals. 
John Boys is most unusual in the university scene in providing intellectual leadership for graduate students while achieving striking success in developing links with industry. John Boys sees himself as an engineer rather than as an academic, having spent an extended period in industry.

Boys did a $\mathrm{PhD}$ in radio science and worked for a software subsidiary of the Racal group in England. This company wrote computer-aided design programmes and Boys worked in the fields of printed circuit board layout and related areas. Boys then accepted a job with a company that made "high strength fasteners" (bolts) for the aerospace industry. Boys worked for this company for over 4 years and invented, among other things, a method of counting metallic parts with a high degree of accuracy, and a machine for the very precise tightening of bolts. The company set up a business based on this, using the tightening technology for assembling aerospace and automobile products. Boys' industrial experience included a strong grounding in electronics applied to the mechanical engineering industry.

Bovs then moved to Canterhurv Iniversitv for 3 vears and worked in ultrasnnics.

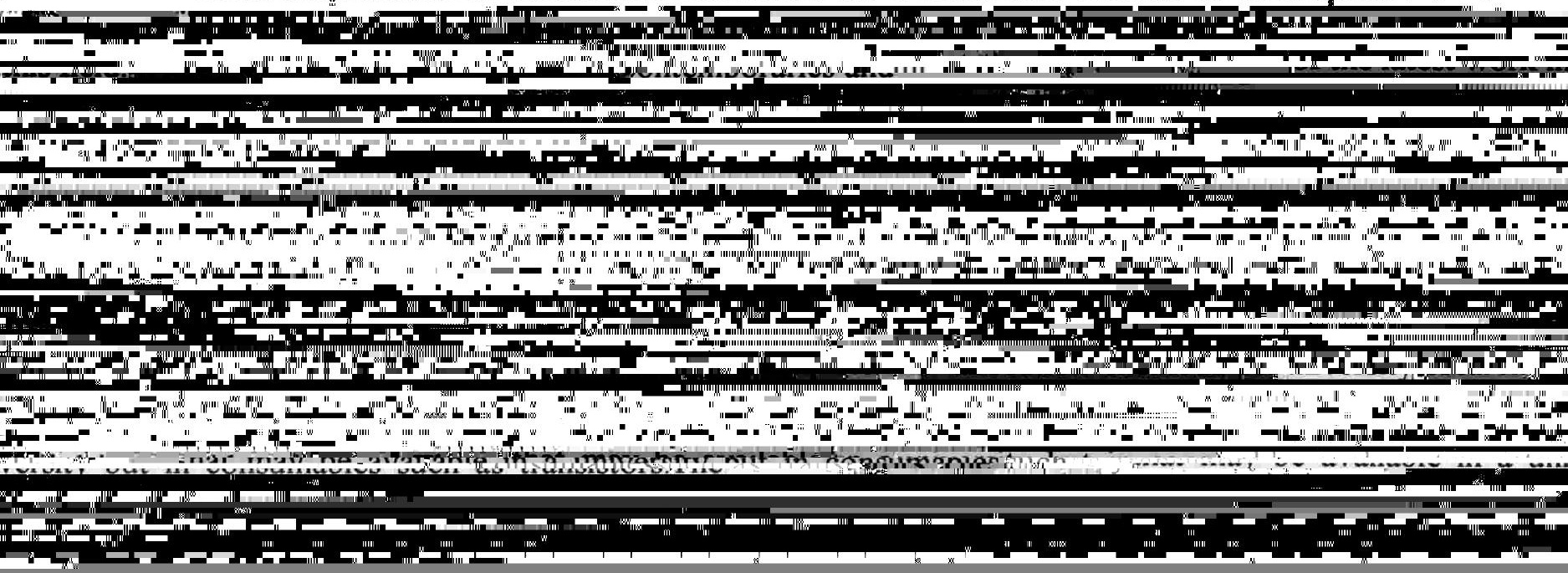


applied nature of the research also lent itself to commercial interaction with companies such as PDL. In fact, by 1991 about $25 \%$ of the Auckland University Electrical and Electronic Engineering Department's budget came from industry (Industrial Equipment News, 1991b, p. 7).

John Boys' PhD students included Ross Green who worked with modified inverters and who now part owns a UK company called the Technology Partnership, and Mike Forster who is now the technical director of Control Techniques, the largest manufacturer of variable speed drives in the UK. By the time Simon Walton began his $\mathrm{PhD}$, Boys had achieved an international reputation in his field and was attracting very able post graduate students as a result. Boys generated new ideas and concepts and students such as Simon Walton investigated them, often generating new ideas themselves.

Simon Walton graduated with a BE from Auckland University in 1980 before commencing a masterate, initially under Bruce Gatland, on a control problem involving induction motors. The masterate took on a life of its own and then, under the direction of John Boys, Walton focused his research on using power electronics to improve the performance of induction motor control.

Walton's work at masterate and $\mathrm{PhD}$ level coincided with rapid advances in consumer electronics and embodied multi-disciplinary approaches that allowed Walton to avoid too much narrow specialisation too early in his work. This allowed him to build up a broader base of expertise that allowed wider opportunities for application.

In the early stages he received some sponsorship from Plessey, until Plessey decided to give up on the market for drives. Walton completed his $\mathrm{PhD}$ in 1986 in his first year of employment at PDL Electronics. In early 1989, Walton was promoted to Senior Design Engineer. Walton had an exceptionally good understanding of the induction motor and its control theory which, combined with his broader understanding of electronics and control, were among the most critical factors in the success of the ASDi. 
Simon Walton had a strong interest and aptitude in technology and power electronics from childhood days. Walton says:

...I always had an interest in electronics, fiddling around, power electronics appealed to me because of its capacity to do damage - as time went on I simply got more interested in it.

Walton was also driven by a desire to solve a problem and shift back the frontiers rather than simply to fulfil academic degree requirements.

\section{Conclusions}

PDL Electronics was founded on technological innovation that gave it a competitive edge in the market. Its motivations in developing the ASDi sprang from its strategic need to use new technology as the core of its business strategy. The profits and market share resulting from earlier research and technological innovation inspired by Byers and his students gave PDL the confidence to invest heavily in the ASDi. The engineering and electrical skills the company had built up through about 15 years of work in AC speed control gave it the competencies to successfully commercialise the innovation.

The growth of PDL Electronics and the focus of its innovative product development has been driven by the vision of the key people involved in the company. The small size of companies and of the total market in New Zealand has also been a major factor. New Zealand companies in most sectors lack the economies of scale available in other countries, relying instead for competitive advantage on economies of scope and flexibility in production for niche markets. Variable speed drives with customised control fitted the need for flexibility.

While New Zealand is a small country, its industrial plants in sectors such as agricultural and forestry processing, metals and petrochemicals provide a microcosm of the world market in these industries. PDL's engineers were always close to and understood the market, and this paid off with PDL's enviable record of picking the 
right technical path when there were competing technological approaches to choose from.

The high degree of technical competition in the industry, PDL's familiarity with the market, and the need to expand internationally to achieve the economies of scale and scope needed in the motor drive market were key motivations of PDL managers such as Keith Valentine and Murray Porteous.

The ASDi is a world-class development, and one of the major New Zealand innovations in the 1980s. It is one of the very best examples of university-industry relations in New Zealand. It illustrates the synergies that result from university research that shifts back the frontiers and injects new ideas into an industrial company that has complementary skills in engineering and technology applications and an intimate knowledge of the market.

The development of variable speed drive technology in New Zealand illustrates the pre-eminent importance of strong and charismatic academic supervisors who can provide intellectual leadership and attract able students to work in their field. The contribution of such supervisors includes the creation of skills and competencies that are later applied, often in different and unexpected ways, in a commercial setting. This is probably a more important contribution than the creation of research results which are then transferred in a linear way from a university to a company.

PDL's association with Auckland University generated new technical ideas and control algorithms embodied in the ASDi but also helped the company on an ongoing basis to keep up to speed with the latest technical developments overseas. Significantly, the innovation depended on PDL having the in-house skills and research and engineering capabilities to turn university ideas and core technology into something workable in the market. University research results only lead to commercial outcomes when companies themselves have the skill-bases and technology "absorptive capacity" to understand and apply them. 
PDL was able to exploit academic ideas and staff and student competencies to go from being a small company vulnerable in its largely domestic market, to being a significant player in international markets. Auckland University gained substantial financial support for its research, as well as a measure of the relevance and suitability for industry both of its research and of its graduate students.

Key lessons from the case are the need for openness and trust, and for the effective knitting together of the academic and commercial inputs involved in innovation. The case also illustrates that the movement of people is the best form of technology transfer, and that technology transfer is often the transfer of tacit know-how and human capital rather than the transfer of codified and research-based knowledge per se.

\section{Postscript}

In 1994, Simon Walton, Murray Porteous and John Penny left PDL to found Innovative Developments Ltd, a technology-based company established to perform engineering consulting and joint venture electronic development. The loss of the company's three key technologists may have profound implications for PDL Electronics in the future, but on the other hand New Zealand has gained a very interesting new start-up company. 


\section{Appendix 1}

\section{Key Events in the ASDi and Associated Innovations}

\section{Key Events}

1964

David Byers joins Department of Electrical Engineering at Canterbury University

February 1976 Technology agreement with Canterbury University (Patents NZ 171872/174825, UK 1486811/2, US 3947736)

November 1976 DJB Series introduced in New Zealand

John Boys joins Department of Electrical and Electronic Engineering, Auckland University

Simon Walton begins masterate research on a control problem involving induction motors

October $1982 \quad$ Microdrive Series introduced

November 1983 ASD Series introduced

August $1985 \quad$ Microdrive Mk 11 introduced

November 1985 Technology agreement with Auckland University

1986

Simon Walton joins PDL Electronics from Auckland University and completes $\mathrm{PhD}$ 
November 1988

April 1989

1989

November 1990

March 1991

April 1991

1992

March 1994
ASDi Series introduced

ASDi launched into European market

(Hanover Trade Fair)

NEDA award to Simon Walton and Murray Porteous for the ASDi

ASDi to $355 \mathrm{~kW}$

ASDi to $500 \mathrm{~kW}$

(Parallel inverters)

Microdrive-3 introduced

(IGBT, "Whisperwave" modulation, incorporating Dynaflux)

PDL receives export commendation from Tradenz

Murray Porteous, John Penny and Simon Walton leave PDL and form a new start-up company 


\section{CASE 2: KIWIFRUIT WINE}

\section{Introduction}

The kiwifruit wine innovation is based on the process developed by Heatherbell et al (1980), with later work done by Lodge (1981) and Withy and Lodge (1982). Most kiwifruit wine is similar to Riesling Sylvaner or Muller-Thurgau wine, with a fresh and fruity flavour and aroma and a high vitamin C content. Several different types of kiwifruit wine are made, including dry, sweet and carbonated wines.

The wine is cheaper to produce than grape and many fruit wines primarily because, while prices of kiwifruit and grapes fluctuate, kiwifruit gives a higher yield per hectare and a higher volume of juice (about $84 \%$ ) can be extracted from the fruit. Fresh kiwifruit, unlike grapes, can be kept in coolstores for up to 12 months without deteriorating, enabling wineries to be kept going all year round. The wine has a short shelf life and is best consumed in the year of vintage, though storage can be prolonged by refrigeration.

Kiwifruit wine earned David Heatherbell and Norman Lodge a Ministerial Award for Technological Excellence in 1987.

\section{Background}

The kiwifruit industry developed first in New Zealand, based on a small quantity of Actinidia chinensis seed introduced in 1904 from China and planted by Alexander Allison in Wanganui. Selection of the Hayward variety by Avondale nurseryman Hayward Wright had, by 1935 , produced plant material with commercial potential. Pioneering work in the mid-1950s by H. M. Mouat of the Fruit Research Division, DSIR, laid a scientific base for variety classifications and comparisons, but the industry only grew substantially from the early 1970 s on. 


\section{Market Background of the Innovation}

Commercial kiwifruit orchards occupied less than 40 ha in the early 1950 s, but totalled 8,000 ha in 1982. In 1982 alone, around another 2,500 ha was planted. Kiwifruit production rose from 2,338 tonnes in 1971 to 17,965 tonnes in 1980 (Lodge, 1981, p. 35). In 1980, 1,968 tonnes of fruit was processed, with exports including canned slices, frozen pulp, frozen slices, and small amounts of freeze-dried slices.

The major external barrier for kiwifruit wine to overcome was the perception in New Zealand that it was an inferior product because it was not made from grapes. Kiwifruit has a strong flavour and people found it difficult to accept that it could be the basis of a quality wine. This barrier proved impossible to overcome, and Prestons eventually gave up any real focus on the New Zealand market once it had established itself in the tourist market.

Export-quality fruit initially commanded premium prices, but as early as the mid1970 s the industry and DSIR scientists realised that production volumes would inevitably lead to large quantities of non-export grade fruit and an associated need for processing. At this time about $20 \%$ of the crop was rejected for export, and the longterm trend was towards more demanding export standards, and therefore an increase in the proportion as well as the total volume of fruit that needed to be processed.

\section{Technical Background of the Innovation}

The first reference to using Actinidia for wine production was made by Graebener in 1894 (see Lodge, 1981 p. 35). A Chinese visitor to DSIR in 1981 mentioned that the people of South China, where the fruit grows wild, have for many years used kiwifruit juice to make a Chinese-style heavy, sweet white wine (Burns, 1981, p. 39). Zukovskij (1950) stated that "Actinidia arguta produces an excellent wine" while Vitkovskij (1972) alluded to an Actinidia-based wine that had "the qualities of 
champagne wine". However, none of these authors validated their claims or gave details of the wine making processes used.

Kiwifruit presents some unique processing problems associated with its high acidity, the presence of proteolytic enzymes which degrade protein, and a tendency to oxidise, leading to colour deterioration in the processed product. Kiwifruit juice is unusual due to its high concentration of quinic and ascorbic acid and its low soluble solid content. Quinic acid causes an astringent taste in kiwifruit juice. When pressed, kiwifruit yields a viscous pulp with little free-run juice being released through pressing.

Because commercial horticulture of kiwifruit had been a world first for New Zealand, and had produced significant crops only from the early 1970s, there was little in the way of an international body of knowledge to exploit. As a result, most of the knowledge base on kiwifruit breeding and selection, production, post-harvest physiology, and on the fruit's composition and processing characteristics, had to be developed in New Zealand.

\section{The Innovation}

In the late 1970 s and early 1980 s the DSIR was a government science department with funding appropriated directly from Parliament. It lacked commercial powers, but on the other hand there were few "user pays" earning requirements or constraints on applied product development or interactive partnerships with industry.

The DSIR at the time tended not to patent or earn royalties, and researchers earned little personal reward from successful technological innovation. Promotion often depended on scientific achievements and academic paper publications. DSIR scientists were not all that well paid, but their work was prestigious, they had a great deal of intellectual freedom and the right to work on undirected research. 


\section{The DSIR Research}

In the mid-1970s David Heatherbell, a DSIR scientist, was experimenting with a wide range of fruit products including feijoas, tamarillos and kiwifruit. This included work on clarified juice products from kiwifruit, schnapps, and distilled kiwifruit liqueurs. At this time Heatherbell heard suggestions that wine could also be made from kiwifruit.

David Heatherbell's work was very much "science push" research that was in advance of industry and market demand, but which still focused on creating a knowledge base that industry could exploit in the future. A positive feature of the DSIR environment was the ability to pursue new opportunities, to think reflectively, and to advance the frontiers of strategic and high risk research. Heatherbell says of this time:

You did feel that you belonged to a little elite, that you belonged to something special, even though it wasn't the highest prestige group in society...I think you had good directors you felt like you wanted to achieve for, and it was something to do with your age as well...I was clearly focused and highly motivated.

Much of Heatherbell's work was multi-disciplinary and he was also aware of work done by Rainer Eschenbruch at the MAF Research Station at Te Kauwhata. Eschenbruch and a technician, Tom van Dam, had attempted to make kiwifruit wine using conventional wine making techniques. The product had bitter off-flavours, and was "grassy, green and stalky" in aroma and taste, with an unacceptable bitterness and astringency.

Using different technology to that traditionally used in wine making, Heatherbell experimented by treating juice samples with pectinese enzymes, with other samples being centrifuged. He noted that samples that had been pre-treated with enzymes changed in taste and aroma and developed a Riesling-Sylvaner character.

A key technical advance was the realisation that fermentation of kiwifruit juice by itself led to a very bitter wine, and that an essential step was enzymatically treating the 
juice prior to fermentation. Heatherbell et al established that juice clarification with pectolytic enzymes to remove residual pectins before fermentation is essential if wines with acceptable aroma and taste are to be produced. The pectolytic enzyme processing removes astringency and bitterness and catalyses the emergence of a fruity, Riesling-Sylvaner style aroma during fermentation. The removal of bitterness and astringency coincides with the removal of flavonoids and a reduction in total phenols.

This pioneering research was summarised in a seminal 1980 publication (Heatherbell et al, 1980). Heatherbell et al also showed how the juice extraction yield could be increased from $55-60 \%$ to $84 \%$ by treatment of the pulp with pectolytic enzyme. Both enzyme and press-aid treatments produced juices with low solids content. Water and sugar was added to raise the soluble solid content and lower the titratable acidity.

Heatherbell's detection of an attractive aroma and flavour resulting from these experimental techniques was a key milestone in the kiwifruit wine innovation.

David Heatherbell continued his work and in 1978 supplied samples to an international wine symposium held in Auckland. Heatherbell hosted several German wine experts attending this symposium in his home, and conducted a blind tasting of kiwifruit wine and a number of grape wines. The experts picked the kiwifruit wine as the best "Riesling-Sylvaner", praising it for its fresh and fruity flavour.

The work of Heatherbell et al was followed by that of Lodge (1981) and Withy and Lodge (1982). The process eventually brought into commercial production included enzymatic treatment before fermentation, adding water to reduce the acidity of the kiwifruit juice, and then initiating fermentation with an actively growing yeast strain. Sucrose was then added to supplement natural sugars to allow an alcohol content similar to grape wine to be achieved. Sulphur dioxide was added during fruit crushing and at bottling to retard browning. 


\section{Technology Transfer and Commercialisation}

David Heatherbell first approached the head of Montana Wines in New Zealand in the late 1970s and sought to interest him in kiwifruit wine making. At this time the grape wine industry was still emerging, and fruit wines were looked down on as inferior products. Montana decided not to invest in kiwifruit wine making.

At the end of 1978 Heatherbell took up a position in the United States. His papers and presentations at meetings served to publicise his breakthrough not only in New Zealand but also led to some kiwifruit wine making in California, France and Italy.

After Heatherbell's departure to the United States, Norman Lodge did further refinement and modification of the process and took up the task of encouraging and facilitating its full adoption and commercialisation in industry. An important step was delivery of papers at conferences to build awareness of the possibilities and to stimulate interest in developing the process further. This aimed to overcome reticence from the existing wine industry and to stimulate new entrepreneurs to investigate the commercial development of kiwifruit wine.

The DSIR at the time had no major commercial revenue requirements, and did not actively manage intellectual property to achieve a financial return. Research results were seen as being publicly available. DSIR at this time tended to be "all things to all men", and an expectation was created that because it was publicly funded the private sector had unlimited access to its services and capabilities. DSIR technologists such as Norman Lodge were able to deal with all clients with few major restrictions. Lodge was able, for example, to assist competitors such as Preston's Kiwifruit Winery and the Kiwifruit Wine Company.

Fruit wine makers initially assumed that kiwifruit wine would be commercialised by the larger and better resourced grape wine makers. However, the existence of a regulation barring the making of fruit wine on the same premises as grape wine to avoid contamination or adulteration effectively discouraged grape wine makers. This 
provided an opportunity for smaller and very entrepreneurial fruit wine makers to enter the market, with at least some confidence that they would not be blocked by larger, established players.

Regulations were also in place preventing the addition of water to grape wines. Fruit wines often needed water added to reduce acidity. Grape wine makers launched a concerted campaign arguing that this distinction gave fruit wine makers an unfair advantage in being able to produce a cheaper product, and that government should regulate against it. This move failed, but anticipating the possible regulatory threat, Lodge and colleagues used a deionisation process using ion exchange resin to reduce the acidity of kiwifruit juice without adding water (see Lodge et al, 1986). This research demonstrated that it was possible to make wine from $100 \%$ kiwifruit juice while still reducing natural acidity levels.

Lodge made a major contribution at this time in providing ongoing technical assistance to companies such as the Kiwifruit Wine Company and Preston's Kiwifruit Winery, to help solve the problems of moving from a laboratory-scale process to full commercial production.

The first commercial production of kiwifruit wine was undertaken by Russell Baker, a solo operator, in Te Puke. His product was on the market by October 1981. Other producers then entered the market, but often in an unsystematic and badly planned way. A difficulty with some early attempts was that wine makers took shortcuts and produced an inferior product, only gradually learning that the published procedures had to be followed precisely. For example, some producers attempted quicker, easier juice yields without full enzyme treatment of the juice before fermentation.

Preston's Kiwifruit Winery entered the market in Easter 1982. This winery was established outside Tauranga by ex-Wellington butcher and builder Paddy Preston, and his sons Warren and Tim. Paddy Preston was an entrepreneurial figure who came to Tauranga armed with a hobby interest in wine making, and who first explored the possibility of buying a kiwifruit orchard in the region. Having learned of the DSIR 
achievements in the media he approached DSIR for further information and his focus shifted to kiwifruit wine.

The Preston family lacked expertise in wine making, and it was a major effort for them to solve problems associated with upscaling laboratory processes that worked with 10 litre samples to commercial production of 1,000 litres of kiwifruit wine at a time. Much of this involved trial and error, learning from other wine makers and machinery producers, and the invaluable technical assistance of Norman Lodge. The Prestons built their winery with largely second-hand equipment and did not invest in substantial new equipment until about 1988. Preston's Kiwifruit Winery is now widely credited with perfecting the total process cycle for kiwifruit wine making, and with producing the best quality product.

In early 1982 Te Puna orchardists David Manton and Bill Smith first discussed the possibility of a kiwifruit winery. Later talks with two other orchardists and some market research undertaken suggested good sales potential for a quality kiwifruit wine, and in 1982 the Kiwifruit Wine Company was formed. This company eventually had 9 shareholders, made up of orchardists and local business people. The principals of the Kiwifruit Wine Company were shareholders who employed specialist staff, rather than being a family or other partnership where the owners were also the wine makers and the business operators.

David Manton then formally approached Norman Lodge with a lawyer and financial adviser, and sought advice on the process, as well as on wine makers with the skills needed to produce the product. Norman Lodge recommended Neville Wilson, a wine maker at Selaks. Wilson was recruited and the Kiwifruit Wine Company was established to produce a wine under the brand name "Durham Light".

The Kiwifruit Wine Company established its winery and produced its first wine in 1983. The winery was named Hayward-Lodge in honour of Hayward Wright, the breeder of the Hayward kiwifruit variety, and Norman Lodge. The company created the Durham Light brand, named after the Light Infantry Regiment stationed at the site 
of the winery at Glen Lyon Place, Greerton from 1864-1866. The winery was granted permission to use the now disbanded Regiment's badge on its labels.

The Kiwifruit Wine Company invested heavily and probably extravagantly in the very best new equipment and plant, including a two thousand bottle an hour automated bottling and labelling conveyor system, to allow for ambitious plans for future expansion. Investment in the winery in 1983 dollars was estimated at over \$1M. Neville Wilson, with some input from Norman Lodge, helped supervise the design and building of the winery.

\section{Marketing and Commercial Aspects}

By 1983 kiwifruit wine was creating a lot of interest due to its novelty and its image as a unique New Zealand product. Durham Light wine was accepted for use in the official residences of the Governor General and the Prime Minister. A number of top restaurants added the wine to their wine lists.

The first significant commercial success for kiwifruit wine however came in the Japanese market. New Zealanders, Europeans and Americans favoured grape wines and treated fruit wines as an inferior product. A possible opportunity was seen in the Japanese market that did not have such biases. The Kiwifruit Wine Company endeavoured to produce a kiwifruit wine with a high vitamin $\mathrm{C}$ content, lightness, and a sweetish character that it believed could appeal to the Japanese. At this time identification of the tastes and preferences in overseas markets was almost guesswork, and only in later years did DSIR and other research institutes develop systematic programmes of sensory evaluation.

The Kiwifruit Wine Company led by its marketing manager, David Manton, took a systematic, professional and team-based approach to marketing the wine in Japan. The key objective was to establish links with a marketing and distribution agent in Japan, and the breakthrough was achieved when a relationship developed with Suntory, the fourth largest liquor distributor in the world. Assistance was requested 
from Norman Lodge in developing the Japanese market. Lodge had some knowledge of this market and went on the company's marketing mission to Japan. The team sent to Japan included David Manton, a grower, an accountant, a legal adviser, a writer for Metro magazine and Norman Lodge, all with specialised roles to play.

The team met with Suntory executives and made a positive impression with their knowledge, preparation and overall approach. Suntory's president was given a bottle to sample. Suntory was impressed enough with the product to feature it in a glossy brochure of wines and spirits.

Durham Light was targeted at the Japanese market, and hopes were held for a niche among young Japanese "office ladies". These were young, single women with discretionary income who were becoming more cosmopolitan and disliked spirits and drinks that had masculine associations. It was thought that a relatively low alcohol ( $8.5 \%$ by volume) kiwifruit wine with a high vitamin $\mathrm{C}$ content would appeal to this market. The Japanese had fewer ingrained prejudices against non-grape wines, since after all their own traditional wines were made from rice, and some other alcoholic drinks were made from sweet potatoes.

The Kiwifruit Wine Company exported 43 crates of wine for display and sampling purposes to the Foodex 83 wine and food festival in Tokyo in March 1983. The early reports from the wine sampling were positive, and the Japanese found it hard to believe it was not made from grape juice.

The link with Suntory gave Durham Light an entry into the Japanese market, and over 2 years about 20 container loads were exported. David Manton managed an advertising campaign in Japan which coincided with a New Zealand Kiwifruit Authority's fresh fruit promotional campaign. At this time, kiwifruit wine was both the only fruit wine and the only New Zealand wine that Suntory imported. In 1985 the Kiwifruit Wine Company also launched a kiwifruit liqueur, also produced by Neville Wilson. 
By 1985 Durham Light Kiwifruit Winery employed just under 20 people at peak times, and by 1986 about $\$ 1.5 \mathrm{M}$ in kiwifruit wine was being exported annually. This amounted to a substantial part of New Zealand's wine exports at the time.

This early success with a relatively large volume of sales gave the Kiwifruit Wine Company an optimistic view of long-term market prospects. However, these sales were to liquor distributors and were used to provide small amounts of stock to a very large number of outlets. The sales did not in fact represent consumer purchases or ongoing demand. With no further marketing and advertising funding available from New Zealand, Suntory realised the product was not selling well and was no longer prepared to put major effort into its promotion.

The poor sales were partly due to the failure of labelling to differentiate the wine, and the lack of the large-scale promotional resources that would be needed to make an impression in a market such as Japan. The marketing of kiwifruit wine may well have confused whether the wine was a distinct new beverage with unique attributes, or simply an undifferentiated copy of grape wine which sought to emulate grape wine flavour without however being "the real thing". For example, Durham Light's label did not feature a kiwifruit, although Prestons' labelling strongly identified the wine with kiwifruit.

The Kiwifruit Wine Company's enthusiastic foray into the Japanese market indirectly helped pave the way for the Prestons. Preston's Kiwifruit Winery became active in the Japanese kiwifruit wine market from 1984, with the company visiting Japan every year since. Preston's participated in a number of trade shows there, but found it a very difficult market from 1984 to about 1988. The key lessons it learnt from the Japanese market were the need to be patient and to think and plan long-term. The Prestons have maintained a relationship with a Japanese liquor importer and distributor for the last 10 years, and by 1988 had established a small but worthwhile niche in the market. 
Only about $15-20 \%$ of Prestons' sales to the Japanese are in fact exports to the Japanese domestic market, with the market for kiwifruit wine in 1994 being dominated by sales of wine within New Zealand to tourists, especially to Japanese tourists. Some of these sales take the form of orders for the wine to be delivered to their homes in Japan.

The appeal of the wine is as a novelty and a souvenir from a New Zealand visit. This has proved a small but profitable enough market for Preston's Kiwifruit Winery. With the potential for tourist arrivals in New Zealand to double or treble in the next decade or so, the prospects for this niche market seem good. In more recent years, transport and input costs have dropped and freeing up of the duty free market has helped the Prestons. There are now 3 major duty-free companies in New Zealand, all of which buy from Prestons' Kiwifruit Winery.

Key success factors for Prestons have been that it is a family business and that Paddy Preston and his two sons had strongly complementary skills and personalities. Paddy Preston provided the entrepreneurial vision, while his sons Warren and Tim had a business and marketing background and a horticultural background respectively.

As a closely knit family business, the Prestons were prepared to live on very little for some years and to weather the difficult times together. In contrast, the Kiwifruit Wine Company, with paid employees and shareholders who wanted a medium-term financial return, did not have this resilience. Over-capitalised, the Kiwifruit Wine Company went out of business after about 8 years.

Perhaps the single biggest mistake of the Prestons was the location of their winery several kilometres down a dead-end road. This meant the company never generated the gate sales which have provided the "bread and butter" cash flow for so many small horticultural businesses. However, what the Prestons lacked in formal business planning was made up for by their drive, family cohesiveness, and Paddy Preston's total absorption in the process of innovation and of building a business rather than trying to forecast and plan around the risks or likely financial returns. By 1988, with 
the help of some innovative marketing, Prestons finally achieved a level of profitability which has been sustained, and the company is now doing well and is also diversifying into grape wines.

\section{Market Influences}

In the late 1970 s and early 1980 s New Zealand was a heavily protectionist economy. This meant that freight and other input costs were high, and the exchange rate was often a disincentive for exporters. However, the kiwifruit industry had been supported through subsidised planting and there were a number of tax and other incentives of value to new companies and emerging industries.

An important feature of the innovation process from the early stages was DSIR's role of acting strategically for the industry, anticipating possible technical or regulatory barriers, and influencing the political, industrial and market environment that impacted on the innovation. DSIR scientists such as Norman Lodge facilitated the fruit wine makers in establishing the Fruit Wine Makers Association, and encouraged them to network and to share information. The Association was set up to lobby and act as a focus for the industry, and to stimulate interest in fruit wines, for example by running annual competitions. The first President of the Association was Graham Oldfield, and later Presidents included Paddy and then Warren Preston. The Association was active in establishing export certification standards and codes of practice for the export of kiwifruit wine, for example to allow control of haze formation and other quality factors.

\section{Background of the Key People}

David Heatherbell grew up on a New Zealand orchard before completing a biochemistry degree at Canterbury University. He worked for the DSIR in Auckland in the early 1960s, which then funded him to complete a doctorate in food science at an American university. Heatherbell has a very impressive publication record in food 
and beverage science, especially in juice and wine product research, and some of this work has attracted substantial international interest.

Heatherbell's time as a $\mathrm{PhD}$ student and later as a researcher in the Pacific North West of the United States was crucial. In this region, the fruit wine industry was bigger than the grape wine industry, and it gave him insights into what might be possible for the fruit wine sector in New Zealand. David Heatherbell had grown up in and always had a strong motivation to help the fruit industry and this provided a crucial focus for his research interests.

Norman Lodge grew up in Liverpool with a background that exposed him, as he said, to the "raw elements of life". His early jobs included as a barman and driving instructor. He studied chemistry part-time at the Liverpool Polytechnic before completing an MSc in Food Science at Reading University. Norman Lodge's technical background is in organic chemistry and he started out working for ICI in heavy chemical manufacturing research. He then went to Pilkington and worked in the field of analysis of glass using radioactive analysis for trace elements. Lodge then spent 7 years working in the analysis of food, drugs and water.

After emigrating to New Zealand, Lodge worked with MAF in a chemical laboratory in the dairy division. After completing a post-graduate degree in food science, which built on his knowledge of chemistry, he transferred to the DSIR's food science group. He was heavily involved in food research as part of a Pacific Islands development scheme. After his success with the kiwifruit wine innovation, Lodge's work increasingly focused on technology marketing in Asia and the Pacific, and on the establishment and management of the DSIR's Singapore office.

Linda Withy is a senior technical officer at HortResearch at Mt Albert. Withy did some important technical work with Norman Lodge in improving the kiwifruit wine making process. 
Neville Wilson earned a diploma in Dairy Technology in 1966 at Massey University. Two years later he obtained a Certificate of Proficiency in Food Microbiology. He spent 12 years in the dairy industry, including 6 years as chief chemist at the Manawatu Dairy Company in Palmerston North. He later joined the St George cannery company as chief chemist, before employment as factory manager at the company's Pukekohe and Dunedin factories. Wilson went on to assist the establishment of an Auckland meat cannery before joining the wine industry. After just over a year at Pacific Wines in Henderson, Wilson spent five years as a chemist at Selaks Wines, assisting in the wine making process.

Rainer Eschenbruch earned his $\mathrm{PhD}$ in microbiology and biology from Freiburg University in Germany. His thesis investigated malolactic bacteria in wine making. Eschenbruch came to New Zealand in 1974 after four years at the South African Oenological and Viticultural Research Institute in Stellenbosch. He became a National Research Advisory Council (NRAC) Fellow at MAF, Ruakura in Hamilton. MAF, Ruakura was responsible for the Te Kauwhata Viticultural Research Station, and Eschenbruch became leader of the wine research effort.

Paddy Preston left school at 15 to become an apprentice butcher with his family business, and he later became a builder. Paddy Preston was driven by a single-minded interest in the kiwifruit innovation and "making it happen". He was as much interested in the journey as the destination. He retained a strong focus on kiwifruit wine making until the process had been perfected and the winery had become well established and profitable.

Significantly, Paddy Preston has now started to move into new things, including grape wine making. His drive now comes from trying to make "the best" chardonnay and methode champenoise under a different brand, and establishing a winery with a restaurant close to Tauranga. 
Paddy Preston's two sons, Warren and Tim, had backgrounds that complemented their fathers. Warren had a business degree while Tim had qualifications in horticulture.

\section{Conclusions}

The kiwifruit wine innovation is a fine example of "science and technology push", where a small but worthwhile new industry is initiated by the technical skills and inventiveness of scientists in a public research institute and fully commercialised by small, entrepreneurial companies. Unusually, a key scientific publication, together with some promotional work, provided sufficient stimulus for private sector involvement. Remarkably, DSIR scientists then played a key role in acting not only as the creators of new knowledge for industry, but also actively facilitating industry lobbying, marketing and promotion for the product.

The key players in the kiwifruit wine innovation complemented each other very well. David Heatherbell provided the scientific foundation for Norman Lodge's more applied and developmental work, and Lodge's closeness to industry and to the Japanese market was crucial to successful commercialisation. Both the Kiwifruit Wine Company and Prestons' Kiwifruit Winery were effective at team-based innovation and marketing, and at using specialised personnel for different parts of the business operation.

The entrepreneurial flair of small companies such as the Kiwifruit Wine Company and Prestons' Kiwifruit Winery is a striking feature of the case, and shows the willingness of entrepreneurs to take both technical and market risks with new technology. The competition between Prestons' Kiwifruit Winery and the Kiwifruit Wine Company reminds one of the turtle and the hare fable. The first entrepreneurs commercialising a new innovation very often fail, and success often comes to those who follow, who learn from the mistakes of others and above all have the staying power. 
A lesson from the case is not to be too "pseudo-analytical". Paddy Preston's optimism may be associated with having left school at fifteen and not having been "educated" enough to over-analyse risks and falter at the thought of taking them. What held the business together was its focus on the future and Paddy Preston's "passion for the vision".

Warren Preston, reflecting back on the difficult times from 1981-1988, wondered whether if he had known in 1981 of the lean years ahead he would have devoted 10 years of his life to the company. If the Prestons had done a detailed business plan, put financial values by their time, discounted the years of effort with little reward, and moved only when detailed market research had been completed, they would probably never have tried to make kiwifruit wine or been successful at it. On the other hand, the lack of planning and attention to detail by Prestons caused unnecessary problems, though the company is now more systematic and is investigating ISO accreditation.

While the commercial success of kiwifruit wine has been modest compared to some earlier expectations, it has found an enduring and profitable small niche in the market. That niche is likely to grow with increased tourist arrivals in New Zealand, with the appeal of kiwifruit wine being as a novel and genuinely New Zealand souvenir or memento. 
Appendix 1

Key Events in the Kiwifruit Wine and Associated Innovations

\section{Key Events}

1894

First known published reference to kiwifruit wine

1904

First kiwifruit seeds imported to New Zealand

1925-1935

Selection of major kiwifruit cultivars takes place

1956

DSIR classifies and trials major kiwifruit selections

Early 1970s

Kiwifruit exports begin on a significant scale

1980

Heatherbell et al publish key paper

Easter 1982

Prestons' Kiwifruit Winery launches its kiwifruit wine

1983

Kiwifruit Wine Company establishes winery, named

Hayward-Lodge

1986

Kiwifruit wine exports at about $\$ 1.5 \mathrm{M}$

1987

Ministerial Award to David Heatherbell and Norman Lodge for kiwifruit wine achievement 


\section{CASE 3: RUAKURA MILK HARVESTER}

\section{Introduction}

The Ruakura Milk Harvester is an electronically-controlled milking system developed and commercialised by MAF Ruakura (later Dairying Research Corporation) and AHI Plastic Moulding Company (later InterAg, a subsidiary of Carter Holt Harvey Plastic Products Group). The system is referred to throughout as the Ruakura Milk Harvester (RMH), though it was known at various stages of its development as a Separate Milk Transporter (SMT) or as an Integrated Milk Harvester (IMH).

\section{Background}

The history of New Zealand's dairy industry is one of social and technical innovation. New Zealand was a world leader in the introduction of the herringbone dairy with rapid batch milking. New Zealand innovators played important roles in the development of two of the major technological innovations in dairying - the electric fence and the milking machine.

\section{$\underline{\text { Ruakura Research Station/Dairying Research Corporation }}$}

Ruakura Agricultural Research Station began life as a farm training establishment and only in 1938 did its focus move from training to research. It began its first research on milking and milking machine technology in 1946. Wattie Whittlestone and Doug Phillips were early pioneers in milk harvesting, and by the end of 1950 an efficient relief valve had been designed to maintain vacuum at a stable level. Whittlestone, Phillips and their team developed a milk flow meter and advanced the whole engineering structure of the machine, including its rubberware and testing methods. This improved system was later marketed by the National Dairy Association (NDA) as the "Ruakura Milking Machine". This machine captured some $60 \%$ of the New Zealand market in the mid-1960s. Research also focused on improved milking 
machine cleaning, vacuum pumps, releasers and pulsators, and these steady and incremental improvements enhanced milking machine efficiency and the health of cows. Whittlestone and Phillips also made significant international contributions to the understanding of the responsiveness of cows to machine milking (see McLauchlan, 1982, p. 138).

At the time the RMH was initiated Ruakura was part of MAF Agricultural Research Division, which later became MAFTech. In 1990 the dairy research effort in MAFTech Ruakura was restructured into the Dairying Research Corporation (DRC). The DRC is now a joint venture between the Dairy Board and AgResearch (formerly MAFTech).

\section{$\underline{\text { InterAg }}$}

While the history of Carter Holt Harvey extends back over a century, InterAg's beginnings can be traced to the early 1940s. A company called Plastic Products was set up in 1941 by the father of Bill Foreman, the founder of a major New Zealand packaging company, Trigon. At one stage Foreman senior experimented trying to make plastics out of casein, and while this work was not commercialised it created some of the technical and market knowledge that led him into the plastics industry.

Plastic Products became a New Zealand leader in plastic moulding and related technologies. The core competencies of the company as it evolved were very much applications in plastics and other materials, moulding, and related fields. On the retirement of the company's founder in 1963 the company merged with Alex Harvey Industries (AHI) and was named AHI Plastic Moulding company.

This company's first major product was a vacuum regulator, followed by the Waikato Milkmeter, a product that ended up becoming a big seller. The company moved into pulsators and then to products such as an isolator claw and a mastitis detector. Much of this work and innovation was undertaken in association with Doug Phillips and Dr Murray Woolford. Later, when Graham Duirs joined AHI as its business manager in 
the early 1980s, it was recognised that the company's quality control and its marketing needed improvement. Duirs focused effort on building up the New Zealand market, revamping the distribution network, and on moving to selling systems rather than a more limited emphasis on components.

At this time an opportunity was seen to improve the flow rate in milking machines. In 1983 AHI introduced the Supamilker, a large bore milking system which rapidly became the industry standard. The Supamilker was devised by Warren Coles. Coles had formerly been milking machine sales manager for the NDA during the time of the original Ruakura Milking Machine. He managed the AHI milking machine business before Graham Duirs joined the company. The Supamilker was a simple redevelopment of conventional milking machines that increased the milk pipeline size. The Supamilker's high capacity milk line speeds up milking and allows the milk to flow below the airflow in the line, which helps eliminate a common cause of vacuum fluctuations. Compared to other machines, the Supamilker's high capacity reduced turbulence in the milk line, with some potential benefits in milkfat quality.

By 1988 AHI had merged with Carter Holt to become Carter Holt Harvey (CHH). AHI Plastic Moulding Company was renamed Plastic Products, before being renamed the Milking Equipment Division and then the Agricultural Division, before finally in 1992 becoming InterAg, a subsidiary of the CHH Plastic Products group.

Within its budget, InterAg is semi-autonomous within the $\mathrm{CHH}$ group, but it does benefit from being part of a larger corporation, for example through its access to the Plastic Products Group's world-class tooling facility. InterAg subcontracts electronics and components manufacturing to other companies, including within the $\mathrm{CHH}$ group, and then assembles and markets the product.

\section{Market Background}

In the early 1980s there was an increasing awareness among dairy farmers of the lack of innovation in milking systems. Particular concerns included milk frothing and 
flooding in spring when cows are at their peak levels of production. This was raised at a political level by the Federated Farmers and by the dairy industry in the Bay of Plenty. The problems of flooding and frothing were aggravated by a trend towards increasing average herd sizes in the Bay. Ruakura at the time was a "centre of excellence" in milking machine technology, with key milking machine experts such as Murray Woolford and his team leader, Doug Phillips. Woolford and Phillips discussed the problems with farmers in the Bay of Plenty. These discussions led Murray Woolford to propose a systematic programme of development of new technology in milking machine design, in response to what was perceived as a market demand from farmers.

\section{Technical Background}

In the early days of the New Zealand dairy industry cows were hand milked. The first milking machines were developed in the 1890s in Europe and were introduced to New Zealand in the early 20th century (Callaghan ed., 1957, p. 179). Over time, milking machines were improved, simplified and made more hygienic, and other technical advances such as farm electrification enhanced their performance and efficiency.

In the early 1980s the standard milking machine embodied design concepts that were decades old. At this time, several different configurations were used in milking systems internationally. The most important were bucket, recorder jar and pipeline milkers. Bucket milkers used a small milk collection vessel with relatively short tubes connected to the teatcups. Recorder jar milking systems collected milk in a vessel located in the bail unit. Pipeline milkers did not use an intermediate collection vessel for the milk, but transported it from a common pipeline to a milk storage vat. In pipeline milking systems milk is often transported over considerable distances (for example 30 metres), and this can result in considerable accumulations of froth in milk receiver vessels.

The standard milking machine conveys milk essentially by blowing air through it. Air mixed with milk means that the vacuum fluctuates a lot. A major difficulty is that the 
vacuum at the teatcup is regulated via the milk flow path. Consequently higher milk flow rates result in higher vacuum losses at the cow, and the milk mass renders the regulator ineffective in controlling local vacuum fluctuations at individual clusters. The vacuum loss significantly reduces milking rates and can cause clusters to fall off in the middle of milking. Excessive air admission is also associated with mastitis levels and the risk of inter-mammary infection.

The entrainment of air in the milk and the violent nature of the flow causes frothing. Froth and entrained air in milk often impairs the efficiency of milk pumping devices, especially those pumps of centrifugal design. Air-milk flow systems also cause serious difficulties in metering milk yield and flow rates because of the amount of air that is entrained.

The air transportation of milk and subsequent frothing is associated with damage to the milkfat. This damage to milkfat is caused by lypolysis (enzyme-induced generation of free fatty acids following mechanical rupture of the fat globule membrane). This is believed to be a major contributor to off-flavours and product loss, including through a shorter shelf life for fat-bearing products such as butter, cheese and wholemilk powder. Churning or fat aggregation may also occur due to air entrainment in milk.

High air levels in the milk may lead to bacterial contamination. Air drawn into the cluster may directly contaminate milk with environmental bacteria, fungi or other material since the air is drawn from the immediate environment of the milking shed.

\section{Relationship Between MAF Ruakura and AHI}

A technologist in AHI Plastic Moulding company, Doug Millar, and Doug Phillips, a milking systems expert at Ruakura, established some of the first links between the two organisations. These relationships were built informally at a personal level with very open access and information flows. The relationship between the company and Ruakura became strong and productive over time. AHI developed and 
commercialised Ruakura innovations and from the late 1980 s paid royalties on the technology. When in the early 1970s the company developed the Milkmeter, the device was tested and approved at Ruakura and over $90 \%$ of production is now sold overseas. Doug Phillips and Murray Woolford in pre-RMH days also worked with $\mathrm{AHI}$ developing such products as claws and pulsators.

AHI's competencies in materials moulding and in dairy equipment fabrication created a technical platform for other types of innovation. Doug Millar worked with Ruakura on problems of rubber quality in diaphragms used in milking technology. Murray Woolford at Ruakura suggested using silicone, the diaphragm was duly changed to this material, and a great improvement in quality and durability resulted. In turn, skills in silicone technology formed a basis for drug release technology, including a core element in a major AHI/InterAg success - CIDR devices.

The CIDR is a drug delivery system based on Ruakura technology and is a major success for InterAg. The CIDR competes in the veterinary drug release market and has gained international regulatory approval. The CIDR is strongly market-driven and is likely to form a building block for future innovation and product development in this field. In a small but growing niche market InterAg is a world leader as a result.

\section{The Innovation}

In 1982 Murray Woolford proposed a break away from incremental improvements to milking machines and to the "patching up" of the traditional system, and identified a major technological goal as the separation of air and milk at the cluster, with the milk being separately transported, and the air flow and hence the control vacuum being achieved through a separate pathway (Woolford et al, 1982, p. 99). The separation of milk and air flow would facilitate the measurement of milk yield, improve milking efficiency, and provide a basis for improving milk quality. Woolford conceived at this time of a Separate Milk Transport (SMT) machine and predicted that its 
microprocessor control could allow milk flow optimisation and udder health monitoring.

Having defined the goal, Woolford forecast the technological pathway to achieve it, predicting that "...the microprocessor will invade the domain of the NZ milking shed and be used to improve milking efficiency" (Woolford et al, 1982, p. 99). Significantly, Woolford also saw that any such milking system had to have a cost, simplicity and efficiency that was appropriate to the New Zealand dairy farm. In the early 1980 s there were two competing air-milk separation systems available internationally, but these were based on fairly simple float valve separation technology. These two systems were the Alfa-Laval Trio-vac system and the Zero Concord system. There is documentary evidence that around 1985/86 one of these companies was involved in covert activities to determine the nature of the Ruakura milking system innovation.

Dr Ken Jury, a director of animal research in MAF at the time, backed Woolford's ideas for applying more advanced technology in milking systems and supported a research programme being put in place.

\section{Joint Venture Between MAF Ruakura and AHI Plastic Moulding Company}

While Ruakura was strong in scientific research, design and electronics it lacked competencies in complex prototyping, short-run fabrication and production manufacturing.

In the early 1980s MAF was still a Government department, funded by Parliamentary appropriation and with few commercial powers. Government research laboratories could not borrow commercially or hold equity and they faced limits on their ability to develop and commercialise intellectual property. Their perceived role was to do "public good" research, the results of which would be freely available to all. In some senses they were handicapped by the expectation that they were "all things to all men" and had to be even handed to all. The public sector environment in the early $1980 \mathrm{~s}$ 
was only gradually evolving towards public sector trading and research activities being free of bureaucratic constraints inherent in government departments. Before this time, government researchers were so constrained that they effectively "gave away" some of their most promising innovations. This was true in the case of the electric fence developed at Ruakura.

Ken Jury informally discussed the constraints Government departments faced in commercialising their technology with Dr Ian Shearer, the Minister of Science at the time. Shearer encouraged Jury to "go ahead and do it in a way that would be open and politically defensible". The informal strategy adopted by Ruakura was to overcome the institutional barriers by as far as possible ignoring them.

Dr John Hutton, Director of the MAF Agricultural Research Division at the time, strongly supported the innovation, and this top-level support within MAF was crucial. For political reasons, MAF felt it necessary in 1982 to solicit registrations of interest in the project from every company in New Zealand that could possibly act as a project partner in developing a new milking machine. This concern to use a politically acceptable process in finding a commercial partner resulted from awareness of the ambiguity in the role of Government research laboratories when it came to commercialising their research results, and from a knowledge that companies could lobby the Minister and argue that publicly funded research results should be widely available and not be captured by any one company.

All companies in New Zealand that could act as partners were invited to register their interest in participating in a joint project to develop and commercialise what was then termed a "new technology New Zealand milking system". A number of companies were assessed in more detail before a short-list of 3 were interviewed in more depth. Ken Jury, Murray Woolford, Pat Joyce and John Hutton were on the interview panel and, after extensive investigation, they offered the partnership to AHI Plastic Moulding Company. 
There is no question that AHI was the company most suited to work with Ruakura on the project. The company at that time was making milk meters, pulsation systems and a mastitis detector and had a strong export focus. However, its selection provoked letters to politicians from rival companies claiming that favourable treatment had been given to AHI. There were questions in Parliament challenging the legitimacy of a Government department entering into commercial arrangements on a proprietary basis with a company. The widespread nature of the tender also served to publicise the technical goals of the project to competitors, and as a result Alfa-Laval moved to adapt an existing machine (already competing overseas) to the New Zealand market, to compete against the RMH. This reflected the institutional handicap that MAF was under in fulfilling technological and developmental goals while still being subject to political pressures. It took about 18 months from the request for expressions of interest to the point where political and other concerns had been resolved, and an agreement entered into with AHI Plastic Moulding company.

The initial agreement between Ruakura and AHI, negotiated primarily by the MAFTech business manager, Fred Phillips, and Jack Jenkins of AHI, lacked specificity and did not include detailed performance targets, goals and deadlines. The agreement focused overly on royalties, at the expense of the project management requirements needed for success such as the documentation of inputs, performance specifications and rights to renegotiate.

During the early developmental stage Jack Jenkins, General Manager of Plastic Products, kept the machine firmly under wraps. Jack Jenkins tried to keep the development ("Project $\mathrm{R}$ " as it was called) secret as long as possible and this adversely affected information flows within the company.

In the early stages the relationship between Ruakura and the company was on a oneto-one basis. Only later was an informal management committee set up, meeting three-monthly, with the chair rotated between Graham Duirs and Ken Jury. Formal agreements took a long time to be negotiated and agreed to. However, when the first prototype was developed, $\mathrm{CHH}$ technical and marketing staff were amazed at the 
level of technology. Ruakura and some company staff were convinced that the system's technical edge could be translated into a competitive advantage in the market, but other company staff lacked the technical skills to understand and confidently manage the technology.

Following the selection of AHI Plastic Moulding Company a wide range of design options for an air-milk separation system were prototyped and tested. Air-milk separation systems in use in some overseas machines generally separated milk at the claw using a float-valve principle, with a dual vacuum system or some form of synchronous pulsation-driven milk removal valve. Such systems however tended to achieve poor separation performance and were inefficient mechanically. After evaluating these and other approaches, the Ruakura team decided on a different technology to separate milk and air at the claw, through intelligent microprocessor control.

\section{Design, Development and Prototyping}

While negotiations were underway with $\mathrm{AHI}$, Woolford was looking for someone with skills in such areas as instrumentation, measurement and applied physics. Dr Robert Sherlock, then at Waikato University, had already had considerable contact with Ruakura, having supervised a number of masterate students who worked on projects in association with Ruakura, including at No 1 Dairy. Sherlock had in fact provided some notional supervision of Murray Woolford's $\mathrm{PhD}$ when Woolford was technically enrolled at Waikato University, though Woolford's research on laser light scattering was largely supervised by John Harvey at Auckland University.

Sherlock was recruited in early 1984 specifically to work on the project, and came on board after AHI had been selected but before the developmental process had got underway. Sherlock at this time had spent 9 years at Waikato University and moved to Ruakura, partly because of dissatisfaction with how university administrative and teaching demands reduced his opportunities to do research. 
Woolford and Sherlock then embarked on an intensive period of technological innovation, leading to completion of the first milking experiments with air-milk separating claws in November 1984. Sherlock focused primarily on the electronics while Woolford gave emphasis to the overall conceptual and system development. MAF probably invested about $\$ 1 \mathrm{M}$ in the innovation over the period of its development, including about $\$ 160,000$ on a milking shed alone.

Woolford and Sherlock developed the key concepts, with their implementation assisted by others at Ruakura such as Alan Wilson, a very able technologist. Alan Wilson did the layout design of the circuit board while at the early stages a skilled technician, Len Stringer, did some important applied engineering work. Jim Pharaoh, Ross Manderson, Ross Stokes and Ray Pryor at AHI were also major contributors to the project. Woolford and Sherlock may have suffered later in the project, after Wilson and a skilled technician had left, from a lack of support from technicians and applied technologists needed to underpin their R\&D at Ruakura.

The two key design concepts promoted by Woolford and Sherlock were the separation of air and milk, and the use of microelectronics as a technical platform to build more flexibility into the milking machine so that the system could be added to and extended.

When the project was initiated, single chip microcontrollers were becoming commercially available in New Zealand. One option was to simply use analogue electronics in a chip encased in epoxy in the claw itself to control the air-milk separation only, with no other functions. This would have allowed the production of something that would look like a conventional machine and would efficiently solve the separation problem. The other option, and the one decided on, was to build more complex electronics that would lay a technical platform for additional functions such as milk yield measurement and monitoring the performance of individual cows.

A key technical observation by Sherlock was relating the opening and closing times of the milk valve to the flow rate of milk. With a single phase outflow of milk from the 
claw at a substantially constant velocity, the milk yield could be determined by measuring the total "open-time" for the valve in the claw. This motivated the choice of a digital control system (based on a microcomputer) so that the computations necessary to implement a milk metering function could be made. This gave a milk metering function done with software and no additional hardware.

At this early stage of design and prototype development the links between AHI and Ruakura were at a technical level, and this partnership worked very well in the early years. AHI engineers built the first prototype, including some hand-made parts. The 3 key components were the claw-piece, the pneumatic control module, and the electronic control module, with some other componentry being essentially standard items from conventional machines. Traditional milk pumps would not work efficiently in the RMH, due to higher vacuum levels in the milk system. The search for alternatives saw the adoption of a new type of pump from a UK manufacturer. This generated the spin-off that these pumps have now been widely adopted in conventional milking machines, and have probably had a beneficial effect on milk quality.

\section{Experimentation and Trialing}

The machine was in fact up and running on an experimental basis at No 1 Dairy very early in the process, with Woolford and Sherlock beginning experimentation with the RMH prototype in November 1984. AHI had a strong technical design and engineering team that played a crucial role at this stage in designing and building prototype systems. AHI's team effectively built the models and fabricated the prototypes, with Ross Manderson, Ross Stokes and Ray Pryor being key contributors.

In early 1986 an 8-unit pipeline system was installed in an experimental herringbone dairy. Trials led to design improvements and an 18-unit single pipeline system was installed during the 1986-87 season. By this time the key components had been developed to the point of commercial prototype stage, but some secondary components of the machine still required attention, having been fabricated from 
existing devices. AHI technologists Alan Wilson and Jim Pharaoh later devised a complex and innovative plastics technology device to implement the pneumatic functions in the machine.

Over two years Woolford and Sherlock milked a split herd of twins - one milked by the RMH and the other by a conventional machine. Over 80,000 milkings it was shown that the RMH reduced air in the milkflow from around $90 \%$ to less than $5 \%$, increased milking speed by $20 \%$, increased milkfat in the vat by $2-3 \%$, delivered milk with a low somatic cell count and reduced milkfat damage (Mountfort, 1988, p. 10). Ruakura trials showed that the RMH almost completely eliminated milk surface froth, and delivered milk with virtually the same free fatty acid content as those measured directly at the cow. This compares to over a doubling of free fatty acid levels for a conventional machine (Woolford \& Sherlock, 1987, p. 60).

By 1987 the reliability of the system had been extensively demonstrated in cow milkings in a dairy laboratory situation. However, this testing ground was quite different from the extreme reliability needed in a milking shed.

\section{Technical Advantages of the RMH}

In the $\mathrm{RMH}$ all machine functions at each cluster, including the air-milk separation process, are electronically controlled. The machine incorporated a Ruakura-designed single chip microcomputer for each bail, to control and monitor functions. Each bail computer provides a display of milk yield, together with a keypad for machine control or cow ID entry. The bail controllers use low cost microcomputer technology allowing flexibility to modify machine functions or software. The RMH made standard a number of functions that were optional on conventional milking machines, such as yield monitoring, pulsation function, end milk flow detection, automated cluster removal and wash control.

The optimum pulsation rate and ratio differs significantly from cow to cow. In conventional systems, pulsation rates and ratios are controlled from a central point. 
However, the RMH allows pulsation to be controlled by a separate bail controller at each milking station. The electronic control technology detects the end of milking and actuates automatic cup removal. It also allows milk metering without the need for separate add-on devices.

The early RMH allowed as a standard feature milk yield monitoring. As the cow enters the bail the farmer enters a number on a keypad. This is an interim measure until automatic cow ID is developed. The machine could monitor milk yield, but initially lacked a fully developed software capability to process the information generated and use it as a management tool.

An optional add-on feature was a basic PC allowing communication with the RMH machine to read milk yields, add to a herd database, and generate reports on cow performance relative to other cows. The full value of the milk yield facility on the machine can only be realised if this microcomputer database option is installed. The RMH machine provides for manual entry of numbers via each bail key pad. The intention was that automated ID systems that are much less labour intensive could be added in the future.

The RMH has more stable milking vacuum, and a greater flexibility to reduce vacuum levels if desired, since the vacuum losses during milk flow are not as great as for conventional systems. Lower vacuum levels are consistent with optimum teat health. The microcomputer was designed to be programmed to initiate pulsation action only after a particular volume of foremilk had been removed, and this is advantageous to udder health. The milker can select 3 modes: Heifer, Cow or Discard. The pulsation modes are selected by way of the key pad, with Heifer mode simply a narrow ratio pulsation setting used in training new or sensitive animals, while Cow mode is a wider ratio, faster milking base pulsation. The Discard mode allows contaminated milk to be diverted to a separate pump or holding tank. The RMH is easy to use, requiring the minimum introductory training. 
The milk produced by the RMH is very close in quality to milk from hand milking. The milk tastes and smells differently from that of a conventional milking machine. Potential gains in milkfat production may result from a higher milk withdrawal rate during peak flow and the consequently improved udder evacuation achieved by the RMH system. The RMH was the first successful milking machine in the world to have a milk meter as part of the overall system design, made possible due to the separation of milk and air. It offers reduced labour costs and access to detailed herd management information on a per milking basis.

\section{Commercialisation}

By 1985 the RMH's core technology was patented, and the patent assigned, in accord with Government policy, to the Director-General of Agriculture and Fisheries. The challenge then faced by Graham Duirs in $\mathrm{CHH}$ in particular was how to commercialise the technology. Duirs planned the commercialisation around the 3 phases of developing the concept, prototype development, and the development and marketing of production models.

Ruakura scientists, while they had no prospect of personal reward from the innovation, had developed high expectations for the likely commercial success of the RMH. In its first year of release in the 1989/90 season 3 RMHs were installed on three farms. The first was installed at a farm run by Mark Ofsoske at Paeroa. This was one of five farms owned by Fielden Farms Ltd. Higher speed milking, and the ability of the electronic control module to produce instant milk production figures appealed to farmers such as Ofsoske. The first machine was installed on a trial basis, with the right to return the machine after 12 months. At this time a single 20 bail machine cost about twice that of a comparable conventional unit (Farm Equipment News, 1990, p. 1).

However, significant technical problems began to occur in a farm situation almost immediately and these proved difficult and time-consuming to solve. The technical problems were compounded by a recession placing financial pressure on farmers. The 
technical problems were essentially teething ones, including inadequate waterproofing of the electronics, and liners and other parts falling off or breaking down. Some of these problems were easily rectified but others took some time to solve or continued to cause problems. After the launch of the machine the company found that the original design of the claw proved unsatisfactory because of the difficulty in manufacturing it, but the company successfully redesigned the claw body. Further improvements were made, including changes to the software made by Sherlock in the light of dairy farmer experience.

It is unclear the extent to which the problems resulted from inadequate field trialing by Ruakura or poor quality management and product support by the company. What is clear is that the technology was such a major step forward that significant technical problems would inevitably occur regardless of how well managed the project was.

Because many problems occurred on dairy farms rather than at Ruakura, solving them created a drain on the time of CHH's technical staff and did not help the profile or reputation of the RMH in the field. CHH's sales and marketing staff were unfamiliar with and scared of the technology and this was a major internal barrier that Duirs had to struggle to overcome. At points throughout the process Graham Duirs had to fight a battle against internal competition within the company for the resources to develop the RMH. Duirs had to "manage downwards" against a fear of the technology from his own staff, and may not have spent sufficient time on "managing upwards" and carrying the top management of $\mathrm{CHH}$ Plastic Products with him.

Around this time the company's export milk meter market came under challenge from new European standards, and the company had to divert technical and other resources away from the RMH into adapting the meter and defending the market.

Problems in the field created strains in the relationship between Ruakura and $\mathrm{CHH}$. Ruakura scientists felt that the company was not putting sufficient financial resources into the development, marketing and promotion of the RMH, or in providing adequate quality management in production or support in the field. In particular, 
quality assurance in manufacturing may have been deficient. The strains in the relationship were exacerbated by poor communication, and this was only partly resolved with formal meetings.

At this time Ruakura scientists felt daunted by a feeling they had created something so big that they no longer had control over it, and that despite a high level of emotional investment in it they could not control all the variables that determined its success or failure.

Graham Duirs was conscious of the technical problems likely to occur in moving into full production of a large volume of machines, and so he set the objective of selling 5 machines in the first year. This was achieved, with the sales being to younger farmers. Ruakura scientists may have had some unrealistic expectations for machine sales in the short-term, and probably under-estimated the effects of the farming recession on the willingness to buy the product. However, the Ruakura scientists themselves did not wish to see further expansion in sales once it became obvious that quality problems in the manufacturing and servicing of the systems remained to be solved. It is noted that some basic technical problems still existed in systems three years after their installation in the field.

CHH's low-key approach to funding and marketing the $\mathrm{RMH}$ in these early stages was criticised by Ruakura staff. CHH's work was financed from current revenue rather than major new capital investment, and this may be interpreted as an overly short-term view of $R \& D$, or as over-confidence regarding the scale of resources needed to successfully commercialise something as complex as the RMH. However, in retrospect $\mathrm{CHH}$ may well have had the right approach because significant problems occurred with the first machines in the field, and large-scale sales at too early a stage would have placed an intolerable burden on CHH's technical servicing personnel. It is also worth noting that the company's total sales at the time were less than $\$ 10 \mathrm{M}$ per annum, and this posed real limits to the resources that the company could commit to the RMH. 
Ruakura scientists attended to technical faults in the field. Graham Duirs also reviewed machine performance in the field on a personal basis. He attended one breakdown of the machine on Christmas day and offered to remove the machine at no cost to the farmer. The farmer concerned, despite being under immense pressure in the midst of a recession, refused the offer and said he would give up milking cows if he had to go back to conventional milking machines. It is very significant that those farmers who bought the RMH never regretted it, and would never go back to conventional milking machines.

With two systems in the field, Duirs then tried to move into the next phase of market testing and development. This included educating dealers and CHH's own staff in installation and servicing. Booklets and videos on the new machine were circulated to selected farmers. A significant constraint, however, was the unfamiliarity and fear that $\mathrm{CHH}$ 's staff had of the technology, with only one staff member being able to service the electronics. After about 2 years on the RMH project Alan Wilson at Ruakura accepted an offer from Graham Duirs to work at $\mathrm{CHH}$, at a time when Duirs was conscious of having to build up his company's technical skills.

\section{Marketing Aspects}

The market envisaged for the RMH was New Zealand dairy farmers, especially those with larger herds and those wanting to produce better quality milk. Graham Duirs was also conscious of the export possibilities, for example to the large-scale dairying operations in the United States. Two were sold to research establishments.

The RMH was initially marketed under the Milkrite brand as "the world's most intelligent milking system". Graham Duirs promoted the machine as the first in the world to offer milking claw milk metering and automatic milk discard.

Ruakura scientists felt that the machine was priced too high, but $\mathrm{CHH}$ argued that any lower price would lose money, especially on a small sales volume. The added complexity of the system made it inherently more expensive, compounded by the 
higher per unit cost inherent in short-run manufacturing and the lack of scale economies. The claw had more tubes and connections and was necessarily more complex than a conventional unit. The microcomputer system that controlled each bail position and the associated control valves and wires contributed added complexity.

By mid-1989 five prototype systems had been sold and were being installed. The sales of the RMH were to more progressive farmers, but the machine was not able to achieve volume sales among the mass of farmers whose primary concern was cost efficiency and who could not justify the higher cost. Milking machine dealers were uncomfortable with the technology, were often unable to fix even minor technical problems that occurred, and were therefore reluctant to promote the system.

While, for example, the elimination of "test buckets" for mastitic cows was of considerable tangible benefit in milking management, the technical advantages of the RMH could not all be turned into "bottom line" commercial benefits. The higher milkfat quality achieved by the RMH did not earn a price premium from dairy companies. The only way of commercially realising the benefits would be if a dairy company paid a premium and could be confident that enough farmers would adopt the machine and deliver a sufficient volume of high quality product to allow market differentiation. The technology provided a technical platform for identification and monitoring of data, but this required manual entry of cow ID data, and the system could not be used for creating records that would be deemed official for herd testing purposes.

Two commercially available air-milk separation milking systems were available overseas as potential competitors for the RMH. An example was Alfa-Laval's Triovac machine which had the vacuum supply to the claw separate from the milk transport system. However, these machines tended not to be engineered around the specific requirements of the New Zealand milking shed configuration, and consequently were less appropriate to, or not available in New Zealand. 
A possible marketing problem may have been that the RMH competes with other products of $\mathrm{CHH} / \mathrm{Inter} \mathrm{Ag}$, and is marketed as the "Rolls Royce" of milking machines. The RMH fits into a defined niche at the top of the InterAg range, but because the company markets a range of different milking machines, there is some overlap and competition between them. InterAg cannot therefore devote its full marketing and promotional energies to the machine.

Mainly to promote the $\mathrm{RMH}, \mathrm{CHH}$ had bought a company in the United States that had a big dealership network. Graham Duirs tried to negotiate a contract with Vermont State University to install a machine there and get the regulatory issues sorted out. Vermont was chosen in preference to a larger dairying area such as Wisconsin, to avoid attracting too much attention from competitors while $\mathrm{CHH}$ got a toehold in the US market. $\mathrm{CHH}$ was unable to overcome the difficulties posed by US dairy regulatory standards. Duirs then used the United States company to market the Supamilker, and after 3 years the company was breaking even. However, $\mathrm{CHH}$ Plastics Products corporate became impatient with the progress made, and found itself at odds with longer term and ambitious plans to use the RMH to build an international agritech company.

InterAg's marketing of the RMH now focuses on its improved milk quality and its ability to gather and allow the processing of data needed for sophisticated herd management. One focus is promotion to dairy companies of the machine's ability to produce milk of a higher quality, not only for differentiated products such as chocolate and some cheeses, but also commodity products such as butter and wholemilk powder. Ruakura has, for example, done some work on the impact of the RMH system on butter flavour, and further work is planned on the implications of the free fatty acid reductions that the RMH achieves.

The experimentation of Woolford and Sherlock demonstrates that improved milk quality occurs, but the price signals paid for such milk do not acknowledge it. Currently dairy companies are still not paying a premium for this higher quality milk, and until this happens farmers lack an incentive to pay the extra costs for the machine. 
This lack of a price premium for quality seems to result from the practice of "bundling returns" from milk sales, which negates attempts to differentiate products.

The RMH continues to be marketed at National Agricultural Field Days at Mystery Creek. The RMH has stimulated or been associated with further developments, for example the development of the Ruakura Touch Tag for automatic cow ID.

\section{Background of Key People}

Dr Murray Woolford is a biophysicist with strong competencies and an international reputation in milking machine design and systems. Woolford's formal training is in physics and mathematics and his biological training was essentially learnt "on the job". Woolford began working at Ruakura in the facial eczema field in his student holidays at university in the $1960 \mathrm{~s}$. He was involved in a number of innovations even as a student, and now has about 12 patents to his credit. When Woolford developed an interest in biophysics, the group at Ruakura was run by Doug Phillips, a milking machine expert at the time who proved a strong mentor for younger scientists. From 1969 Woolford worked at Ruakura on various aspects of milking machine design, as well as on other biophysics projects such as electronic measurement of grass yields.

In the mid-1970s Woolford did a masters degree supported by MAF, and became interested in laser light scattering. He then advanced to a $\mathrm{PhD}$ involved with applying similar technology to bovine sperm to measure motility. In the years leading up to the RMH, Murray Woolford and Doug Phillips were looking at alternative pulsation systems and engaging in theoretical studies of infection transport within the milking environment.

Dr Robert Sherlock came to New Zealand from Britain in 1975 to take up an academic post in physics at Waikato University. Sherlock was an experimental physicist by background. He was attracted, as much as anything, by the possibility of moving into more interdisciplinary research involving biological systems. Robert 
Sherlock was a Reader in the Physics Department at Waikato University before moving to Ruakura.

In the 1980 s, scientific careers depended greatly on more basic research publications and on peer review. Both Woolford and Sherlock had to forgo opportunities that would have resulted from more basic research, in order to devote time to a proprietary and confidential commercial development, the outcome of which was uncertain. Only very modest rewards have resulted from their innovative performance, and these have been trivial recompense for the energy and creative endeavour they both sank into the innovation.

Graham Duirs has a background in dairy science, working in the National Dairy Laboratory. In the late 1970 s he was involved in introducing somatic cell counts into New Zealand dairying. These are now subject to an industry standard, as free fatty acid levels may be in the future. Duirs has an excellent understanding of dairy science internationally, including milk quality and hygiene with a focus on mastitis, as well as a strong interest in milking machines. He also has a strong background in technology transfer, including from his time at the National Dairy Laboratory.

Graham Duirs moved from a research position into a marketing manager position for Alfa-Laval. Duirs spent some months working for this company before moving to AHI. Graham Duirs shared with Robert Sherlock and others involved a passionate commitment to the RMH and was highly motivated to make it a success. Duirs is now General Manager of Business Development for AgResearch CRI.

\section{Conclusions}

The RMH is a major technological achievement, ranking at the highest level of technical innovation within New Zealand in the 1980s. While New Zealand has been innovative in milking machine components, the $\mathrm{RMH}$ is not only a radical technological advance but is also a completely new milking system. 
However, the system has so far not been a major commercial success. The RMH was released on the market in the late $1980 \mathrm{~s}$, coinciding with a major recession in the dairy industry that saw a dramatic drop in milkfat payouts. This was undoubtedly a major external factor that limited its commercial success. There are currently only about 14 RMHs in the field. Royalties paid to DRC from the RMH have nowhere near covered costs and the company has not yet recouped its investment. Nevertheless, both scientists and industry people still believe the system embodies much of the future of milk harvesting technology and that its "time will come" in the market.

The RMH was initiated within MAF when it was a government department and over the course of its development the philosophies and structures of public sector research changed several times. Changes included the implementation of "user pays" for much scientific research, the merging of MAF's Agricultural Research Division and Advisory Services Division, the establishment of Crown Research Institutes (CRIs), and the formation of the DRC as a joint venture between the Government (later AgResearch) and the Dairy Board. In addition, from 1990 most public funding for research was placed on a contestable basis and allocated by the Foundation for Research, Science and Technology. It is remarkable that the innovation got on the market given the discontinuities and institutional uncertainties associated with these changes. This perhaps suggests that if the motivation, personal commitment and intellectual energies are there, all kinds of institutional barriers can be overcome.

The constraints government departments faced in technology transfer and commercialisation significantly impeded the development of the RMH. The lack of commercial powers was a critical barrier to innovation and reduced the incentives for researchers to transfer their technology to industry. However, towards the end of the development of the RMH the DRC had more commercial powers as a result of its restructuring and of the science reforms. The commercial powers and right to earn royalty and other commercial income for his organisation was a key motivator for DRC's Director, Ken Jury. 
Since the formation of the DRC, farmer interests have stressed the importance of its independence and been reluctant to allow the DRC to side with any particular commercial product. It is possible that the relationship with $\mathrm{CHH}$ could not have developed, or at least would be substantially different, if the DRC had been in place at the time the RMH was being developed.

The RMH was to a significant extent a technology-led innovation, and this itself caused some of the early difficulties. In striking contrast, the CIDR was a market-pull innovation that embodied significant new technology and has proved outstandingly successful both technically and commercially. More sophisticated market input earlier in the development process to link the performance attributes of the $\mathrm{RMH}$ more explicitly to farmer benefits and to higher payouts by dairy companies for better quality milk, together with improved quality control in on-farm applications, would have improved the system's commercial prospects. The joint venture between Ruakura and the company should probably have been managed on a cross-functional basis to embed concurrent engineering principles into the development and commercialisation of the system.

There may have been an over-emphasis on the science and an under-emphasis on the technical functionality of the machine in a practical dairy shed situation. For example, when the machine was released at field days farmers commented that the milk metering capability was of limited value unless there was also a means of analysing the data and using it as a management tool. This may illustrate how the technical attributes of the machine may not have been adequately tailored to the practical needs or opportunities of farmers. However, the shortcomings of the milk metering capability were fully understood by the Ruakura scientists, and it was seen as an interim technology before more advanced metering could be developed. Given the lack of resources, the milk metering capability put in place was the best that could be achieved.

The low sales of the RMH may imply that some of the problems associated with air entrainment, such as milk flooding, were not as serious as Ruakura scientists believed. 
But an important factor may be that the development of larger volume main milklinebased machines such as the Supamilker offered at least a partial solution to some of these problems, using more familiar and conventional technology at a lower cost. The Supamilker was an incremental improvement to conventional milking machines that addressed the problem of milk flooding and took some of the market away from the $\mathrm{RMH}$, a system that addressed the same and other problems but with a more sophisticated and expensive approach.

New Zealand competes well in niche markets where economies of scope rather than scale prevail. However, with the RMH the scale of the resources needed to successfully develop the innovation were high in relation to the size of the New Zealand market. The New Zealand market for top of the range "Rolls Royce" machines may have been too small to generate the domestic sales needed to provide the cash flow to support more ambitious export marketing. As a result, production volumes never reached the level that could achieve production economies, and allow the marginal cost of each machine to be reduced.

New Zealand innovators are often exceptional in product innovation but less effective at the production and manufacturing technology needed to make a product cheaply and to very high quality standards. Inadequate developmental investment by $\mathrm{CHH}$, difficulties in the cost-efficient manufacture of reliable RMHs, and associated with this, inadequate technical servicing in the field, were major problems with the innovation. The RMH was thoroughly tested scientifically, but may well have been released too early, before the teething technical problems were solved. This created unnecessary problems for $\mathrm{CHH}$ 's technical people and for the image the machine created with some of its first buyers.

The more fundamental difficulties with the RMH's development and commercialisation resulted from the market conditions and the "people side of innovation", including institutional and management processes, rather than the technology per se. Murray Woolford and Robert Sherlock complemented each other well personally and technically and the social dynamics within Ruakura were good. 
However, a core weakness in the development of the RMH was a pervasive lack of trust between the key players in Ruakura and in the company. This resulted from, or at least manifested itself in, a lack of openness at many stages in the process. Graham Duirs also faced significant internal difficulties within his company.

Graham Duirs appears not to have been given the information, the confidence, or the time from CHH Plastics Products to deliver on the machine's full potential. And yet the development and marketing strategy of Duirs seems to have been thought through, and was a reasonable approach for such an innovation.

The lack of a formal agreement that specified meaningful and measurable goals, and the informality of the relationship, exacerbated the tensions between Ruakura and the company and allowed ambiguity and distrust to fester.

A major organisational weakness was the lack of a project leader or champion able to coordinate a project team drawn from both Ruakura and the company, and to command adequate resources from both organisations. While Woolford and Sherlock were very committed project champions for the technology, and Graham Duirs for the commercialisation of the innovation, none of them had the overarching responsibility of "pulling it all together," or the power to do so. Jack Jenkins initiated the company's involvement in the innovation and promoted it, but then gave the task of making it happen to Graham Duirs. Duirs however had not been involved from the very beginning, so the innovation lacked a product manager or champion who could carry the whole thing through from the very early stages.

The Technology for Business Growth (TBG) scheme now in place would probably have solved many of the difficulties experienced with the RMH, because this scheme insists on a high standard in management of technology. Interestingly, only in recent years have public funding mechanisms such as the TBG enhanced technology management skills and fostered properly-structured project management. 
The emotional investment made in the innovation by key players such as Robert Sherlock and Graham Duirs was quite extraordinary, and was the major factor in keeping the innovation alive when otherwise it would have been abandoned. As Robert Sherlock said later "who would have thought that this seemingly straightforward thing would turn out to be so difficult to implement in practice."

Murray Woolford, Robert Sherlock and Graham Duirs were motivated by a strong and in fact emotional commitment to "making the innovation happen". The challenge and intellectual excitement of applying advanced new electronics technology to a set of dairy farm problems, and the teamwork that existed between Sherlock, Woolford and $\mathrm{CHH}$ technical staff, was very rewarding for those involved. This led to a confidence that was sensed by those farmers who became interested in the machine. This in turn engendered a very strong feeling of loyalty by innovators such as Robert Sherlock to those farmers who demonstrated their confidence in the technology by being prepared to pay twice what they would pay for a conventional machine. This feeling of loyalty to the 12 or so farmers who bought the machine was the single most important factor in innovators such as Sherlock continuing to work on the machine into the early 1990 s, despite their frustrations.

On a positive note, the RMH demonstrates that "invention is the mother of necessity" and that superior technology will, if it is used, create a dependency by the user, who in turn will refuse to go back to inferior technology. The "acid test" of this is that farmers who have bought an RMH have refused to go back to conventional milking machines.

\section{Postscript}

On the restructuring of MAFTech as part of the science reforms, Graham Duirs ensured that the agreement was transferred to DRC to follow Woolford and Sherlock. The new agreement now in place between the company and the DRC acknowledges that the development phase is now past and identifies agreed responsibilities in 
relation to ongoing support. It foreshadows and provides a framework for automatic identification and for data handling and processing technologies that could be added to the RMH.

The intellectual property rights of the RMH now belong to the DRC. InterAg is now a successful company, its success very much dependent on past innovations such as the Supamilker and the CIDR. Bill Thompson became General Manager of InterAg in 1992 and recognises the potential of the RMH. Thompson has appointed a product manager to promote the system. These changes have been positive and some further progress is being made with the RMH. The key challenge for InterAg is to encourage dairy companies to investigate the potential to differentiate their products by utilising the RMH's contribution to better quality milkfat. A key goal is to get dairy companies to "ask the question" and at least to investigate the differentiation possibilities.

Machines have now been in the field for over 5 years, but components have been changed and improved over that time. Some aspects of the RMH still need to be improved. Ongoing work on the RMH includes improvements in the manufacturing reliability of the various components in the machine, including such factors as improved waterproofing of the electronics and adding automatic cow identification to the RMH. Automatic identification means that as the cow enters the bail its number is read electronically rather than through the current practice of having to key in the number. Robert Sherlock is now working in the field of automatic identification and in data handling and processing in the milking shed environment. Automatic identification is now in the RMH at Ruakura and at on-farm sites. Murray Woolford is working in the field of milk composition work for the Dairy Board and in immunisation research. Work is continuing on some topics relevant to the RMH, such as in-line milk conductivity and composition sensing.

The prospects for the RMH or variations on it seem reasonably positive for the future. Standards are beginning to be tightened for the control of milkfat damage due to air entrainment. These are set out in the draft NZCP 3: Hygienic Design and Layout of 
Farm Dairies. One New Zealand dairy company is starting to place emphasis on better quality milk with lower free fatty acids.

The emphasis in New Zealand agriculture is now moving from stocking rates and total volume of production to improving per animal performance and enhancing quality. The RMH's ability to meter, to measure, and in the future to automatically identify cows should be important management tools in the future. Dairy herds may become more differentiated in the future, for example some cows in a herd may produce a lactose-modified milk, others a hyper-immune milk and the RMH, with automatic identification and other technical extensions, may be able to recognise such cows and separately handle their milk.

With tariff reductions resulting from GATT, it is possible that other countries will develop new, non-tariff barriers such as more rigorous technical standards governing food safety and purity. These could well impact on the dairy shed environment and markets may emerge for milking systems such as the RMH that can achieve higher levels of milk hygiene and milkfat quality.

Any move to impose ISO standards on the milking shed environment could be a boost for the RMH system, although it is always possible that such standards could be written to exclude the RMH. Increasing demands for accuracy in herd recording standards could well be met by the RMH's ability to monitor dairy cow performance at every milking. 


\title{
Appendix 1
}

Key Events in the Ruakura Milk Harvester Innovation

\author{
Key Events
}

1969

Murray Woolford becomes involved in milking machine research at Ruakura

1975

Robert Sherlock emigrates to New Zealand and joins the Physics Department at Waikato University

1982

Murray Woolford outlines proposals for the $\mathrm{RMH}$ at the Ruakura Farmers' Conference

Early 1984

MAF solicits registrations of interest for a company to participate in a joint project for the development of the RMH

June 1984

Robert Sherlock joins Ruakura at No 1 Dairy

1984

AHI Plastic Moulding Company and MAF begin joint development of RMH

November 1984 Sherlock and Woolford conduct first experiments on RMH prototype

1985 Patent awarded for "A Method and Means for the Machine Milking of Animals"

Early 1986

8 unit pipeline RMH installed experimentally at Ruakura 
$1986 / 87$

$1987 / 1988$

Early 1989

1989

1992
18 unit pipeline system trialed at Ruakura

AHI Plastic Products is restructured as part of Carter Holt Harvey

RMH installed on first dairy farms

Sale and installation of five RMHs

InterAg established as a subsidiary of $\mathrm{CHH}$ Plastic Products 


\section{CASE 4: FP4000 INTELLIGENT FIRE ALARM INNOVATION}

\section{Introduction}

The FP4000 is an intelligent microprocessor-based fire alarm and fire protection control system. It combines both conventional and analogue addressable detection, and uses modular construction and an addressable serial communications loop. It was developed by Vigilant Fire and Evacuation Systems, a Christchurch-based company, and launched on the market in 1988. On its launch the FP4000 was an immediate success, dominating the New Zealand market despite the building and construction recession that set in after the 1987 sharemarket collapse. The FP4000 was a significant technical step forward and in 1990 it won a TELARC Design Mark award.

\section{Background}

The background of the FP4000 fire alarm system can only be understood in the context of the development of fire alarm companies in New Zealand from early in the century.

\section{The Development of Vigilant Fire and Evacuation Systems}

The history of Vigilant Fire and Evacuation Systems can be traced back to the launch of the Vigilant company in Christchurch in 1914. This company was set up to market the Vigilant Fire Alarm invented by Mr M. Moloney, a Post and Telegraph Office electrical engineer in Christchurch. In the process of expansion Vigilant bought the May-Oatway company in Dunedin. This company had been set up to commercialise the May-Oatway fire alarm, invented by Mr May, who was also a Post and Telegraph Office engineer. The modern electric fire alarm is therefore essentially based on the early work and innovation of May, Moloney and other New Zealand technologists, and this formed the basis of over 75 years of subsequent evolutionary improvement of fire alarm technology in New Zealand. 
From 1915 to 1946 the Vigilant company traded with only moderate success, primarily because there was little recognition of the importance of fire detection and protection systems in New Zealand. During this period the company designed, patented and marketed many different fire detectors and control panels and built up a considerable body of experience. While only about 200 alarms had been installed by 1946, the company's alarms had built up an impressive record of "saves".

It took the tragic Ballantyne's fire in Christchurch on 18 November 1947 to radically change public, official and business attitudes to fire protection systems. The Ballantyne's building was equipped with a Vigilant fire alarm system, but due to negligence by the company it had not been maintained and was out of action when the fire started. The fire claimed 41 lives, and a subsequent Royal Commission of Inquiry had a major impact on the understanding of, and demand for, fire detection and alarm systems.

Based on this market demand, and with an improved detector available, Vigilant expanded its sales and grew substantially from 1948 to 1955 . Branches were established in major New Zealand cities, and during this period the company also started manufacturing fire brigade alarm receiving equipment.

While Vigilant in New Zealand evolved as a fire alarm-based company, Wormald Brothers in Australia, founded in 1911, was developing primarily around its sprinkler business. The two companies were therefore based around complementary markets and technologies, and when Vigilant became part of the Wormald Group in 1961 a strong strategic fit and synergy was created.

As a wholly-owned subsidiary of Wormald Brothers the company traded from 1961 to 1963 in competition with Wormald Electric. In July 1963 the electrical division of Wormald Brothers and the Vigilant company were integrated. This saw the company expand to cover a wide array of detection and alarm systems for fire, burglary, gas and industrial hazards. 
By the late 1960s, Wormald New Zealand was operating as a publicly-listed company, with the Australian company having a controlling share and representation on the Vigilant board in Auckland. While corporate policy was determined in Australia, the companies traded separately. The New Zealand company had a high degree of autonomy over its R\&D budget and initiated its own R\&D and product and system development in the fields of fire alarms and associated technologies.

As part of the larger Wormald group, Wormald Vigilant was able to obtain access to overseas microelectronics technology, and also teamed up with other parts of the Wormald group for major projects. These included work on the Maui drilling platform and the Tiwai Point aluminium smelter.

By the early 1980 s the company had about 250 staff employed throughout New Zealand, including in the Christchurch head office and development and production facility, and in contracting and servicing branches throughout New Zealand. The company was involved in a broad range of fields, including building management systems, and the specialised design of systems that were custom-made to a client's specifications. Examples of these included the MERE mortar calculator for the Ministry of Defence, exchange switching equipment for the Post Office's Landmobile radio system, and specialised applications of the company's Safe automatic fire alarm monitoring system for Porirua, Sunnyside and Kew hospitals. Other products and systems produced by the company included microprocessor-based products, telemetry systems such as Lotac, small-scale industrial and process control systems, and the electronically-based Warp 4 animal weighing system based on an NZAEI prototype and developed jointly by the company and Rathglen Scales Ltd.

However, the company's diversifications away from fire alarms still built on the company's core competencies of detection systems, embedded software, and electronic hardware. The core competencies in the company depended on the integration of electronic hardware and software design and innovation. The company, for example, recruits staff with an electrical engineering and electronic hardware background to develop software, acknowledging the close interrelationship between 
the technologies. This is especially important for a company that has to develop its own customised hardware technology, since engineers who are also developing software are better able to diagnose problems that relate to the interface between the hardware and software.

\section{The Company Today}

Today, Vigilant Fire and Evacuation Systems is part of the Tyco group and entirely overseas owned. However, it still has substantial autonomy over its R\&D, and it develops and manufactures products for the international market.

The company invests a percentage of its total sales in R\&D. The company decides on its own R\&D priorities, except for larger projects, or those involving other companies within the group, and generally finances new product development out of ongoing revenue, with developmental expenditure expensed as it is incurred. The company is analytical in its product development planning and endeavours to do cost/benefit forecasts on new innovations based on likely sales.

The company internalises most of its R\&D, though it has used outside technical input on some occasions, for example for assistance in ideas relating to mechanical design. It has however tended to temper these ideas with the practicalities of manufacture. In particular, the company has always had to ensure that any ideas or design innovations take account of cost factors that are crucial in its market.

The company rarely patents, primarily because of the cost and time involved. It does however vigorously protect and enforce its copyrights. It aims to be a leader in the market, and in the case of the FP4000 competitors took about 5 years to catch up and produce a competing product. The company has a well established quality management system and is on the point of achieving ISO 9000 accreditation.

Like so many New Zealand companies, Vigilant is essentially a leader in a niche market, exploiting economies of scope rather than economies of scale. The lack of 
volume and associated cost pressures remain big issues for the company. The company has to be cost competitive to compete in its market. The innovation strategy of the company is very much to develop new, market-linked products that embody new ideas, but also to drive cost out of the product, often through an evolutionary process of continuous product improvement.

While in the forefront of the technology, the company tends to use commodity components, preferably those that are multi-sourced, rather than using leading-edge technology. The price differences are striking, with often the latest technology dropping in price by a factor of 10 within 2-3 years of launch, when it becomes a commodity component produced in volume. A lot of effort within the company also goes into reducing rework and improving the cost efficiency and environmental acceptability of production processes.

\section{Market Background}

For much of its history Wormald Vigilant was both a development and a contracting company and this gave it a strong customer focus. At the time the FP4000 was developed, the company offered a nationwide installation and a 24 hour service network. Over the last 25 years the company has moved on occasion into other fields, such as building management and control and security systems. However, the strong links with the contract installation and maintenance of fire detection systems, and the influence of long-serving managers and technologists, has meant that the company has retained a core focus on the fire detection and protection market.

However, the company's involvement in building management systems from about 1980 gave it some useful exposure to the field of intelligent building technology, especially the concept of building systems management moving away from centralised computer control to distributed intelligence to minimise the effects of malfunctions (New Electronics, 1988c, p. 19.) 
In the mid-1980s the company was aware of overseas technological trends and that its existing product range was becoming dated, and it was also conscious of opportunities resulting from a construction boom, especially in high-rise buildings. Much of this was construction of high-rise buildings that had particularly stringent requirements for fire detection and protection. The company, while the dominant player in New Zealand, faced threats of competition from new entries or smaller players and saw a need to retain a competitive edge through new, technically superior products.

The company was also aware of addressable fire alarm systems overseas. These produced localised information, for example detecting a fire in a specific hotel room and alerting reception to it. At this time, a number of major hotel contracts were emerging or pending, and these were important in forecasting a likely market for the system.

The company undertook thorough market analyses, focusing on what the customer wanted, and this was enhanced by the feedback the company received from those of its branches involved with installation and servicing in the field. This was crucial to the success of the FP4000, since it involved in-depth discussions with customers and with the contracting and servicing side of the business.

\section{$\underline{\text { Regulatory Issues }}$}

New Zealand has a long history in fire detection and alarm systems, and because of this has developed its own standards over many years. The FP4000 met the requirements of New Zealand standards NZS4512 "Automatic Fire Alarm Systems in Buildings" and NZS4561 "Manual Fire Alarm Systems in Buildings".

Vigilant is represented on the standards committees in Australia and New Zealand. New Zealand standards governing fire detection and protection systems differ in some important respects to those of other countries. Agencies such as the New Zealand Fire Service have been very particular in the standards they wish to see applied in 
New Zealand. This has indirectly assisted the company, since competing overseas companies do not always find it easy to comply with the local standard.

This effect of the New Zealand standards has proved double-edged however, since fire alarm systems developed by Vigilant to meet New Zealand standards are often not suited to the export market. However, the main impact of standards on Vigilant really relates to how they influence the technology, since standards set clear technical guidelines that must be adhered to.

Currently, other countries are up with, and in some respects ahead of, New Zealand in the use of advanced technology in fire alarm systems, and Vigilant monitors standards associated with these technologies to ensure it is "up with the play".

\section{Technical Background}

New Zealand has a long history of involvement in fire alarm systems and related technologies, and the FP4000 should be understood as part of a continuum of new product development and evolutionary technological change. This has encompassed crude electrical devices through to more advanced electro-mechanical, electronic, and "intelligent" fire detection and alarm systems.

Towards the end of the nineteenth century, some commercial premises in Dunedin and Auckland began to install automatic sprinkler systems, and street alarms began to appear in the main centres from the 1880 s. Alarm technology advanced rapidly in the early part of the century and by the 1930s private fire alarm connections in commercial premises enabled brigades to monitor buildings automatically.

In the early years of the century, Dunedin was still a centre of New Zealand manufacturing and a technology leader in such fields as electrical engineering, communications and radio technology. The innovation in the city resulted partly from individual entrepreneurs and partly from the technicians and engineers trained in the Post and Telegraph service. 
Mr G. Porter, chief motorman at the Dunedin central fire station, invented the Duplex Fire Alarm system after four years of study and experimentation. In 1911 Porter applied for provisional protection of his fire alarm technology, and shortly after this a company was formed to take over the invention. The Dunedin Fire Board was the first to place an order for the Duplex system and the first installation of it was by the Roslyn Borough Council in 1913. By 1948 thirty Duplex systems had been installed in New Zealand (Little, 1948, p. 153).

During the early stages of the development of fire alarms, a number of alternative approaches were tried. These included bowed strip fixed temperature devices, bimetallic strip fixed temperature devices, and "rate-of-rise" types (Underwood, 1971).

Rate of rise detectors such as the May-Oatway included those made up of bi-metallic strips or bowed strips which essentially activated alarms by the effects of heat on the behaviour of different metals. The May-Oatway detector was triggered by the effect of heat on a copper wire, which causes the wire to sag, and through the medium of a sealed tube containing mercury, completes an electrical circuit which in turn activates an alarm.

Up until 1969 Vigilant's systems were still based on electro-mechanical technology, but it then began moving into electronics on an evolutionary basis. A major part of this evolution into electronics resulted from the ongoing recruitment of recent university graduates with knowledge of the latest technological developments. The company launched New Zealand's first electronic fire alarm system in the early 1970s, and about 10 years later launched a more advanced technology system.

By 1987 the company had taken over another business that was working on a modular distributed fire alarm system. This system had some significant shortcomings, including security concerns, but it did help provide a conceptual basis for the development of the FP4000. 


\section{The Innovation}

The innovation process for the FP4000 began with a comprehensive market analysis based on what the customer wanted in fire detection and alarm systems. This was facilitated by the company's contracting branches that were closely linked into customer needs and how those needs were changing. The market analyses identified high-rise buildings as the fastest growing market niche for fire alarms. The company then focused on the right technological solution to fire alarm systems for high-rise buildings, and identified the distributed loop arrangement as best accommodating the needs of such buildings.

The General Manager of Wormald Vigilant at the time, Martyn Gall, saw a need to do something different in the marketplace, and was able to work closely with the product development and the contracting side to match product design, development and engineering with factors such as installation, maintenance, servicing, architectural and building trend considerations.

The company established that in high-rise buildings a distributed loop arrangement led to substantial cost savings in wiring, improved flexibility, and allowed for expansion of the system once it was installed. A senior engineer in the company, David Sharp, and others analysed the cost savings that could be achieved with a distributed structure which avoided the need to bring all the cable wiring back to one central location. This showed that significant savings could be achieved, especially in highrise buildings. Only when this hard economic analysis had been done did the design process commence.

David Sharp investigated addressable systems in the UK and Europe and concluded that a market niche existed for a product that would meet the New Zealand regulatory standards. Sharp looked at a system produced by one of the company's associates overseas which was technologically advanced, but too elaborate for the New Zealand market. 
Design work on the FP4000 began in 1987, with Richard Cree as development manager. Cree's aim was to come up with a professional, well designed and well performing product in as short a time as possible, within the parameters of cost, appearance and projected sales. The design clearly had to meet New Zealand standards for fire alarms, and the choice of a distributed loop arrangement created some difficulties in meeting this standard. Richard Cree led a process of testing a number of alternative technical approaches to meet the standard, while ensuring that the distributed structure and customer-oriented operating requirements of the product could also be met.

The design concepts for the new system were developed by Cree and two product managers, David Sharp and David Prosser. This work was supported by other engineers, including Ewan Fraser, who had done a lot of work on microprocessors, and a new graduate from Canterbury University Engineering School, Mike Holdaway.

Richard Cree acted as project leader of a team that included David Sharp, David Prosser, Mike Holdaway and about three other engineers doing the software and hardware development. The project was broken down into its two major component parts. These were the main fire alarm panel and the responder. Both of these had a hardware and a software component. The project team was essentially structured around a hardware and a software specialist on each of the two main components, an engineer working on the mechanical componentry, and an engineer working on the PCB layouts, with these six people working on the project full-time. The project, including all the electronics, was designed and developed entirely within the company, with the minor exception of some external consultancy advice that was sought on an aspect of the mechanical design.

The innovation itself took about 12 months of intensive R\&D effort, and probably cost around $\$ 1 \mathrm{M}$, though the innovation built on past $R \& D$ investment and antecedent technologies. 
While there was interaction among development managers and technical staff, most in the team concentrated on their bit of the system. David Prosser did a lot of the technical ground work, including communications, and the design of some of the responders. Ewan Fraser concentrated on the FP4000 main cabinet and responders, while Mike Holdaway worked mainly on software for the fire alarm panel.

One of the most difficult parts of the innovation was achieving the right balance between price and technology. The innovation could not be allowed to price itself out of the market, but at the same it had to be robust enough to stand up to field use and fulfil the functional performance and operating requirements of the customers.

A number of technical decisions made at the early stages of developing the FP4000 limited the future expansion and development of the system. While appropriate for the FP4000 as a stand-alone product per se, the software structure did not fully lend itself to later developments, and with the wisdom of hindsight a multi-tasking system may have been more appropriate. This would have facilitated later additions to the software. This shortcoming occurred due to the speed with which the product was developed, some inexperience among a number of technical people, and a failure by managers to foresee the limitations that might emerge in future from some of the technical decisions in relation to the software design and architecture. More fundamentally, it may have reflected a tendency to see the innovation in isolation, rather than as forming one step in an evolutionary process of technical improvement which would form a building block for later developments, and which therefore should have incorporated software and other technology that provided a technical platform for "follow on" products and innovations.

Choices made in software development did reflect design trade-offs, since building a generic applications platform that is more flexible and expandable may involve compromise in the "fitness for purpose" of a given product developed for a specific application. However, other systems that may have competed with the FP4000 in fact failed because they were too elaborate, or their technology was designed to have a 
very wide generic application, lacking the specificity of the FP4000's technology to a well researched and very focused market niche.

\section{Performance and Operating Features of the FP4000}

The major technical features of the FP4000 are the communications loop, the alarm signalling, the indicators and controls, and other advanced features:

\section{Communications Loop}

A major feature of the FP4000 is the alarm responder communications loop. Whereas conventional systems require heat/smoke detector groups to be individually wired back to the main control unit, the FP4000 has only a single loop of four wires laid around the building.

A number of addressable responders are located around the protected premises. Detector circuits and control outputs wire locally to these responders, which are connected in a four wire loop to the main control unit. The loop has high security integrity, such that a partial or complete break or short anywhere on the loop is detected and isolated automatically. All communications and system operations are maintained even in the presence of the fault condition. This is achieved by the dual path nature of the loop and the fault isolation facilities incorporated in each responder. Virtually any fire protection measure can be implemented automatically by programming the FP4000, including returning lifts to the ground floor, closing smoke stop doors, and activating other control processes.

The responders are designed to cater for a wide range of detector types, such as smoke, heat and flame detectors. A relay output responder is also available for remote evacuation or control functions. 


\section{Alarm Signalling}

The FP4000 is suitable for connection to the various types of fire brigade alarm receiving equipment, and it is authorised for connection to New Zealand Fire Service remote receiving stations.

In addition to brigade signalling, the FP4000 also provides the power supply and control of a range of alerting devices for evacuation control. All alerting devices may be wired to the main controller. Alternatively, local devices may be controlled by a local relay output responder. Provision has also been made for the connection of a separate evacuation control system for specialised applications.

The FP4000 monitors detector circuits and allows for display of alarm conditions at multiple locations, control of evacuation devices, individual identification of operated or dirty detectors, supervision of sprinkler systems, sophisticated ancillary control functions, and a variety of remote signalling options.

\section{Indicators and Controls}

Individual fire indicators are provided for each zone. Indicators may also be programmed to display other types of information. A number of remote zone display units may be connected optionally. These allow the remote display of the indications provided on the main controller.

\section{Advanced Features}

The FP4000 utilises the flexibility and intelligence of microprocessor-based electronics, and advanced programming features are available in the field to trained service and installation personnel. The programmable features include customised control functions, fully programmable circuit/zone allocations, and monitoring of remote evacuation circuits. Provision is also available for the supply of alarm 
information to building services systems. An optional printer is available for the recording of all events.

\section{The F4000}

Around the time that the FP4000 was being conceived, Wormald in Australia had tried to develop an addressable fire alarm system that included a wide range of options aimed at meeting market needs in a lot of different countries. The Australian system development failed partly because it was an overly elaborate system designed to meet the needs of many different markets, rather than being more customised or specific to a particular market and set of regulatory standards.

The Australian company then asked Vigilant if the FP4000 could be adapted to meet the standards prevailing in the Australian market. Wormald Vigilant responded to this opportunity in 1989, producing for the Australian market a modified version of the FP4000 called the F4000. The F4000 shared with the FP4000 a common microprocessor and a common core of software code. However, the lack of flexibility and extendability in the FP4000 software was carried over into the Australian version of the product and this hampered further upgrade of the F4000 system.

\section{Background of Key People}

Richard Cree completed an electrical engineering degree at Canterbury University and joined Wormald Vigilant in 1979. He worked as an engineer on both hardware and software within the Wormald group. This included significant work experience on a major project in Australia with Wormald Security operations, with Cree maintaining regular contact with the Australian side of the operation ever since.

David Sharp began as a cadet in Vigilant in 1969, did his NZCE in the company, and from early on gained a wide range of experience in the company. David Sharp's time 
with Vigilant was broken with several years as a schoolteacher, before he rejoined the company in 1993.

Martyn Gall was General Manager of Wormald Vigilant when the FP4000 was initiated in 1987. Gall had the vision to see the need to develop the product and get it on the market within a tight time-frame. Gall joined Wormald Vigilant from Tait Electronics, worked for the company for some years, and then later rejoined Tait, where he is now General Manager. This pattern of movement between Christchurch electronics companies is not unusual and reflects interlinkages and networking between generally non-competing companies in the city. A common pattern in Christchurch in the past has been for technologists to start out in Tait Electronics or Wormald Vigilant, and in some cases the Post Office, before moving to smaller companies, or starting their own.

Mike Holdaway did a BE in electrical engineering at Canterbury University and joined Wormald Vigilant straight from university in 1988. Holdaway wrote much of the software for the FP4000. Most of his time in Vigilant has been spent on the FP4000 and F4000 systems, but he has also been involved in PC-based programming for other products and in the development of the evacuation panel, with some input into aspects of hardware design.

\section{External Influences}

The major external influence on the FP4000 was the trend towards high-rise building construction in the mid-1980s, as well as the regulatory standards environment. The economic reforms of the 1980 s did not have a major influence, although the more flexible labour market facilitated some down-sizing and the company has benefited from a lower cost structure in New Zealand, compared for example to Australia.

The Wormald Vigilant company has developed most of its technology internally, especially in areas such as software programming, but has occasionally used external 
consultants for some specialised assistance and ideas, for example in some aspects of design. The company did receive some financial support from DFC earlier in its history, as well as some modest amount of public funding for technological innovation in the 1980 s, and has occasionally used DSIR to tackle specific technical and quality assurance problems. However, these external influences have not been crucial.

The company has always kept up to date with the trade and technical literature, what competitors are doing, and international standards in fire alarms and related technology. However, the main external source of new ideas has been the customers. The FP4000 and the company's competitive strategy as a whole was greatly influenced by the opportunities presented by technological advances in electronic hardware and software.

\section{Conclusions}

The FP4000 was a major technical and commercial success, due to the skills and competencies of Wormald Vigilant's staff. The skills of the company in fire detection and protection have been transmitted over time through recruitment and training of new engineers and their training on the job.

A great deal of new product development in the company has been evolutionary and based on careful appraisal of existing designs to form a basis for product improvement and the incorporation of new technology and design concepts. Much technology is codified in manuals that form the building block or technical platform for future product development and innovation. However, the skill-base in the company is very largely built up and maintained over time through "learning by doing" and the transmission of knowledge among staff.

Vigilant develops most of its technology internally, but does depend on customers and contractors to define the domain within which product innovation occurs and to generate a lot of the ideas and technical specifications which drive innovations such as 
the FP4000. The specificity of the company and its innovations to a tightly defined market niche is a strength that has enabled it to concentrate its marketing, technologies and skill-bases, but which also limits its diversification and future growth potential. Many of the company's competencies, such as electronics hardware and embedded software and detection systems, have potential for generic applications. However, the company has tended to perform best when it has maintained a strong focus on its core niche in fire detection and protection systems within a very specialised regulatory, market and technological framework.

The informal technical network and mobility of people between electronics and technology-based companies in Christchurch, and the output of skilled engineers and technologists from the Canterbury University School of Engineering, have been important success factors for companies such as Wormald Vigilant.

The FP4000, especially its software, should probably have been planned not as a single innovation but as a technical platform with multi-tasking software and other features that would allow expandability and extensions at a later date. A lesson from the case is the need to plan ahead, especially in relation to ensuring that the technology creates a more flexible technical platform for future evolutionary expansion and development.

\section{Postscript}

In 1990 the Wormald group went through a major reorganisation, and as a result the Australian manufacturing side of the business was transferred back to New Zealand. The company's middle management has now shrunk to the point where there is no layer between Richard Cree, the General Manager, and the product managers and senior engineers. By doing away with much of its middle management the company has achieved a flatter organisational structure, and this means that engineers now do work, such as on specifications, that formerly would have been done by managers. This has essentially been an empowerment process for the engineers, and project 
leaders are now responsible for projects rather than that responsibility being at a higher management level.

Since about 1990 Vigilant has been the major manufacturer for the Australian as well as the New Zealand market. When the FP4000 was initially developed the company's market was essentially New Zealand. At this time Wormald Vigilant included the product development and manufacturing as well as the contract installation and servicing businesses, and the General Manager had direct responsibility for both parts of the business. However, the company now has only two big customers, which are the contract and installation companies within the Wormald group in Australia and New Zealand. One of the downsides of this is that the company no longer has a direct link with the contracting side of the business and lacks the customer feedback and input into product development that resulted from that. This may well cause some difficulties in future in maintaining a sharp customer focus for the company. 


\title{
Appendix 1
}

\section{Key Events in the FP4000 Innovation}

\author{
Key Events
}

1967

Wormald Vigilant establishes R\&D team

Early 1970s

Wormald Vigilant brings in New Zealand's first electronic fire alarm

1975

Wormald Vigilant becomes involved in microprocessors

1987

Design work begins on FP4000

1988

FP4000 launched on the market

1989

F4000 developed for the Australian market

1990

FP4000 wins TELARC Design Mark award 


\section{CASE 5: ALATAL 821 INNOVATION}

\section{Introduction}

Alatal 821 is a whey protein hydrolysate made from lactalbumin, a milk protein. It is made by the controlled enzyme treatment of whey protein isolate to produce amino acids, peptides and polypeptides. The enzyme treatment retains essential amino acids, and maintains high protein quality. Alatal 821 has high nutritional value, greatly reduced allergenicity (100,000 times less than unprocessed whey proteins), high solubility and clarity, low fat, ash and lactose content and a good flavour.

Alatal 821 is designed for use in infant formulae, especially for babies with low tolerance of conventional bovine milk products, and for a range of formulations for the adult market, including sports food formulations and diets for hospital patients.

Alatal 821 was jointly developed by NZ Milk Products at its North American Regional Development Centre (NARDC) in Santa Rosa, California, Whey Products (NZ) Ltd (a Dairy Board subsidiary), the NZ Dairy Research Institute (NZDRI), and the NZ Dairy Group's Anchor Products plant at Hautapu.

Alatal 821 won the 1993 Tradenz award for new export products and the PrintpacUEB Multiwall group award for industrial products. Production has risen from 50 tonnes in 1993 to 150 tonnes in 1994, major sales have been achieved in Europe, the United States and North Asia, and the product is rapidly becoming a major commercial as well as technological success for the New Zealand dairy industry. Alatal 821 is now creating a technical and market platform for further diversification and product innovation in the speciality food ingredient and hydrolysates market. 


\section{Background of Dairy Industry}

Innovations such as Alatal 821 can best be understood in the wider context of the development of the dairy industry and its strategy.

\section{Milk Characteristics and Industry Structure and Strategy}

Two characteristics of milk have helped drive the evolution of the industry's market structure: its perishability and its technical complexity. Because milk starts deteriorating the moment it leaves the cow, and because the fresh milk market is limited, the value of most dairy farms rests on the ability to process milk into less perishable products and to market them internationally.

Because milk has to provide the sole source of nutrition for young mammals it is a very complex and complete food and a rich source of nutritional components. Casein alone can form the basis for an extraordinary range of products, including food ingredients, plastics, artificial silk, and coatings for TV screens. Whey can be processed into whey powders, lactose, ethanol, calcium additives, and protein concentrates such as lactalbumin. Alatal 821 is just one of many products that has been developed from lactalbumin alone.

\section{Historical Development of New Zealand Dairy Industry}

In the 1920 s the New Zealand dairy processing industry was made up of several hundred dairy companies, and dairy products were essentially sold at the factory door to overseas buyers. The vulnerability of dairy farmers as "weak sellers" to the market power of overseas buyers led to a cooperative structure emerging, to allow some control over processing and marketing. From the 1930s through to the 1960s the industry extended its cooperative structure further down the value chain, from processing to export marketing and distribution. 
Through the 1960 s and 1970 s the Dairy Board saw that British entry to the EEC and subsequent market access problems, and the price-driven nature of commodity exports with low margins, meant that the industry had to diversify both its markets and its product range. The Dairy Board's strategic response was to diversify its markets to reduce dependence on Britain. It began to differentiate so that it could increasingly compete through branded products that competed on the basis of functional performance and technical characteristics rather than price. It reduced its dependence on the commodity forms of butter, cheese and milk powder exports. It began to develop premium products for the industrial ingredients market, including protein-based products from casein and whey.

\section{Development of Industry's Technical Base}

The dairy industry developed scientific and technical skills to tackle such practical problems as the reliability of cheese starters and butter and cheese quality. The industry recruited world-class scientists, and some major early successes built industry confidence in science as a core part of business strategy.

In 1921 the NZ Cooperative Dairy Company set up a laboratory to provide scientific assistance in butter and cheese making and in the production of dried milk and casein. A group of dairy companies in South Taranaki established a laboratory in 1925 to provide a more scientific basis for cheese making. The industry and Government jointly established the NZ Dairy Research Institute in 1927.

As the industry developed it became clear that high levels of technical skill were needed not only in research laboratories but also in manufacturing plants and throughout the industry. Over time, more emphasis was placed on all parts of the industry being able to communicate at a similar technical level and this was fostered by graduate recruitment, by the development of a graduate training programme, and by encouraging staff movements through all parts of the sector. 
The industry is now New Zealand's largest single investor in R\&D, with total investment of around $\$ 52$ million a year. This is about $1 \%$ of total sales and proportionately similar to that of its major food industry competitors.

The dairy industry's R\&D is coordinated and funded primarily by the Dairy Board and now consists of the NZDRI, which performs more strategic and early stage development research, the dairy company development centres, which handle most product and process development and manufacturing scale-up work, the regional development centres, which provide offshore market liaison and product development tailored to their particular markets, and the Livestock Improvement Corporation. Joint venture or publicly-funded research is also undertaken in the Dairying Research Corporation, Crown Research Institutes (CRIs) and universities. The Dairy Board also funds a Chair in Dairy Science and Technology and a strategic alliance for nutrition science at Massey University.

While specific product development is undertaken by regional development centres and by dairy companies with their own funding, the Dairy Board is still dominant in setting the research direction and priorities for the industry. This itself is a live issue within the industry since the regional development centres and offshore subsidiaries generate sales that can support their own, more decentralised R\&D, and the New Zealand-based dairy companies can also support R\&D-based innovation that focuses on niche markets.

\section{The Industry Today}

New Zealand is generally accepted as the world's most efficient milk producer. There are about 13,000 dairy farms supplying cooperative dairy processing companies and about 1,000 farms that supply the domestic liquid milk market. The industry is highly vertically integrated, with milk produced mainly on family-owned farms, and almost all processing is undertaken by producer-owned cooperative dairy companies. The industry has a very tight and cooperative culture and this is reflected in a high degree of commitment at all levels of the industry to working in the interests of the dairy 
farmer. The value of a dairy farm is determined largely by the value the companies and the Dairy Board can create through processing and marketing. Processing is now undertaken by 16 dairy companies, of which 5 are the dominant players. The North Island-based New Zealand Dairy Group alone processes around 47\% of New Zealand's milk production.

New Zealand produces around $1.5 \%$ of the world's milk output but has about $25 \%$ of world trade (Hussey, 1992). With exports of around $\$ 3.29$ billion the dairy industry is New Zealand's largest single export earner (Cleland, 1993). The Dairy Board is the industry's statutory single seller export marketer with a mission of maximising the income of NZ dairy farmers through the global marketing of dairy products. The Dairy Board is effectively a "cooperative of the cooperatives" and it determines the mix of products and markets that will maximise returns to dairy farmers.

The Dairy Board owns five regional development centres in Britain, Singapore, the United States, Japan and Germany to facilitate and provide technical support to its international product development and marketing. It also owns a host of marketing, distribution, processing and technology-related companies that make up an international marketing network.

\section{Market Background to Alatal 821}

In about 1991 it was recognised that hydrolysates were carving out a market niche of their own and a business strategy was developed within Whey Products (NZ) for whey hydrolysates as their own defined business. This strategy is now extending to protein hydrolysates as a whole.

In the early 1990 s the nutritional applications market was seen to have major potential for the New Zealand dairy industry. There are a number of sub-segments within this market. These include the fickle and rapidly changing sports nutrition market, functional foods ("nutraceuticals"), the adult medical nutrition and the weight 
management markets (Oliver, 1994). However, the infant formula market is the largest and most well established of the nutritional market segments.

Market analysis by Dairy Bard subsidiaries hefore Alatal 821 was developed showed that around $10 \%$ of the European infant formula market was met by products marketed as hypoallergenic or reduced tolerance products. Only $1-3 \%$ of babies are in fact allergic to bovine milk protein, and for only a tiny number is the allergenic reaction life threatening. However, a significant market exists for more digestible milk proteins with low allergenicity that can improve the comfort of babies, and therefore the comfort of their parents. This is a "comfort food" market rather than a health food market. Because babies are restricted to just one food source, development of infant formulae with all of a baby's nutritional requirements was a major market opportunity. Another potential market was in sports nutrition, especially as an ingredient in protein fortified beverages, for example for body builders and weight lifters.

The Dairy Board has long been involved in the infant formula and food ingredients markets, and though reduced tolerance products did require more sophisticated analytical testing, development of a more specialised and technically demanding product such as Alatal 821 was not entirely new territory.

While the development of Alatal 821 was stimulated by customer interest from Europe, the customer had not stipulated specifications that had to be met. The European market was however seen as a good indicator of likely market appeal in other regions, such as the United States and Japan. Santa Rosa researchers and their New Zealand-based collaborators had broad indications of customer requirements, and were able to build on their substantial knowledge base to design a product with a technical functionality that would meet a broad base of customer expectations. 


\section{Technical Background to Alatal 821}

Whey was originally a waste by-product from the cheese and casein making process that was fed to pigs, sprayed back onto paddocks or dumped. It was therefore a low or negative value product that also posed significant environmental problems. By the late 1960s the dairy industry was devoting research effort to added value whey processing. A greater scientific understanding of the composition of whey allowed the industry over time to begin to turn this waste stream into a source of differentiated and higher added value products.

In 1982 the Dairy Board established the Whey Products corporation to focus on the processing and marketing of whey-based products. Whey Products (NZ) forms part of the Protein Division of the Dairy Board. It has its own board and R\&D and capital budget, though $R \& D$ and capital investment above a certain level has to be approved by the Dairy Board itself.

Early work on whey processing helped build up the scientific base to tackle some of the more difficult challenges, such as extracting value out of raw materials such as lactalbumin. Lactalbumin is an insoluble protein made by the heat precipitation of whey protein. It has a higher protein efficiency ratio than most other protein sources but its insolubility makes it a kind of non-functional "nutritional sand".

At the time the Whey Products corporation was established six plants were producing large quantities of lactalbumin as a bread improvement ingredient. A crisis occurred when the potential customer for lactalbumin declined to buy the product, and the Dairy Board was left with a large amount of lactalbumin it could not dispose of, as well as surplus processing capacity. The Whey Products corporation had to close a number of plants in the short term, but it then began to develop a longer term strategy to exploit the ability to make the lactalbumin soluble and thereby open up wider potential applications for it. Hydrolysed protein for such applications as 
hypoallergenic diets had been around for about 40 years but there was little understanding of the potential of lactalbumin for such products.

In 1984 the Dairy Board successfully hydrolysed lactalbumin as a world first. This was a fundamental achievement that opened up potential new market opportunities because of improved flavour and amino acid profile relative to other proteins. A research programme was then initiated to develop and commercialise hydrolysed protein products. While some initiatives such as the development of a casein-based insect attractant failed, progress was made in making lactalbumin soluble and in the development of food ingredient formulae for infants with low tolerance of milk products.

Work on lactalbumin built on experience the dairy industry had already gained in altering the functionality of casein. Enzyme treatment of caseinates had led to the development of the food ingredient Alanate 220, a significant success for the industry.

While some other attempts to develop casein-based products with specialist applications failed, work on hydrolysing lactalbumins at NZ Milk Products in Santa Rosa was beginning to create some potential in the sports food area. This work on lactalbumin-based hydrolysates in the United States effectively kept the lactalbumin business afloat in the years leading up to the development of Alatal 821. The use of hydrolysed lactalbumin in sports food applications created the success and confidence that encouraged further work in the nutritional foods area, and acted as a flagship for the development of later lactalbumin-based products, including Alatal 821.

\section{Innovation and Product Development up to Alatal 821}

By December 1984 NZ Milk Products (USA) had developed three generic lactalbumin hydrolysates, branded Alatal 815, 816 and 817. By 1986 some customer interest had been shown in these products, especially in the potential of Alatal 817 in the infant nutrition market. Its potential was however restricted by the molecular 
weight profile of the product. In November 1985 a Japanese customer asked the Dairy Board to produce a non-bitter hydrolysed product for infant formula. Alatal 817 was offered but not accepted.

There were some difficulties in the hydrolysis research programme in the early years resulting from the "product push" drive to find markets for products rather than to tailor them to the market, and a lack of foresighted project planning and leadership. There were also some difficulties in communication and management of technology between the different parts of the dairy industry involved (Walker, 1993). However, it is worth noting that in the early years the market itself was not yet aware of, or ready to define its need for new products. Technologists ended up playing an important role in educating customers on the potential of new products and fostering demand for them.

In June 1987 a potential niche market for hydrolysates for infant products was identified. However, it was clear that the molecular weight profile needed to be modified, and in 1988 NZ Milk Products (USA) requested NZDRI to allocate some of its membrane separation technology capabilities to the project. This project was dubbed 'Project Nina' and its goals were to reduce the high molecular weight profiles by ultrafiltration, for preparation of hypoallergenic lactalbumin hydrolysates. Project Nina trials continued over 1988/89, with success achieved in August 1989. This was the first successful use of membrane separation in this area.

In 1989 work was undertaken in the United States with three major customers, but none of this was brought to fruition. The reasons were customer indecision over requirements, some market concerns over the use of hydrolysed proteins in dairy foods, flavour problems, and difficulties in technology transfer and communication between NZDRI and NZ Milk Products (USA).

By the late 1980 s Nestle, partly based on some work by Australian researchers, had established not only that hydrolysis of milk proteins makes them less likely to produce an allergenic reaction in babies, but also that flavour defects from the hydrolysis 
process could be minimised if whey rather than casein proteins were used. Nestle launched its resulting "Good Start" product in the USA and Germany, and despite early marketing problems over its claimed hypoallergenicity, it has since gained a significant market share. Whey Products (NZ) saw a market in supplying ingredients to Nestle's smaller rivals that intended to compete with the Good Start product.

In 1990 research was undertaken at Santa Rosa and at NZDRI for two customers using lactalbumin and whey protein concentrate as bases. Progress was made in using a microfilter for a product with an intermediate molecular weight profile. The essential requirement was to remove both the large peptides that have allergenic potential and free amino acids that are less readily assimilated by the body. This was a major technological challenge. In 1991 agreement was reached with a Japanese customer over test methods, and by the end of the year discussions had commenced on the scaling up of production for the Board's first sale of whey hydrolysate for hypoallergenic infant food formulae.

By 1991/92 substantial sales of some solubilised hydrolysates had been achieved in the United States, especially of Alatal 816 which was used in body-building products. The earlier work developing relatively simple lactalbumin hydrolysates had by this time created a cumulative body of expertise in the industry, and laid a technical platform for the development of the more technically demanding and advanced Alatal 821 hydrolysate.

\section{Developing Alatal 821}

Focused development of Alatal 821 began in mid-1991. NZ Milk Products (Europe) had identified market potential from discussions with infant formula manufacturers in Europe, and this potential was discussed with NZ Milk Products in Santa Rosa. While the Santa Rosa researchers focused on specific markets and product developments for the North American market, in the field of hydrolysates they thought more globally. The New Zealand dairy industry's product development strengths in hydrolysates 
were really built up in Santa Rosa. Most of this was fairly independent research, but with some liaison with NZDRI on the scientific information and test methods. NZ Milk Products (Europe) had a fair idea of what product was needed and could even project likely volumes and selling prices.

While Santa Rosa researchers had good links with customers, Alatal 821 was developed without detailed customer specifications being set. In effect, customers were still unsure of precisely what they needed and were looking for guidance from their suppliers. The Dairy Board had the skill-base and market awareness to "take a punt" on what specifications the customer would require. While this was a guess, it was an educated and technically informed guess with a high degree of general customer focus and market awareness softening what would otherwise be an overly "technology push" innovation.

Before Alatal 821 was produced Julie O'Sullivan in NZDRI had been working on a whey protein hydrolysate for another company and had spent 3 months at Santa Rosa. This early work was very customer-specific, but helped form a basis for the Santa Rosa researchers to embark on the Alatal 821 development, which was more broadly focused on a wider set of possible applications and customers. O'Sullivan only became involved again when Alatal 821 had been developed at a bench scale and was ready to be commercialised.

Alatal 821 is made by the mild and precisely controlled enzyme treatment of whey protein so that essential amino acids remain intact and the protein remains high in quality. Without any enzyme producers in New Zealand with sufficiently advanced technology, it was decided not to proceed with a strategic alliance with a single enzyme producer but to remain open to all producers that could provide enzymes to the required standard. This decision worked in the case of Alatal 821, but the Dairy Board may be disadvantaged in some respects, compared to some overseas competitors, in not having a local enzyme producer that can tailor enzymes to the specific needs and opportunities of the New Zealand industry. 
Because of the diversity of enzymes and enzyme suppliers, it was decided to investigate the activity of specific enzymes on specific proteins. However, after 2 years of effort it was realised that a commercially valuable understanding of all reasonably common enzymes and the protein substrates would require 10 years of effort and a multi-million dollar R\&D investment, and that this was beyond the resources of the Dairy Board.

\section{Product Development and Testing}

By late 1991, Santa Rosa had developed small pilot-scale samples, and in liaison with technical marketing staff, these were submitted to potential customers in Europe. The response was positive and one customer in particular requested several hundred kilograms, with the aim of replacing a whey protein hydrolysate in an existing product. This feedback gave confidence to proceed to pilot-scale production. At this time, market planning focused on two possible applications: reduced hypoallergenicity for infant formula, and clean flavour and clarity in solution for adult medical products.

A key feature of Alatal 821 is the very precisely defined range of peptides present and the demands this places on analytical measurement. At times during the Alatal 821 development $30 \%-50 \%$ of the funding was spent on the very precise measurement and analysis needed to produce a product to very tight specifications. It was necessary to measure allergenicity, residual enzyme activity, protein levels, fat, microbiological requirements, and to meet the analytical requirements needed for process control.

The NZDRI's involvement in Alatal 821 really began with High Performance Liquid Chromatography (HPLC) assays for hydrolysates, and also with work on enzyme selection. Specifically, NZDRI drew on work completed in 1984 on the development of analytical methods relating to peptide-sized profiles and the degree of hydrolysis, essentially measuring how many peptides had been produced to indicate how hydrolysed the protein was. 
A key challenge was coordinating between Santa Rosa technologists such as Marsha Swartz, Dr Chao Wu and Neal Van Degrift and New Zealand technologists, especially those at NZDRI. There were significant communication problems between NZDRI and Santa Rosa, primarily because very difficult technical issues, for example in molecular weight profiling, had to be worked through on a basis of common technical understandings. For example, technical problems such as how a chromatogram should be interpreted had to be resolved by fax between NZDRI and Santa Rosa.

A major technical problem was reducing allergenicity in the milk protein. Unlike other hydrolysates previously manufactured, membrane technology played a major role in reducing allergenicity in Alatal 821. The membrane technology removes larger molecular material, thereby removing the allergenic content from the milk protein. Santa Rosa was not strong in ultrafiltration technology, and it was recognised that full-scale commercial production of Alatal 821 needed a large membrane plant. Such plants were already available in the New Zealand whey processing industry. The New Zealand dairy industry had considerable expertise in membrane technology and these were complemented by manufacturing strengths in New Zealand in process control and quality assurance. It was decided to transfer pilot development from the United States to New Zealand to capitalise on these strengths.

In September 1992 DRI began doing pilot trials and in August of that year Santa Rosa technologists involved in the development came to the NZDRI and worked with technologists from Whey Products (NZ) and the NZDRI on pilot trials. Samples from these trials were then used in product development trials involving key target customers in Europe.

\section{Production Start-up and Launch}

The initial market response was encouraging, and in November 1992 Whey Products (NZ) invited New Zealand dairy companies to submit proposals for the commercialscale manufacture of Alatal 821. NZDRI trialing was well advanced by the time tenders were called for in December 1992. Anchor Products, part of the NZ Dairy 
Group, was selected to manufacture the product at its Hautapu site. A target of just four months was set for commercial production to commence. A difficulty was that production depended on the use of existing membrane plants in the dairy industry, these plants were used in the dairy season, and the limited window of opportunity was between May to August when the equipment was otherwise lying idle. Hautapu proved an ideal site however, with its cheese making vats and on-site driers suited to make the product, and with sufficient knowledge of enzyme processes in cheese making to form a basis for understanding of the enzyme hydrolysis process used in manufacturing Alatal 821. NZDRI transferred analytical techniques to Hautapu to enable analysis of the product on site.

The innovation was advancing very fast at this time, with a high degree of confidence in the market and in the feasibility of commercialisation. That the innovation worked so well is a credit to the teamwork and commitment of those involved at Santa Rosa and NZDRI and the excellent coordination skills of Andrew Revfeim at Whey Products (NZ). Regular conference calls maintained links and there were staff exchanges between New Zealand and the United States. Neal Van Degrift and Dr Chao Wu in Santa Rosa, who acted more or less as product champions, were able to follow the innovation all the way to NZDRI and Hautapu.

The availability of capital equipment, analytical capabilities and of plant available at Hautapu during the dairy off-season were key success factors at this stage of the innovation process. The Hautapu plant was utilised in the off-season, so only the marginal costs of the capital equipment were incurred. About $\$ 75$ million in plant was used but only around $\$ 1$ million of new investment was needed to commercialise the product. The development costs far outweighed the research costs. However, there were many other unquantified or uncharged for contributions all the way through, including peoples' time, and investment associated with bringing the product into full commercial production. 


\section{Full-Scale Production}

There were some delays in moving from trialing at NZDRI to production at Hautapu, and these can probably be attributed to Hautapu personnel not having been involved in, or been observers at, the earlier NZDRI trials. However, scientists from Santa Rosa, the NZDRI and Whey Products (NZ) undertook full-scale trials at Hautapu in February 1993. These trials were successful and provided crucial control data for the production campaign.

The Alatal 821 manufacturing process involves a series of precisely controlled enzyme reactions resulting in a hydrolysate with the desired molecular weight, reduced allergenicity and a good flavour profile. A major problem in hydrolysing whey proteins is the bitter and brothy flavour that results from peptides created. A major technical challenge throughout the development process was understanding the actions of individual enzymes to minimise the off-flavours.

Production of Alatal 821 has to be stringently monitored and controlled as the slightest contamination of the product renders it useless. High Performance Liquid Chromatography (HPLC) was used for on-line control of hydrolysis. HPLC is used at Hautapu in conjunction with standard parameters such as $\mathrm{pH}$ and temperature to control hydrolyses as they occur. Customer requirements posed great demands on the objective measurement technology needed to measure allergenicity-related properties at very low levels. Santa Rosa researchers developed an innovative and low-cost Enzyme Linked Immunosorbent Assay (ELISA) for whey proteins to meet this requirement.

Successful commercial production began in April 1993, a major achievement given the extremely tight time-frame. NZDRI assisted in the initial scaling-up of the process but now only provides some assistance with assays on a routine basis. 


\section{Marketing and Commercialisation}

Whey Products (NZ) had very good links with infant formula manufacturers through the Dairy Board's network of off-shore subsidiaries. These market links were complemented by the technical networks maintained by NZ Milk Products (USA) and the NZDRI.

Despite strong competition, Alatal 821 is now well positioned as a premium product earning very good margins. The competitive advantage for the product results from the industry's ability to tailor it to specialised market needs, New Zealand's strong competencies in hydrolysis, membrane technology, objective measurement technology, and the manufacturing of product to stringent quality standards. The use of very pure lactalbumin with high nutritional value as a raw material has been a major competitive advantage, as Whey Products is the only commercial producer of lactalbumin in the world.

Ongoing sales of Alatal 821 in the infant formula market have now started in Europe, the United States and North Asia, and further evaluation is underway for customers in the sports nutrition field. Three new customers have been recruited in the last year. Important benefits from the success of Alatal 821 include the opening it is creating for the New Zealand dairy industry in the nutritional and functional food ingredients markets, the learning curve the industry has moved through to achieve success, and the potential for Alatal 821 to act as a technical and market platform for further innovation and product development.

Apart from infant formula and sports nutrition applications, major growth potential exists for hydrolysates in physiologically functional foods and in medical applications, such as easily digestible food products for patients recovering from surgery. The Dairy Board's customers continue to demand new hydrolysates with different molecular weight profiles and this continues to influence the research agenda for the Board. The NZDRI is continuing work on methods of analysing products, means of improving the flavour of hydrolysates by reducing bitterness and controlling flavours, 
and the development of novel processes for making hydrolysates (Dairy Exporter, 1994b, p. 82).

A key focus is now on capturing the benefits of Alatal 821 and other innovations. The specificity of Alatal 821 to customer formulations constitutes a form of "sunk cost" that makes it expensive for customers to change their suppliers. In effect, once a food manufacturer incorporates Alatal 821 into a food product it is likely to be in that product for a long time, because the analytical testing that is needed dissuades food manufacturing companies from the arbitrary changing of such specialised ingredients.

The New Zealand industry's expertise in hydrolysis R\&D and availability of capital plant and sophisticated manufacturing techniques constitute major barriers to competing whey processors entering the infant food formula hydrolysates market. The skills in testing and measurement amount to barriers to competitive entry, while the purity of lactalbumin and New Zealand's monopoly over its production confers a further competitive advantage and market entry barrier.

The dairy industry has relied on commercial confidentiality rather than patenting, but this is no longer adequate. Other countries, especially the Japanese, use patents and pre-emptive publication to restrict competition, even in widely applied and established technologies, and this is forcing the Dairy Board and its subsidiaries to be more active in these intellectual property protections.

\section{Background of Key People}

Dr Robin Fenwick is Development Manager of the Dairy Board's Protein Division. Fenwick did a PhD in protein chemistry and joined the Dairy Board in the mid-1970s. Fenwick has had a crucial role in creating and maintaining the scientific base underpinning whey protein and hydrolysate research. 
Andrew Revfeim is now Technical Manager (Hydrolysates) in Whey Products (NZ). Revfeim is a chemical engineer who joined the Dairy Board after graduation in 1986. Revfeim initially worked in protein extraction before becoming a specialist in the hydrolysates business.

Marsha Swartz is leader of the Santa Rosa research team working on hydrolysates. She has a masters degree in food science and has wide experience in a range of companies, especially those dealing with retail food products. She has spent 14 years with the NZ dairy industry and her time with NZ Milk Products has been entirely in research. The key members of her team at Santa Rosa such as Neal Van Degrift and Dr Chao Wu have qualifications in food science and chemical process engineering and generally had prior experience in the food and beverage sector before working in dairy research.

Julie O'Sullivan completed a biotechnology degree at Massey University in 1988 and worked for several months at the Leather and Shoe Research Association before taking up a research position at the NZDRI. She assumed responsibility for NZDRI's work in hydrolysates in 1990. She has recently completed a masters degree in biotechnology and bioprocess engineering.

\section{Conclusions}

Alatal 821 is a technically demanding product that depends on a strong scientific, marketing and production base. The Dairy Board is probably the only New Zealand business with the vertically integrated structure and the concentration of $R \& D$, marketing and production resources needed to successfully carry through an innovation of such magnitude and technical complexity.

Alatal 821 should be seen as part of a continuum of product and process development that has been driven by the Dairy Board's diversification and added value strategy, and which results from an accumulated scientific and technological base that has been 
built up in the industry since the 1920s. The product depends on antecedent technologies and marketing and production competencies, and is as much a platform for future technical and market developments as it is a "stand alone" product per se. Alatal 821 demonstrates to the market the New Zealand dairy industry's ability to make technically advanced hydrolysates, has shown the industry the potential of the ingredients market, and has enhanced the interactive dialogue with customers that best allows specific customer needs in the hydrolysate field to be communicated to the researchers.

The development of Alatal 821 from concept to commercialisation within a two year time-scale was a major achievement that drew on the Dairy Board's international scientific and marketing resources and on the vertically integrated nature of the industry. The Dairy Board and its subsidiaries successfully balanced the tension between the Board's dominance in industry $R \& D$ and the value of devolving some product and process development to the regional development centres and to companies. Clear criteria and strategies governing what research should be directed by the Board, and what should be driven off the market interface by development centres, subsidiaries and dairy companies could well help facilitate new product development in future.

The innovation reflects the industry's strong commitment to developing premium products with precisely defined properties and consistent quality to meet the needs of a demanding market. The 'fit' between the product development and the Dairy Board's strategy of moving away from commodity products and into added value markets based on product differentiation and specialisation was fundamental to success.

Other Alatal-type products that have lacked a specific customer focus have languished for years without significant sales. However, the customer-driven model is not always appropriate and there is sometimes potential for a technology to languish for some years, only to find that its time eventually comes. The development of Alatal 821 shows that customer awareness and consciousness can allow products to be 
successfully developed without very detailed customer specifications being set. To be customer-driven can be a reactive strategy that would mean that the Dairy Board would be invariably lagging behind the needs of customers. In the case of Alatal 821 , Nestle had demonstrated the market potential of the concept, and other producers were anxious to catch up. The Dairy Board and its subsidiaries, as ingredient suppliers, were able to offer an answer before customers were in a position to specifically define the product required. However, such success depends on the ability to produce tangible product samples rather than simply new product ideas or "disembodied technology".

Unlike other investments that are subject to diminishing returns, scientific research creates knowledge that is irreversible. This irreversibility of technical change, and its creation of a cumulative knowledge base, is important in understanding not only the success of Alatal 821 but how the asset specificity of the R\&D investment in the product also creates barriers to competitors entering the market.

The scientific knowledge base underpinning Alatal 821 was complemented by skills and know-how that could be adapted and applied to new products as they emerged. While some research and product development on lactalbumin-based hydrolysates did not achieve commercial success, the early work was a crucial part of developing the cumulative knowledge base needed for Alatal 821. Early failure to achieve commercial success with other hydrolysate products was therefore an important part of an iterative process of often tacit and uncodified learning by doing, adaptive learning, reviewing the R\&D process and improving on it until success was achieved.

Marsha Swartz, Dr Robin Fenwick, Neal Van Degrift, Dr Chao Wu and Julie O'Sullivan were involved in Alatal 821 essentially all the way through, and this was important to its success. However, staff movements within and outside the industry are very high and increasing, with much of this driven by the building up of dairy industry capabilities offshore. The benefits of staff movement in terms of technology transfer, personnel development and maintaining high levels of technical competency throughout all parts of the industry are fundamental to its success. Such staff 
movement is actively encouraged and expected and rates of retention within the industry after 8 years are still about $70 \%$. However, a major problem in the industry is that high staff movement leads to discontinuity in product and process development, and aggravates the already difficult problem of coordinating multinational R\&D and market development strategies.

In production of high volume products generic skills that are mobile throughout the industry help ensure that all parts of the industry are speaking the same technical language. With products such as butter and cheese the broad skill-base in the industry means that mobility is not a problem but a profound strength. However, with very specialised and differentiated markets, skills must cumulate over time, they are specific not generic, and high mobility will tend to fragment competencies rather than transfer and upgrade skills throughout the industry. Building an advanced technology food business in niche markets requires a critical mass of specialised and centrally concentrated skills, and spreading those skills thinly throughout the industry seems counter-intuitive.

The Dairy Board may need to consider whether its approach to staff movement within the industry needs to be quite different for specialised and differentiated niche markets than it is for the higher volume, more commodity-based markets.

Some minor glitches in the development process could well have been avoided if some of the commercialisation and marketing decisions had been made earlier and all the key players were involved early in the R\&D process. Secrecy may have hampered the trialing and upscaling work by NZDRI, since companies such as Anchor Products were advised too late to participate in or observe the trials. This in turn created some technical problems in bringing Alatal 821 into full-scale commercial production, problems that could have been avoided if Anchor Products had been involved in the trials.

Key success factors in Alatal 821 were the high levels of motivation and teamwork of those involved from Santa Rosa, NZDRI and Anchor Products, and the remarkable 
facilitation of the process by Andrew Revfeim in Wellington. The process was grounded in mutual respect, a common purpose and a good spirit among the key players. A technologist involved in Alatal 821 termed the innovation:

...bloody good fun...I don't come to work for any other reason but to have fun. Pressure is fun. If you're not working under pressure it becomes "why am I doing this?"

The facilitation and associated teamwork succeeded in carrying the innovation through in spite of the lack of a more formal and structured project management system with clear lines of authority. The innovation process was inevitably complicated by the international coordination required, but the necessary cooperation was fostered and this overcame the lack of a more formalised R\&D project management system.

However, the lack of a project leader with an overview of the innovation process and the power to command resources and work on a cross-functional basis is an interesting feature of the Alatal 821 case. Its success reflects the skills of those involved but it does not imply that the project management structure for Alatal 821 is the model for the future. The Dairy Board is keeping its product development process under review, and the Board seems geared to extend even further its leadership role as the exemplar of technological innovation in the New Zealand food industry. 
Appendix 1

\section{Key Events associated with the Alatal 821 Innovation}

\section{Key Events}

$1982 / 83$

NZ Milk Products, Petaluma develops 3 generic lactalbumin hydrolysates

October 1984

November 1985

1985-88

1987

June 1987

May 1989
Good quality lactalbumin hydrolysed at Opotiki

Japanese company asks Dairy Board to produce a non-bitter hydrolysed casein product for infant formula (Alatal 817 offered but unacceptable)

MAF tests hydrolysates as potential insect attractants, but then loses interest

NZ Milk Products in Europe identifies potential market for hydrolysed products Alatal 815,816 and 817 in sports food, health and diet food fields

Potential market for non-allergenic hydrolysates for infant products identified

NZDRI develops new method to test for free amino acid levels in hydrolysed products

Success with 'Project Nina' membrane fractionation achieved 
January 1990

1991

Mid-1991

December 1991

January 1992

January-May 1992 Process optimisation

\section{August-}

October 1992

December 1992 Selection of site for commercialisation

February $1993 \quad$ Full-scale trials

January-

March 1993

April 1993

1994 concentrates and NZ Milk Products (USA) customers

Formulation of a development plan

NZDRI scale-up trials

Production commences
In response to customer requests, research is carried out at Petaluma and in NZDRI using lactalbumin and whey protein

Hydrolysates work structured as a programme of its own

Initial concept discussion between NZ Milk Products Europe

Development of pilot-scale samples and submission to potential

Plant design, installation and modification

Major ongoing sales achieved in Europe, USA and North Asia; production trebles 


\section{CASE 6: LOIN BONER INNOVATION}

\section{Introduction}

The loin boner is a meat processing machine that removes the rear part of the backbone from the attached (longissimus dorsi) muscle tissue of lambs. The loin boner was developed by MIRINZ's Boning and Cutting project in association with Richmond Ltd. It was fully commercialised in 1990.

The loin boner is a major technical and commercial success. It increases meat yield by between $10-15 \%$, throughput by up to $30 \%$, reduces labour costs and produces a more consistent and better quality product. For a typical meat processing plant, the machine pays for itself in about 8 months, or in about 4 months with a double shift operation.

\section{Background}

The development of the loin boner must be seen in its wider institutional, market and technical context.

Institutional Background

The Meat Industry Research Institute of New Zealand (MIRINZ) was established in 1955 to undertake research in support of the meat industry. In the early years MIRINZ was funded by Government, the Meat Industry Association (MIA) and the Meat Producers Board. MIRINZ started as a scientifically-based research institute and later developed a strong applied engineering capability. This engineering capability included provision of workshop and engineering services to support the Institute's research effort. Over time, MIRINZ set up special engineering projects involved with automation and processing, with each project headed by an engineering manager. 
The loin boner was developed during a period of major institutional change within MIRINZ. By 1988 MIRINZ's government grant had been replaced by a system of direct contracting between itself and DSIR. In 1989 Government radically restructured its science policy, with public research funding pooled and allocated on a contestable basis by the Foundation for Research, Science and Technology (FRST). In 1988 the collapse of Waitaki International Ltd, turmoil in the sheep industry, and a threat of withdrawal of funding from the Meat Industry Association (MIA) was placing MIRINZ under a lot of pressure. The MIA agreed to extend funding for 1 year and this gave MIRINZ management the opportunity to reappraise its strategy and to take a more commercial approach to its business.

After a review by Denis Hussey and David Campbell of ACIL in Australia a Meat Research and Development Council (MRDC) was formed in 1990. The MRDC is funded by a levy on slaughtered stock. The MRDC was initially intended to be independent but in fact acts as an arm of the Meat Board, and it has not been entirely free of meat industry politics.

Over 1988/89 Dr Doug Wright, the Director of MIRINZ, and the MIRINZ executive implemented major changes to help it cope with the new environment. The MIRINZ executive approved the Institute's involvement in international marketing of technology and technical cooperation, and the membership base of MIRINZ was expanded. The Institute also sought to expand its commercial earnings away from its reliance on the major funding agencies.

\section{Management of Technological Innovation within MIRINZ}

MIRINZ learnt early on that successful innovation in the meat industry requires dialogue with companies at the conceptual stage, to ensure that developments address real problems, and that commercially unrealistic specifications do not become locked in. Often MIRINZ developments focus on a bottleneck to production, such as labour costs in processing, shelf life of meat or meat tenderness, where clear performance goals can be set and used to provide a specific and commercially measurable focus for 
the research. Typically, machinery developments vary in time-frame depending on the complexity of the task, funding, and the availability of equipment and facilities. The development of an innovation from project proposal to full commercial adoption can take from just over a year to almost 8 years (Wickham, 1992).

MIRINZ has a very planned approach to management of its mechanical engineering innovations. MIRINZ typically sets up a management committee to oversee its major technological developments. The management committee normally comprises representatives from industry, the R\&D funders and MIRINZ. A project manager is appointed to manage each development, reporting to the management committee. This management structure has the benefit of a clearly identifiable project leader, industry involvement from inception, and a high degree of "ownership" from all the major players.

At the time of the loin boner development, the approach taken by Doug Wright was to ensure that a project team was established and to let it "get on with the job" without too much top-down control. Project managers were accountable for the outcome and given a high degree of management flexibility over the process of getting there. This approach proved very successful in the case of the loin boner.

\section{Market Background}

While New Zealand produces less than $1 \%$ of the world's meat production, its share of international trade is high, with over $50 \%$ of the world's sheep meat trade. About $95 \%$ of lamb and $55 \%$ of mutton production is exported (Hussey, 1992).

The production of export lamb cuts increased from 61,000 tonnes in 1981 to 160,000 tonnes in 1991, corresponding with a decline in exports of unprocessed lamb carcases. The move over this decade from the export of carcases to lamb cuts meant that meat companies had to place more emphasis on the performance and productivity of their boning rooms. 
In the early 1980 s the meat industry was faced with over-production of some types of sheep meat, such as mutton, with much of this over-production resulting from the Livestock Incentive Scheme introduced in the mid-1970s, and Supplementary Minimum Prices (SMPs) introduced in 1978. The existence of a "mutton mountain" of carcases to process stimulated interest in automated meat processing and led to the development of the frame boner.

The economic reforms initiated by the Labour Government in 1984 had a dramatic effect on the meat industry. Subsidies for the sheep industry were removed by 1985 and contraction in sheep numbers from the mid-1980s eventually led to a decline in slaughterings and exacerbated over-capacity problems in the meat industry.

In the mid to late 1980 s the reliability and cost of labour was a major issue, with high absenteeism, high Accident Compensation Commission (ACC) costs due to workplace injuries, and a greater overall processing cost structure than is the case today. The labour productivity of sheep processing in the mid-1980s was far below what it was for other animal-based industries, and the sheep industry was conscious of the need to compete against beef, pork and poultry, all of which had lower processing costs per kilogram. For example, in the mid-1980s person hours to dress $10,000 \mathrm{~kg}$ of edible meat were as follows:

Table 1: $\quad$ Person Hours to Dress $10,000 \mathrm{~kg}$ of Edible Meat

Average Person Hours

66

48

25

18

15 6

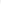

8

5
Typical Weight per Carcass $(\mathrm{kg})$
Mutton

Chicken

Beef

Pork

Source: MIRINZ 


\section{Technical Background}

Early attempts at automated machine boning failed to produce good results, primarily because the variation in bone size and lack of uniformity in animals from the same breed, and even the same grade, meant that too many variables were unpredictable. Unlike automation of cars, whiteware or other products where all sizes, angles and other parameters are predictable, no two animal carcases are exactly the same. This has imposed severe limitations on mechanical engineering-based automation of meat processing, and has posed major technical difficulties in applying more advanced sensory technology and robotisation to meat processing.

In the late 1970 s mechanical technology was developed to invert carcases to facilitate manual and mechanical pelt removal. This paved the way for a series of inverted dressing machines to perform a range of tasks. In the early 1980s MIRINZ licensed Ellis Hardie Symington (later to become APV) and MacEwans Machinery to commercialise dressing machinery emerging from MIRINZ's mechanical dressing project. Millers Mechanical worked with Ellis Hardie Symington/APV and in 1993 APV's licence was formally assigned to Millers. In 1991 MacEwans Machinery's licence was assigned to an Australian company, Construct Engineering. Much of the work on inverted dressing was led by Dr Graeme Longdill, who later became head of the Development Engineering Division of MIRINZ. Longdill and others at this time encountered barriers to adoption of technology resulting from poor labour relations in the meat industry, and companies faced great opposition from workers to technology that was seen as labour saving or deskilling.

In the early 1980s key people in MIRINZ such as Lyn Frazerhurst, then head of the Development Engineering Division, and later Graeme Longdill, Project Manager of the Mechanical Dressing project, began to focus on the whole cost structure of sheep carcase processing, and the potential for automation to reduce labour costs. The early focus was on improved mechanical processing, although MIRINZ and other research agencies also began assessing robotics, with a long-term vision of fully automating meat processing plants. 
MIRINZ's involvement in machine boning from the early 1980 s focused on reducing labour costs and producing structurally intact, whole-tissue product with high consumer appeal. The mechanical processing work was organised into a mechanical dressing project and a machine boning project, with each of these projects controlled by management committees from the meat industry.

In 1983 MIRINZ began development of a frame boner machine to remove the soft sides from whole mutton carcases, that is to remove all muscle tissue on the outside of the skeletal frame. The first two years of this work used an experimental prototype to establish the principles, and by $1985 / 86$ the focus was on the design and construction of a prototype machine for boning over the ribcage and down to the pelvis. In the mid-1980s a proprietary pork shoulder boning machine adapted for mutton was tested in a commercial boning room, and this work further assisted in developing MIRINZ's skill-base in the area (MIRINZ, 1985, p. 21). By this time, MIRINZ had also built up very substantial research experience in shoulder and leg boning.

\section{The Innovation}

Alan Dean was a production manager in Richmond Ltd in 1988 and was responsible, inter alia, for the further processing of lamb cuts at a number of the company's plants. At this time boneless loin eye muscle was in demand, but the manual boning was labour intensive and produced low yields and a variable quality product. Richmond depended then, as now, on external sources of technology. The company was aware of the need to improve productivity and performance and was conscious of the need to search out and adopt external ideas and sources of innovation.

In 1988 a group from Richmond Ltd that included Alan Dean visited MIRINZ and inspected a number of its recent developments, including the frame boner. A production prototype of the frame boner had been successfully trialed at MIRINZ in 
1988. At trialing stage the frame boner successfully boned two soft sides from the skeletal frame with yields comparable to good manual boning standards, and generally achieved excellent meat quality.

While the frame boner proved too complex and unwieldy for the practical needs of the meat industry, Alan Dean was struck by the potential for part of the frame boner to be adapted to the boning out of the loin muscle. The two components identified by Dean were the marking down knives and the flexible disc and plough combination. These two components could be combined for the removal of loin eye meat (part of the longissimus dorsi muscle) from lamb loins (lumbar vertebrae). Dean discussed with colleagues in Richmond the potential for machine boning of loins. Shortly after, he approached Gordon Wickham (then Project Manager of MIRINZ's Boning and Cutting Project) at a meat research conference, and asked whether it was possible to isolate the loin boning part of the frame boner and turn it into a stand-alone innovation.

The loin boner was not therefore developed in isolation but formed part of a continuum of sheep meat engineering process innovations beginning in the late $1970 \mathrm{~s}$. While the loin boner was a development from the frame boner, the loin boner itself formed the technical platform for the later chine and feather boner development, and also for later work on beef and pork boning.

MIRINZ technologists such as Gordon Wickham were keen to see the technologies developed as part of the frame boner applied in industry, especially since by this stage it was clear that the frame boner was unlikely to be a major commercial success. In response to the interest from Richmond, Wickham and his team, drawing on the technology developed for the frame boner, began work on a machine that focused purely on the boning out of loins. This work was assisted by the mechanical engineering services section of MIRINZ and the associated workshops. The management committee that guided the development of the frame boner essentially carried on to oversee the development of the loin boner. 
The first stage of development was to produce a machine that could remove the eye muscle from the backbone of a carcase. In the case of the frame boner a flexible disc was used to push the meat off the spinal column. These discs were made of stainless steel spiral wires in a continuous loop that followed the natural curve of the rib cage. The flexible disc gave good meat yield but was difficult to manufacture to a consistent quality and there were concerns about its service life. Faced with these difficulties, and after discussion between MIRINZ and industry people, it was decided in the case of the loin boner to move to a plough device to follow the bone contours and remove the meat that way.

Some technical problems were encountered due to variations in the size and shape of the carcase vertebrae. In early trials the fixed width of the plough was too narrow and the cut-out rate wasn't high enough. The response was to produce ploughs of varying height and width, to accommodate the range of animal sizes likely to be encountered over a typical processing season.

Alan Dean and his Richmond colleagues worked closely with MIRINZ during the early stages of the development. Richmond was especially concerned to ensure that the innovation would not be too big or too expensive to install and integrate into the plant operations. Dean visited MIRINZ and provided input both on the test bench model and prototype, and participated in trials on the prototype using meat supplied by Richmond.

The relationship between Richmond and MIRINZ gave a sharp commercial focus to the development, with the company clearly signalling commercial requirements relating to the size, benchmark price and throughput needed for the machine to be a commercial success. MIRINZ had good industry links and has had less of a tendency than most research institutes to develop technology on a "science push" basis, without acknowledging the need to focus on real industry problems, and to meet the cost, functionality and practical operational requirements of companies. Dean was crucial in supplying practical input, and also in maintaining relationships with meat plant staff 
who ultimately had to make it work. He was also adept at screening out "sciencepush" technology that failed to meet industry needs.

With major progress made in the boning of loins, a further opportunity was seen to remove the muscle from the whole of the saddle from the fifth rib right back to the end of the lumbar vertebrae. The management committee was actively involved all through the process, and made the decision to extend the machine to debone saddles. The machine eventually developed therefore performed 2 functions and became a loin/saddle boner.

\section{$\underline{\text { Trialing }}$}

Trialing of meat processing equipment in working plants is crucial to successful commercialisation. Trialing at a plant, and if necessary redevelopment based on experience with trialing, is an integral part of the research because meat processing innovations tend to succeed or fail on practical performance in the difficult working environment of a meat plant. This is especially important given the variability in animal size and condition, so that prototype trialing in a research lab may test only a small number of the parameters and variables actually encountered in a commercial plant. The trialing phase is also important in identifying the likely service life of components.

Dean and a colleague trialed meat on the prototype loin boner at MIRINZ. By the time the first prototype was trialed at Richmond's plant at Oringi most teething problems had been solved, and while adjustments needed to be made at Oringi, there were no major technical shortcomings in the machine. Adjustments were done by Richmond staff, but with some technical assistance from MIRINZ.

The trialing conducted on site at the Oringi plant focused on the machine's performance in a working environment. Trialing can be quite a sensitive process with some companies, since companies involved in trials are future customers for the innovation, and MIRINZ's pricing of machines reflects the likely commercial benefits. 
Some meat companies were not always open about all the commercial benefits of a machine for this reason, and even where most variables were measurable, it was not always easy to quantify the detailed commercial benefits. However, the relationship between MIRINZ and Richmond staff was excellent during this period, and the openness and free exchange of information was a key success factor.

\section{Adoption of the Innovation within the Company}

Key MIRINZ managers such as Doug Wright and Graeme Longdill had built up extensive experience in commercialising innovations in industry, and were aware of some of the pitfalls. For example, difficulties had been experienced with the CAPTECH technology, a major packaging innovation that drew on in-depth, basic scientific research. The CAPTECH technology had been released too soon, to companies that lacked understanding of the basic microbiological science and were inclined to take short cuts. This threatened the credibility of CAPTECH in the market.

The experience with innovations such as CAPTECH shaped MIRINZ's attitudes to the "people side" of technology implementation. MIRINZ insisted in contracts with companies adopting the loin boner that staff be trained, and that MIRINZ would be involved in the setting up of machinery until company staff were familiar with and understood the technology.

A major challenge in meat automation was managing its workplace and social impacts, especially given concerns about unemployment, poor labour relations in the meat industry, and the strength of trade unions at the time the loin boner was developed. MIRINZ had itself addressed these concerns and Doug Wright met with a Meat Workers union leader to discuss the issues. The key arguments advanced by MIRINZ in favour of automation were that without it the industry would be uncompetitive in the long run, and that automation could improve the quality and safety of jobs by automating the dirty, dangerous and more repetitive tasks. 
Richmond generally had good labour relations at Oringi, and management and staff had a history of working together on innovation and process improvement, for example on developing new meat cuts. Manual loin boning was seen by workers as a "fiddly" and less popular job. Workers were paid on the number of carcases they could process, and increased throughput due to the machine countered any potential for job losses. A crucial point was that boners already employed had job security, and while the machine led to major labour productivity gains, these did not threaten the existing jobs of staff already employed.

Boning room workers therefore actively facilitated the development of the innovation, and put forward their own suggestions on the location and other aspects of the adoption of the machine. Because staff were involved at the trialing stage they understood the technology, how it worked, and the impact it would have in the workplace when it came to be adopted. All these factors greatly assisted the successful commercialisation of the innovation.

The safety committee at the Richmond plant approved the machine and MAF verified that hygiene requirements would be met. Other companies then came to view the machine at the Richmond plant. While these companies were competitors, the commercial advantage to Richmond came from obtaining the first two machines at a major discount, and gaining a market edge from being the first to adopt it. Richmond had about a year in which it was the only company operating the loin boner, and this gave it an expanded market share as the higher throughput of the machine allowed it to meet unsatisfied customer demand. Other companies then adopted the machine and began to catch up in the market.

\section{Commercialisation and Marketing}

MIRINZ had an active patenting policy and patenting was normally completed before innovations went into plants. However, MIRINZ's commercialisation and marketing 
strategy for the loin boner centred on manufacturing the machine itself, and demonstrating its technical advantages and economic benefits.

\section{Manufacture of the Machine}

To better capture some of the benefits of the innovation and to ensure quality control in the commercialisation of the technology, MIRINZ decided to not only develop the machine but manufacture and market it as well. While this created some concern among engineering companies that had traditionally manufactured and commercialised MIRINZ innovations, it allowed the Institute to move further down the value chain, and significantly contributed to its ability to strategically manage the commercialisation and marketing of the technology and to earn more of a return from its success.

\section{Technical Advantages}

The loin boner had some major technical advantages that became the selling points in the commercialisation and marketing of the machine. These were:

\section{Increased Yield}

The loin boner increased meat yield by $10-15 \%$. Compared to manual boning, meat yield is improved due to the superior consistency and repeatability of machine boning, and machine boning is better suited to following the contours of a carcase, especially when the bones are not of a predictable shape. Manual boning can only approach the meat yield of machine boning if an inordinate amount of time is spent on it.

\section{Increased Throughput}

One machine operator can process 6 carcases per minute with a loin boner while a manual boner will only process about 1.5 carcases in the same period. 


\section{Consistency and Appearance}

While the output and quality of manual boning is influenced by a host of factors such as tiredness, the time of day or week, or skill levels and experience, machine boning produces much more consistent and predictable results. The loin boner removes meat more cleanly and meat is free of nicks caused by knife cuts in the muscle.

\section{Occupational Health}

Tiredness and the speed or repetitive nature of manual boning leads to occupational health problems, including OOS, accidents and psychological stress. The loin boner in contrast separates the cutting device from the operator, and improves the safety and quality of the job. This reduces accident rates and other costs associated with occupational health and safety.

\section{Meat Hygiene}

Meat hygiene is crucial to the shelf life and market acceptability of chilled products. Machine boning reduces product handling by human hands, with potential benefits in meat hygiene. There are, however, still some unresolved issues relating to the ease of cleaning the loin boner.

\section{Fit Between Technology and the Workplace}

The loin boner is a user-friendly machine that has a good fit with the workplace, in the sense that it is relatively small, to a great extent it can be tuned and maintained by company staff without too much reliance on MIRINZ, and it is a stand-alone machine that does not have to be integrated into a large chain. 


\section{Economic Benefits}

The above technical advantages of the loin boner translated into measurable economic benefits that were quantified by MIRINZ $(\mathrm{Ng}, 1992)$.

About 27 million lambs were slaughtered in the 1991/92 season. Assuming that 20\% of the annual kill of 27 million lambs was processed into short loins and racks, and that a machine was operated on a single shift for 230 days a year, the following economic benefits occur:

\section{Table 2: Economics of the Loin Boner}

\section{Base Data}

Labour

Cost of installed machine

Capital charges

Machine charges

Processing Costs Per Unit

Manual boning

Processing rate

Machine boning

Yield gain from

machine boning

Processing rate

Labour cost

Consumables

Net gain per carcase:

\section{Total Economic Benefits}

Estimated actual benefit in 1991/2

Potential benefit to the industry:
$\$ 170$ per 420 minute shift day (40 cents/minute) $\$ 150,000$

$27 \%$ made up of $10 \%$ interest, $10 \%$ depreciation, $7 \%$ R\&M

42 cents per minute

1.5 carcases per minute at a labour cost of 26.7 cents per carcase

54 cents per carcase ( $12 \%$ or $36 \mathrm{~g}$ per carcase)

6 carcases per minute

6.7 cents per carcase

1.5 cents per carcase

65.5 cents

$\$ 2 \mathrm{~m}$ annually

$\$ 3.5 \mathrm{~m}$ annually 


\section{$\underline{\text { Pricing and Sales }}$}

MIRINZ felt confident enough to "take a gamble" on making 2-3 of the machines, funding their manufacture from a previous year's financial surplus. The figure of around $\$ 100,000$ seemed, in 1989 , to be about the benchmark price that companies were prepared to pay for a machine with the performance of the loin boner. MIRINZ made significant profits on each machine sale. Some companies criticised MIRINZ for its pricing policy for the loin boner, and in response to this MIRINZ gave a discount on the machine in the first year to companies that had contributed through the Meat Industry Association to past MIRINZ boning and cutting research.

The release of the innovation was quickly followed by a substantial number of orders as New Zealand meat companies saw the success Richmond was achieving with it. Several were sold in Australia. MIRINZ staff found that Australian companies were technologically some way behind New Zealand competitors, including in having the engineers on site who could assist in the adoption of the technology. The decision to market the machine overseas generated some ill-feeling in the industry. However, by this time MIRINZ had lost guaranteed industry funding and was expected to operate as a commercial organisation. Overseas sales were also important in MIRNZ achieving international credibility, and the Institute has subsequently benefited substantially from overseas contracts in the meat processing machinery field.

By mid-1992 19 loin boners were operating in New Zealand and overseas, and by this time more than $60 \%$ of New Zealand's export lamb loins were processed on the loin boner (MIRINZ, 1992).

\section{Benefits to MIRINZ}

The success of the loin boner had a very positive impact within MIRINZ. A major gain to the Institute was the development of commercial skills and confidence from carrying through an innovation to full commercialisation within a tight time-frame, 
capturing substantial benefits, and achieving credibility internationally as well as in New Zealand.

The loin boner success encouraged further innovations such as the chine and feather boner that drew on the skill-base that had been built up. The basic technology could be adapted to other animals, including beef and pigs. In October 1991 the Beef Boning Project was begun, with an initial focus on loin boning. In 1993 MIRINZ won a prestigious $\$ 1$ million international contract for the development of a pork loin boning machine. This project was funded by a joint venture between the UK Meat and Livestock Commission and the Japan Meat Technology Institute.

\section{Background of Key People}

Dr Graeme Longdill joined MIRINZ in 1973 as a mechanical engineer. He then completed a $\mathrm{PhD}$ in mechanical engineering at Auckland University, with support from MIRINZ. Longdill headed the mechanical dressing project that developed the inverted dressing system for sheep chains. At the time the loin boner was developed Longdill was head of MIRINZ's Development Engineering Division, and in 1991 he was appointed Director of MIRINZ.

Dr Doug Wright was appointed Director of MIRINZ in 1987. He led MIRINZ through a period of major change in the late 1980s, and managed the Institute while the loin boner was being developed.

Gordon Wickham was Project Manager of the Boning and Cutting project at the time the loin boner was developed. Wickham came from a farming background, did an aircraft apprenticeship with the NAC, and then spent several years working with VSA in a number of under-developed countries. His time overseas included very diverse and practical work in applied technology and mechanical engineering. $\mathrm{He}$ then worked as a design engineer for Alcan, before completing a BE in mechanical engineering at university. After some university work in data processing he joined 
MIRINZ in 1984, becoming Project Manager of the Boning and Cutting Project in 1987. In 1990 he was appointed manager of the Shoulder Boning Project.

Weng Ng was born in Malaysia and came to New Zealand as a mature student. He qualified in engineering at Canterbury and Auckland universities and spent some years in the car industry in materials handling and quality assurance. He then worked from 1981 to 1987 in the agricultural machinery industry. He also completed polytechnic papers in electronics and electrical engineering. He joined MIRINZ in 1988, bringing to the Institute his strong background in mechanical design and engineering. Weng $\mathrm{Ng}$ was involved in, and made a major contribution to, the trialing stage of the loin boner innovation.

Alan Dean was brought up on a farm and has spent his entire career in the meat industry, working as a farm worker, meat inspector and in virtually all major tasks in meat processing plants. He also completed a meat technology course at Massey University. He was a production manager for Richmond at the time the loin boner was initiated. He has spent 12 years with Richmond, initially as a production manager, then as technical manager, and is now plant manager at Richmond's Otaki plant.

\section{Conclusions}

The loin boner was a major technical and commercial success for MIRINZ, and has achieved very significant economic benefits for the meat industry. The major advantage of the loin boner was not in fact the intended savings in labour costs, but rather the improved meat yield. This was important at a time when there were major concerns about the effects of automation on employment. While MIRINZ earned substantial commercial income from the loin boner, the real economic benefits have been captured by the meat companies. MIRINZ, for example, earned probably around $\$ 2$ million gross from the sale of about 20 machines, and yet the innovation is 
earning the meat industry as a whole around $\$ 2$ million each year on an ongoing basis.

It took MIRINZ only about a year to develop the loin boner, trial it in a plant, and bring it to a stage where it could be brought into full commercial production. This was a very tight time-frame for such an innovation. The speed and success can really be attributed to the cumulative technical platform that had already been created by the frame boner, the facilities and competencies available in MIRINZ, and the simple and effective project management structure available in the Institute. The drive and initiative of those involved such as Wickham, $\mathrm{Ng}$ and Dean, the rapport between MIRINZ and meat company staff, and the ability of key players such as Wickham and Dean to communicate at a similar technical level were key success factors.

The "mini-task force" approach of a management committee that marshalled and directed industry interest was essential to the success of the loin boner. The high level backing of Doug Wright and Graeme Longdill, and their willingness to let Wickham and his team "get on with the job" were vital.

Where both management and boning room staff supported an innovation it went smoothly, but MIRINZ found in other innovations that top-level management commitment is inadequate without involvement, a feeling of being part of the decision making, and a sense of ownership from working people. For example, Fortex top management was a "fast adopter" of new technology but took a top-down approach, whereas in Richmond key people in the plants were involved and decisions on adoption were more devolved and taken on a plant by plant basis. In the same way, interest and commitment from the workforce will be stymied by management if the top level is not adequately committed.

The loin boner was really based on integrating existing technology into a system and applying it in a new way. The loin boner is "appropriate technology" that was a relatively simple way of addressing a problem, rather than being based on the most scientifically advanced solution. A key to the loin boner's success is that it focuses on 
doing one specific job in meat processing. Ambitious visionaries have sought to automate, robotise and transform whole meat plants. Attempts at innovations that aim to transform whole industries at one stroke seem to fail, and a key to the success of the loin boner is that it aims to do one narrow and specific job.

The loin boner worked because the scientific side of the innovation did not override the practical functionality of the machine, and its application in a meat plant environment. However, in the longer term specific and focused applications of machine vision, robotics and advanced sensory technology may have the potential to achieve major performance gains in automated meat processing (see Automation and Control, 1993a).

\section{Postscript}

Further engineering and automation development work continues at MIRINZ, but the chances of adoption are severely limited by the collapse of a number of major companies such as Fortex and Weddells, by low profitability and associated shorttermism in the industry. Companies are now looking for a payback period of 6-12 months for new engineering innovations. Because the total size of the machinery market is small, MIRINZ lacks the economies of scale in production that could allow it to greatly reduce the unit price of new engineering developments. Much meat processing machinery is only used on a seasonal basis, so the return on an automation investment is obviously limited where plant is operated only for part of a year. Many of today's industry problems are structural or related to procurement difficulties and excess capacity, rather than being technological or labour productivity problems.

At the time the loin boner was developed MIRINZ had funds available for trialing, so that the cost to the companies involved could be minimised. In the 1990s, MIRINZ no longer has such discretionary funds to spare. When the loin boner was developed technologists such as Gordon Wickham had a high degree of flexibility to change 
direction, but now fixed term contracts, especially those with industry funders, are agreed to in advance, leading to a lot of inflexibility in the system.

MIRINZ now has a number of developments "on the shelf" awaiting trial, but the MRDC and FRST are reluctant to fund further work which is seen as appropriable by companies. This itself may raise the issue of whether there is a gap in the public and private mechanisms to support technology transfer and associated trialing. 


\title{
Appendix 1
}

\section{Key Events in the Loin Boner Innovation}

\author{
Key Events
}

1978

MIRINZ begins work on mechanical dressing in conjunction with DSIR and Meat Industry Association

1983

MIRINZ Boning and Cutting Project begins work on mechanising boning operations

1983

Work begins on the frame boner

1984

Gordon Wickham joins MIRINZ

June 1988

Weng $\mathrm{Ng}$ joins MIRINZ

July 1988

Prototype frame boner successfully trialed at MIRINZ

1988

Richmond Ltd identifies potential for machine removal of boneless loin eye meat

1989

Loin boner successfully trialed

December 1989 First loin boner installed

October 1991

Beef Boning project begins

1993

MIRINZ wins overseas contract to develop a pork loin boning machine 


\section{Appendix 2}

\section{MIRINZ's Boning Machinery Development Process}

MIRINZ has generally used the following formalised process in its development of meat boning innovations:

\section{Stage 1: Project Proposal}

- With industry input, identify the potential development area and quantify requirements

- Research the potential benefits for the process, the processor and the industry

- $\quad$ Formulate and submit proposal(s) for funding to R\&D funder(s)

- $\quad$ Granting of funding

\section{Stage 2: Bench Scale Testing}

- Finalise the specifications of the product entering and leaving the boning process

- Finalise the machine performance specifications necessary to meet the requirements, eg. production rate, minimum and maximum product size, maximum machine dimensions, and desired number of operators

- Generate ideas for possible ways of performing the required boning process

- Prioritise these ideas, then bench test them in order of priority to identify the likely boning process solutions

\section{Stage 3: Proof of Concept}

- From successful bench test results, construct, test and develop proof-ofconcept process(es) and machine(s) 


\section{Stage 4: Production Prototype}

- From the successful proof-of-concept stage, design, construct and trial in MIRINZ a production prototype machine. This machine would be manufactured to a standard of hygiene and safety acceptable for use in meat plant boning rooms

\section{Stage 5: Industry Trials}

- Trial production prototype machine in a meat plant boning room under normal boning room operating conditions

- Collect and record information on machine performance, production rates achieved, yields obtained, manning requirements, product consistency and/or quality achieved

- Compile and release trial results to industry

- On verification that the machine meets specification requirements for both product and machine, commercially release machine

\section{Stage 6: Commercial Manufacture}

- $\quad$ The technology owner(s) select a licensee

- The licensee manufactures and markets the machine

(Wickham, 1992, p. 318) 


\section{CASE 7: TREOTEK INNOVATION}

\section{Introduction}

Treotek is a wool spinning innovation that allows fine yarns to be produced from coarse New Zealand cross-bred wools, and superfine yarns to be produced from New Zealand fine wools. The Treotek technology was developed by the Wool Research Organisation of New Zealand (WRONZ) and commercialised with Alliance Textiles, with some assistance from the Government's Emerging Technologies (later the Technology for Business Growth) programme.

The Treotek process is known as 'tri-component spinning'. Tri-component spinning uses two non-wool filaments to capture and support the wool fibres during spinning. Of the 2 non-wool yarns, one runs through the yarn while the other wraps around the outside. As a result as few as 20 fibres rather than the $40-50$ normally required can be contained in the yarn cross section. This means that markedly finer yarns can be spun from New Zealand wools without sacrificing yarn strength or processing efficiency. Treotek yarn is spun at Alliance Knitting Yarns in Mosgiel, and is woven at Alliance Fabric and Apparel in Timaru, as well as by Norwellan Textiles in Australia and John Fosters in England.

\section{Background}

The development of Treotek must be seen in its wider institutional, industrial, market and technical context.

\section{$\underline{\text { Institutional Background }}$}

WRONZ's roots go back to the 1930s. In 1938 the Wool Industries Research Institute (WIRI) was set up to provide technical support for New Zealand's many small woollen mills. In 1957 the wool scourers joined WIRI. After the New Zealand 
Wool Board recognised the need for a scientific base for the wool industry and set up a scientific advisory committee the Wool Research Organisation was established by Act of Parliament in 1961. Some of the science needs of the sector at this time were met by Wool Board grants to the International Wool Secretariat (IWS) in London.

In 1968 WIRI was merged with the Wool Research Organisation to form WRONZ. This organisation focused initially on basic research, but over time WRONZ's focus has moved from basic scientific research to more applied technological development. Over WRONZ's existence the breakdown of scientific research to technological development would be about 30:70 (Carnaby, 1994, p. 5). In 1971 WRONZ established a textile processing plant at Lincoln that formed the basis for an expanded capability in applied technology and product and process development.

Since its formation WRONZ has produced well over 1000 technical papers, patents and articles and grown in size from 33 to around 133 staff. It has a remarkable record of technological innovation which, for economic impact and in proportion to the size of the organisation, compares very favourably with any other New Zealand research institute. WRONZ has several world-class inventors on its staff and all share a great faith in their own ideas, personal drive and the ability to sustain high levels of energy and enthusiasm in turning ideas into commercial reality.

WRONZ now operates as an independent incorporated society with its own directors. It is funded by the Wool Board, the Foundation for Research, Science and Technology (FRST) and by commercial clients from the private sector. The Wool Board uses levy funds to support selected research projects while FRST funds more strategic and underpinning research. Neither organisation seeks to directly manage or control the technology and the mission of WRONZ is to use its technology to improve the economic competitiveness of the New Zealand wool and wool-using industry, thereby enhancing returns to wool growers.

WRONZ from about the early 1980 s began to move away from concentrating solely on process innovations that would benefit the wool industry as a whole and started to 
focus as well on niche product development. An obvious goal was to produce new products from coarse wool that would be able to compete in the higher added-value markets occupied by fine wool or by synthetics. An early attempt to establish a WRONZ presence in product development was the appointment of an experienced textile technologist, Keith Jowsey. However, at this time WRONZ's links with textile companies were less developed and the industry had less interest in innovation because of tariff protection. Attempts at this time to move into knitwear were not successfully commercialised.

However, in 1982 Jack Watt was appointed to WRONZ and the Institute began to develop a competency around him. From about 1989 this appointment started to pay big dividends to WRONZ and to the industry and this area now represents around $25 \%$ of WRONZ's activity. Jack Watt, Dr Peter Ingram and Ian McFarlane are among the key researchers in this field. In addition to its current director, Dr Garth Carnaby, Keith Jowsey and Jack Watt, WRONZ in the lead up to the Treotek development had built up significant skills in wool processing and yarn spinning through recruits such as Dr Jim Lappage and Dr Nigel Johnson. Dr Lappage was a highly regarded wool processing specialist who, before joining WRONZ, was involved in the development of Sirospun in CSIRO. Dr Nigel Johnson was recruited by WRONZ from his former yarn manufacturing lectureship at the University of New South Wales.

In the late 1980s WRONZ began to reduce its dependence on Wool Board and Government funding by building up more income from direct contracts with companies. This strategy was given great impetus by Dr Garth Carnaby who, as Deputy Director at the time, was responsible for expanding WRONZ's private sector income. This focused WRONZ on the "sharp edge" of trading the currency of its technology to companies competing in the consumer market. As at 1993/94 33\% of WRONZ's income was earned from the private sector, $25 \%$ from FRST and $42 \%$ from wool growers (Labes, 1994, p. 15). 


\section{Alliance Textiles Background}

Alliance Textiles developed from a number of small mills established in towns such as Oamaru and Timaru in the late 19th century and grew up behind protective trade barriers. The company in its modern form emerged with the takeover of the Timaru Worsted and Woollen Mills Ltd by Oamaru Worsted and Woollen Mills Ltd in 1960, to form Alliance Textiles (McLean, 1981). In 1980 Alliance Textiles bought out Mosgiel Ltd from its receivers.

Alliance Textile's fortunes were driven largely by cyclical commodity prices determined overseas, and research and innovation played a peripheral role in its business strategy. In the early 1980s, in the lucid description of one commentator:

The previous generation of [Alliance Textiles] management had lived through an era of feeling that only tariff protection and export incentives, subsidies in some form or another, made a textile industry in New Zealand viable at all, and that they were fighting a rearguard action against attrition and the eventual disappearance of the textile industry here. So it was rather negative protective thinking...it seemed to me to be largely a collection of aging [men] hoping that the company would hold together long enough for them to reach retirement age.

By the mid-1980s Alliance had been reduced to a limited product range and its technology was outdated. The Labour Government elected in 1984 initiated a process of trade liberalisation and lowering or removal of protective tariffs and this, together with the 1987 sharemarket crash, meant that the company's future became uncertain. In 1989 Alliance Textiles was a subsidiary company of R\&W Hellaby Ltd which was itself a subsidiary of Renouf Corporation, a publicly-listed company. The company's product line consisted of woollen yarns, including carpet yarns, woollen fabrics, hand knitting yarns, weaving and machine knitting yarns and Swanndri clothing. It had mills in Oamaru, Timaru, Mosgiel and Milton, but divisions in the company such as Alliance Knitting Yarns in Mosgiel and Alliance Fabric and Apparel in Timaru acted as an integrated group of companies. 


\section{Industry Background}

New Zealand is the world's largest producer of coarse wool, the third largest wool producing country in the world and is responsible for around half the world's exports of coarse wools (Hussey, 1992, p. 190). However, wool is a relatively minor fibre in an intensely competitive world market and its price is determined by international demand from off-shore textile processors.

New Zealand's sheep industry is based on multi-purpose sheep that produce both meat and wool, rather than sheep such as the merino that are farmed for fine wool production. New Zealand's wool clip is largely coarse wools of around 35 microns, which are less suited to high value applications such as quality clothing. Demand for coarse wools grew up around machine made and hand knotted carpets, bedding, upholstery and some apparel. This is a narrow range of applications and the New Zealand wool industry has been in a state of gradual decline from about the 1960s on. Over the 30 years ending in 1991/2 the value of New Zealand greasy wool fell from $\$ 2.3$ billion to $\$ 0.93$ billion in constant dollar terms (Labes, 1994). Over this period production was essentially static but clean wool prices fell from $\$ 11 / \mathrm{kg}$ to $\$ 4 / \mathrm{kg}$.

The Wool Board's strategy from the 1960s until recent times has been to influence the demand for New Zealand wool by generic promotion through the International Wool Secretariat (IWS) and by the export of process-related technology to improve the efficiency of off-shore wool processing. The IWS focused on generic wool promotion rather than supporting more differentiated strategies that promoted wool in a wide range of different, niche-oriented applications competing in different markets. The IWS, arguably, also tended to favour promotion of fine wools. The IWS has tended to a narrow view of the wool market and this was sometimes reflected in a view that WRONZ should be developing pure wool products rather than products such as Treotek that combined wool with other materials.

The IWS has failed to reverse the long-term trend for wool to lose market share to other fibres. Wool represents around $5 \%$ of world fibre production compared to $10 \%$ 
in the early 1960s. Generic wool promotion, by favouring price competition, has had the effect of benefiting producers of cheaper, commodity-type wools rather than fostering product differentiation, quality and functional performance. Such a strategy has been anathema to the fostering of niche-oriented product development. However, the IWS's strategic influence has greatly diminished in recent years.

The wool industry has sought to reverse a seemingly intractable decline in the industry's fortunes, and the report 'Strategic Directions for the Wool Industry 19922000 ' sets a goal of achieving and maintaining the price of clean wool at $\$ 8 / \mathrm{kg}$. WRONZ has established two key inter-related strategies to achieve this: the building up of international demand through product innovation, and increasing the value added to New Zealand wool in early stage processes prior to export. Specifically, WRONZ research now aims to influence world demand for wool by changing the product mix through the development of new consumer products, especially for higher added value niche markets, and enhancing existing wool products or reducing their cost of manufacture.

\section{Market Background}

Due to lifestyle changes and consumer preferences the long-term trends in textile apparel have been for finer, lighter and softer clothing. Ongoing investment in synthetic fibre R\&D has continually stretched the lead of these fibres over coarser wool, with acrylic on the knitwear and polyester on the woven apparel side posing major threats to New Zealand coarse wools. New Zealand does not have the domestic market, scale economies or cheap labour to compete in many high volume markets. While New Zealand has to a great extent eliminated tariff protection for most of its industries, significant barriers exist to market access for wool products in other countries such as the United States. 
The IWS over a period of 18 months recently invested around $\$ 8$ million in a review of global market trends and the implications for wool R\&D. Dr Garth Carnaby, WRONZ's managing director, sits on a committee that meets six monthly around the world with marketing people from IWS and with the Chief Executive of CSIRO. And yet the most important detailed stimulus for WRONZ has been its private sector clients. Annual negotiation of contracts with companies is itself a valuable source of new market-driven ideas for WRONZ, and it has been direct links with companies that have stimulated WRONZ's niche product development activity, albeit within a broader global priority framework.

\section{$\underline{\text { Technical Background }}$}

While synthetic fibre research aims to design new fibres and technologies with specific technical and performance features, wool research has to focus on exploiting the inherent traits of wool as a natural fibre, or changing or building in new characteristics. A number of technical barriers have stood in the way of wool product innovation to allow coarse wools to compete in the premium price, added value market where products compete on quality and functional performance characteristics rather than on price.

A fundamental technical constraint in wool processing was the need to have a twofold warp yarn in fabrics, rather than a single yarn produced by the spinning frame. Single yarns could not withstand the processing demands of the weaving process. Sirospun, a CSIRO innovation, provided a technical solution to this problem and was developed for finer wools. Sirospun was championed by the IWS but this innovation has not been relevant to New Zealand growers of coarse wool. A second fundamental constraint in using wool to make lightweight fabrics was the need to have at least 4050 fibres in a cross section of worsted yarns. Treotek was developed to solve this technical difficulty.

Some results of earlier niche product-related research included a process for using coarse wools in fine tropical suitings. A five year programme of joint research 
between WRONZ and the HESC (Hand Evaluation Standards Committee) resulted in 1987 in the development of luxury tropical worsted cloths containing $30-60 \%$ of 35 micron wool. The first garments made from these fabrics were released onto the Japanese market in 1988. The main significance of this development was that it demonstrated that coarse wools could be used to make luxury apparel and that the technology could be developed to make the cloth fine enough and to minimise prickle.

\section{The Innovation}

The earlier research was important in building the confidence to develop processes such as Treotek and in creating the knowledge of the science, engineering technology and market requirements that allow new conceptual insights to occur.

\section{Conceptual Development}

The idea for a tri-component spinning technology to produce lightweight fabrics from coarse wool came to Garth Carnaby in an aircraft high above Alaska on his way to Japan to participate in meetings with the HESC. The HESC is a group of weavers, finishers, fibre producers and academics and includes around 24 Japanese companies active in the worsted industry. Carnaby had been at the IWS centre in Yorkshire, England examining the Sirofil innovation, a spin-off from Sirospun.

Garth Carnaby has around 20 patents to his credit and he submitted a patent application for multi-component yarn in August 1988. He has been a prolific generator of new ideas for wool-based innovations and the WRONZ needle was one of his most striking successes. As Carnaby says of his new ideas:

\footnotetext{
...basically I work when I'm not asleep...When the penny drops a sense of absolute certainty overcomes you about the inevitability of the technology eclipsing what currently exists. It all happens within an hour. An invention happens when you make mental connections between unrelated things. The experience is the real high, because you're excited with the possibilities.
} 
By the time Carnaby returned to New Zealand he had made sketches of the concept and immediately discussed the possibilities with Jack Watt, a very experienced WRONZ worsted technologist. Carnaby's idea was to put a very fine (non-wool) yarn structure around wool fibres at the moment when the yarn is constructed on the spinning frame. This tri-component process would allow the spinning of yarn with 20 rather than 40-50 wool fibres and would allow weaving as a single yarn, circumventing the need to have two foldings of the yarn.

\section{Link with Alliance}

In late 1991 Alliance Textiles was in real difficulties and its ownership structure was in fact not fully resolved until 1993. At this time Alliance Fabric and Apparel managers in Timaru considered limiting production to blankets and Swanndri clothing. However, the General Manager, Alistair Coleman, recognised that limiting the product range and staying in the commodity market with few barriers to competition spelt long term bankruptcy for the company. Alliance Textiles responded by building the profile of the Swanndri brand in Alliance Fabric and Apparel, and moving into the protective clothing market niche under the Protek brand. These tentative moves into more differentiated product niches helped lay a basis for the move into commercialising the Treotek technology.

The competitive pressure that Alliance Textiles was under was a stimulus to its managers to take a risk which, if it paid off, would give the company a future rather than accept a slow decline in a price-driven commodity market. The leadership of Bruce Munro, the company's managing director, was crucial at this point since he saw the company's future as depending on technological innovation, skill development, workplace reform and a total quality management approach to business.

Before Treotek was developed, WRONZ and Alliance had a long standing (but not close) relationship, and both were linked into the HESC network. WRONZ was anxious to build a stronger relationship with Alliance as part of its strategy to reduce 
its dependence on the Wool Board and Government funding. WRONZ's future was bound up with Alliance since the company was by far the biggest in the New Zealand industry and if it collapsed it would threaten the long-term viability of wool processing in New Zealand as a whole.

The willingness and energy of WRONZ to promote and market its skills to the private sector was fundamental to forging a relationship with Alliance. WRONZ had been forced to adopt a more commercial strategy by earning money from companies rather than rely on more stable and predictable funding from the Wool Board or Government, and this lent urgency and focus to its strategy.

Garth Carnaby and colleagues gave a presentation to Alliance Textiles and the enthusiasm for Treotek shone through. Carnaby drove back to Lincoln with Bruce Munro, Alliance Textiles' Chief Executive, and they discussed the possibilities for further cooperation in R\&D. The very good working relationship and rapport established between Munro and Carnaby laid a platform for the development of a strong link between the two organisations and a shared commitment to Treotek.

Munro was committed to making new technology, education and training core to the company's competitive strategy. He quickly saw the potential to exploit WRONZ technologies and was confident enough to invest substantially in the development of Treotek. This was a courageous move, as Alliance was in serious difficulties and investment in Treotek was pivotal in a series of Bruce Munro initiatives that effectively saved the company.

While WRONZ could have taken the innovation offshore to more financially stable companies, the link with Alliance was the right approach to commercialisation since the technology represented a lifeline to the business and it therefore had a compelling incentive to put the resources into it and make it a success. The availability of some public funding through the Government's Emerging Technologies Programme (later Technology for Business Growth) programme encouraged the development, with 
Alliance Textiles and WRONZ submitting a successful joint application to this programme in December 1989.

\section{$\underline{\text { Technological Development }}$}

Moving the tri-component concept through to full commercial development involved a number of discrete phases, the most important of which were the development of a WRONZ prototype, machinery development for the spinning system based on this prototype, developing and trialing new products based on the Treotek yarns, and associated marketing and commercialisation.

WRONZ in the past used the IWS as the route through which new technology was transferred and commercialised. The IWS however was committed to the Sirospun technology and was reluctant to put the resources behind Treotek. WRONZ therefore worked through its Japanese academic and industry contacts in HESC, integrating aspects of the Treotek development with plans by Japanese academic and industry interests to upgrade objective measurement technology in the textile spinning process. The development of Treotek was therefore able to leverage off the technical development work by HESC.

The early process and machinery development work on Treotek was funded by the Wool Board through WRONZ, while Alliance Textiles funded the product development work with some help from the Technology for Business Growth (TBG) programme. Keith Jowsey, a senior technologist, was seconded with funding from the TBG to liaise between WRONZ and Alliance in commercialising the technology.

\section{Prototype Development}

Based on Carnaby's crude sketches, Jack Watt built a spinning frame within WRONZ and took over the process of developing the spinning technology. This was itself a major technical challenge and involved design features which were themselves significant innovations. The existence of an in-house engineering capability in 
WRONZ and of extremely able technologists such as Jack Watt was crucial because it enabled ideas to be turned into prototype form and trialed, and it gave WRONZ the ability to produce tangible samples or models for companies rather than "disembodied ideas". This was especially important given the lack of a substantial in-house advanced engineering capability in textile companies in New Zealand.

\section{Development of Spinning System}

The spinning process took about 12 months to refine and involved converting one side of a WRONZ spinner, designing a way to put extra apparatus above the spinner, and the design and sourcing of new equipment.

Major problems in developing the spinning system were caused by the feeding of the binder thread during the yarn spinning process. A difficulty was ensuring that all 3 threads ran at the same time, since Treotek depends on the spinning into yarn of the 3 components and breaks are hard to detect. Lighting was improved to enhance the detection of breaks in the spinning yarn, but with 240 spindles in each machine and several machines overseen by one operator it is difficult to pick up all breaks in a commercial environment. A binder yarn break may go undetected by an operator since the yarn can continue to spin with only one binder. If undetected for several hours this can lead to the large-scale production of substandard yarn and later weaving faults which in turn can downgrade whole batches. However, a high level of supervision and quality control by Alliance Textiles has been able to cope with this difficulty in a commercial setting.

The Treotek spinning process as finally developed allows the spinning of fabrics that combine the lightweight luxury feel of fine wool fabrics with the strength and form retention of strong wool fibres. The fabric developed through the Treotek technology is one-third lighter than the conventional weight of $450 \mathrm{gms}$ per square metre but retains the natural strength and abrasion resistance of coarse wools. Martindale abrasion tests show Treotek fabrics have up to three times the abrasion resistance of comparable worsted fabrics. The yarn spun is stronger because it is wrapped with a 
synthetic filament and can be woven without twisting with another yarn. Treotek has high natural crush resistance.

It is therefore possible to spin fine yarns from coarser wool fibres which have better performance characteristics than similar fibres made from fine wools or synthetic fibres. Treotek achieves cost savings by using coarser wools for lightweight fabrics. It also has the potential to produce ultra-fine yarns from fine merino wool. Treotek has outstanding pattern clarity and further enhances design opportunities for wool yarns because fabrics can incorporate combinations with cotton, silk or other textiles to create new or unusual features.

\section{Developing and Trialing New Products}

A spinning frame at Alliance Textile's Mosgiel Mill was converted for Treotek spinning and the early product development work focused on apparel fabrics. HESC and Alliance Knitting Yarns exchanged visits and the yarn was promoted to Japanese textile interests for high quality suiting. WRONZ supplied a series of samples to HESC and the Japanese group contributed its own expertise and design input. The Japanese had a technological input into the finished product rather than the yarn construction and used different finishing techniques to enhance the quality of the product.

Professor Kawabata of Kyoto University was the chairman and a driving force of HESC and encouraged HESC to refinish the fabric to achieve improved functional properties. WRONZ was successful in involving a range of Japanese companies in trialing Treotek samples. Wearer and Finisher members of the HESC group in Japan examined Treotek fabrics and obtained further yarn samples to conduct trials in 1990. HESC members met in late 1990 to evaluate Treotek fabrics both subjectively and using objective test data supplied by Professor Niwa of Nara Women's University. Some Japanese test results showed that fabrics produced by the Treotek process had properties more similar to silk than to wool, but at the early stages HESC tended to 
over-emphasise price factors at the expense of the technical performance of the technology.

While Treotek allowed the spinning of lighter fabric yarns it did not solve the problem of stiffness and prickle in coarse wools. While impressed with the physical properties of Treotek fabrics it was felt that the handle was still too harsh for current fashion. Moves were then made to make further samples of the yarn using mixed micron tops in an attempt to provide more softness, while still maintaining performance.

After Alliance Knitting Yarns at Mosgiel learnt how to spin the wool using the Treotek system, Alliance Fabric and Apparel in Timaru then became involved in weaving it into fabrics. WRONZ continued to provide significant assistance and Alliance staff solved minor technical problems through trial and error and through the application of skills built up in the company in areas such as applied chemistry.

Alliance Fabric and Apparel in Timaru had already been involved in producing mixed micron tops, mainly for Japanese applications for lightweight suiting, and became involved in Treotek initially with an eye to the lightweight suiting market in Japan. The company sent its finishing manager to Japan. However, after extensive testing and trialing it became obvious that the most promising medium-term application for Treotek was in fact in the upholstery area.

The first Treotek upholstery yarns were woven in the UK in trials arranged by the IWS and the Wool Board. The IWS did support some market research for Treotek. The upholstery fabrics demonstrated improved abrasion resistance over the equivalent all-wool product. However, the IWS did not commit significant resources to the development because it competed with the Sirofil process which the IWS owned the trademark for, and this may have slowed down the commercialisation of the process. 


\section{Marketing and Commercialisation}

By 1992 a number of applications for Treotek yarn had been trialed and the yarn was moving rapidly to full commercialisation. By 1992, it was clear that Treotek yarns would not easily find acceptance in knitwear, but that the yarn would have a wide appeal in upholstery. The advantages of Treotek over conventional wool yarns in upholstery fabrics were seen as increased abrasion resistance, the ability to make fabrics of a clean and clear definition, and to make lightweight cloth.

In the period leading up to Treotek the Wool Board had focused much of its funding of WRONZ R\&D on finding new applications for coarse New Zealand wools. This meant that when WRONZ came to develop Treotek in the market it may have been overly influenced in the early stages by a perceived need to use very coarse wools. However, the handle of Treotek-based fabrics has yet to meet Japanese requirements for the higher value apparel uses, and this market niche represented a "false start" that may have significantly delayed the commercialisation of Treotek. However, more recent efforts to exploit the technology with finer wools have quickly resulted in commercial success.

Alliance Knitting Yarns, under the leadership of its General Manager, Stuart Hammer, marketed Treotek-based yarns under the Treotek brand for the upholstery market. In 1993 the first major sale of Treotek was made, to refurbish the interior seating on New Zealand Rail's Interisland ferry the Aratika. The Treotek fabric used on the Aratika has additional stain resistance and fire retardant treatment, plus a UV block for increased colour fastness to light. Treotek was chosen ahead of cheaper synthetic fibres because of its superior functional properties and appearance.

The focus on upholstery therefore gave Alliance and WRONZ a market proving ground for the technology and allowed the company to achieve a return on its investment within a relatively short time-frame. Other applications such as woven and fine gauge knitted apparel have more recently become the focus of a parallel development programme and have attractive longer-term prospects. 
The early success with upholstery opened up new possibilities in more highly patterned fabric and in aircraft upholstery. Alliance Fabric and Apparel at Timaru saw the opportunity to move into the airline upholstery market. This is around a $\$ 150$ million a year market with a few large suppliers. The company felt confident that the Treotek technology gave it the ability to produce the technically best fabric for this market. Norwellan Textiles in Australia was already established in that market and had accreditation from Boeing, and Alliance Textiles developed a partnership with it to fully exploit the technology in the airlines market.

The resulting Flightweave development, a light but hard-wearing Treotek-based seat fabric, was unveiled to the world's airline industry at the Asian Aerospace 94 show in Singapore in 1994. Flightweave is about 30\% lighter than conventional materials used on aircraft seats and is flame resistant. Trials of the fabric are underway in Air New Zealand, Qantas and British Airways. Alliance Textiles and Norwellan Textiles now jointly market the fabric which is produced at two mills, one in New Zealand and one in Australia.

\section{Intellectual Property Protection}

WRONZ's core mission is to develop and transfer technologies that add value to the New Zealand wool clip, and its funding from the Wool Board is on that basis. WRONZ has an active patenting strategy and took out patents on both the Treotek concept and some of Jack Watt's machinery innovations needed to develop it. WRONZ has dispensed with open publication of much of its research in favour of offering confidential material to particular clients on a proprietary basis. Alliance Textiles is now using technology to create an edge in the market through products and processes that are difficult to imitate. The company relies significantly on inhouse tacit technology and know-how, incremental process improvement, and a strategy of using technology as a competitive tool to capture for itself much of the benefits of technological innovations such as Treotek. Franchising is an option which Alliance will likely explore if it cannot meet the global demand for yarn. 


\section{Subsequent Developments}

The convergence and interrelationships between wool product and process innovation reflects strong "cross overs" in technology, and this in turn means that innovations such as Treotek can lay a basis for subsequent developments.

The Treotek technology has been combined with yarn bulking technology for woollen fabrics. Treotek has been combined with the Protek technology to produce new flame and heat-resistant fabrics with exceptionally high abrasion resistance and lighter weight. A lightweight Protek development based on Treotek fabric has been released for motor-sport end uses, and new applications of Treotek in the protective clothing and Swanndri areas are also feasible.

Skills built up within Alliance Textiles in the course of developing machine-washable fabrics for Protek have been applied to the development of the Flightweave fabric. "Cross overs" of technology among several products have encompassed flame retardability and machine washability technologies. The generic nature of much of this technology means that equipment can be more easily afforded because of higher volumes of throughput.

Currently, further work is still underway on the use of Treotek fabrics for apparel applications, and Japanese companies maintain an interest in the yarn's potential for quality apparel. Alliance Fabric and Apparel is looking at apparel fabrics that utilise the WRONZ Spin-bulk technology in combination with Treotek.

\section{Background of Key People}

Garth Carnaby was leader of the Textile Physics Group in WRONZ in 1987, before becoming WRONZ Deputy Director with responsibility for much of the organisation's longer-term strategic planning. He has received many awards, distinctions and 
patents during his career in wool research and is a Fellow of the Royal Society of New Zealand. He was appointed Managing Director of WRONZ in August 1992.

Bruce Munro is Chief Executive of Alliance Textiles, with very extensive business experience in the insurance, automotive and wine industries. $\mathrm{He}$ has acted as a "trouble shooter" in a number of businesses. He is now a member of the Wool Board.

Jack Watt joined WRONZ in 1982, having been recruited from Britain. He is a very experienced synthetic fibre and wool processing and product development technologist of international standing. He is now part of WRONZ's senior management team.

Stuart Hammer is General Manager of Alliance Knitting Yarns in Mosgiel. His background is in production planning and production management in the textile industry. He has a very detailed knowledge of the market and process requirements of key parts of the industry.

Alistair Coleman is General Manager of Alliance Fabric and Apparel in Timaru. He was brought up on a farm but began his professional career in the motor trade. Before joining the textile industry he was involved in finance with a trade and marketing focus and picked up knowledge of branding, marketing and commercialisation which assisted in his later work with the Treotek and Protek developments. Coleman joined Alliance Textiles in 1987 in a financial role and then moved to the Timaru plant in 1989 as General Manager of the top-making plant. He was also a director of a wool scouring company. He took up his current position in September 1991.

Keith Jowsey has spent his entire career in the textile industry and joined Alliance Textiles in 1966. From 1971-1977 he worked as a senior scientist in WRONZ, before rejoining Alliance and spending time as Group Technical Manager, Mill Manager and Group Operations Service Manager. He was seconded as an Associate under the 
Emerging Technologies Programme (later the TBG scheme) to liaise between WRONZ and Alliance in the development of Treotek.

\section{Conclusions}

Treotek is a major technological innovation that depended on the conceptual insights of Garth Carnaby and the ability of Jack Watt and Alliance Textiles staff to translate an idea into a new technological development. The innovation built on Carnaby's knowledge of state of the art worsted technology developments in Britain, such as spin-offs from the Sirospun technology, on a good grasp by WRONZ of the interface between technology and the consumer products market, and a special appreciation of the international science underpinning textile technology.

The success of Treotek was a strong endorsement of WRONZ's strategy of moving into added value product development for the onshore industry, and of its move into company-specific innovation. WRONZ now has the confidence of major textile companies in New Zealand and abroad in its ability to deliver technologies that confer a competitive edge. It has built up its company-level business and reduced its dependence on the Wool Board and Government funding. Each technological success has enhanced WRONZ's confidence further. WRONZ now has very good industry links and transacts its private sector business in an environment of trust and close cooperation. The success of Treotek has cemented the relationship between WRONZ and Alliance. The Chief Executive and other top managers of Alliance now visit WRONZ on a regular basis, and vice versa.

The success with Treotek is paying both economic and cultural dividends to Alliance Textiles. The development of Treotek cost about $\$ 2$ million, of which around $\$ 250,000$ was the research cost. This does not include the cost of antecedent research which helped create the knowledge base and generic technological platform underpinning Treotek and other wool processing technologies. The economic benefits of Treotek and 10 other WRONZ innovations were assessed by Scobie and 
Jacobsen (1994). The analysis built in research and return from investment lag times and used a total investment horizon from 1962 to 2021 . The study demonstrated an internal rate of return of $65.5 \%$ average over all the projects, or a return of $\$ 11.40$ for every $\$ 1$ invested. Using relatively conservative assumptions the report concluded that Treotek had a total present value ( $\$ 1992 / 93$ ) of $\$ 43.31$ million. Together with its other innovations, achievement of ISO 9000 accreditation, skill upgrading and more flexible working practices, Treotek has demonstrated the success of Bruce Munro's strategy of making technological innovation and niche product and market differentiation central to the company's innovative strategy. Because Treotek worked WRONZ is now emboldened to bring other ideas to Alliance. Treotek has been a catalyst both for Alliance to be seen as a high-tech textile company and for investment by the company in new plant. Alliance Textiles has converted a significant number of spinning frames to Treotek and is forecasting strong revenue growth from Treotekbased products.

The success with the innovation means that Alliance Textiles' top management is now committed to the positioning of R\&D as a core part of its business. Alliance Textiles now spends about $3.5 \%$ of its budget on R\&D. The company does not have an R\&D manager and Bruce Munro has a firm belief that the divisional general managers have the responsibility for generating and carrying through new technological innovations. Alliance has developed its skills in technology management, has increased its commitment to quality management and to the use of measurement technology, and it is now more effective at identifying and solving technical process bottlenecks.

Treotek illustrates the importance of the receptivity to new ideas and technologies in companies, and the willingness to foster an innovative culture that will turn those ideas into commercial outcomes. The vision and drive of Bruce Munro, Alistair Coleman and Stuart Hammer, and the willingness of Alliance Textiles staff to accept new ideas, learn new skills and adapt to new technology was fundamental to the success of Treotek. The experience of Bruce Munro and Alistair Coleman outside the wool industry ensured their awareness of the new possibilities and helped counter the 
influence of some traditionalists in the IWS and HESC who initially had somewhat of a "mental block" to Treotek.

The Employment Contracts Act provided important leverage in implementing more flexible workplace practices within Alliance Textiles. Total quality management, customer focus throughout all levels of the organisation, team-based participation and improved information flows helped create an environment in which innovations such as Treotek could be successfully commercialised. The leadership of Munro, Hammer and Coleman was paramount and inextricably linked to workplace reform and changing company culture. For example, ISO only succeeded in Alliance Fabric and Apparel after Coleman changed the culture and ensured that the workplace foundations were in place.

The TBG scheme played an important though not pivotal role. Its support for a seconded technologist spending part of his time in the company and part in the research institute created an extra channel of communication between WRONZ and Alliance Textiles.

The wool industry has historically emphasised the market needs of the sector as a whole, and in hindsight such a generic approach implies that wool-based innovation should benefit all wool growers and users in an equitable way. This generic approach is appropriate to a homogeneous industry where all players can benefit from an innovation, but seems counter-intuitive when premium returns can only be achieved by differentiation, niche product development, and proprietary and specialised technologies that competitors find difficult to imitate.

The success of the Treotek innovation resulted partly from its focus on new applications for New Zealand coarse wools in very specific niche applications. As a platform for branded, differentiated products developed in close liaison with customers the Treotek development is almost the antithesis of the IWS and Wool Board's erstwhile strategy of generic and undiscriminating focus on wool as a commodity product. 
Both the Wool Board and WRONZ are now focusing on new product development and new uses for wool, with an emphasis on adding value onshore and targeting more differentiated, niche markets, rather than trusting in the nebulous and difficult to measure benefits of generic promotion and technical development under the aegis of the IWS. The Wool Board is now concentrating its marketing and administrative effort on New Zealand wool users globally.

Success breeds success, and just as Carnaby's confidence in his ideas grew from the WRONZ needle innovation, the confidence of both WRONZ and Alliance has received a sufficient boost from Treotek to lay a basis for other ambitious innovations in the future. 


\section{Appendix 1}

\section{Key Events in the Treotek Innovation}

\section{Key Events}

1982

WRONZ and HESC begin work on tropical worsted cloth

1985

Tropical lightweight worsted cloth incorporating crossbred wool created, using advanced measuring equipment and a scientific knowledge of wool structure

1987

Lightweight worsted suiting cloths containing $30 \%$ by mass of 35 micron wool blended with merino wool adopted by Japanese worsted manufacturers and tailors

1987

Garth Carnaby conceives of idea for Treotek on flight over Alaska

August 1988 Garth Carnaby submits patent application 225679 for multi-component yarn

1989

Alliance Textiles in financial difficulties

August 1989

Garth Carnaby visits HESC in Japan and discusses opportunities to develop Treotek

December $1989 \quad$ WRONZ and Alliance Textiles (Munro as Managing Director) submit joint application to Emerging Technologies programme 
July 1990

1990

Late 1990

Late 1990

1991

1991-92

March 1992

August 1992

September 1992

1992

1992

1992
Emerging Technologies project on Treotek commences

Treotek yarn spinning process under trial in WRONZ

Spinning frame at Mosgiel converted and used to trial Treotek, successfully producing Treotek yarn

HESC group in Japan examines Treotek fabrics and expresses interest in further samples to conduct trials

Members of HESC in Japan conduct trials of Treotek fabrics

Focus of Treotek moves to upholstery

Alliance Fabric and Apparel begins Quality Management programme

Garth Carnaby becomes Managing Director of WRONZ

Emerging Technologies/TBG project on Treotek and other processes finishes

Trialing of Treotek in Japan continues, with a focus on apparel applications

Treotek-based cloth finished by Alliance Textiles and by Japanese

Treotek samples for knitwear applications fail to achieve success 
1992

1992

1992

1992

1993

1993
Trials undertaken on use of Treotek yarn for protective clothing

Treotek upholstery yarns spun for use as samples in Alliance Textiles weaving plant and for an Australian customer

First small orders of Treotek-based yarn supplied

Alliance Textiles trademarks the new process with the Treotek brand

Treotek selected for Aratika upholstery

Joint venture established between Alliance and Norwellan

Textiles 


\section{CASE 8: GS 2085 APPLE VARIETY INNOVATION}

\section{Introduction}

The GS 2085 apple is a cross between the Gala and Splendour varieties, produced through controlled pollination by the DSIR (later HortResearch). It is a large, rosy pink fruit with flesh that is creamy coloured, crisp and with a fine texture. It is juicy with a sweet and slightly tangy flavour. GS 2085 is a late maturing apple with the eating and storage quality of Splendour and the thicker skin of Gala.

The GS 2085 innovation must be placed in its wider industry, institutional, technical and market context.

\section{Industry Background}

New Zealand's two most important apple growing areas are Nelson and Hawkes Bay, with other important regions being Canterbury and Waikato. The total New Zealand apple crop was almost 23 million cartons in 1992/93, of which just over half were exported (Export News, 1993a). Total export earnings were $\$ 320$ million in 1993/94.

The New Zealand Apple and Pear Marketing Board has the largest pipfruit product range in the world and achieves the highest premiums. The Board won the GovernorGeneral's Supreme Award for Exporter of the Year in 1993, an award sponsored by Tradenz and Air New Zealand. Around one third of the apples the Board receives are processed, it has over half the fruit juice market in New Zealand and is dominant in mineral water. The Board is New Zealand's single biggest beverage exporter but the highest returns come from supplying fresh fruit to the export market. In 1993 the Board exported 1,400 apple products, 292 pear products and 15 apple concentrates to 56 countries (Orchardist, 1993a). 
The industry saw the dangers of weak selling early in its existence and the New Zealand Fruit Export Control Board was created under the Fruit Control Act 1926. This Board had a statutory monopoly to market fruit on behalf of exporters. The Apple and Pear Marketing Board was then established in 1949 to act as the sole export and domestic marketer of New Zealand pipfruit. The Board became involved in processing in 1962. The Board is now involved in promotion, research and development, marketing, distribution and quality management. The Board has two main foci: maximising returns to growers through the fresh fruit exporting side of the business, and maximising return on assets through other activities, such as processed products and fruit juices. Since the Board was established the market has grown from $\$ 750,000$ in total export earnings from 4 export markets in 1949 to $\$ 349$ million in export earnings from about 56 countries in 1992/93.

The Board has a long history of innovation in its transport, marketing and institutional arrangements, as well as in technological innovation. The Board's marketing innovations include its pioneering of the export of German apples to England and English apples to Germany. In 1971 the Board ended its connection with the Conference Lines and established its own export shipping arrangements and associated fruit transportation technology. This allowed it to exercise more control over the distribution of its export product. In 1974 the Board moved away from the auction system into a system of private treaties and wholesale arrangements in Europe. Since then, the Board has strengthened its offshore market and distribution system in Europe, Australia and North America. The Board has emphasised the need to exercise control as far as possible down the value chain in pipfruit marketing and thereby maximise returns to growers, and this has been reflected in its approach to the development of new varieties.

The Fruit Industry Plant Improvement Agency (FIPIA) was set up in 1981 to administer the introduction and development of new plant varieties and to allow a more systematic approach to their trialing and commercialisation. In 1982 it was structured as a company jointly owned by the Apple and Pear Marketing Board (APMB) and the New Zealand Fruitgrowers' Federation. Before FIPIA was set up 
MAF and DSIR were involved in introducing and screening plant varieties, but trialing of these was spasmodic, only small numbers of trees were planted out with growers and there was inadequate follow-up.

In 1983/84 the APMB began to fund DSIR pipfruit breeding, initially in pears and later in apples. FIPIA has been involved since 1985 in commercialising fruit varieties released by the DSIR. The APMB took over full control of FIPIA in 1990 and it has established a New Product Development Committee that facilitates the process of linking new variety development with market needs. The New Product Development Committee is a communication liaison group that brings together researchers, technical people, product development people, FIPIA and marketing staff.

In 1984 MAF withdrew from the provision of quality assurance services to the pipfruit industry and forced it to pick up the costs. This had a profoundly beneficial effect on the industry since it had to employ skilled technical people to provide quality management and other technical services, and this has substantially enhanced the ability of the industry to interpret and commercialise the results of research.

The Board has been criticised for its statutory control over the export crop and for stabilisation policies that do not always translate price premiums for specific varieties back to growers. The effect of price stabilisation (or "smoothing") has been to reduce the rate of change to new varieties. This may have positive effects, by ensuring that growers do not respond pre-emptively to short-term premium earnings from new varieties that are not sustainable in the long-term. It also helps maintain a balanced portfolio of varieties that can allow the Board to service a wide range of markets and consumer preferences. Price stabilisation has now been dispensed with, but the Board has strong majority support from pipfruit growers to retain its marketing powers.

The Board provides information on new varieties rather than prescriptive advice. Growers are entrepreneurial in identifying sports, taking a risk and "having a go" with new varieties. The culture of the industry has been to use new varieties as the major source of competitive advantage. The concentration of most growers in the Hawkes 
Bay and Nelson has facilitated informal, "over the fence" information flows that accelerate the rate of diffusion of new varieties and of technical information.

The industry is one of the better-performing export sectors and many growers have had the surplus income to make risky investments in new varieties. Since the mid1980s the industry has been less stable because of economic, market and trade reforms, strong international competition, changing tastes, adverse climatic events, criticism of the APMB structure, and deregulation of the domestic market. This instability has been a major spur for the Board and industry to be innovative and to diversify into new varieties and into new markets such as in Asia.

The search for new varieties is pivotal to the Board's strategy, and in 1993128 new apple and 25 new pear varieties were introduced. The varietal composition of the New Zealand apple industry is changing rapidly as shown in Table 1 below:

\section{Table 1: The Varietal Composition of New Zealand's Apple Exports}

Variety

1988

Granny Smith

Red Delicious

Cox's

Braeburn and

Royal Gala

Other

32

30

8

\section{Percentage of Export Volume}

1991

20

21

9

$15 \quad 36$

15

Source: Hussey, 1992

In 1993 more than $70 \%$ of fresh fruit export earnings were from Braeburn and Royal Gala. 


\section{Market Background}

Europe is still the biggest export market but the Board has a major presence in North America and Asia. After 20 years of effort it has now achieved access to the Japanese market. It is diversifying into a number of non-traditional markets, including Eastern Europe and Mexico. New Zealand's major export competitors are Southern Hemisphere countries such as Chile, Australia and South Africa. While New Zealand has in the past struggled to compete with competitors such as Chile on cost or closeness to markets, it has an edge in new varieties, in marketing and distribution, innovation, technology, and in its "single desk" selling structure. The competitive advantages conferred by the industry structure are matched only by the South African industry. South Africa is a strong competitor even in premium, New Zealand-bred varieties such as Royal Gala and Braeburn, and much of its strength flows from its single desk Board structure.

Tastes in apples differ markedly among countries and have in the past been slow to change. However tastes now seem to be changing more rapidly. Recent trends in major markets favour larger fruit with brilliant coloured and unblemished skin, crisp texture, and a mild sweet flavour. Other important varietal factors for the export market include post-harvest behaviour, a thick skin to minimise damage, and production factors such as yield, tree form and health, timing and duration of harvest, and susceptibility to plant health problems.

The Board has differentiated itself from its commodity competitors at all levels, including for processed products as well as new varieties, and has pursued an aggressive branding strategy. In 1991 the Board adopted the ENZA brand. The Board has sought to control the distribution of its product and about $70 \%$ of New Zealand's pipfruit exports are sold directly to retailers by Board-owned companies.

While new varieties are a core part of industry strategy, the Board as far as possible aims for year round supply of a comprehensive range of varieties that can meet the needs of all customers. This requires it to carefully balance the need for the price 
premiums for new varieties to influence planting and production by growers, while at the same time maintaining substantial export volumes of more traditional varieties.

\section{Institutional Background}

The DSIR established a Fruit Research Division in 1948 to handle all its horticultural research, other than that undertaken by the Plant Diseases Division. From the 1970s on both MAF and the DSIR expanded their investment in horticulture with much of this driven by the success of industries such as pipfruit and kiwifruit.

The science reforms initiated in 1989 saw the horticultural research capabilities of MAF Technology, DSIR Fruit and Trees and DSIR Plant Protection incorporated into the HortResearch Crown Research Institute (CRI). HortResearch is now a Crownowned company registered under the Companies Act and with full commercial powers. The new commercial focus of the CRI has helped strengthen its relationship with industry but has also raised concerns about the appropriate balance between "public good" research to benefit the industry and the Institute's commercial earning objectives. Upon the establishment of the CRI the APMB extended a broader research agreement already in place with DSIR by setting up a specific agreement governing plant breeding.

\section{Technical Background}

Apple growing has been established in New Zealand since the middle of the 19th century. In 1875 woolly aphis broke out in New Zealand and the resulting devastation forced growers to look at new resistant varieties such as Northern Spy. An Auckland nurseryman, H.E. Sharp, for the first time in New Zealand used scientific apple breeding techniques to produce a number of important selections such as Mona Hay and Sharp's Late Red. By 1925 American sweet flavoured apples such as Red Delicious and Jonathan were established in New Zealand and were rapidly replacing traditional English and European varieties. 
Most new apple varieties have been natural mutations or sports and New Zealand growers have an impressive track record in spotting their potential and breeding from them. Although the first controlled apple crosses have been attributed to Thomas Knight in 1906, in New Zealand GS 2085 is the only new variety resulting from a cross by a scientific institution that is achieving substantial success.

To achieve success in a single generation a large progeny population is necessary. It is estimated that progeny populations of 30,000 seedlings are needed to confidently combine 5 characters (such as fruit size or skin colour) in a new selection (McKenzie, 1983). Apple breeding is also a long-term business: in the past it took 10 years to select a new hybrid from a progeny population (although HortResearch plant breeders now take as little as 4-6 years), and another 10 years to reach full commercial production. It may take several more decades for growers to master the production and post-harvest management of the variety, and for the variety to attain full acceptance in the market. For example, Braeburn was discovered in 1952 and released in 1970, but has only been a major variety in the market in the last decade.

J.H. Kidd, a very progressive Wairarapa grower, saw the opportunity in the 1920 s to combine the rich aromatic taste of English apples with the bland sweetness and good appearance of the best American types. The result was Kidd's Orange, a cross between Delicious and Cox's Orange Pippin, which was successfully established by 1931. Encouraged by this success Kidd continued with hand pollination. Much later, he was visited by Dr Don McKenzie, a DSIR scientist in Havelock North, who saw the potential for one of Kidd's crosses, a hybrid between Kidd's Orange and Golden Delicious. After Kidd's death this cross was further selected in 1965 by DSIR scientists at Havelock North Research Orchard and named Gala. Commercial production of Gala commenced on a substantial scale in 1970 .

The Braeburn sport was discovered on the Nelson property of Eustace and Norman Williams in 1952. Braeburn may well have been a natural cross between Lady Hamilton and a Cox-like apple. Braeburn was successfully developed with a focus on the European market, but it had post-harvest problems that required significant effort 
to overcome. In 1954 1,000 apple cultivars were imported by Dr Don McKenzie for trial at the Havelock North Research Orchard. None of these have had continuing commercial success, although Spartan had some success as a cultivar for around 10 years.

Splendour was discovered and selected by C. L. Roberts and released in 1964. A sport of Gala, Royal Gala, was found by Matamata orchardist Bill Ten Hove on his orchard in 1969. Ten Hove had in fact been introduced to Gala by Dr Don McKenzie, and Royal Gala was released on a substantial commercial scale in 1973. Don McKenzie earned great mana in the industry from his efforts in the 1970s and early 1980s and was "intraprenuerial" in raising funds from a local fruit growers' association to support further pollination for breeding research. $\mathrm{He}$ worked on "bootleg projects", initially as a sideline to his work as a plant physiologist, and essentially produced results for his managers as a fait accompli. His entrepreneurship made him a role model for younger acolytes such as Allan White. In the same way that McKenzie inherited Kidd's new varieties, Allan White took over McKenzie's selections and this formed the basis for his breeding programme.

\section{The Innovation}

Impressed by the success of Gala, Don McKenzie had initiated a systematic programme of breeding of new varieties, producing three very large families with populations of 40,000 seedlings each. One of these families was developed in cooperation with Dr Yoshida of Moroika Fruit Tree Research Station in Japan. Another series of crosses made between Red Dougherty and Golden Delicious have not been commercially successful. The third family was a series of crosses between Splendour and Gala, with McKenzie aiming at an eventual replacement or supplement to Red Delicious. Splendour is a popular and very high quality apple with good flavour but is prone to bruising. Gala has a thicker skin and is more suited to the export market. The aim of the crosses was therefore to combine the best features of both apples. 


\section{Selection and Trialing of GS 2085}

GS 2085 was one of about 100 selections made out of a fruiting population of about 4,000 seedlings. Gala was the seed-bearing parent and Splendour the pollen parent of the variety. An initial progeny population of 40,000 was reduced to 4,000 by elimination of seedlings susceptible to woolly aphis, black spot, and mildew. About $20 \%$ of the survivors produced fruit of good colour and quality.

Allan White continued the selection programme after McKenzie retired in 1984. Further selection was undertaken with some external advisory input until, through a process of elimination, GS 2085 became one of about six selections that were trialed in orchards. Of other Gala/Splendour selections GS 330 is also showing promise and significant plantings of this variety have been made.

Trialing of the GS crosses at these early stages was a little ad hoc, and systematic sensory evaluation, market analysis and study of cultural characteristics was not rigorously built into the trialing process.

\section{A Parallel Development: The Taylor's Gold Innovation}

An interesting parallel development to GS 2085, and worth comparing with it, was the commercialisation of the Taylor's Gold pear. Taylor's Gold was a sport of Doyenne du Comice, found on the property of Wendy and Michael King-Taylor at Riwaka in 1985. The potential of this pear was quickly recognised by the APMB's Product Development Manager, David Cranwell. Joe Pope, the Board's Chief Executive, saw the 'fit' between the pear's technical characteristics such as flavour and colour and the market potential. Against the pessimistic views of some specialised marketers, Pope and David Cranwell acted as product champions for the variety. Taylor's Gold has proved a major success with several thousand cartons successfully exported by 1994 and around 300,000 trees in the ground. The rapid uptake of this new variety was partly driven by growers wanting alternatives to 
pipfruit varieties with low returns or, in the case of new entries to the industry, alternatives to declining crops such as tobacco.

\section{Capturing the Benefits in New Zealand}

The DSIR's Division of Horticulture and Processing submitted an application to the Commissioner of Plant Variety Rights in August 1989 for the GS 2085 variety, with "GS 2085" as the breeder's reference number, and under the proposed denomination of "SCIROS". Plant variety rights for a term of 23 years under the name SCIROS were awarded to the DSIR in September 1991, and patent protection has since been obtained in the United States. Reciprocal variety rights need to be obtained in other countries when new plant material is placed in those countries. Royalties of $\$ 1.50$ are paid to HortResearch on each tree sold.

Against a backdrop of mutual respect and a long-term and productive partnership between HortResearch and the APMB, the industry is concerned about the control of the results of CRI research. The Board is now placing increased emphasis on commercial confidentiality to protect New Zealand's advantages from overseas competitors. Tight control of new plant material is especially important because New Zealand's excellent reputation for innovation in apple varieties makes it a target for competitors. The openness of the New Zealand industry, of its science establishment, and the history of relatively open exchange of new plant material is in marked contrast to other more secretive competitors such as South Africa. However, there is also awareness within the Board and in HortResearch that New Zealand benefits enormously from the exchange of plant material and that any overly restrictive approach may lead to retaliatory barriers emerging in other countries.

The APMB and FIPIA have now agreed that New Zealand growers would be given about 5 years of exclusivity over new tree varieties. This translates into a competitive advantage of about 9-10 years by the time new plant material is released overseas and volume production comes on stream. New biotechnology techniques may also aid the protection of the intellectual property embodied in new varieties. Tracer genes can be 
inserted to embed a genetic 'fingerprint' into new tree varieties. Other strategies to protect premium earnings from the variety may include licensing or franchising production by Northern Hemisphere or other growers, to complement production from New Zealand and provide year-round supply without eroding margins for the New Zealand grower.

\section{Commercial Release}

After GS 2085 had been under evaluation for around 2 years the New Product Development Committee recommended to the Board that the full release be delayed another year in order to best capture the commercial benefits. The Board initially agreed to this. However, at this time the industry was in a trough and grower representatives on the Board pressed for the early release of GS 2085 on the basis of the available information on its potential. Growers felt that the industry desperately needed a new variety and as result the Board, despite the reservations of marketers, overturned its earlier decision at its next meeting and decided on its release. This decision was partly motivated by awareness that the release of New Zealand plant material to overseas competitors had in some cases eroded the premiums earned by New Zealand growers, and a need was felt to move quickly to establish a competitive advantage.

Allan White was concerned that inadequate trialing and evaluation had been undertaken at the time the variety was released and his concerns were shared by marketing people in the industry. Although trees were released and planted without adequate information on production methods or market prospects, this was a risk that was understood and accepted by growers. About 147,000 GS 2085 buds were released in the first year and a further 200,000 were released in 1993 alone. GS 2085 is now the fifth most commonly planted apple variety in the country. With over 500,000 trees in the ground the volume of GS 2085 likely to come on stream in 3-4 years will pose a huge marketing challenge for the Board. 


\section{Orchard Performance of GS 2085}

GS 2085 produces high quality, large fruit even from young trees, it is an early fruit producer, and has low susceptibility to bitter pit, powdery mildew and apple scab. GS 2085 has inherited Splendour's eating and storage quality but it may also have inherited that variety's susceptibility to russet. There are significant regional variations in the performance of different apple varieties, for example between Nelson and coastal Hawkes Bay and cooler climates such as Canterbury and inland Hawkes Bay.

GS 2085 seems suited to East Coast districts, Blenheim, Canterbury, parts of Hawkes Bay, and Central Otago. Its performance in wetter parts of Nelson and the Waikato is uncertain because of russet. The apple is also prone to storage scold which is a problem because the chemical used to treat it, DPA, may eventually need to be phased out. On lighter soils GS 2085 may be subject to leaf drop problems. However, on balance the orchard performance of the variety looks very promising.

\section{Marketing and Commercialisation}

The APMB tends to become heavily involved in new variety developments when the trees are available for trialing on commercial properties. GS 2085 trees have been available to New Zealand growers since 1991. Because of the niche GS 2085 occupies it is well positioned to earn price premiums, but at the same time it has to be marketed as part of a basket of varieties where the objective is to maximise total returns to the New Zealand grower rather than returns from an individual variety. Production may grow from 100,000 cartons in one year to 500,0000 cartons 2 years after that. It will be a challenge to market such high volumes of GS 2085 as well as Braeburn, Fuji, and Granny Smith at the same time, especially given the high crosselasticity of demand that exists among a number of these varieties.

GS 2085 has good colour, shape, flavour, and storage quality and has a very wide appeal compared, for example, to Braeburn which is more a European-style apple. 
The German market has a reputation for innovation in new food products and may well be a leader in the market acceptance of GS 2085, as it was for Braeburn. The U.S. market is more conservative and places a higher value on appearance, and Braeburn has not fulfilled its potential there as a result. However, the good appearance and flavour of GS 2085 augurs well for the variety in the U.S.

David Cranwell, Product Development Manager for the Board, is responsible for managing the development of new varieties. This involves preparing regular evaluations of varieties from different sources, including market feedback information, sensory evaluation, handling, and cultural information which forms the basis of a variety database which is available on a confidential basis to New Zealand growers only.

Selection is both objective (eg. screening out for mildew) and subjective (appearance). Cranwell's work aims to take much of the subjective judgement out of the choice of new varieties, by facilitating a more scientific basis for it. This approach is driven by some difficulties that have occurred when growers have planted large quantities of varieties such as Fiesta and Granny Smith on the basis of incomplete and anecdotal information or subjective advice.

Trial of new varieties on different rootstocks is undertaken by growers in different regions, while an international network of retailers tests varieties and provides market information. In 1992 Cranwell began using sensory evaluation for new pipfruit varieties, using the HortResearch unit in Auckland and the Dairy Board's sensory unit in Singapore. Sensory evaluation undertaken at the Dairy Board's Singapore facility has produced positive results for GS 2085's taste and shape, and most in the industry believe that the variety will be a major success.

An important aspect of marketing is the naming of the variety, and this has caused some discomfort within the industry. A name was suggested about 3 years ago but rejected on marketing grounds. Some have argued that delaying naming has been itself a deliberate and effective marketing tactic. However, on balance the ongoing 
delay is seen by most as a serious shortcoming in managing the development and market introduction of the new variety.

It is difficult to forecast the market lifespan of GS 2085 but it is likely to be around 10-15 years as a premium variety, after which increasing volumes may well turn it into a commodity apple. While Red Delicious and Granny Smith have had many decades of substantial popularity, changing tastes, new markets and competition from new varieties seems to be reducing the time-frame in which a new apple can earn premiums.

\section{Subsequent Developments}

The success of GS 2085 has been instrumental in the expansion of HortResearch's pipfruit breeding programme. In the early 1980s Allan White was alone with one part-time technician, but his programme now has about 8 full-time staff. Allan White's programme includes longer-term breeding using parents, or building in varietal features that may not currently be popular but which could well fill important niches in future decades. Other Gala and Splendour crosses from the mid-1970s include GS 330 and GS 472. GS 330 is well advanced in trialing while an "old fashioned" apple, OPS 2429, may also have promise.

Apple breeders internationally are working with a narrow genetic base. Around two thirds of the apple cultivars released in the world over the last 30 years originate from 5 parents: Golden Delicious, Cox's Orange Pippin, Red Delicious, Jonathan, and McIntosh (Noiton et al, 1994). This genetic uniformity is a threat to the apple industry because of inbreeding defects and lack of robustness in the face of disease or ecological change.

To counter this, in 1990 DSIR initiated a pipfruit genetics programme. This programme is headed by Dr Dominique Noiton and has as its major objective broadening the genetic base for apple breeding and extending the scientific tools available to complement the established techniques for apple breeding based around 
hybridisation and selection. An aim is to maximise the genetic variability within the apple population and thereby open up new possibilities for varieties with quite different characteristics. This involves the planting of seedlings at orchard sites in Hawkes Bay, Nelson and Otago. The aim is to ensure that the focused breeding of new commercial cultivars is complemented by a longer-term strategy of broadening the genetic base to underpin breeding to meet future and quite unpredictable tastes and preferences.

New DNA and isoenzyme techniques are being applied to "fingerprint" cultivars. Isoenzyme analysis makes it a lot easier to predict whether a variety or selection has the desired genetic characteristics. There is increasing awareness in the industry of the need to reduce the use of pesticides, and HortResearch is now active in plant breeding to foster natural resistance to plant diseases.

The APMB is increasingly using sensory evaluation techniques and is aligning market information with the cultural and production characteristics of new varieties. The Board now has one grower in each region paid to dedicate one hectare to trialing new varieties on 3 rootstocks. This process should allow the development times of future promising varieties to be reduced substantially. More reliance is being placed on directly ascertaining consumer preference rather than relying on intermediaries such as retailers and marketers. While quality and leadership in new varieties remain core to the industry's strategy, low chemical residues, and clean, green and sustainable production are major emerging issues for the late $1990 \mathrm{~s}$.

\section{Background of Key People}

The late Dr Don McKenzie was a plant physiologist in the Plant Diseases Division of DSIR who developed the apple breeding programme within the organisation. $\mathrm{He}$ retired in 1984. 
Allan White's family have been orchardists for four generations and he runs his own orchard on a part-time basis. He was appointed to a position as a technician at the Goddard Lane Research Orchard in Havelock North under Dr Don McKenzie in 1975. From 1981 he began to assume responsibility for the apple breeding programme and took full responsibility in 1984 .

David Cranwell has been Product Development Manager for the Apple and Pear Marketing Board since 1992. His family has been involved in the pipfruit industry since the $1890 \mathrm{~s}$. He completed a Diploma in Horticulture at Massey University and ran his own landscaping business before spending time with MAF and then joining the Apple and Pear Marketing Board as a field officer. He has very wide experience in the industry in the field service, in research, and very extensive marketing-related experience in Europe and Asia.

\section{Conclusions}

New Zealand's fruit breeding successes illustrate the importance of the single-minded individual, ranging from Hayward Wright in kiwifruit to Bill Ten Hove, J.H.Kidd, Don McKenzie and Allan White in pipfruit. Many of these individuals had a lifelong dedication to fruit breeding and a love of their jobs, and like Allan White and David Cranwell came from a long family line of orchardists. Don McKenzie's entrepreneurship provided much of the focus and intellectual leadership for a more scientific base to pipfruit breeding in New Zealand, but his work has to be understood in relation to those that came before such as J.H. Kidd, and those in HortResearch who have continued and greatly extended his work.

The GS 2085 is a major achievement in plant breeding resulting from the skills built up over many years by breeders such as Don McKenzie and Allan White. It is a very positive outcome from collaboration between HortResearch and industry. GS 2085 was developed from the base of New Zealand's remarkable legacy of private sector selection and commercialisation of natural apple mutations. 
New Zealand's apple breeding effort is essential to adapting imported plant material to local circumstances, and to creating a competitive advantage in a market where New Zealand cannot compete on cost or price. The release of GS 2085 was partly "technology push", but was also informed by a clear understanding that it is through new varieties that premium earnings in the market can be achieved.

The commercial potential of the cross is likely to be realised because of the pipfruit industry's capacity for trialing, sensory evaluation and marketing. The success so far has drawn heavily on those in the Board such as David Cranwell who have a multidisciplinary perspective, and who understand the strategic fit between new pipfruit varieties and the marketing opportunities.

The Apple and Pear Marketing Board is an exemplar in the use of branding and control over marketing and distribution to create market power in pipfruit marketing. Key challenges for the industry are the need for a longer-term vision of what new varieties are needed as a function of the market opportunities, and the need to appraise the impact of a new variety on the overall portfolio of pipfruit exports.

The Board only became systematically involved in GS 2085 from about the late 1980 s, even though it was crossed in 1974. The Board should have been involved earlier in the process and undertaken rigorous trialing over a number of regions and through sensory and post-harvest evaluation. The success of the Board in commercialising the Taylor's Gold sport in 9 years, from discovery in 1985 to substantial export performance in 1994, demonstrates what can be done when the skills of variety assessment, evaluation, production and marketing can be brought to bear within commercially-driven deadlines.

The Board and HortResearch have yet to fully crystallise the right balance between capturing the benefits of pipfruit innovation in New Zealand, while at the same time retaining access to the international networks, exchanges of ideas and new plant material that are needed to foster an innovative and outward-looking system for the development and commercialisation of new pipfruit varieties. 


\section{Postscript}

In late 1995 the brand name "Pacific Rose" was finally registered for the GS 2085 variety. 


\title{
Appendix 1
}

\section{Key Events in the GS 2085 Innovation}

\author{
Key Events
}

1964

Splendour released

1965

Gala released

1969

Apple breeding programme commences at DSIR's Havelock

North research orchard

1974

Pollination of GS 2085 at Havelock North research orchard

1985

Selection of GS 2085

1985

GS 2085 recommended for commercial evaluation

August 1989

DSIR applies for plant variety right for GS 2085

1991

Apple and Pear Marketing Board obtains worldwide marketing rights for GS 2085

September 1991 Plant variety rights granted for GS 2085

1992

Positive response to trial shipments of GS 2085

1993/94

First significant harvest of GS 2085

1993/94

Further 200,000 GS 2085 trees planted 


\section{CASE 9: XAB-17 BEACON INNOVATION}

\section{Introduction}

The XAB-17 lighthouse beacon was designed and developed by Vega Industries Ltd, a private company based in Porirua, in response to specifications and tender requests from the United States Coast Guard. The XAB-17 Beacon is a fully automatic rotating marine beacon that is solar powered and energy efficient. The beacon automatically switches itself on at dusk and off at dawn, introduces new lamps when existing ones fail or time-out, monitors itself for correct operation, and switches on a stand-by beacon or alarm in the event of a failure. The XAB-17 was developed in parallel with the VRB-25 Rotating Beacon, both in response to the needs of the US Coast Guard.

\section{Background}

The XAB-17 Beacon innovation needs to be understood in relation to its technical, company and market background.

\section{Technical Background}

DSIR became involved in optics R\&D in World War 11 under the direction of the Auckland Technical Development Committee. The Dominion Physical Laboratory, the precursor to the DSIR's Physics and Engineering Laboratory (PEL), was actively involved but most of the key effort focused around university groups in Auckland and Christchurch. This university work was coordinated by Ernest Marsden, then Director of Scientific Developments and the key DSIR liaison person with the armed services. By the end of the war this effort had produced mirrors for signal lamps, working parts for hand prismatic compasses, mortar sights, and assorted bubbles for army instruments. The legacy of this wartime work gave PEL New Zealand's major 
competencies in instrument making and objective measurement technology, as well as substantial capabilities in optics (see Atkinson, 1976).

In the post-war years the Marine Department became concerned with the limited useful range of major New Zealand lighthouses. PEL physicists were called in to measure the light intensities of the beams in question. A special technique was devised for this task and the intensity of the beams was determined. From the results it was possible to calculate the maximum range of each light under various weather conditions (Atkinson, 1976). After this success the National Roads Board received help from PEL in measuring the performance of lamps for street lighting, which required the laboratory to develop specialised equipment. A key strength of DSIR at this time was its instrument making workshops and facilities, and the ability of its technologists to demonstrate scientific ideas in practical working prototypes, and to fabricate instruments and products to demanding specifications. This capability reflected a multi-disciplinary approach, especially at the technical officer level.

\section{Company Background}

Vega Industries Ltd is a designer and manufacturer of lighted navigational aids and optical, electronic and electro-mechanical instruments. Vega Industries' roots can be traced to the 1960s and to early work done in the Physics and Engineering Laboratory (PEL) of DSIR. Norm Rumsey, a PEL physicist and mathematician in the Optics Section of PEL, had a strong theoretical interest in optics and in 1963 designed a navigation light, known as the PEL sector light, to control marine traffic in the Paremata harbour entrance. Each PEL sector light is tailor-made using computer programmes developed by Rumsey to manage the complex optical calculations involved. The PEL sector light projects a precision, multi-coloured beam of light, allowing mariners observing the colour of the light to determine their position relative to the safe channel. By 1970 the light was earning royalties for the DSIR, but its full commercial potential only came to be realised after Vega Industries was set up to market the innovation. 
Vega Industries Ltd was incorporated on 12 April 1972 as a private company with 4 shareholders, with its initial focus being the commercialisation of the PEL sector light. It grew out of a small company owned by John Ruddick and his wife that made navigation lights, and which had been advised by the New Zealand Inventions Development Authority to increase the company's size and expand its shareholding base. John Ruddick became its first Managing Director, with other key shareholders including Bob Barnes and George Bunce. Vega expanded into sector lights, with Bob Barnes of Barnes Optical providing a significant technical input.

The PEL sector light has been widely adopted throughout the world, and Vega has since developed a wide range of marine navigational aids such as rotating beacons, signal projectors, lamp changers, naval searchlights, as well as navaids for aeronautical use such as a Precision Approach Path Indicator (PAPI).

John Rochfort, now Managing Director, joined the company in 1977. One of his first projects was a visual approach slope indicator system that applied principles used in marine navigation to aviation control at Wellington Airport. In 1983 the company began developing a traverse light to guide large ships into English wharves, as well as automatic lamp changers, and signal projectors for the Ministry of Defence. In response to requirements for the ANZAC frigate project, Vega achieved ISO 9001 accreditation and, against strong international competition, won the only "design and build" contract involving unproven technology in the whole project. In the lead up to the XAB-17 innovation, Vega in the early 1990s researched, developed and marketed a rotating sector beacon installed at the Port of Napier, a high-intensity sector light which provides the main lead into Port Botany in Sydney, and a wide-angle oscillating boundary version of the PEL sector light for the Port of Tauranga.

Apart from some assistance in its first decade from the DFC, and in more recent times some minor grants from a Business Development Board and from Tradenz, the company has survived in a competitive market through its own efforts. After its initial success in commercialising the PEL sector light Vega has found it difficult to utilise the publicly-funded technical infrastructure on an ongoing basis, relying instead on its 
own technological competencies. This is primarily because of the inability of public research agencies to meet tight commercial deadlines, to achieve the technical quality standards, and to provide the testing services required in Vega's very specialised market. John Rochfort regrets the decline in the ability of Crown Research Institutes (formerly agencies such as the DSIR) to do the instrument making and interdisciplinary applied technological work that can make productive and practically apply scientific results. In the 1990 s technologists may be overly specialised, which in the long-term may deprive companies such as Vega of staff with a broad skill-base and an understanding of the conceptual basis of different technologies.

While navigational aids are its major business, Vega also handles design and machining work for other clients, most of it in very small or one-off production runs. These contracts have ranged from cavity resonators for the Post Office to a fingerprint machine for the Police. Vega does most product manufacturing internally, except for some specialised components such as circuit boards. In some cases, Vega has had to build a machine to make just one small part. The cost of one-off product development, such as the injection moulding, is often very significant and Vega is very conscious of the need to design products to be simple enough to manufacture, thereby keeping the price down.

The lack of standardisation of products makes it difficult to achieve economies of scale and has limited Vega's ability to grow. The business is capital intensive for a small company and Vega has invested substantially in capital equipment, including in advanced CNC turning and milling machines. The company typically undertakes one large system project a year. Vega is currently developing a maritime ship control system for the Hong Kong government.

In 1994 the company had 6 shareholders and a staff of 9. Key staff are the Managing Director, John Rochfort, and the Marketing Manager, Martyn Cook. John Rochfort owns his own separate company that builds the computer technology required in Vega's lights, with this technology being constantly upgraded to meet new technical demands. Rochfort writes some software, but also depends on some external 
software development. The company employs 6 workshop staff, who perform both R\&D and production manufacturing, and an office manager. Vega draws on a range of consultants and companies to provide specialist technical or subcontracting services. It retains the services of Norm Rumsey in optical design and Rod Ruddick in electronic design. Companies providing services include Strobe Engineering, as well as Industrial Optics Ltd for lens manufacturing, and Hella Industries for injection mouldings. John Iorns, a director, assists in management and accounting while Peter Clarke assists with the quality system.

Vega Industries began exporting from its establishment in 1972 and now exports around $90 \%$ of its production. It currently invests around $25 \%$ of total sales on R\&D. It strongly focuses on the marine navigational market and quality control is typically undertaken by staff with extensive sailing experience. However, its core business could be best defined as instrument making for niche markets, rather than being exclusively locked into the marine and navigational markets.

\section{Market Background}

Marine safety is governed by international agreements which place a high premium on reliability. The agencies responsible for marine safety make up a tightknit and conservative group which communicates freely on technical matters. The United States Coast Guard maintains 231 major lighthouses in the US, of which 106 are required to have a night-time range in excess of 20 nautical miles. With the most extensive and diverse range of lighted maritime navigation aids in the world the US Coast Guard is the biggest market as well as the technology leader. It has been a multi-million dollar funder of R\&D in companies to develop marine navigation-related technology. While it meets its needs by contracting companies to produce required products rather than making them internally, it manages a rigorous testing programme that fulfils military standards and performance criteria. Other lighthouse authorities in the world, including in New Zealand, make use of products first developed for the US Coast Guard. 
Technological progress is driving changes in the market for lighthouse and navigational aid technologies. With major lighthouses now fully automated the major efficiency gains will result from reducing through-life operational costs, essentially the energy and maintenance costs. Global Positioning Systems (GPS) are likely to reduce the number of minor lights, but the major lighthouse services are likely to continue to rely on shore-based lights because of mariner beliefs that other systems are not failsafe.

Vega faces international competition in its core market from companies in Holland, Germany and France and also has to overcome such market barriers as the "Buy American" preference policy in the United States.

In its earlier years Vega was a technology-based product development company, but from 1990 and with the encouragement of a market research grant from Tradenz, Vega began to take a more systematic approach to marketing. Martyn Cook evaluated a range of marketing options and Vega put in place a worldwide sales and distribution system through the London-based firm $\mathrm{AB}$ Pharos Marine, the world leader in the marine navigational aids market. Vega sector lights are now also marketed by Zeniya Lights of Japan.

Vega does not now patent most of its innovations because of the cost and time involved, relying instead on commercial confidentiality to protect clever technical details of its innovation such as the optics, and capitalising on its technical reputation. The niche-oriented nature of the market means that competition is from relatively small companies, and the technical difficulties of the optics involved, the need for customised, tailor-made products with very small or one-off production runs, all serve to discourage competitors from entering the market, or create barriers to entry from existing competitors. 


\section{The Innovation}

In 1991 Martyn Cook undertook market research and promotion in the United States. This began with the promotion of existing products, but in the course of this he identified a forthcoming tender for a Landfall Beacon (lighthouse light) for the US Coast Guard. The US Coast Guard saw an opportunity to exploit changing technology to address technical inefficiencies in the performance of its existing lighthouse network. At this time the standard 24 mile lighthouse beacon operated by the Coast Guard consisted of $600 \mathrm{~mm}$ searchlights mounted on heavy steel turntables. Each of these lights had a 1000 watt lamp and the turntable required a further 600 watts to operate. A typical installation had a total power requirement of 1600-2600 watts and was energy intensive. Solar power was uneconomic for installations above around 400 watts of all-night consumption. Existing lighthouses depended on diesel generators for remote areas, including back-up generators for emergencies, or mainline supply involving expensive cabling, some of it submarine. Such cabling deteriorated, was expensive to maintain or replace, and often had adverse environmental impacts, for example due to power line reticulation through sensitive environmental areas.

\section{Specifications and Tendering}

In 1991 the Aids to Navigation section of the US Coast Guard issued a solicitation (call for tenders) setting out specifications and technical performance requirements for a new landfall beacon that would be sufficiently energy efficient to economically use solar power. In preparing its specifications the US Coast Guard was conscious of a range of technical developments that could allow major performance gains. These included new light sources such as xenon-arc and metal-halide that emit more light energy per joule of electricity consumed than existing tungsten-halogen lamps, new developments in switch mode power supplies, and new optical technologies that allow more emitted light to be captured and held within a beam rather than being dissipated as stray light. 
The solicitation was based on a careful comparison of the through-life costs of existing mains or diesel generator-powered beacons compared to solar-powered units that could be developed. There was a requirement for $1,360,000$ candela effective intensity, a range of 26 nautical miles, the motor driving the turntable could not consume more than 8 watts, it had to be solar powered and have an automatic lamp changer so that the light would only need to be relamped once a year. The xenon-arc lamp that would be required to meet the specifications needed a wattage of 100-250 watts. This set of specifications was technically extremely challenging, especially compared to existing lighthouses with a lesser range which consume 3.5 kilowatts of power with a 1,000 watt lamp and an effective intensity of $1,360,000$ candelas. The beacon had to be able to operate unattended for 12 months in temperatures ranging from -24 degrees $\mathrm{C}$ to +65 degrees $\mathrm{C}$, with humidity up to $100 \%$, and with exposure to salt and sunlight.

Vega had built up expertise through the xenon-arc signalling searchlight it designed for the ANZAC ship project, but it clearly needed to extend its expertise in turntable drive systems, precision optical reflecting systems, and high-frequency SMR power supplies. Vega responded to the solicitation by submitting a tender that demonstrated the company's understanding of the technical problems, something which competing companies could not match. Its tender had to be $6 \%$ lower than a US corporation or $12 \%$ lower than a small US company. However, the Coast Guard made clear that Vega's success was overwhelmingly due to its ability to articulate its grasp of the problem and set out possible technical solutions, rather than due to its price.

The design and development contract was awarded to Vega against international competition on 31 March 1992, with the requirement being to design, develop and produce two prototype beacons, and with the tender price being $\$ 300,000$.

\section{Design and Development}

Vega had only one year to design and produce a prototype that would meet the technical standards stipulated in the contract. The Coast Guard paid for the R\&D on 
the beacon, much of it concerned with cracking the technical problems associated with fulfilling the specifications. Vega reviewed existing designs and technologies to identify the best technical route to solving the problems posed by the specifications. Xenon-arc technology was needed to achieve the energy savings required in the specifications. Only one lamp from a German company that did not exceed 150 watts had the expected life needed for a lighthouse.

Vega's optical design consultant spent over 3 months elucidating different technical approaches to meeting the requirements for the xenon-arc lamp, before Rochfort made a decision on the most practical solution. Vega designed the parabolic reflector lens. No New Zealand company or laboratory had the ability to deposit a specialised coating needed on the beacon's electrical mirror because of an inability to measure the wavelength. Vega therefore designed the die and contracted a Californian company to produce the die and provide the service. The resulting reflector has a multi-layer reflectivity-enhancing coating deposited under vacuum that produces reflectivity in the visible light range in excess of $94 \%$.

Vega contracted Cadac Ltd, an innovative New Zealand start-up company that had developed a unique brushless DC electric motor (see Gilbertson \& Knight, 1992), to develop drive circuitry for its motor so that it could be incorporated in the beacon. After about 7 months effort it was clear that Cadac would not succeed, so Rochfort and an electronics consultant retained by Vega decided on an alternative motor drive system. This motor drive system was developed to prototype stage over about 4 days, after which circuit boards were made up. Vega adopted Cadac's motor stator, wired to Vega's specifications, while Vega itself made the other part of the motor which required a lot more accuracy, for example to measure the magnetic pulses and to achieve speed control.

Vega also had to develop an auto-injection transformer and igniter system to start the lamp, and contracted the Wellington company, Futureworks, to develop a switch mode power supply that would provide both the boost circuitry and the drive circuitry for the lamp itself. A specification requirement was the ability to measure the hours 
each lamp had done, so the switch mode power supply includes a computerised system that records this for the lamp. Each time relamping occurs a reset button is pushed that starts recording again.

The energy into the rotating head had to be controlled and recorded. Vega's policy was to avoid the use of any materials or parts, such as mercury slip rings, that could have adverse environmental impacts at any time in the future. A problem was that brushes on slip rings are designed to carry current at all times. Brushes are designed to drop a volt in order to work, but with only 12 volts, Vega could not accept a 1 volt drop. Vega had to find a slip ring material and a brush that wouldn't create too much of a voltage drop. The minimum voltage that could be supplied is around 11 volts, or as much as 18 volts, so the R\&D on the brush system had to achieve an effective compromise within tight technical parameters.

A master logic controller electronically manages all the functions of the beacon, including self monitoring, a solar switch circuit controlling activation and deactivation of the light, activation of stand-by lights in the event of beacon failure, and provision for remote monitoring of rotation and of the number of back up lamps remaining. An electronic multiplexer monitors the optic head in service and redirects power to the next optic set in the event of lamp failure or time-out. The circuit design electronics for this was done by Vega.

Based on long experience with suitably durable materials for marine navigation aids, Vega built the light using an aluminium with very good corrosion-resistant properties. Vega also, for the first time, used special suspension mounts to counter the problem of high-frequency vibration that Rochfort had observed in elevated structures such as lighthouses.

\section{Success of the XAB-17}

The XAB-17 converts electrical energy into useable light energy very efficiently. It uses about $10 \%$ of the energy of existing lighthouse beacons. The light flashes by 
rotating, achieving an effective intensity of 2,121,200 candela. The XAB-17 is light and portable, which facilitates installation in difficult and isolated locations.

The technical performance of the XАB-17 compared to existing beacons is set out below:

Table 1: Technical Performance of the XAB-17 and Existing Beacons

\section{XAB-17 Existing Beacons Energy Saving}

Lamp Size

150 watts $\quad 1000$ watts

$85 \%$

Single Optic

Power Consumption

175 watts

1000 watts

$82.5 \%$

Turntable Power

Consumption

3 watts

600 watts

$99.5 \%$

Total System

(single beam)

185 watts

1600 watts

$88.4 \%$

Total System

(dual beam)

367 watts

2600 watts

$85.9 \%$

(Source: Vega Industries, 1993)

In 1994 the XAB-17 Landfall Beacon and the VRB-25 Rotating Beacon earned Vega first prize in the ECNZ Rutherford Awards, awarded for their energy efficiency, commercial excellence and environmental acceptability.

At the end of 1994 the Coast Guard will have completed extended trials of the Landfall Beacon and it is likely to earn Vega substantial revenue over at least ten years from the US, with some sales potential in Europe. The US Coast Guard has already made substantial orders for the VRB-25 Rotating Beacons, and orders are expected to follow from Australia, South-east Asia and Canada. Vega is now working on further contracts for the US Coast Guard. 


\section{Background of Key People}

John Rochfort completed part of a Certificate in Engineering in New Zealand, followed by a Diploma in Industrial Electronics and certificates in vibration analysis and dynamic balancing and in celestial navigation in Australia and the United States. Rochfort worked from 1960 to 1963 in DSIR (PEL), starting as a technical trainee. DSIR stimulated and challenged Rochfort at this time, and developed his skills in applied technology spanning a range of interlinked disciplines and skill-bases. He then spent over 13 years in Australia as a researcher, designer, instrument maker and service engineer in Menzies Research Laboratories, Chrysler Experimental Ltd and Tosco Ltd, including significant involvement in optics work. A number of his inventions were patented by these companies during this time. After a short period back in the DSIR as a technical officer involved in instrument development he became factory manager of Solid State Equipment Ltd in Lower Hutt. In 1979 he was appointed to his current position as Managing Director (as well as chief technologist, designer, researcher and factory manager) of Vega Industries.

While John Rochfort regrets that he missed out on advanced, university-based scientific training, he is in fact regarded as one of the world's foremost optical engineers. Like other brilliant instrument makers such as Brian Hennessey of Hennessey Grading Systems, Rochfort has an extraordinary ability to apply inductive insights and lateral thinking to practical technological applications. His innovation has often focused on meeting practical needs, and on developing his own product, system or technical solution where one could not be bought off the shelf.

Norman Rumsey graduated with a BSc in mathematics and physics at Auckland University in 1943, followed by masterates in mathematics (1944) and physics (1946). After a period of war service in the Navy he joined the Physics and Engineering Laboratory of DSIR in 1947, from which he retired as head of the optics laboratory in 1982. From his retirement he has been retained by Vega Industries as an optics consultant. 
Martyn Cook completed an honours degree in mechanical engineering at Auckland in 1975 , followed by a diploma in teaching. He then completed an MBA at Victoria University in 1989. After time as a physics and mathematics teacher he worked as an engineer and sales engineer, a project manager in a market research company, and a strategic planner for a construction company. He started work for Vega Industries in 1991 as a marketing consultant and director, before commencing a period of VSA service in 1994.

\section{Conclusions}

The XAB-17 innovation reflects the ability of small New Zealand companies to compete in niche markets where total world sales are too small to attract the interest of major overseas technology-based companies. The complexity of the technology discourages and acts as a barrier to competition, and enables small companies such as Vega that master the technical challenges to capture the benefits.

Vega has benefited from its links with lead users. The US Coast Guard is a discerning and demanding customer and sets rigorous technical standards which, when achieved, confer market prestige on those companies that can meet or exceed those standards. Vega has the ability to integrate different technologies in marine navigation, and to do the in-house engineering and instrumentation to fulfil demanding performance specifications. It lacks scale economies but effectively exploits economies of scope.

The XAB-17 owes much to the technical skills built up by John Rochfort during his time in DSIR, and in private sector workshops, tooling and instrument making facilities. These skills are cumulative and based on international exposure to private and public sector technologies. While significant growth and diversification possibilities exist, Vega may well be overly dependent on one key technologist. However, it has major opportunities to capitalise on its international reputation and to earn premiums from specialised technological competencies that are hard for others to imitate. It also has the potential to break out of the constraints imposed by one-off or 
small-scale production runs, by identifying opportunities for the development and commercialisation of standard products. 


\title{
Appendix 1
}

\section{Key Events in the XAB-17 Innovation}

\author{
Key Events
}

1977

John Rochfort joins Vega

1991

US Coast Guard issues specification for a 26 mile Landfall

Beacon

31 March 1992 Vega awarded contract for the design and development of the Landfall Beacon

March 1993

Vega completes design for XAB-17 Beacon

1994

Vega wins ECNZ Rutherford Awards for the XAB-17 Landfall Beacon and the VRB- 25 Rotating Beacon 


\section{CASE 10: GREENWELD INNOVATION}

\section{Introduction}

Greenweld is an adhesive system that allows fast gluing of wood over a wide range of moisture and temperature ranges. Greenweld allows timber to be glued without drying, removes moisture content as a key quality control variable for gluing, and avoids the need for specialised adhesive-curing equipment. The Greenweld process as finally commercialised involves cutting defects out of unseasoned lengths of sawn timber, finger-jointing the short lengths of timber into continuous lengths of higher value timber using the Greenweld adhesive technology and, if a dry product is required, kiln drying the longer finger-jointed lengths. Greenweld allows unseasoned short lengths that would otherwise be chipped to be finger-jointed into saleable lengths, followed by kiln drying and planing to final size for sale as high value structural engineering components.

Greenweld was developed through collaborative work by the Wood Strengths and Structures and the Wood Materials groups within the Forest Research Institute's Wood Technology Division.

\section{Background}

The Greenweld innovation must be placed in its wider industry, technical and institutional context.

\section{Industry Background}

Forestry is New Zealand's third biggest export industry, earning around \$2,000 million in export earnings from a total wood harvest of around 14 million cubic metres per year. The industry is based on 1.4 million hectares of mainly radiata pine softwood forest. The forest processing sector includes pulp and paper mills, plywood, particle 
board and panel plants, and around 260 sawmills. Most forestry exports are logs and pulp and paper but there is also a diverse and growing solid wood products sector.

The sawmilling sector is pivotal to the long run economic performance of the forestry industry as a whole. This is because of the potential of the sector to add value and allow the industry to diversify away from a dependence on price-driven commodities. Sawmills also produce the low-cost wood residues that help underpin the cost competitiveness of the pulp and paper sector.

The sawmilling sector has enormous potential for growth and innovation but is made up of mainly small companies with low skill levels, backward technology and limited technology management capabilities. Sawmill managers tend to a short-term outlook dominated by day-to-day problem solving and their plant and technology is ill-suited to exploiting the added value opportunities increasingly opening up in international markets. In the past, sawmill managers have typically lacked formal qualifications and developed their skills through learning on the job. In more recent times, professional managers in the sawmilling and solid wood product sectors have tended to hold qualifications in accounting and other commercial fields rather than in technology. These managers have lacked the ability to interact effectively with the Forest Research Institute (FRI) on technical matters, but in some cases have responded positively where FRI has supported its technological initiatives with sound business planning and cost-benefit analysis.

In recent times the sawmilling industry has come under increasing pressure to minimise the environmental impacts of its waste streams. The increases in log prices in recent years have focused industry thinking on the potential for low value waste streams to be a source of high value products, rather than representing a cost or adverse environmental impact for the industry. 


\section{$\underline{\text { Technical Background }}$}

In some sawmills around $20 \%$ of the volume of timber is likely to be chipped or used for other low grade purposes. Short timber lengths that are chipped or sold for other low-value uses are worth around $\$ 60$ a cubic metre, versus around $\$ 400$ a cubic metre for longer finger-jointed lengths.

An important means of adding value to short timber lengths is to finger-joint them together to form longer lengths of timber for high value uses such as in structural engineering. Finger-joints are usually made by machining wedge-shaped fingers into the end grain or side grain of pieces of timber, applying adhesives to the exposed faces of the fingers, matching the fingers on any two pieces of timber so they dovetail together, and applying end pressure to lock the fingers together.

There are a number of major technical deficiencies in the conventional finger-jointing process. Conventional finger-jointing involves sawmilling of unseasoned timber, kiln or air drying, and cutting out defects from timber, leaving short lengths of high grade dry timber. These short lengths are very expensive to dry, preservative treat and machine.

Kiln drying before finger-jointing can lead to timber distortion if timber is packed incorrectly. For conventional finger-jointing the timber must be dried to around $12 \%$ moisture content, and after defects are removed up to $30 \%$ of the wood may be discarded, drastically increasing the cost of the dried timber. The defect removal and finger-jointing process is carried out on timber that has already received a great deal of processing in the form of drying, or even preservative treatment and machining, and this means that any rejected defects constitute an expensive waste.

It was widely recognised internationally that the ability to glue green or wet wood together without drying would be a major advance in finger-jointing technology. There was therefore a significant body of international literature and experience in 
gluing wet wood and in finger-jointing technologies, and this had aroused interest in the Forest Research Institute (FRI).

From the early 1970s FRI technologists developed an interest in finger-jointing and finger-joint testing. FRI was aware of a Canadian method of finger-jointing green wood developed in the early 1970s. The Canadian WFPL process involved passing wood through a continuous kiln so that each piece was heated up and the fingers were dry before it was jointed together. This method worked effectively but involved an expensive and cumbersome method of drying the wood through air blasting, which had the effect of heating the timber up and speeding the curing of the glue. Hank Bier in the Wood Strength and Structures group of the Wood Technology Division in FRI had a long-standing interest in finger-jointing and suggested some possible approaches in the mid-1980s. However, FRI only launched a concerted attack on the problem when commercial revenue requirements, uncertainties over Crown funding, and the sharper strategic focus resulting from strategy development within the Wood Technology Division came together from the late 1980s.

\section{Institutional Background}

FRI developed from an experimental station at Whakarewarewa, Rotorua in 1947. The focus of FRI's early research was production forestry, but it later developed strong capabilities in forest processing, wood technology, and in pulp and paper research through the PAPRO collective. In recent years FRI has increased its focus on adding value to wood products and extending the range of applications of radiata timber.

FRI was funded through direct Government appropriation as part of the Ministry of Forestry and also earned commercial income from industry. From the mid-1980s the Government began reducing direct appropriations to place FRI on a more commercial footing and to force industry to pick up a higher proportion of the R\&D costs. As part of the reforms of New Zealand's science system, on 1 July 1992 FRI was 
restructured as a stand-alone Crown Research Institute (CRI) with full commercial powers.

FRI's Forest Technology Division undertakes the Institute's production forestry research. This Division has over time succeeded in commercialising some of its major technological innovations. As "user pays" began to have a major impact in the mid1980s, this Division was able to extend its earning base from public funding and commercial contracts to include a stream of royalty and license income from such technology as its software innovations. In contrast, the Wood Technology Division which undertook FRI's solid wood product and processing research was more weakly positioned to deal with the new commercial environment. It lacked substantial earnings from licensed technology. It serviced a sector that had a lower market concentration than the plantation forestry and pulp and paper sectors and which was dominated by smaller firms with less commitment to long-term R\&D.

From 1987 Dr John Butcher, the Director of the Wood Technology Division, initiated a systematic strategy of diversifying earnings by focusing on technologies that could potentially be commercialised in industry. Butcher was motivated by a need to avoid the short-termism in research resulting from a dependence on commercial contract earnings. He realised that his Division could not grow or diversify by providing research services to the sector, and the early stages of the science reforms had created great uncertainty about the future of public research funding. He was also conscious that the undiscriminating transfer of research results as a "free good" meant no one company had the incentive to commit the developmental investment needed for the effective commercialisation of technology.

Butcher's approach was to identify and concentrate effort on a small number of major technological opportunities where FRI had an international understanding of the technology and the ability to build on and apply existing Institute capabilities to meet the needs of the sector. This strategy involved the identification of the broad areas that wood product innovation could focus on, with scientists able to create opportunities in these areas through whatever scientific methods or paradigms seemed 
most appropriate. This strategy led to a focus on areas such as the hardening of radiata to improve its durability and functionality, anti-sapstain treatment, and environmentally safe preservation systems, which in turn led to the vapour boron innovation. It was this strategy of encouraging new ideas focused on the strategic needs of industry that led to the identification of gluing of green timber as an important technical opportunity.

Butcher effectively established a process that encouraged the generation, capture and exploitation of new ideas, fostering peoples' creativity within the parameters set by the Institute's core capabilities and by industry needs and opportunities. By 1988 Butcher had this strategy in place. His Division suffered some revenue shortfalls as it struggled to meet financial targets while moving investment into the identified areas of technological priority. However, the strategy proved extremely effective over the longer term for the Wood Technology Division, leading to innovations in wood hardening, anti-sapstain technology, vapour boron wood treatment and to Greenweld.

\section{The Innovation}

The commercial pressures FRI was under in 1987 led to "brainstorming" sessions to generate new ideas for industrial technologies that could be commercialised to earn revenue for the Institute. At a December 1987 session of the timber engineering group Jeff Parker, a technologist in the Wood Strength and Structures team, suggested that the successful development of a green finger-jointing system "would be of considerable benefit to industry and a licensing agreement would provide a cashflow for the laboratory."

The proposal was to build on earlier Canadian technology and apply it to radiata. In its green (unseasoned) state radiata was a very wet timber and it was clear that it would pose new technical challenges in finger-jointing technology. At this time collaboration was envisaged between FRI's timber engineering, adhesive chemistry and wood drying technologists. Jeff Parker began working on the idea in early 1988, 
with this early lab-scale work undertaken in FRI's finger-joint cutting operation. This work included experimenting with flash drying the wood, using existing glues in new ways, and modifying the finger-jointing process itself.

Jeff Parker and his colleagues were effectively a composites engineering group but Greenweld involved processing and adhesives chemistry, and the ability of the team to make connections across disciplines was essential to make progress in finger-jointing. While New Zealand as a whole is not strong in polymer chemistry and adhesives technology FRI had built up considerable expertise in chemical applications in wood processing through the efforts of scientists such as Dr Robert Franich and Dr Terry Lomax.

The major technical problem encountered in gluing green wood with water-based adhesives was migration of the glue into the wood, so that the glue became too diluted to form an adequate bond. The technical challenge was therefore to develop a glue process that cured the adhesive rapidly enough to avoid migration. A number of alternative technical approaches were tried within FRI from 1988 on.

\section{Alternative Technical Approaches}

The approach initiated by Dr David Plackett, at the time an engineering and chemistry research field leader in FRI, was to use surface activation chemistry to glue wet wood by adding a chemical to the glue surface to inhibit glue migration. This appeared to be successful but tests later showed that the chemicals were behaving differently from expected and that surface activation was not a feasible technical solution. Terry Lomax, a chemist in David Plackett's group, then suggested using high molecular weight chemistry to stop the migration of the adhesive. This involved waiting for the glue potlife to progress to the point where the molecular weight was high enough and apply the glue to the green timber to be jointed. Lomax's approach worked well technically, but it was difficult to adequately control the curing of the glue in practical industrial applications. The glue kept curing, meaning that there was only a minimal 
time in which the adhesive was in a state to glue green wood but still be moist enough to apply to the timber.

Robert Franich, a senior and distinguished chemist in FRI, suggested that the curing process depended on the $\mathrm{pH}$, and that changing the $\mathrm{pH}$ would enable the process to be effectively controlled in an industrial setting. The idea was to pre-cure the glue to its ideal state and add ammonia to stop the curing. However, experimentation showed that the chemical did the opposite and made the glue cure very quickly. This however was a key finding, because it meant that the chemical could be used as an accelerant to catalyse an almost instant bonding of the joints.

Franich's contribution was a crucial technical step forward but it did not itself solve the problem. Jeremy Taylor, a young technologist in the Wood Strength and Structures group, then experimented further and in a key step applied the accelerant to the wood rather than the glue. This meant that a standard adhesive could be used since it was the accelerant that allowed the rapid curing. The glue could be put on the wood at an earlier stage and when the joint was formed the accelerant would catalyse rapid curing before the water could cause glue migration. A key advantage of this was that the normal potlife of the glue was still appropriate, and conventional fingerjointing machinery, a glue applicator, a spray system to apply the accelerant chemical, and a ventilation hood were all that was required for the process to work in an industrial setting.

\section{Early Development Work}

Taylor persisted with his work against a backdrop of competing technical approaches. Surface activation was still promoted by others as a more effective technical attack on the problem. It was at this stage that Dr Justin Williamson, a recently recruited scientist with a background in structural engineering and statistical modelling, became involved in the work and the team became Parker, Taylor and Williamson, with some assistance from chemists such as Robert Franich. A range of chemicals were experimented with and Williamson undertook statistical analysis of the results. 
With the Wood Technology Division under pressure throughout 1988 to raise commercial revenue, longer-term research was suffering. At this time Jeremy Taylor was involved in commercial work and the team had a strong motivation to develop technology that would provide a stream of income that would reduce the pressures to earn short-term commercial revenue. The Greenweld process was clearly promising and the innovation did not require large-scale capital investment, since it aimed at using existing machinery to exploit a new adhesive system. Justin Williamson and Jeff Parker kept working on Greenweld with a minimal time allocation devoted to it. Work continued on the processing parameters, pressure and assembly times, the testing and validation of bonding strengths, the durability, and ensuring compliance with standards. However, throughout 1988 and 1989 the project was quite marginal in terms of FRI's commitment of resources to it.

In July $1989 \$ 15$ million in new funding was approved in the Budget to form an initial basis for a contestable funding system to give effect to the Government's science reforms. The DSIR structured this funding as the Priority Research Contracts Scheme (PRCS) and called for bids. Applications were received and transferred to the newly established Foundation for Research, Science and Technology for decision on allocations. The Foundation approved a $\$ 100,000$ bid from FRI for "Improved utilisation of low grade timber." At this time, the three alternative technical approaches to the gluing of green wood had been experimented with at laboratory level, but FRI's focus was coalescing around the method developed by Franich, Taylor and Parker.

The success in winning PRCS funding was crucial because it built the Greenweld team's confidence and gave it leverage as it sought internal support for commercialisation of the process. The PRCS funding allowed further development of the process and the completion of pre-commercial trials to the point where financial and technical feasibility could be demonstrated. 


\section{Patenting}

By early 1990 the commercial potential of the process was clear and John Butcher became concerned at the danger of FRI compromising its intellectual property position if too many details were disclosed too early. Butcher moved to get a provisional patent in place. Finger-jointing of lower grade lengths of timber to higher value longer lengths was the most commercially promising application of Greenweld and the patent application was based on this. Fast drying wood adhesives were not new and the novelty in the FRI innovation was the fast gluing of wet wood, and the overall Greenweld process as a package. The provisional patent application, filed in 1990, focused on adhesive technology to glue wet wood. This meant that the scope of the final patents awarded may be too narrow to encompass the wider possible applications of the technology. For example, the ability of the technology to glue wood together at very low temperatures and to glue dry wood were not claimed in the patent application, and FRI is now trying to extend intellectual property protection to these features.

The full patent application had to be submitted within a year of the provisional application. It was extremely difficult to find the money for the patent. However, with the application process lagging technologists such as Justin Williamson raced against time and met a deadline set by the expiry date of the provisional patent. Jeff Parker, David Plackett, Jeremy Taylor and Terry Lomax are the names on the patent, but the Greenweld team members also pay tribute to the contribution of Robert Franich in closing a key knowledge gap. In 1991 patent applications were filed internationally.

\section{$\underline{\text { Trialing and Promotion }}$}

With the patent going through there was an urgent need for a strong commercial link to ensure that trialing could be undertaken in a commercial environment. FRI was constrained by its lack of in-house finger-jointing machinery of a standard that would enable trials to be conducted and demonstrated to industry on FRI premises. 
Proposals for FRI investment in a finger-jointing machine were declined by FRI management, at least partly because the uncertainties associated with the CRI establishment process had led to a cautious approach to new capital investment.

The first trial of Greenweld in a commercial setting was conducted in late 1990 at Carter Holt Harvey's (CHH) Taupo plant. This and subsequent $\mathrm{CHH}$ trials were a success and the company intended using the process to finger-joint Douglas fir for the Australian market. However, $\mathrm{CHH}$ then lost access to Forestry Corporation's Douglas fir and the project came to a halt as a result. At this time, a senior scientist in FRI's timber engineering group approached the owner of a financially struggling sawmilling business, asking him to act as a marketing consultant to assess and promote the commercial potential of the system in a real industrial setting.

This marketing consultant was appointed with an ill-defined mission of promoting and commercialising Greenweld. He was enthusiastic and energetic and stimulated a lot of interest in the technology, especially among smaller companies. However, he lacked the technical expertise and systematic approach to oversee trials of a technology that involved both toxic chemicals and the need to meet tight technical parameters in finger-jointing applications. Toxic chemicals were sent in the mail with written instructions on their use, substandard chemicals were used, and the safety and efficacy of the process was compromised.

ICI made the three-part resorcinol type-adhesive system for Greenweld, consisting of the chemical, the adhesive and the hardener. Because the glue used was relatively expensive the marketing consultant proposed a cheaper adhesive. Though this seemed to work at a laboratory stage it proved inappropriate in an industrial setting. Subsequent progress has since been made on screening alternative and cheaper resins, and on more basic research to better understand the chemistry of the process.

The consultant did not work alongside the FRI technologists or with ICI as the chemical supplier, and his lack of understanding of the technical parameters caused some major difficulties in trialing and promotion of the technology. As a result of the 
consultant's efforts the technology's reputation was damaged, especially when ammonia was used without fumehoods and small sawmills adopted the process without proper quality management systems being in place.

Members of the Greenweld team led by the marketing consultant conducted two poorly-handled trials in Australia, and problems were experienced with one type of press system unsuited to Greenweld applications on very wet timber. The consultant did persuade one Australian and five New Zealand companies to attempt to adopt the technology but gave inadequate technical advice and support. This left technologists such as Jeff Parker and Jeremy Taylor with a legacy of technical problems to solve. However, this problem solving has itself provided valuable feedback to FRI and these companies are now using the process effectively.

The major negative impact of the marketing consultancy was its effect on the morale, involvement and sense of ownership of the key FRI technologists. The consultant's role was never clearly defined, he had the effect of turning FRI managers and staff against one another, it became unclear who had an overview of the innovation, the key FRI technologists felt disempowered and "squeezed out", and FRI lost a lot of ground as a result.

\section{Further Development}

The Greenweld process required only minor modification to the finger-jointing process, for example installation of fumehoods, to work effectively with existing finger-jointing machinery. In 1992 Lakeland Timber Processors designed and built a new finger-jointer incorporating facilities to use Greenweld. The Lakeland Timber Processors' finger-jointer was tailored to local users, and while not designed specifically for Greenweld it has been easy to attach and programme the Greenweld applicator into its operations. At the same time Canterbury University began developing an in-line tensioner to prove joints for structural use. 
In 1991 and early 1992 John Butcher was heavily involved in the CRI establishment process, David Plackett was managing the Division, but there was some confusion over who was managing the Greenweld project itself. The project by this time was costing the Division around $\$ 300,000$ a year. By mid-1992 interest had been shown in the technology from Europe, India, Australia, North America and from about 40 New Zealand companies. However, by this time the innovation was hampered by serious human resource management problems, mainly stemming from the appointment of external consultants and lack of effective project management. This meant that the key FRI technologists in the Greenweld team lacked a sense of "ownership" of the project. FRI management had appointed a financial consultant to provide input into the financial side of the innovation. The Greenweld team felt it was not adequately consulted over an early marketing report commissioned on Greenweld, and over a technical evaluation of the process undertaken in Britain.

In July 1992 Dr Russell Burton, FRI's Manager, Wood Products, began taking charge of the Greenweld process. With the financial consultant's contract completed, Burton decided not to renew it for Greenweld, and addressed the financial issues himself. From July 1992 Russell Burton focused on the longer-term research opportunities associated with Greenweld, while Jeff Parker was appointed operational director to manage the technical aspects of the commercialisation process. Burton encouraged Parker, Williamson and Taylor to work closely with industry users as the champions of the technology. Allowing technologists who have developed an innovation to be active in helping carry it through to full commercialisation was fundamental to the eventual success of Greenweld.

Based on a detailed business plan prepared by Justin Williamson, Russell Burton pulled together an operational plan governing commercialisation of Greenweld. $\mathrm{He}$ also acted as a facilitator and a link person between Parker's team and FRI corporate management. Burton provided a key financial and economic input into the commercialisation process but also understood the technology sufficiently to interpret and articulate its benefits. The operational plan provided vision and direction for the Greenweld innovation, elucidated the further technological and market development 
required, and provided a clear work plan for the team to follow. This plan was central to Greenweld's longer-term success.

From 1993 Parker's role as operational project leader was complemented by Justin Williamson taking over the underpinning R\&D work, allowing Parker to concentrate on the applied technology, machinery, industry liaison and technical back up aspects.

\section{$\underline{\text { Commercialisation }}$}

In mid-1992 Parapine Timber in Upper Hutt became the first company in the world licensed to use Greenweld. However, the uptake of the technology in New Zealand was poor, partly because of the low technical understanding of the system, the shortterm outlook of sawmill managers, and the inept nature of the trialing and promotion by FRI's marketing consultant. Some companies were also reluctant to depend purely on a research institute to provide an ongoing technical support service for innovations such as Greenweld.

FRI decided to take the technology offshore and also to build closer commercial links with companies that could supply the chemicals and technical services to the sawmilling sector. John Butcher understood that in some cases the best form of technology transfer was not direct links from FRI to the end user companies but to work through intermediaries such as chemical or wood-drying companies that provided a service or input to the end users. FRI management convinced their Board that commercialisation required substantial investment, and the Board accepted a $\$ 110,000$ financial exposure associated with the process of licensing the technology offshore.

An important breakthrough for Greenweld was its adoption by the Australian sawmilling company SEAS Sapfor. SEAS Sapfor was assessing ways of avoiding the waste involved in chipping short lengths and had heard of the Greenweld process. Les Cunningham, one of its project engineers, visited FRI and Lakeland Timber Processors in mid-1993 and put forward a case to his company to invest in Greenweld 
and the Lakeland finger-jointer as a system. After the company agreed, two of its staff went to Rotorua and Jeff Parker and a colleague, Doug Stewart, demonstrated the technology to them. They also visited the ICI Adhesives and Resins plant at Mt Maunganui. The first Australian installation of Greenweld was installed at the SEAS Sapfors mill in Tarpeena, South Australia in September 1993, with assistance from Jeremy Taylor. Some technical problems were resolved in technical meetings involving Taylor, Parker, Williamson, Doug Stewart and ICI Adhesives and Resins staff.

SEAS Sapfor is ISO certificated and its quality manager worked with FRI to produce a Greenweld manual for the company. Greenweld-bonded wood is used in timber engineering structures and the strength of the bond is crucial to its acceptance in international markets with varying regulatory standards governing building materials. FRI is covered by professional indemnity insurance but not product liability insurance. A detailed quality manual for Greenweld was prepared by FRI with this manual excluding FRI from liability for applications of Greenweld outside the guidelines in the manual. FRI produced guidelines on the total system to allow a wide range of users to produce their own quality manuals.

Dyno Polymers, a large chemical supplier, was licensed in 1993 to exploit Greenweld in North America, with options for Central and South America. After this, FRI commenced negotiations with ICI New Zealand and ICI Australia Operations Pty to exploit the technology in the New Zealand, Australian and Pacific Island markets. Jeff Parker and other FRI technologists concentrated on technical applications and back up in end user companies, while Russell Burton had primary responsibility for commercial negotiations with ICI.

In 1994 FRI licensed the Greenweld technology to ICI New Zealand. ICI was granted an exclusive licence to exploit the technology commercially in Australasia and it pays a royalty to FRI for every cubic metre of timber produced using the Greenweld process. ICI has the expertise to provide useful feedback to FRI on further developments of the Greenweld system, and the involvement of this company has 
encouraged adoption of the technology by wood processing companies that were reluctant to do so while the process was fully under FRI control.

In 1994 FRI and the Building Research Establishment (BRE) in Britain signed an agreement through which the BRE will act in a technical capacity for FRI in the exploitation of Greenweld technology in Europe. A first step in this has been the investigation of ways to improve the performance and value of Sitka spruce. In 1994 $\mathrm{CHH}$ revived its interest in Greenweld and prospects look bright for the process in New Zealand solid wood processing companies.

\section{Benefits of Greenweld}

Greenweld is starting to deliver major benefits to both industry and to FRI.

The Greenweld process is easier and less expensive than the Canadian WFPL process, allows increased kiln drying efficiency and reduces processing costs. Unlike the WFPL process Greenweld does not require heat input and can be easily installed in existing factories. With Greenweld, defects are removed before kiln drying, which means all the dried timber is suitable for use in the final product. Timber containing defects does not have to be kiln dried so costs are reduced. The effective capacity of timber-drying kilns is increased because instead of only $50-70 \%$ of kiln-dried timber appearing in the final product as in the conventional finger-jointing process, the entire kiln-dried volume can be used. Greenweld makes it possible to upgrade unseasoned timber products such as framing. Greenweld is at least as strong as conventional finger-jointing.

The process works on both wet and dry timbers and the quick setting time (about 5 minutes compared to up to 24 hours with conventional technology) means that fingerjointed material does not need costly equipment to accelerate curing, and the material can be used almost immediately with almost no interruption to processing. Greenweld can joint dry timber without radio frequency curing. 
Greenweld allows a greater proportion of a tree to be converted to higher-value uses, and reduces environmentally harmful waste products as a result. Greenweld allows wastes to be removed early in the production process before they start to generate costs, and avoids having to dispose of treated wastes.

The Greenweld process can reduce stockholding by producing grade/length combinations to order, allows targeted exploitation of the market for uniform, quality products and can generate energy savings by avoiding the energy-intensive processing of reject or low quality material. The overall cost of Greenweld is similar to that of conventional finger-jointing, with rapid payback periods depending on throughput.

Greenweld has allowed FRI to extend its skills in adhesives and surface chemistry. It has given FRI a vista into the adhesives industry, enhanced its links into the sawmilling industry, expanded its servicing work in materials testing, and boosted its reputation in the field of adhesive applications in wood product innovation. The relationships FRI has developed with industry are now less fuzzy and generic, partnerships have been established with companies, and this has given a lot more commercial focus to FRI developmental research. It has also provided FRI with a generic and evolutionary applications platform that will allow the Institute to expand into related areas, and provide the cashflow to support this. The success has built up FRI's commercial skills, its confidence in commercialisation of its technology, enhanced its intellectual property capabilities, and given its technologists a truer appreciate of the value of their contribution.

\section{Future Opportunities}

The Greenweld technology has a host of potential future applications in laminated products, plywood and particle board production, and in other process applications. Income generated by the Greenweld technology is funding the development of parallel and new FRI technologies. Greenweld has formed a platform for spin-off technologies and wider downstream applications. New applications being explored include bonding of dry wood and gluing of non-radiata species such as Black spruce, 
Jack pine, Western red cedar and Northern white spruce. Greenweld has been successfully applied to the side gluing of timber.

\section{Background of Key People}

Jeff Parker joined FRI as a technical trainee in 1974. He received a thorough grounding in a wide range of FRI activity under a technicians training scheme. Parker completed a NZ Certificate of Forestry with a specialisation in wood technology and a Certificate of Engineering (Mechanical). In 1985 he completed the equivalent of an MSc in timber engineering, timber technology and wood protection at the Imperial College of Science and Technology in London.

Jeremy Taylor has been a technologist in FRI since 1986. He developed strong inhouse skills in testing and analytical methods in FRI before becoming involved in Greenweld from its inception in 1988.

Dr Justin Williamson completed a masterate degree in structural engineering at Auckland University and a $\mathrm{PhD}$ involving statistical modelling at Vancouver University. He joined FRI as a research scientist in 1988.

Dr John Butcher is Manager of the Corporate Development Division of FRI and formerly headed the Wood Technology Division. Butcher spent 20 years as a research scientist in wood preservation. He was very active in international research groups and organisations involved in wood preservation and wood protection, was a member of the Ministerial Science Task Group charged with overseeing the establishment of Crown Research Institutes, and in 1992 served on the Science and Technology Expert Panel (STEP) advising Government on New Zealand's long-term science priorities.

Dr Robert Franich joined FRI in 1973 and is now a senior scientist and a Fellow of the Royal Society. His major achievements include the application of chemistry to an 
understanding of the Dothistroma fungus toxin, development of possum lures, wood hardening and environmental monitoring innovation, and input into the Greenweld innovation.

Dr Russell Burton was a research scientist in chemical and process engineering. His early research included work for the New Zealand Energy Research and Development Committee on conversion of raw materials into liquid fuels. He was then appointed to FRI and worked in process economics, pilot plant development and composite products. He worked closely with John Butcher in managing innovations such as vapour boron and wood hardening. In July 1992 Burton was appointed Manager of the Wood Products Division.

Dr Terry Lomax is a research chemist in FRI. Lomax completed his $\mathrm{PhD}$ in surfactant chemistry at Auckland University, and spent a period as a junior lecturer and then as a researcher at National Womens' Hospital. He spent over 2 years as Chief Chemist for Petersons Chemicals in Auckland before joining FRI.

\section{Conclusions}

The Greenweld process is a major technological and commercial achievement. It resulted from FRI's intimate understanding of the technological needs and opportunities of the forest products industry and from the strategy initiated by FRI managers such as John Butcher to develop and commercialise innovations that could earn FRI a stream of income from licensed technology. Above all, it depended on the creativity of FRI technologists, their ability to understand the fit between industry needs and opportunities, and their multi-disciplinary understanding of timber engineering and chemistry.

Central to the Greenweld success was FRI's ability to create strong commercial relationships with individual companies. FRI accepts that commercialisation of innovations such as Greenweld does not stop with licensing but takes the form of 
longer-term business relationships with companies, and the provision of extensive technical and back up services.

FRI sells not science to industry but technological packages with forecasted rates of return, evidence of technical feasibility, and the ability to practically apply these packages in a commercial setting. CRIs cannot easily sell ideas or research results to industry but must have the in-house capability to develop prototypes, trial processes, and make the investment in the refining of processes and in technology demonstration to ensure effective commercialisation in industry. FRI's solid wood product laboratories may well be under-capitalised and ill-equipped to undertake the in-house experimentation and trialing needed to create technology packages suited to uptake in a fragmented sector that is dominated by small and technically backward companies.

The Greenweld case suggests that CRIs require discretionary funding and the ability to seed new ideas to counter inflexibilities inherent in funding from the Foundation for Research, Science and Technology. The Priority Research Contract Scheme (PRCS) funding was invaluable because of its timeliness. However, the key benefit of the PRCS was that it was more open ended and less objective driven than the Foundation's Public Good Science Fund (PGSF), and it supported research focused on applied technologies with proprietary applications.

A major motivation of FRI technologists was to use their expertise to help New Zealand industry by attacking real industry problems, bottlenecks to production, waste minimisation and added value opportunities. The key players involved in Greenweld were motivated by the satisfaction of carrying something through to commercial reality and by a sense of ownership and participation. Delays in the commercialisation of innovations such as Greenweld and vapour boron have occurred primarily because the motivation of key technologists dropped as a result of a sense of alienation or disempowerment, not because of technical problems, or even barriers to new technology in industry. 
Motivation and staff retention remain key problems for FRI. The Institute is losing significant numbers of scientists and technologists to industry, partly because of low morale resulting from the new science system and uncompetitive remuneration. There is a deep-seated problem in FRI in retaining key staff in a commercially focused environment at a time when forest product companies are gradually becoming more aware of the need to upgrade their own, in-house scientific and technical capabilities. It is also difficult to reward individuals for innovation when multi-disciplinary teams have worked together in a complementary way, and where key innovators have depended on the wider science infrastructure and on antecedent research.

Greenweld was based on cumulative expertise built up through servicing fingerjointing and a wide range of other technologies in the forest processing sector. Greenweld depended on multi-disciplinary research and the ability of timber engineers to draw on core competencies such as adhesive chemistry which had been built up through basic and strategic research by scientists such as Robert Franich and Terry Lomax. This team work was especially crucial in aligning chemistry with engineering applications. Scientists such as Franich and Lomax share with musicians a pattern recognition ability, and their knowledge of basic chemistry and of the industry enabled them to apply their knowledge in a problem-solving way.

FRI achieved most of its success with Greenweld by marketing it to intermediary companies such as ICI that provide inputs to the end-user sector. The involvement of adhesive companies illustrates the distinction between the end use of technology and the companies that are most likely to first adopt and commercialise. The sawmilling companies were the first targets for commercialisation, and while they saw the benefits, they were slow to adopt the technology because of inept marketing and demonstration by FRI's marketing consultant, and a lack of the technical understanding and quality management systems needed to solve the technology adoption problems needed for successful commercialisation.

The Greenweld case illustrates the need for strong and unambiguous project management, clear line control, with project teams commanding discretionary 
resources and which involve all the key players in the project from inception to full commercialisation. Teamwork is essential in complex innovations and "solo operators" typically have a deleterious impact on the management of technological innovation.

Marketing and financial consultants who deprived the key technologists of a sense of ownership of the innovation, who lacked any commitment to FRI, and who did not understand the technology impeded the commercialisation of Greenweld. When management or marketing of the innovation was taken from the Greenweld technologists enthusiasm dropped, and only when Russell Burton created an effective project management structure was the innovation process put back on track and carried through to successful commercialisation. Key success factors for Greenweld included Burton's ability to weld together a common vision and a team approach, the shortening of the decision making process, and the returning of enough power and discretion to the Greenweld team to give its members the sense of ownership from which so much motivation flows. 
Appendix 1

\section{Key Events in the Greenweld Innovation}

\section{Key Events}

Early 1970s

Mid-1970s

1986

1986

$1986 / 87$

December 1987

Early 1988

1988

1988

1989

Late 1989
FRI undertakes work on gluing wet timber

FRI investigates Canadian method of finger-jointing wet wood

Hank Bier proposes one approach to fast finger-jointing

Terry Lomax involved in experimentation on gluing green wood

John Butcher begins development of technology commercialisation strategy in the Wood Technology Division

Jeff Parker suggests a focus on green gluing finger-joints at "brainstorming" session

Jeff Parker undertakes work on green gluing finger-joints

Justin Williamson joins FRI

Work underway on use of surface activation for gluing wet wood

Priority Research Contracts Scheme set up

FRST awards contract to FRI for Greenweld process 

Harvey plant in Taupo

1990

1990

July 1992

1992

September 1993

1994

1994
Provisional patent filed for Greenweld process

FRI marketing consultant undertakes trials

Russell Burton appointed Manager of the Wood Products

Division

Jeff Parker appointed technical manager of Greenweld project

Greenweld installation commissioned at SEAS Sapfor plant at Tarpeena, South Australia

Greenweld licensed to ICI

FRI and BRE sign agreement for promotion of Greenweld in Europe 


\section{CASE 11: DUAL FUEL KIT INNOVATION}

\section{Introduction}

The DieselGas dual fuel kit innovation is an electronically-controlled conversion kit that allows the substitution in diesel engines of diesel with gas. The kits were developed by the Lower Hutt company DieselGas, with early versions in use in New Zealand from 1984, but with the kits only being fully commercialised in 1993. The DieselGas dual fuel kit innovation comes as two models: a "Standard" model for engines up to $250 \mathrm{hp}$ and a "Matchtorque" model for larger engines.

\section{Background}

The DieselGas dual fuelling innovation must be understood in its wider market, company and technical context.

\section{Market Background}

The world's reserves of natural gas are enormous and will be increasingly exploited as oil reserves dwindle. With the "oil shock" of the 1970s interest in alternative fuels increased, largely to augment insecure or expensive oil supplies, and to a lesser extent because of the lower pollution from gas compared to fuels such as diesel.

Currently the world market for alternative fuels is driven largely by political factors, that is by Government tax and pricing policies, rather than by the cost of production. New Zealand converts much of its natural gas to petrol, generates electricity with it, and maintains a pricing structure that does not currently allow a sufficient price differential to favour gas over petrol and diesel as a vehicle fuel. However, markets exist in other countries where different tax and pricing policies make it attractive to substitute natural gas for diesel, and where there are environmental benefits due to 
lower diesel smoke emissions as a result of gas substitution. Ongoing instability in the Middle East has also maintained interest in many countries in alternative fuels.

Dual fuelling to substitute gas for diesel can substantially lower fuel costs in countries where diesel is more expensive than gas, and can also reduce the smoke emission pollution from diesel engines. A small amount of gas gets rid of a lot of diesel smoke, but the effect is greater with older than newer diesel engines. Engines run on a diesel/gas mixture generally last longer.

\section{Company Background}

DieselGas's roots can be traced back to work from the late 1970 s by a specialist diesel engineering technologist, Harvey Reid, and to the evolution of the Lower Hutt company, Solid State Equipment.

In the 1960s Harvey Reid completed an apprenticeship as a diesel mechanic, before moving to the more specialised field of diesel fuel injection repair and maintenance in Timaru. He then spent from 1972 to 1975 managing the diesel fuel injection section of a Wellington company, before in 1975 becoming Managing Director of Diesel Progress, a company specialising in diesel injection repairs. He developed an interest in dual fuelling of diesel engines in the late 1970s, but only linked up with Solid State Equipment in 1983.

Solid State Equipment was founded in 1971 by ex-DSIR technologists George Jones and Neil Poletti. The company's first major product line was making navigation beacons. It later developed a wide range of other products and technologies through contract research, including a multi-fuel dispensing pump, and electronic applications in the sporting, computing, burglar alarm and emergency lighting fields. Solid State began working on microprocessor technology from 1974.

The company has developed over 20 different datalogger models for applications such as sewerage flow, diesel engine control, well depth studies, corrosion mitigation, 
geothermal research, and a general purpose field logger with a wide range of multipurpose functions. In the mid-1970s the company developed an advanced field datalogger embodying computer technology that was in the forefront of New Zealand technology at the time. It developed further expertise in computing and microelectronics through developing a piezoelectric composite oscillator ("crystal driver").

In 1977 Solid State was in financial difficulties but was assisted by the Development Finance Corporation (DFC) through a loans and royalties agreement. The DFC took about one-third control of the company and encouraged it to implement effective accounting practices. The DFC involvement also helped Solid State's credibility in dealing with the business and financial community.

Solid State now operates as an R\&D company that focuses on electronic solutions to practical problems, and that commercialises the results of its research. It does little advertising, generating most of its business through its reputation and by word of mouth. It operates out of two converted houses in Lower Hutt. It functions as a contract R\&D laboratory rather than as a vertically integrated R\&D-based manufacturing company. The company has developed a lot of products in response to research contracts commissioned by clients. Because of the nature of its business, its production runs are small and sometimes one-off. It maintains only a one person assembly operation, which at times is only a part-time position. While at one stage it had 20 staff it now employs around 6 and has no desire to grow.

DieselGas was formed in 1983 by Harvey Reid and by George Jones and Neil Poletti of Solid State Equipment. DieselGas currently undertakes CNG and LPG R\&D, as well as road vehicle design and certification, heavy vehicle engine dynamometer testing, the provision and installation of its $\mathrm{CNG} /$ diesel dual fuel kits, mechanical engineering consultancy, and Natural Gas Vehicle (NGV) industry planning and consultancy. DieselGas forms part of Energy 2000, a consortium of New Zealand companies with natural gas vehicle-related interests. 
Technical Background

Dual fuelling of diesel engines with natural gas has been carried out since the $1930 \mathrm{~s}$. At this time some diesel engines, mainly used for power generation, were designed to run a fixed pilot injection of $5 \%$ to $10 \%$ diesel, with the balance of the power coming from natural gas. However, New Zealand only developed significant interest in dual fuelling from the mid-1970s, very much due to the economic impact of the "oil shocks" of that time. Use of CNG and LPG is subject to strict technical and safety standards. These standards are strict, sometimes inconsistent and costly to achieve, but on the whole they provide a helpful set of market-related specifications for companies to meet.

In 1979 Solid State Equipment was asked by a client to assist in developing metering technology to measure the dispensing of CNG. After 4 years of work Solid State produced a $\mathrm{CNG}$ meter that was a technical success but a commercial failure. However, it did give Solid State some familiarity with CNG technology, and with the application of electronics to gas measurement and control. Solid State Equipment also built up experience in automotive technology through its Taupo-V datalogger, which was developed as a commissioned research project to monitor engine operating conditions. Solid State therefore built up expertise in important engineering and electronic fields in the late 1970s and early 1980s while working in isolation from Harvey Reid.

\section{The Innovation}

In 1978 Harvey Reid developed an interest in dual fuelling technology, partly in response to a client who wanted some equipment fitted to a diesel pump so that he could convert that equipment to run on LPG and diesel at the same time. From 1978 to 1982 Reid experimented with a number of methods of dual fuelling of diesel engines with $\mathrm{CNG}$. These methods included vacuum systems, hydraulic, and various mechanical systems. He chose to work on CNG rather than LPG because it was a 
technically easier fuel to work with and there seemed to be more potential for it in New Zealand.

While the economy had got past most of the trauma of the "oil shock" by the early 1980s, the Government was still actively committed to alternative fuels. However, after several years of solo effort, Reid realised in 1982 that mechanical technology lacked the sophistication needed for dual fuelling and that electronics was required. At 2 am one morning, after agonising over a key technical problem he was grappling with, Reid saw a possible solution and by $6 a m$ he had sketched the design of a proposed electronic dual fuel kit. This design later became the basis of a patent, and Reid commenced his search for the electronic skills needed to advance his innovation beyond the limits of mechanical technology.

\section{Establishment of DieselGas}

The development of the DieselGas dual fuelling innovation is inseparable from the emergence of the company itself.

By 1983 Reid had a conceptual outline of his innovation, and conscious of his lack of expertise in electronics, he began looking for a partner with these skills. $\mathrm{He}$ approached a number of companies in the Wellington region, and then met Neil Poletti and George Jones at a trade fair in Wellington. In 1983 they set up DieselGas, initially as an informal joint venture and then in 1984 as a private company. The emergence of the DieselGas company was a key organisational step forward since it provided Reid with a framework for development of his dual fuelling ideas, and gave him access to the electronics, software and to some of the business skills that he lacked.

\section{Early Development of Dual Fuelling Kits}

The company then embarked on an ambitious programme of dual fuelling $R \& D$, and had a vehicle running on dual fuel by the end of 1983 . Through 1984 and 1985 two 
engineers were typically working on the innovation at any one time, with funding from the company and from the DFC. DieselGas began working on an LPG/diesel dual fuel kit development project in 1985, with the initial work undertaken with the Ministry of Works and Development (MoWD). An engine was donated to the project by the Mack Truck company and this was used in dynamometer testing. The initial funding of this work was from a DFC Applied Technology Programme loan which covered the first two years of work. Reid continued running his existing diesel injection repair business, while keeping at least one engineer working on the dual fuelling project from 1986 on.

In 1986 the Government removed the subsidy from natural gas. While natural gas was still cheaper than petrol this move had a major impact because it was perceived as a loss of faith in gas as an alternative fuel. DieselGas at this time had borrowed a lot of money from the DFC and had around $\$ 500,000$ in debt. Oil prices had dropped internationally and the company's accountants suggested closing the business down. However, DieselGas struggled through with the help of the DFC, motivated by a belief in its technology and by the need to keep faith with and retain the trust of its creditors and business colleagues. In November 1987 DieselGas identified a means of controlling the combustion rate of dual fuels to avoid detonation and to allow substitution of around $80 \%$ of the diesel with LPG. From 1988 the prospects for alternative fuels seemed to improve. Reid sold his diesel injection business that year and in 1989 moved full-time into DieselGas to devote himself to the innovation.

Reid proved persistent in raising finance for his projects, and at one stage phoned a DFC analyst almost every day for a year in the course of raising capital. Reid approached politicians such as Mike Moore for advice and he explored the potential for tax and other incentives for his innovation. Reid, over the life of the project, received several hundred thousand dollars in incentive and grant finance, including export tax incentives and Applied Technology Programme (ATP), Technology for Business Growth (TBG) and Business Development Investigation Grant (BDIG) funding. DieselGas received substantial R\&D funding from Australian sources in the form of subcontracted work for an Australian company on LPG dual fuelling, and on 
gas extraction from coal mines to power coal transportation vehicles. Much of this $\mathrm{R} \& \mathrm{D}$ funding was embodied in the product price rather than funding for research per se.

\section{Developing Dual Fuel Kits}

Over the period 1984 to 1989 DieselGas made significant technical progress. It designed a unique servo-controlled gas valve and worked on the design and application of actuators, transducers and associated hardware. Dedicated electronic hardware and software was developed to allow individual engine and application tuning, with these developments complemented by the application of advanced combustion science through the use of dynamometer engine testing. Several designs had been patented by 1989 in around 20 countries and considerable experience had been built up.

However, in 1989 DieselGas, having invested around $\$ 500,000$ in the innovation, failed to realise it had taken the wrong technical approach by working on dual fuelling with LPG rather than CNG. Only later did the company switch its focus back to CNG/diesel dual fuelling which it had begun work on in the early 1980s. While the LPG work built up a cumulative skill-base in dual fuelling technology, the inability of the company to choose the right technical path early on, and to know when to stop when it was following the wrong technological pathway, cost the company at least 5 years and a substantial amount of money.

By 1990 DieselGas was carrying out production engineering for electronic CNGdiesel kits and installing an engine dynamometer to allow kit application work to continue. Both of these activities had been partly funded by the Foundation for Research, Science and Technology (FRST) through its contestable funding system. Harvey Reid had travelled to the US and identified a source of high-speed valves which allowed for the design of an electronically-controlled diesel injection system. Several different design variations were tested. DieselGas by late 1990 had a full-time managing director, an office assistant and three part-time technical personnel, 
including shareholder directors. By this time about $\$ 800,000$ had been invested from all sources in the dual fuelling project. However, funding then ran out and work essentially stopped until further support was obtained from FRST in the form of applied research funding.

DieselGas applied for a TBG project in August 1990 as a cooperative project with the DSIR. DSIR had some interest in dual fuelling technologies and DieselGas had a good technical relationship with DSIR's Peter Waring in its dual fuelling developments. The TBG project aimed to develop an electronic LPG/diesel conversion kit to substitute up to $80 \%$ of the diesel with LPG. The major market opportunity was seen as the Boral Group of companies in Australia. This Group ran a fleet of around 1,000 trucks and had a network of LPG sales outlets. TNO in Holland had produced a low substitution LPG/diesel kit using 20-30\% LPG to $70 \%$ diesel. However, Boral Gas tested these kits on some of its trucks, and because of the low substitution rate supported DieselGas's alternative technology.

The TBG provided $50 \%$ of the salary for two engineers to work on the project in DieselGas. Tom Holtslag was employed from November 1990, followed later by Trevor Lister. In parallel with the TBG LPG/diesel project DieselGas provided consulting services to South-east Asian countries, helping to develop CNG-related industries in those countries. It also advanced the production engineering of its Standard CNG/diesel kit with a focus on its sales potential in Latin America and Eastern Europe. This work was assisted by the BDIG scheme.

The TBG project was based on earlier work indicating that the LPG supplementation of diesel fuelling could be increased substantially by controlling the initial ignition using diesel fuelling and subsequent injection. The project demonstrated that this principle was correct, and that high substitution of LPG for diesel fuel was possible without the onset of detonation, provided that the rate of pressure rise due to the initial injection of diesel fuel for ignition purposes was carefully controlled. 
With the assistance of TBG funding the mechanical and electronic hardware and the software were enhanced to improve the load and substitution levels. Problems were encountered with the solenoid valves used to deliver and meter the diesel to each cylinder. The TBG project proved useful in characterising the diesel injection spray used in earlier tests. The project supported the building of a single cylinder prototype electronic diesel injection system which reproduced injection characteristics and allowed control of fuel delivery volume and timing.

However, the project encountered two major problems: an inability to control the diesel fuel injection pressure to the prescribed time/pressure profile, and the unforeseen aspiration of LPG into the cylinders of the engine which retained normal diesel fuelling. A major difficulty was obtaining the correct diesel line pressure for the LPG cylinder. It also proved extremely difficult to analyse the dynamics of the injection control system.

By the end of 1992 Boral Transport had invested around $\$ 300,000$, the TBG had spent $\$ 83,000$, and DieselGas itself had invested over $\$ 100,000$ in the project. TBG funding for the project finished in September 1992, at which point the project was abandoned.

\section{Marketing and Redevelopment}

While struggling with its LPG/diesel dual fuelling kit, DieselGas was in parallel redeveloping and making progress with its $\mathrm{CNG} /$ diesel kit. The small price differentials between diesel and gas, the slow acceptance of CNG as a diesel replacement, and poor quality conversion equipment have constrained acceptance of dual fuelling technologies in New Zealand and forced DieselGas to look for overseas markets. The Gulf War in 1990, and ongoing unease in the Middle East, to some extent had revived interest in alternative fuels. However, New Zealand's isolation and the travel costs to attend alternative fuel and NGV conferences and trade and marketing events had posed a major constraint to the company's marketing efforts. 
By 1990 the CNG/diesel kit was well advanced with a price of around US\$6,000 per unit. Harvey Reid launched the CNG/diesel kit at an NGV 90 trade fair in Argentina in October 1990 but did not make any sales. It became clear that the price would need to be at least halved to achieve any penetration in the market. George Jones argued consistently for more rather than less electronics, and his view eventually prevailed with Reid.

The product was heavily re-engineered in 1991 with more complex software to produce a simpler, cheaper and more reliable product which at the same time had greatly improved performance. The product redevelopment included modular production and software to produce the three control servos in software rather than hardware, which in turn eliminated a printed circuit board for each servo. The gas valve redevelopment produced a valve that was only $20 \%$ of the original weight but had $60 \%$ of the capacity. The valve was capable of supplying sufficient gas for engines up to $225 \mathrm{~kW}$ with larger engines using multiple valves. The redevelopment produced a simple product with a much higher performance, cut costs by around twothirds, and was crucial to achieving the competitive price needed for the first sale.

\section{Technical Performance of the Dual Fuel Kits}

The DieselGas CNG/diesel conversion kit, as finally launched on the market, consists of a microprocessor-based engine management system which at any given engine load or speed determines, among other variables, the amount of diesel and gas fuelling for optimised diesel substitution and overall fuel economy. DieselGas dual fuel kits achieve significant energy savings at full engine loads. The electronic system is designed to maximise the diesel substitution under all speed and load conditions.

The Matchtorque and Standard DieselGas dual fuel kits have some significant advantages over competing products. Most dual fuel systems seek to optimise diesel substitution at a set load/speed point, with performance sub-optimal at other settings. The Matchtorque system gives optimal performance at all loads and speeds. The Matchtorque $\mathrm{CNG} /$ diesel conversion kit can be applied to almost any automotive, 
marine, railway or industrial diesel engine and was specially developed for retrofitting to existing diesel engines. It is especially suited to high power output turbo-charged and inter-cooled engines of greater than $200 \mathrm{hp}$. The system controls ingested air volumes as well as diesel and gas fuel supplies, resulting in enhanced light load efficiency.

The Standard electronic dual fuel kit is fully programmable, with options including diesel servo and air servo feedback, diesel injection timing variation, exhaust temperature, water and oil temperature sensing, exhaust brake switching, low CNG switch to full diesel, altitude and/or ambient temperature compensation and knock sensing.

The DieselGas kits have simple design, easy installation, low maintenance and are tamper-proof. Each engine conversion is individually programmed to match the engine, original power and torque curves. No major engine modifications are needed for kit installation.

\section{Commercialisation}

DieselGas was approached in 1992 by a local Pakistani living in New Zealand with links to a company in Pakistan that wanted to develop a CNG dual fuel industry. Staff from this company visited New Zealand. In early 1993 ECOTEC CNG (PVT) Ltd of Pakistan confirmed an order for 69 dual fuel kits at around $\$ 2,000$ each in Pakistan, to be fitted to a fleet of service vehicles belonging to the Sui Southern Gas company in Karachi.

The DieselGas kit had been developed for markets with well-developed service infrastructures and skilled service staff. DieselGas therefore had real problems in marketing in less developed countries such as Pakistan and Turkey, because of the Government bureaucracy, lack of awareness of $\mathrm{CNG}$ as a fuel, rough roads and low maintenance skills. When DieselGas received orders from Pakistan, Reid recognised that new challenges were posed by the relatively unsophisticated nature of the market, 
with a need to tailor the product to the market to ensure ease of installation and local maintenance. It took 18 months for the first contact to be made till the shipment of the product. This was the first substantial sale for DieselGas and a big morale booster for the company.

The Matchtorque system has been in continuous use for eight years in New Zealand and has attracted world-wide interest. The company has now made dual fuel kit sales in Australia, South Korea, Turkey and Pakistan. The sale in Turkey was the direct result of contacts Harvey Reid made at a Natural Gas Vehicles (NGV) conference in Kiev. DieselGas is endeavouring to develop new markets for its kits, especially in less developed Asian countries, and it is undertaking market development work in Indonesia, Turkey and Pakistan.

By 1994 DieselGas had invested over \$1.5M in the CNG/diesel fuel kit, with the total investment by all parties being around $\$ 2 \mathrm{M}$. However, sales of around $\$ 2 \mathrm{M}$ are projected by the end of 1995 . The Matchtorque system has recently been chosen by BHP for its upcoming dual fuel trials, and DieselGas is now dealing with major engine manufacturers such as Caterpillar. The company is exploring other new opportunities, for example providing dual fuelling technology for Moscow buses, and the company may also develop a CNG/petrol dual fuel kit.

\section{Background of Key People}

Harvey Reid completed an apprenticeship as a diesel mechanic and serviced a wide range of diesel engines for some years, before developing specialised expertise in diesel fuel injection technology. From 1972 to 1975 Reid was service manager of Lucas Industries Ltd, responsible for running its diesel fuel injection service department. From 1975 to 1978 he managed a diesel injection repair business. Harvey Reid holds world-wide patents in CNG/diesel and LPG/diesel dual fuelling technology. 
George Jones completed a BSc in physics at Otago University in 1964, developing a strong understanding of basic science. He joined DSIR in 1964, and after a period as a scientific officer in Antarctica became a scientist in the electronics design section of the Physics and Engineering Laboratory in Lower Hutt. In 1971 he launched Solid State Equipment in partnership with Neil Poletti, and in 1974 became full-time in the company. Jones is dedicated to his work and to his principles and is a committed pacifist who refuses to participate in any projects with the Ministry of Defence.

Neil Poletti began in DSIR as a technical trainee in 1960, completing an NZCE in 1964. He spent 9 years as a technologist in the Physics and Engineering Laboratory in DSIR, before in 1969 taking a job as a development engineer in Natronics Ltd in Sydney. After 3 years in this company he co-founded Solid State Equipment in Lower Hutt in partnership with George Jones.

\section{Conclusions}

The DieselGas dual fuel kit resulted from extraordinary perseverance over some years and from the cumulative skill-base built up by three key individuals. Harvey Reid was kept going by a belief in his product and by the motivation that comes from "experts" arguing that it couldn't be done. The positive synergies between Reid, Jones and Poletti were crucial for success. The single-minded passion of Harvey Reid, and his knowledge of diesel engines and mechanical hardware, needed to be complemented by the electronic hardware skills of Poletti, and the software and physics expertise of George Jones. Jones' ability to temper enthusiasm with more objective critical appraisal, and to assist Reid in learning how to manage an R\&D programme was crucial. Reid's ability to recognise his limitations and work as part of a team was fundamental to eventual success.

The case illustrates that success has to be planned for to avoid the costs in time and money of inadequate appraisal of the technical and market parameters early in a research programme. Over the period 1983 to 1992 DieselGas put considerable effort 
into LPG dual fuelling, and yet its major commercial success has been with CNG because it is technically easier to work with and more acceptable in the market.

The case demonstrates the need to be open to new ideas and new technologies and to be aware of alternative technical pathways to achieve a given goal. DieselGas went down several technical "blind alleys" from 1983, with one of these costing about 5 years of development time, until the company basically reverted to its original $\mathrm{CNG}$ /diesel design. However, these failures were themselves useful learning experiences, with much of this learning being generic and providing valuable insight into other technologies or products of interest to the company.

Solid State and DieselGas have had bad experiences in business, and Jones and Reid are adamant that ethics and trust are at the heart of good business relationships. The DieselGas case illustrates the importance of the "people side of innovation". The trust between people is fundamental to success and Harvey Reid argues that customers buy "because they like and trust you" rather than just because they like the product.

DieselGas has shared with other technology-based companies a difficulty in raising capital from banks reluctant to support high risk projects. The company takes a conservative attitude to debt, and lack of capital will continue to limit its growth and development.

$R \& D$ and product development funded by customers is a major source of development finance for companies such as DieselGas and Solid State Equipment. Such R\&D is often product-specific, and may be funded by payment for an end product delivered. The contracts for such research are often tightly specified and leave little room to earn premiums. $R \& D$ companies that do not undertake vertically integrated manufacturing and volume production find it difficult to grow, because research contracts from other parties do not allow substantial premiums to be earned, and research results are not embodied in tradeable products. 
Solid State and DieselGas are examples of R\&D companies that provide an essential part of a country's technical infrastructure and which are niche-oriented and almost "cottage industry" in scale. As technological "cottage industries" they lack the scale economies to compete in large-scale volume manufacture. However, they have the flexibility and creativity to perform in smaller, niche markets that larger international companies do not have a sufficient incentive to compete in. 


\section{Appendix 1}

\section{Key Events in the Dual Fuel Kit Innovation}

\section{Key Events}

1974

1975

Solid State begins work in microprocessing technology

1978

1978-1982

Harvey Reid starts business repairing and servicing

diesel pumps

Harvey Reid develops interest in dual fuel kits

Late 1982

1983

1985

1989

Harvey Reid moves full-time into DieselGas

April 1990

FRST invests in CNG/diesel dual fuel kit

1990

Harvey Reid attempts to market dual fuel kit in Argentina

1991

Product is redeveloped

1993

First significant sale of DieselGas dual fuel kits in Pakistan 


\section{ANALYSIS OF DATA}

\section{Introduction}

In exploring the role of learning processes in underpinning and catalysing technological innovation, this thesis draws on the theoretical insights from the management, neo-Schumpeterian, evolutionary economics and new growth theory literature. These provided the broad theoretical backdrop against which the empirical research was undertaken.

This chapter outlines the data generated and the key themes and variables highlighted by the research, and presents the results of the open, axial and selective coding processes. Core categories of variables that provide explanatory insight into technological innovation are then developed. These provide a basis for the advanced analysis of the research findings and the model building set out in the Conclusions and Implications chapter.

\section{Overview of Open Coded Data}

The case study research generated a mass of open coded variables. These are listed in Annex 3, which also sets out how the variables are organised into axial categories. The following provides an overview of the open coded data and sets out the key themes arising from it. This data is discussed for convenience within the 5 broad research areas.

\section{Origins of Innovation}

A firm's ability to innovate is bounded by its strategic behaviour, by the human capital and competencies that it has built up cumulatively over time, its social and technological learning processes, and its interplay with its external search and selection environment. 
The origins of innovation lie in the interplay between a firm, with its internal competencies and processes, and the wider (and often global) environment. Firms within New Zealand have different capabilities and are positioned at varying points inside the bounds of the world's "technological production possibility frontier". Some internationally competitive firms and industries, such as in agritech, industrial drives and horticulture are at the outer rim of the world's technological production possibility frontier. The technological capability of other firms fall far short of this, and their potential to innovate is correspondingly limited. Dynamic and interactive technological learning processes at the level of a firm constantly shift its technological possibility frontier.

Technological learning is integral to the origins of innovation, because it serves to catalyse processes through which new ideas, insights and sources of technology can be made economically productive. New ideas and learning processes do not occur in isolation but are localised and domain-dependent. Technological learning is localised in the sense that it tends to occur within, or it branches off from techniques that are already in use, and from the interaction a firm has with its search and selection environment (see Nelson \& Winter, 1982).

Technological innovation is an interactive process (Kline, 1985; Rothwell, 1992), and technological learning is a process of continuous interactiveness (see Freeman, 1994). Interaction between a firm and its external environment is fundamental to innovation because it expands the diversity and richness of the ideas, technologies and market niches that firms can select from and turn into new opportunities. The diversity and richness of the competing ideas in the external environment from which firms make selections helps drive the rate of evolutionary technological change. This technological change is greatly influenced by the extent to which firms link with and exploit the international body of knowledge.

Especially since the economic reforms of the mid-1980s, New Zealand firms have increasingly looked internationally, so that the environment from which ideas can seed new technological developments has been extended beyond New Zealand. For 
example, the Treotek innovation was significantly influenced by Japanese technologists, and the Phoebe fat measurement innovation has its genesis in Japanese and Australian applications of nuclear technology to measure moisture levels in coal. MAF's scallop enhancement programme was developed in conjunction with Japan's Overseas Fisheries Commission, vapour boron was developed by FRI in collaboration with Imperial College, London, while Alatal 821 involved collaboration between New Zealand and American researchers.

New Zealand's economic history has shaped the origins of its innovation. New Zealand's evolution as a "trade colony" of Britain has meant that much innovation was stimulated by the transport bottlenecks of servicing distant markets with biological products that change continuously from harvest to delivery to the customer. These influences have stimulated many of the innovations recorded in the Annex 1 Database of Innovations, including in packaging, objective measurement technology, conveyancy, automated grading, sensory technology, powder handling, processing to improve shelf life, controlled atmosphere storage and transport, and data loggers to monitor the condition of products over time. However, geography and transport costs are not always major factors constraining New Zealand innovation. PEL in Marton for example lacks a port, airport or significant local market, but can compete in fuel dispensing and security electronics with competitors in their home markets in Europe and North America.

New Zealand's domestic environment and natural resource endowments have led to strong concentrations of innovation around the dairy, meat, horticulture, forestry and agritech industries. This reflects the extent to which technological innovation has its origins in demand from domestic industries, which leads to innovations being concentrated around industry clusters (see Porter, 1990). As shown in the Annex 1 Database of Innovations, the biologically-based primary sectors are particularly significant users of new innovations, for example, animal vaccines, logging machinery and milk measurement technology. The "behind the farm or forest gate" primary industries are not themselves major direct producers of innovations, except in fields such as plant breeding, but rather create a demand for innovations from the 
manufacturing, electronics, secondary and tertiary processing and servicing industries. Many innovations result from particular characteristics of the biologically-based industries, such as the perishability of their products. For example, perishability creates processing and shelf life constraints, but has also helped drive the processing investment and industry vertical integration in sectors such as the dairy industry.

Often it is the lack of a resource, or a specific problem in the resource base or the natural environment that has stimulated innovation. Examples have included steel making processes using iron sands and earthquake shock absorbers. Innovation has also focused on upgrading the value of waste or low value materials such as lactalbumin, whey, short timber lengths or export-reject kiwifruit. Innovations such as Treotek have exploited innate characteristics of raw materials, such as coarse wool fibres that would otherwise be a disadvantage in the market. The unreliability of labour, the need for improved safety as with the loin boner, and reducing environmental impacts such as with the dual fuelling development have also been key stimuli for innovation.

Market or customer links have often triggered innovation and these links are almost always crucial at some stage in the ongoing development of an innovation. These customer or market-related origins of innovation have encompassed such drivers as the cost of production, and solving technical or quality control problems as with the Ruakura Milk Harvester.

Lead users and discriminating customers (see von Hippel, 1986) are often key to the origins of innovation and associated technological learning processes. This is demonstrated in the FP4000 fire alarm and the loin boner innovations. In some cases, lead users may set extremely demanding technical specifications that in themselves drive a learning process that leads to major technological advances. An example is the demands placed on Vega Industries by the US Coast Guard's lighthouse beacon specifications. However, learning from markets and customers is only possible when a firm has the internal competencies that enable it to interpret, adapt and apply 
external ideas and technologies and allow it to interact in a stimulating and catalytic way with its environment.

The origins of innovation must be seen not in isolation but as part of a technological continuum. Past ideas and technologies seed or lay a technical platform or knowledge base for new ones. Innovations build on those that came before and the quality or functionality of a new innovation will typically be higher than that of antecedent innovations (see Grossman \& Helpman, 1991b). The integrated circuit built on knowledge created through the development of the transistor, and in turn laid the basis for the information technology revolution that has transformed modern economies. In New Zealand, research on the properties of the dairy protein casein stimulated a proliferation of later applications of protein chemistry to different product opportunities. The father of Bill Foreman, founder of the major New Zealand plastics company Trigon, made plastics out of casein when New Zealand was deprived of plastic imports in World War 11. Robert Franich, an eminent FRI scientist who was a key player in the Greenweld technology, found his knowledge of casein chemistry to be catalytic in leading him to the key insights underpinning FRI's wood hardening innovation. Casein now forms the raw material for an artificial paua food, buttons, artificial silk, and the coating of TV screens, as well as being a food ingredient in a range of markets. Technological learning that is built up cumulatively within a field can therefore involve significant economies of scope, since it often has generic and multiple applications. Such economies of scope and generic applications reflect the non-rival characteristics of much of this learning.

In many cases, the origins of new ideas or technologies lie in systematic R\&D effort in research institutes in New Zealand or overseas, in published scientific papers, or in technology demonstrations. In most of the case studies innovation has drawn heavily on overseas research endeavour, and in all cases it has drawn in an evolutionary way on past research and technological innovation. Formally-organised R\&D, in the sense of controlled experimentation in a laboratory-type environment, is highly desirable in most innovations and necessary in many. Obviously, in-house R\&D enhances a firm's receptivity to external sources of science and technology (Gambardella, 1992). As 
shown in the DieselGas case, learning from "failed" research, the process of "organisational forgetting" (Lundvall ed., 1992), or of "unlearning" (see Starbuck, 1996) helps to sharpen the focus of future research, search and selection processes or creates new spin-off opportunities that can be explored.

While the creation of new knowledge and technology always requires "research" in the very widest sense, technological innovations can flow from firms that lack formally-structured R\&D. Fisher and Paykel, for example, marshalls the skills of all staff from production workers to senior design engineers in innovation, rather than depending on a separately-organised R\&D team. This reflects a view that an innovative firm is a learning organisation and that the whole of the organisation can be the "R\&D" or the "innovation" department, rather than having these activities separately structured.

The limits of the model of research-based knowledge creation leading in a linear way to innovation are demonstrated in the large number of innovations developed through market-driven applied technology rather than systematic R\&D effort. However, innovations such as kiwifruit wine, GS 2085 and the Ruakura Milk Harvester show that the more traditional models of innovation based on strategic scientific research in centralised research institutes still work in some cases, especially in homogeneous, biologically-based industries. Formal seminar and industry presentations were key learning processes leading up to the loin boner and the ASDi, while the Greenweld innovation illustrates the value of structured idea-generating processes such as "brainstorming" techniques.

The internal culture of organisations significantly influences the origins of new innovations. The free exchange of ideas and open communication in firms, in the universities, the former DSIR, and in research institutes has helped foster an environment in which important new ideas or insights have emerged.

Ideas for an innovation are often stimulated by a trigger event or stimulus that generates a "bright idea", very often in the course of tackling a real problem. Arrow 
(1962b) argues that learning does not occur through repetition, but involves knowledge being built up by actually doing things and tackling real problems, through fixed views being challenged, and through people being forced to continually revise their understanding of a problem as new information comes to hand.

Garth Carnaby with the Treotek innovation, Robert Franich in wood hardening technology, and Harvey Reid in DieselGas all had flashes of insight or recognised a pattern or set of connections that provided a key insight into a new innovation. As in the float glass innovation, conceived by Pilkington while washing the dishes, innovators often experience a key insight after extended musing over a problem, but while engaged in some other, non-work related activity. Serendipity, or a sudden flash of insight, does not however occur in isolation from other origins of innovation. "Luck favours a prepared mind", and men such as Carnaby and Franich are very strong scientists or technologists fully imbued in the context of the problems they address.

\section{Dynamic Processes Over Time}

Technological innovation is about "extending the frontiers" in a dynamic way, rather than the rearrangement of fixed inputs in an existing market within the broadly given state of technology. The thesis research highlighted the inherently integrative and dynamic nature of technological innovation, the processes through which the benefits of innovation over time can be captured, the skills and techniques applied in innovation, and how people and firms can be organised to manage dynamic innovation and technological learning processes.

Innovation can be characterised as the "carrying out of new combinations" (see Schumpeter, 1942) or as the "craft of combination" (Elam, 1993). As an integrated process, technological innovation involves the bringing together of people, ideas and technologies and their dynamic management over time. This requires strategic leadership or governance through which a firm focuses its resources on innovative opportunities, the ability to combine existing skills and technologies in a new way, and 
through systemic innovation to link different technologies together to achieve major performance gains.

Much of the dynamics of innovation over time relates to capturing its benefits, by speed to the market, through asset specificity and embedded uniqueness, creating barriers to competitive entry, confidentiality, branding, differentiation, and intellectual property protection. Competitive strategy often aims to migrate away from commodity and price-driven competition to earning premiums through competition on the basis of quality, new functional properties and performance characteristics. This in turn allows a market edge to be sustained by the accumulation of specialised assets and the high barriers to competitive entry they create, and through tacit technology that is difficult to imitate.

At the early stages of an innovation competitive strategy requires the choice of a robust core design (see Rothwell \& Gardiner, 1988; 1989). This is illustrated by the industrial drive innovations outlined in the PDL Electronics case. Conversely, the failure to create a robust design that forms a platform for later development is illustrated in the FP4000 case. Once a robust design is chosen investment is irreversible and fine-tuning only is possible. At a more advanced stage the preferred design among competing options is identified by the market, volume builds up, opportunities for scale economies emerge, leading to firms gearing up for mass production and acquiring specialised and complementary assets. The asset specificity so created is a major barrier against competitive entry. In the case of agritech innovations by firms such as Tru-Test and Gallaghers, and mobile radio communications from Tait Electronics, early market entry has meant that regulatory standards have been designed around the product, creating barriers to other competitors. Once established in one market, core designs, processes and technologies can then spill over into other sectors. For example, dairy processing knowledge and technology has spilled over into sectors such as wine and aquaculture.

Time is a competitive weapon to capture benefits, as illustrated in the PDL Electronics and Vigilant cases. However, time pressures can mean firms take short 
cuts or produce technology that is suboptimal, or which has not been adequately trialed. The Ruakura Milk Harvester was put into the field while technical problems were still being solved, while the benefits of the kiwifruit wine innovation were captured by "fast followers" such as Prestons rather than by the wine makers who first commercialised it. Other innovations may be defeated by a combination of lack of timeliness and following the wrong technological pathway. The development of Advanced Testing Equipment (ATE) for the NZ Army that ended up being "leapfrogged" by superior technology is an example.

Formal and codified skills, and analytical business management techniques such as financial and market planning, can be effectively applied in the more dynamic and stochastic processes of technological innovation. Obviously, technological innovations of the highest potential will fail if there is a complete disregard for planning, financing and marketing. The lack of commercial powers and structures hampered innovation in Government science departments such as DSIR in the past (see Bray \& Perry, 1994). Improved financial, market and business planning would have enhanced the process for many innovations, such as the Ruakura Milk Harvester, kiwifruit wine and the DieselGas duel fuel kit, among many others. Since the reforms of New Zealand's science system that began in 1989, the formal business planning of research institutes has been an important success factor, as illustrated in the Greenweld case.

But formal planning, analysis, measurement and codification can also dampen the enthusiasm and "animal spirits" of an innovator, primarily because business planning techniques are suited to the management of risk but not the management of uncertainty. Innovators tend to be free thinkers who critically question and adopt unstructured approaches (Twiss \& Goodridge, 1989). Innovation sometimes benefits from unreflecting instinct and from the use of and respect for intuition rather than an over-emphasis on detailed and formal planning. The Prestons with their kiwifruit wine innovation, and Murray Woolford and Robert Sherlock with the Ruakura Milk Harvester, are examples of innovators whose extraordinary efforts may have been discouraged if formal business planning had shown "how hard it was going to be". 
A firm needs the formal organisational structure, work practices and culture suited to fostering dynamic innovation processes. Formal organisational design and structure influence the ability to manage technological innovation, but even more important is the way people are organised less formally. Innovative forms of team and workplace organisation aim at creating a "social architecture" that integrates people's skills, fosters the flow of information and real-time communication, and accelerates the response time and improves the flexibility and adaptiveness of project teams. This has been characterised as the "rugby approach" to innovation (Takeuchi \& Nonaka, 1986). It is axiomatic in the literature that organic structures and the use of task forces, project-based teams and other cross-functional communication mechanisms facilitates the learning, flexibility, adaptation and cross-fertilisation needed in innovation (see Robbins et al, 1994). The evidence from the case studies supports the conclusions reached by Brown \& Eisenhardt (1995, p. 364) that:

..successful product development involves relatively autonomous problem solving by crossfunctional teams with high communication and the organisation of work according to the demands of the development task.

As shown in the FP4000 case, innovations as well as organisations must be flexible, with key design principles not locked in too early to be modified later, and with a clear longer-term vision in place of how an innovation will create a technical platform for future developments.

The ability to manage dynamic innovation processes is ultimately dependent on people, and the social processes through which they relate to and work with each other. There is a rich international literature on key roles that people play in innovation, for example on the roles played by product champions and top-level sponsors (see Smith et al, 1984; Steele, 1989). The New Zealand evidence is in line with what is known internationally about key innovation roles. Team and workplace reform-based initiatives must be supported by good "people relationships" and a business culture that fosters the cohesion, empowerment, toleration of diversity and continuous improvement that is needed in innovation. This is illustrated in the 
Treotek case, where Alliance Textile's workplace reform initiatives only succeeded after the people relationships and cultural foundations had been put in place.

Investment in learning-related strategies and in human capital creation is crucial in innovative firms. These learning strategies will fall within the domains important to the firm and draw heavily on external stimuli from other firms, trade events and literature, and external providers of science and technology. These learning strategies will be dynamic and will encompass systematic learning and learning by doing, and the creation of tacit and uncodified knowledge bases. Learning and skill-base development may be specific to the firm, or be more generic in nature. A firm needs to build up and retain over time competencies of high specificity to the firm, while more generic competencies, or specialised skills needed only occasionally, can be more mobile or can be bought in. This distinction between specialised and more generic skills is highlighted in the Alatal 821 case.

\section{Background/Past Experience of Key Players}

The performance of people in innovation depends on their past background and learning experiences, as well as on the structures and institutional and social processes that make their skills productive. Variables relating to the background of people include systematic learning experiences in different countries, industries and workplaces, formal education and training, learning by doing and tacit knowledge development, the influence of family background, and "orthogonal learning" experiences that may arise, for example, from recreational interests.

Innovators very often have a rich and diverse background in a technical or industrial field, often with international experience, or they may have worked at different levels within an industry or organisation. Innovators often have a strong technical background that builds confidence, or they may come from a family of high-achieving professionals who have taken risks and achieved success by doing so. An innovator may have taken an early risk, found it has paid off, and gone on to further and riskier innovations with the enhanced confidence that flows from success. Success often 
leads to innovators trusting in their ability, sometimes to the point of exuding an infallible persona that can engender from others exceptional loyalty and willingness to "go the extra mile".

The contribution of human capital and skill-bases to innovation is closely associated with the mobility of human capital through the economy. This may take the form of overseas technologists moving to New Zealand and playing a key role in an innovation, or the mobility of people among clusters of firms, such as among electronics businesses in Christchurch, or between research institutes, universities and firms.

Many of New Zealand's most significant technology-based firms have been started by innovators who have spun-off from other businesses, taking their skills, ideas and technological competencies with them. Examples include Robinsons Industries (from Fisher and Paykel), Switchtec (from Tait Electronics), and Innovative Developments, started by the team of ex-PDL Electronics technologists that developed the ASDi innovation. Other firms have been started by technologists who spun-off from government agencies with strong technological competencies. Examples include Vigilant (from the Post Office) and Vega and Network Communications (from the DSIR). Technologists may have a core skill-base which can be applied in different applications across a range of firms. Alan Fish developed his skills in optoelectronics in DSIR, applied them to meat grading technology in Hennessey Grading Systems, to the entertainment industry in Microworld, and then to seafood processing in Exactics Process Innovations.

There is still at least some place in innovation for the "backyard" innovators, many of whom have a broad-based technical background. These innovators are often stimulated by frustration with technical problems or bottlenecks, or see opportunities in recreational or leisure activities as well as in the market economy. Examples of innovations by solo inventors have included the electric fire alarm, and in much more recent times, the Odjob concrete mixer, the kiwifruit-based product Eklanite, and the Powerbeat battery. However, despite the folklore appeal of the solo innovator 
celebrated, for example, in Riley (1995), technological innovation is more generally a team-based process carried through by firms with significant discretionary resources.

\section{$\underline{\text { Motivations }}$}

Technological innovation involves the interplay between people and institutions. People are shaped by institutional relationships, and themselves shape institutions. Underlying the interchange between people and institutions are peoples' motivations. Motivations encompass "what makes people tick" as individuals, and how individuals relate to and motivate, or are motivated by groups. It includes how individuals align themselves to the higher interests or values of the group.

The neoclassical view of economic motivations is that they are based on short-term, self-interest maximisation. However, such behaviour can erode the trust, longtermism and focus on higher order goals often required in innovation. Trust is important in technological innovation because it is a process that is subject to uncertainty. Performance in innovation is difficult to specify in advance, create incentives for, embody in contracts, or measure and reward. People may know that their part of an innovation process is going badly, and may objectively quantify poor financial and marketing prospects and intractable technical problems. However, they often subsume their analytical judgement by trusting, perhaps uncritically, a selfsacrificing innovator whose commitments are irreversible and whose focus is on higher goals that all in a firm can share in and benefit from. This willingness to trust is a pervasive influence on the motivations of people and their behaviour in the innovation process.

Because the social benefits of technological innovation often exceed the private benefits that can be captured, and because of the personal sacrifice and time lags before benefits are achieved, the commitment innovators make to innovation is very often "irrational" in a narrowly economic sense. Innovators are often motivated by values, beliefs and incentives that are non-financial or material and which are higher than themselves, or at least external to themselves. Businesses focused on such goals 
as benefiting customers or society, or producing the best quality product, are more likely to make money than those that focus corporate energies exclusively on profit or financial goals. Angus Tait of Tait Electronics emphasised that:

If you set out to make money then you might not succeed in building a business, but if you set out to build a business and you do it right then you will certainly make money.

(Tait, 1989).

This philosophy also works at the product level: Fisher and Paykel's medical humidifier was developed unquestionably for an altruistic, health-care reason, but made money as a spin-off.

People's motivations include their creativity, in the sense that creativity is itself a motivator and shapes people's behaviour. Creativity-related variables include pattern recognition, lateral thinking, and generating new ideas by sustained musing on a problem, often outside of the work context in which the problem arises. Innovators often treat their innovations as a form of self-expression, almost a means of perpetuating one's identity in a technology.

The innovation process can itself be the highest form of motivation. Innovators often revel in the journey rather than the destination, the process not the outcome. This love of the process of innovation is often a powerful motivator, but must be tempered by a sufficiently clear focus on the outcomes and the deliverables, and by a discipline that avoids too many deviations into "blind alleys". For example, failure to recognise and withdraw from the blind alleys set back DieselGas's dual fuel kit innovation by some years.

A firm requires leadership to align the motivations of individuals with the purposes of the organisation, and to manage the dynamic change and adaptiveness inherent in technological innovation. Innovation leaders must understand their inner motivations and value systems, behave in accord with them and with their own nature. Innovation 
leaders typically have vision and an ability to articulate that vision in simple terms that followers can understand. Their commitment and energy is perceived by others as exceptional and novel, it reinforces a follower's belief in the unique knowledge and abilities of the leader, and therefore his capacity to deliver. This in turn means that innovation leaders will be capable of building trust, and of motivating others in an innovation team to exceptional levels of performance.

\section{External Influences}

Innovation can never be divorced from the external influences a firm is subject to, including a country's economic and regulatory policy framework, and the interaction between a firm, its markets and external sources of ideas and technologies.

Major New Zealand innovations, such as Fisher and Paykel's medical innovations, and agritech innovations from firms such as Tru-Test and Gallaghers, were developed at a time when New Zealand was a highly regulated and protectionist economy. The patterns of technological innovation reflected in the Annex 1 Database of Innovations and in the case studies include many innovations that were developed in such an economic environment.

The external influence of protectionism from 1935 to the mid-1980s had the effect of stimulating local manufacturing. For example, Fisher and Paykel began business marketing imported whiteware, but after import controls were introduced from 1935 on it had to become a whiteware manufacturer to supply its market. Protectionism and import controls stimulated a very broad but thin manufacturing base, in many cases with only one firm servicing a particular market segment. Firms often focused on technologies such as agritech that have a specialised home market and could not be bought "off the shelf" from overseas. These niche markets in some cases were microcosms of larger world markets. New Zealand firms typically lacked the scale economies and the advanced technology needed for high-volume international markets. This in turn meant that these firms, to survive, had to evolve into businesses 
competing through economies of scope and rapid responsiveness to customer needs, rather than through cost competition based on scale economies.

This need for flexibility, and the potential to exploit economies of scope, in turn stimulated innovation in firms such as Scott Technology, Howick Engineering and Fisher and Paykel Production Technology that make production technology for short, customised, or flexibly-managed production runs. Industrial equipment businesses such as PDL Electronics have been able to use local firms as a testing bed and microcosm of the world market for their products over a very broad and differentiated industrial front. This historical legacy has meant that innovative New Zealand firms often compete in niche international markets where total world sales may be less than $\$ 100-200$ million a year. Such a market is too small to attract interest from the big international players, and the technology is too difficult or specialised for low-cost competition from less developed countries.

In 1984 the New Zealand government began a widespread process of deregulation, placing reliance primarily on market forces to determine decision making in the economy. In neoclassical economics, the competitive workings of markets should determine prices for goods and services and the cost of money. Price signals should act as a language that communicates real values that economic agents can respond to, so that resources can then be allocated to their highest valued use. Macroeconomic stability does help innovative businesses to plan strategically over the longer term, constrains input costs, and allows market signals to more clearly articulate longer term consumer preferences. Microeconomic flexibility helps foster workplace management practices that foster innovation, and which improve the response times of innovators to opportunities and to dynamic change.

Deregulation has shaped the pattern of technological innovation in New Zealand. Much automation innovation such as in meat engineering was designed to reduce labour costs and to remove uncertainties associated with the unreliability, availability or seasonality of labour in a regulated environment. Since the economic reforms from the mid-1980s, and the freeing-up of the labour market, there have been less pressures 
for such labour-saving innovation. However, over the same period the economy has become more open to overseas competition and this has stimulated other innovations that aim to improve the productivity of capital plant and of production processes in industry.

The ownership structure of firms can significantly influence technological innovation, both as an external influence on the firm, and in relation to its effect on a firm's "strategic governance". Innovative, privately-owned firms such as Vega, Tait Electronics and PEL have maintained a long-term focus on technological innovation and made it integral to their business vision and strategy. In contrast, many publiclylisted firms have taken a shorter term view under shareholder pressure for annual dividends.

Overseas ownership can also impact on the extent to which firms invest in technological innovation. Businesses that are subsidiaries of overseas firms, or R\&Dbased firms such as Glaxo and Allflex that began in New Zealand and were later bought or had their head offices transferred abroad by offshore investors, tend to undertake little R\&D in New Zealand. Overseas-owned firms that do undertake R\&D in New Zealand tend to focus on adapting overseas products to the New Zealand market (see Johnston, 1991). This can lead to "truncated development" where overseas-owned firms act as marketing and distribution outlets, rather than creating and marketing their own innovations.

A key external influence on innovation is the public technostructure of educational and training agencies, research institutes, agencies such as the Patents Office, libraries and computer networks that help foster or underpin innovation in firms. The structure and commercial powers of these agencies are important, but it is notable that significant and commercially successful innovations such as the earthquake shock absorber emerged from the DSIR at a time when it lacked the commercial powers and skills now seen as fundamental for commercial performance. However, institutes such as the DSIR have produced many "science push" inventions such as instruments that addressed laboratory problems rather than commercial opportunities. 
Commercialisation of these and other research institute inventions has often fallen down because of the gulf in the culture, technical and commercial understanding between research institutes and businesses (see Bray \& Perry, 1994).

The major contribution of the public technostructure to innovation has surely been the supply-side provision of education and training, and the creation of research results in areas of importance to New Zealand industry. However, government agencies have also created a demand-side stimulus to innovation, particularly in telecommunications and defence. Innovations developed to meet the needs of public sector customers have included defence electronics from Marine-Air-Systems and Oscmar, a mortar calculator from the DSIR, signalling technology from Vega, a locomotive "black box" from PEL, and software and communications innovations from a host of software and electronics firms.

Technological innovation is an externally interactive and non-linear process that involves the confluence of technological capabilities and market needs within the framework of an innovating firm (Rothwell, 1992, p. 222). This confluence between technology and the external influences of the market often depends on interactive communication with customers and is catalysed by new ideas and sources of learning. Peters \& Waterman (1982, p. 193) argue that “...excellent companies are better listeners", while Rothwell (1991, p. 101) concludes that successful innovative firms tend to have higher levels of communication with external clients.

External customer influences also shape the detailed focus and specific applications of an emerging innovation. Alan Dean of Richmonds spotted the potential of one part of MIRINZ's mutton frame boner and provided much of the direction needed for later success. Customers created the specifications for the Vega beacon, and were central to the broad focus of the Dairy Board on the reduced tolerance milk protein market. However, it is worth noting that the Alatal 821 success was achieved despite the lack of detailed customer specifications in the early stages of the innovation, and ongoing interactions with customers during the innovation process itself were minimal. Fear of customer perceptions and reactions can also stifle innovation. A successful process 
from Talon Developments to produce cholesterol-free butter was not commercialised by the dairy industry for fear of exacerbating consumer concerns about cholesterol in dairy products.

Lack of external stimulus and challenge fosters a defensive, inward-looking culture where people become self-reinforcing clones of each other. Alliance Textiles developed behind protectionist barriers. A new manager from outside the industry, and the catalytic stimulus of WRONZ, was necessary to the transformation of that firm and the success of innovations such as Treotek. Many innovations that have lacked adequate interaction with and responsiveness to the market in the early stages, such as the DieselGas dual fuel kit and GS 2085, tended to be delayed or ineffectively developed and implemented as a result. Frequent interaction with the external 
The application of the above criteria through selective coding led to the development of 3 core categories of variables: the Dynamics of Significant New Technology, Human Capital, and Social Processes. Details of variables encompassed in each core category are set out in Annex 4.

The core categories in turn laid the building blocks for the development of a conceptual model of technological innovation, and for the conclusions and implications outlined in the next chapter. The following outlines the core categories, discusses them in relation to how they meet the criteria set out above, and makes some observations on the key themes within, and in some cases across the core categories of variables.

\section{Dynamics of Significant New Technology}

The variables within this core category share several common characteristics. They involve, or are associated with, new technical performance or functional characteristics. Significant new technology embodies new technical characteristics that deliver improved quality, performance or "fitness for purpose" that is objectively measurable. In contrast, imitative or trivial product development is associated with high cross-elasticities of demand and R\&D redundancy, and can therefore lead to a loss in social welfare. Most of the variables within this core category generate externalities, lay a technical platform for future innovations, or give rise to social benefits that exceed the private benefits that can be captured.

Significant new technology is shaped by its past and its social and cultural context, but is also itself a shaper of society and of the economy (see Bijker et al eds., 1987; Bijker \& Law eds., 1992). The core category encapsulates the interplay between social, institutional and market processes and technological change, and the dynamic aspects of how significant new technology behaves over time. The dynamics of significant new technology over time flow from its inherent characteristics. These include the irreversibility of technological change, its cumulativeness, the trajectories it follows, and its systemic and clustering characteristics. 
Technological innovation based on significant new technology is irreversible, in the sense that inventions cannot be uninvented, and users will not go back to substandard or redundant technology. Technological learning is a cumulative process that draws on codified and in-house tacit knowledge built up within a firm's domain, and extends and further accumulates that knowledge in a dynamic way. Irreversibility and cumulativeness are partly driven by the asset specificity and the high sunk costs associated with new technology. A small technical edge created by a new technology can achieve an early edge in the market and cumulate into technological dominance. The interaction between a firm and its search and selection environment, as well as historical and institutional factors, may then create particular technological trajectories or pathways that shape the ongoing development of the technology (see Sahal, 1985; Dosi et al, 1994). Network and systemic externalities can then be exploited and clusters of innovations may emerge around a core technology. For these reasons, a technology that is in some respects sub-optimal (in the sense of technical performance or fitness for purpose) may still achieve market dominance.

Significant new technology often creates a technical platform for other follow-on innovations. These technical platforms tend to be process rather than product innovations, though they make new products possible. Significant new technology allows a firm or an economy to deliver more with less. Often this will take the form of new combinations of raw materials, in the sense that a new design combination of metals, chemicals and circuitry in a computer will deliver many times the information processing speed and capacity of older technology that combined metals, chemicals and circuitry in a different way 10 years ago (Romer, 1993).

Significant new technology may be a "non-rival good", that is a good which, while the cost of its creation may be high, will have a very low cost of dissemination to many users. Examples of non-rival goods include the basic principles of software engineering, of the semiconductor, or the principles underlying the invention of the wheel. The ability of many firms to use a non-rival good at a minimal or near zero marginal cost, or for that matter, for generations of scientists to cite the same fundamental scientific paper or insight without having to repeat the research, is at the 
heart of economic growth since it allows an economy to produce rising output from fixed physical and labour resources (see Romer, 1986; 1993).

Competitive advantage can be created by such strategies as price competition for a given commodity, or by creating new products, processes or services that embody improved functional or performance characteristics. Without significant new technology that delivers improved performance, price competition will bid away premiums and will reduce firms to being price takers that lack the surpluses to invest in improved productivity, research and new product development. The competitive edge and quasi-monopoly that can be created by significant new technology allows surpluses to be earned and reinvested in further technological development and economic growth.

Significant new technology, over the longer term, shifts the technological production possibility frontier outwards. It is the key driver of downstream innovations, spin-off benefits ranging from new products based on a new technical platform, through to systemic innovation from convergent technologies. The creation of significant new technology is also associated with the creation of new skills and human capital, tacit technology, learning-by-doing and learning-to-learn processes.

\section{$\underline{\text { Human Capital }}$}

This core category groups together the variables of skills and competencies, and the associated intangible assets of information and both codified and tacit knowledge. It has a high degree of specificity to technological innovation, since science and technology-related human capital are the key resources in innovation. Essentially, variables within this core category constitute disembodied human capital. When human capital is embodied in physical artefacts it forms a quite different part of a firm's capital stock. The core category includes the past experience which is reflected in a person's human capital, as well as the core competencies and intangible assets of a firm. The core category includes differentiated learning-related variables. 
Human capital embodied in technology-based firms constitutes a stock of untraded and intangible assets. However, stockmarkets tend to value only tradeable and tangible assets, thereby seriously understating the valuation of technology-based firms. This in turn leads to an under-investment in them by the market. This is partly because intangible capital stocks such as knowledge and skills do not provide a form of collateral against which banks feel confident lending long-term risk finance.

The human capital core category is a key element of all case studies, and is a driver of other variables. Human capital is not only the core productive resource of a technology-based firm but also helps shape the "neighbourhood of search and selection", in the sense that the knowledge and skills of people in a firm will largely determine the bounds of its ability to externally search for and select new ideas and technologies.

This core category is at the heart of an understanding of technological innovation, because the variables it encompasses are intimately linked with other categories of variables, and they drive or substantially influence those variables.

\section{$\underline{\text { Social Processes }}$}

Social processes in innovation relate to the interplay between institutions and individuals, to the perceptions of and feelings people have towards each other, and to the social relationships and shared values that drive behaviour among people. This core category encompasses variables relating to leadership, institutional and social structures, and the role of trust, teamwork and communication in innovation.

Technological innovation requires strategic leadership to focus a firm's competencies on economic opportunities. Strategic leadership is important to innovation because it fosters long-term and integrated planning and investment. Leadership enhances stability, and learning takes place more effectively in a stable environment because of reduced transaction costs (see Langlois, 1992). Leadership involves external and internal social processes and interactions. It encompasses the dynamic management 
of external relationships, as well as fostering a sense of ownership, the internal empowerment, effective communication, and the marshalling of the skills and capabilities of people in an organisation.

The social processes in a successful, technologically innovative firm often flow from the leadership provided by a firm's founder or leader. Innovation leaders have to be disciplined, committed, hard working, and have sufficient self-esteem to overcome setbacks. They typically have exceptional self-reliance and a drive to turn ideas into practice. The knowledge that an (often patriarchal) figure is motivated by the long-run survival and growth of the business and will look after them helps shape the attitudes of staff, and from that loyalty and committed performance will flow. The perception others have of the integrity, expertise and the irreversible commitment of a leader to a value system higher than himself is fundamental to the cohesive relationships between people that are at the heart of innovation management.

To make their human capital-related assets productive, firms have to provide the institutional and social structures that foster innovation. The institutional structures for technological innovation must facilitate communication, so that tacit knowledge that could not easily be made productive in hierarchal organisations can be effectively exploited (see Child \& Bate eds., 1987). This communication yields better and more timely information but also builds team cohesion and trust, which in turn further breaks down barriers to communication and increases the receptivity to new information and ideas (see Brown \& Eisenhardt, 1995, p. 368). As an uncertain and dynamic process technological innovation is difficult to formally plan, and the expectations and evaluation of people's performance is subject to measurability problems. Transaction cost economics highlights opportunism or "self seeking with guile" as sources of transactions costs in business relationships. It is argued that detailed contracts and stringent controls are therefore needed to reduce these transaction costs (see Williamson, 1985; Hosmer, 1995).

However, it is difficult to "buy" creativity through a formal contract, to place a labour market value on tacit knowledge, to manage innovators in a hierarchal way, or to 
contract for the extraordinary and unplannable efforts often needed in innovation. As a result, new forms of management emerge that rely on informal or "implicit contracts". These implicit contracts effectively constitute shared values and understandings that allow people to predict how others will behave towards them and with each other in the absence of formal guidelines, rewards and sanctions. At the core of these implicit contracts is trust.

Bromily \& Cummings (1992) argue that trust can reduce transaction costs. Arrow (1971) laid an earlier theoretical base for this by arguing that information is most likely to be accepted and absorbed through personal contact which helps to establish trust in the reliability of information on the part of the recipient. Hirsch $(1978$, p. 78) argued that trust is a public good and necessary for the success of economic transactions. Michalos (1990) thought of trust as:

....a relatively informed attitude ...to allow oneself...to be vulnerable to harm in the interests of some perceived greater good.

Many variables within this core category reflect how people perceive and relate to each other, which in turn flows from how an individual's past behaviour gives confidence in how an individual will behave in the future. This understanding of how someone will behave creates trust. It also improves information flows that are crucial to fast moving and dynamic innovation processes. High trust and cooperative environments therefore help manage or reduce uncertainty, minimise the transaction cost problems of "guile and opportunism", foster information flows and help enhance organisational performance.

Social processes have high specificity to technological innovation because, while the early stages of technological innovation may be "thing" or artefact driven, the later stages are heavily driven by the particular social processes and interactions needed in innovation. The dynamism of technological innovation, and in particular its integrated nature and dependence on cross-functional learning, means that the key innovators must be involved all the way through and they must work as a team. Teamwork builds 
a sense of ownership which in turn is a source of motivation. Teamwork also fosters the multi-disciplinary input required throughout the innovation process, rather than disciplinary or specialised inputs being segmented in a serial, linear and "pass the baton on" process. Innovators must see themselves as part of a whole complex system and not as a segment within it, and must work as a team so that learning processes integrate all the organisation's sources of knowledge and expertise.

Case studies such as Treotek, the loin boner, and Alatal 821 demonstrate that social processes that foster trust, open communication, cooperation and mutual respect are key drivers in innovation. It is argued that effective informal relationships between people are necessary conditions of innovation, and that the best strategic planning, organisational design and contractual arrangements will fail if the social processes in innovation are dysfunctional. The personal rapport between Garth Carnaby and Bruce Munro, the empowerment vested in the MIRINZ engineers developing the loin boner, and the superb international facilitation of Andrew Revfeim with Alatal 821, demonstrate that positive and informal social interactions and processes between people are necessary conditions of technological innovation. Conversely, poor communication, low trust and strained relationships between people hampered the development of the Ruakura Milk Harvester, Peter Witehira's Powerbeat battery, and in some respects and at various stages the Greenweld innovation.

\section{Conclusions}

This chapter provided an overview of the variables generated by the research and outlined the results of the data analysis process. The data analysis process identified both the necessary and desirable conditions for successful technological innovation by uncovering categories of variables that provide explanatory insight into the technological innovation process.

The necessary conditions of technological innovation are those that constitute "core categories" of variables as identified by the data analysis process. These core 
categories express clusters of interlinked variables that are highly specific or unusually present in technological innovation, and drive or are strongly causative on it. In the absence of any one of these core categories innovations will either not be initiated, or the innovation management process will be badly handled or dysfunctional, and the benefits to society and the innovating organisation will be minimal or non-existent.

Many other variables and categories of variables generated through open and axial coding reflect desirable and positive conditions for successful technological innovation. The chance of success is maximised when all or most of the desirable conditions are present, but the absence of these desirable conditions will not always, or necessarily, greatly impede the innovation process.

In the next chapter, the results of the data analysis process are further developed into a model of the technological innovation process, and then conclusions and implications from the research are set out. 


\section{CONCLUSIONS AND IMPLICATIONS}

\section{Introduction}

The research in this thesis has sought to deepen understanding of how technological learning processes underpin and catalyse the key drivers of technological innovation. The Dynamics of Significant New Technology, Human Capital and Social Processes have been identified as core categories of variables that underly the technological innovation process and the creation of competitive advantage.

This chapter explores and further develops these core categories, elucidates the relationships between them, and then shows how they give rise to a thesis of technological innovation as a differentiated learning process. The chapter gives expression to this in a model of technological innovation, and sets out the implications of this for the theory of technological innovation, with particular reference to a small, open economy such as New Zealand. Finally, it sets out implications for business and policy managers and suggests further research.

\section{Conclusions about the Research Problem and Thesis Proposition}

Successful performance in technological innovation requires the effective strategic management of three groups of related variables: the Dynamics of Significant New Technology, Human Capital and Social Processes.

\section{Dynamics of Significant New Technology}

The key variables within the Dynamics of Significant New Technology core category relate to its non-rival nature, technical platform effects, asset specificity, irreversibility, cumulativeness and economies of scope. The major theoretical or explanatory insights into variables within this core category come from evolutionary economics, new growth theory and neo-Schumpeterianism. 
Knowledge and technology created through research and learning is often non-rival and non-excludable. It is non-rival because new ideas and new knowledge can be used in many different applications in different firms at the same time, and because one person's consumption of it does not stop another from using it. For example, the same scientific papers on kiwifruit wine making techniques were adopted and applied by several different wine makers. Knowledge is often non-excludable because it is difficult for inventors or scientists to capture the benefits for themselves and exclude others from them.

Significant new technology is associated with increasing rather than decreasing returns (see Romer, 1986). It creates technical platforms that form a basis for downstream innovation and technical change. For example, earlier plant breeding led to new apple varieties such as Gala and Splendour, which in turn laid the genetic base for the GS 2085 cultivar. Significant new technology creates competitive advantage, and the asset specificity, embedded uniqueness or intellectual property rights associated with it hamper competitive entry and allow that advantage to be sustained over time. This is illustrated in the Alatal 821 and ASDi cases, and in agritech innovations recorded in the Annex 1 Database of Innovations.

Cumulativeness and path-dependency help drive technological trajectories over time, which in turn sets the bounds and frontiers around which technological learning occurs. New technology often leads to economies of scope because learning and human capital is often generic in nature and transferable (see Dodgson \& Rothwell eds., 1994). This is reflected, for example, in the ability of technologists in Vega Industries to apply their skills to a wide range of different applications across a range of industries.

\section{$\underline{\text { Human Capital }}$}

The key variables within the Human Capital cluster are skills, including those built up through past experience, information and knowledge (both tacit and codified). Information theoretics, new growth theory, neo-Schumpeterianism, and those 
elements of evolutionary economics relating to the effects of past experience provide the major theoretical insights into the Human Capital cluster.

Human capital in the widest sense forms the key resource underpinning the creation of significant new technology and is intimately linked with it. Human capital includes formalised skills and encompasses the creativity of people in generating new ideas and concepts beyond the bounds of existing "textbook knowledge". A firm's human capital-related core competencies (see Prahalad, 1993) and its learning capabilities are inextricably linked and co-dependent. Specialised skills may be of high asset specificity and be tacit as well as codified. They can provide a difficult to replicate competitive edge that can cumulate into an enduring advantage, as illustrated by Vega's specialised tacit knowledge base in optics technology. Generic skills can underpin economies of scope and lay a platform for diversification into new products, and in some cases into new market or technological paradigms.

Information theoretics argues that information is an economic good that is quite distinct from other classes of goods (see Lamberton, 1986). Although information may be costly to produce, the marginal costs of dissemination are often so low that social efficiency may be achieved if the information is free, or at least available at very low cost. The producer of information should not therefore capture the information completely if social efficiency is to be achieved. When embodied as knowledge, information may be superseded but it does not depreciate in the same sense as a physical asset. This is because new knowledge provides a building block for further advances in understanding and the accumulation of additional knowledge.

Information is not a productive factor unless it is received, understood and embodied in new technology. Human capital and related variables are important to the absorption and embodiment of new ideas, information and technology, as well as to their creation. The economic value of information depends not only on the incentives to produce it but on the receptivity of economic agents to it. This requires learning processes to catalyse the absorption of information and its expression and application in the form of knowledge-based human capital and new technology. Low technical 
understanding at both a management and a workforce level is pervasive in many industries in New Zealand. For example, a major barrier to the widespread adoption of the Ruakura Milk Harvester was the low level of skills and human capital in the businesses involved in manufacturing the innovation and servicing it in the field.

R\&D-based human capital requires complementary assets such as manufacturing and production engineering capabilities to shape and embody it in commercialised products and processes. Without embodiment, the valuation of human capital, for example that of an R\&D lab that is a provider of research results, will always be discounted. This is illustrated by the difficulty both DieselGas and Vega had in achieving business growth when they operated largely as contract R\&D firms rather than using $R \& D$ as an input into more vertically-integrated business activities. At the same time, part of a firm's human capital should remain disembodied in the sense that a firm must retain, independently of its sales of products and processes, a technical platform of human capital that accumulates over time and can be applied generically to future product and process development.

\section{$\underline{\text { Social Processes }}$}

The key variables within the Social Processes cluster are those associated with strategic governance, interactive team learning, and the importance of trust and cooperation in the management of uncertainty over time. While most variables in this cluster are empirically rather than theoretically derived, the literature relating to the management of innovation is valuable in understanding these variables and their interrelationships.

Technological learning is a social process that is best undertaken within a strategic context. In the early stages of the DieselGas innovation, and with other innovations covered in Annex 1 such as the Powerbeat battery, learning took place too much in isolation from complementary skills, and was not given a strategic business focus. Pralahad (1993) saw a firm's competencies as “technology times governance times collective learning". However, it is probably more precise to argue that strategic 
governance encompasses the strategic directions, goals and policy framework in which a firm's competencies are made productive through focused technological learning, and through the embodiment of its outputs in new innovations.

Strategic governance has a public policy and economy-wide as well as a firm-specific dimension. Van den ven et al (1989), Dodgson (1991; 1993), and Rothwell (1991) all highlight the importance of government policy and corporate strategy in providing a governance structure to facilitate networking relationships and learning processes. The relationship between Government policy and regulatory frameworks and the firm is illustrated, for example, in the kiwifruit wine and DieselGas cases.

New technology often integrates multi-disciplinary skills and technologies from inside a firm, and from external, and often international sources. Technological innovation is therefore an interactive process that blends the diverse skills of people working together. This is highlighted in such cases as Alatal 821. New information and technology has to be rapidly interpreted and applied, because of dynamic competition, and because a complex and integrated technology will require technical inputs to be delivered on time. This has to be reflected in how people are organised to work together. As such, technological learning and innovation is essentially a social and team-based process. Team learning is essential because it is teams not individuals that are the fundamental learning unit in organisations (see Senge, 1990). Team learning accommodates and often thrives on conflict, and always requires cooperation. Cooperation depends on trust between people, which in turn is grounded in such individual behavioural traits as integrity, competence, consistency, loyalty and openness (see Butler \& Cantrell, 1984).

Innovations developed in a high trust environment such as Alatal 821 and the loin boner were commercialised far more effectively than those, such as the Ruakura Milk Harvester, developed in a low trust environment. A high trust environment empowers a team in managing dynamic processes that require constant interaction, rapid communication, parallel learning, and the ability to integrate design, $R \& D$, marketing and production engineering processes. It also demands an appropriate organisational 
structure to empower the team and create an environment in which they can deliver. This will typically involve flat management structures, cross-functionalism, devolution and empowerment. These proved effective, for example, in the FP4000 intelligent fire alarm innovation.

\section{$\underline{\text { Relationships Between Core Categories of Variables }}$}

The effective management of technological innovation requires an integrated understanding of the relationships between the Dynamics of Significant New Technology, Human Capital and Social Processes categories of variables. These core categories were analysed as set out in the Methodology chapter. The analysis aimed to identify a unifying principle or key idea across all core categories. This key idea had to be pervasive across the core categories and be an enabling or catalytic factor that made other variables productive.

The data analysis gave expression to differentiated learning processes as the key theme that interrelates the dynamics of new technology, human capital and social processes. This is illustrated in Figure 1 below:

Figure 1: Relationship Between Core Categories and Differentiated Technological Learning

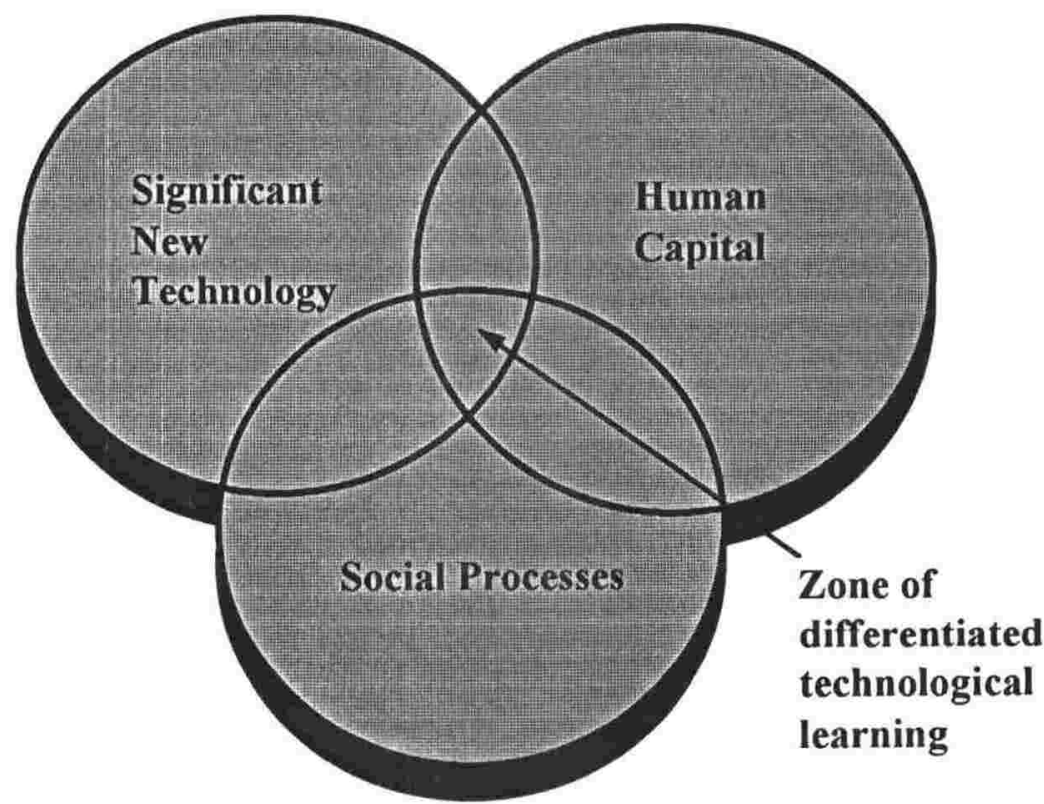


The pervasiveness of differentiated learning variables across the core categories is illustrated in Annex 5. Differentiated learning integrates and catalyses the core category and other variables and makes them productive of outcomes. The salient features of technological learning are its domain-specificity, its interactive and social nature, and its differentiation.

\section{Domain-Specificity of Learning}

A key feature of technological learning is that it is context-specific and occurs within domains. While an international pool of public knowledge exists, turning that knowledge into economic performance is a localised process. Learning develops from the neighbourhood of existing competencies and technological and market paradigms (see Cohen \& Levinthal, 1990). It involves "new combinations" that apply existing knowledge in new ways.

Learning is not confined to absorption or adaptation of the known and understood but is also a creative process that encompasses the imaginative endeavours of individuals and teams. However, even path-breaking, creative learning still builds from antecedents and is shaped by its domain. The limits of the domain in which learning can occur are set by the human capital and the competencies within an organisation and by its external interactions and sources of stimuli. This domain is broadly analogous to the Nelson \& Winter (1982) concept of a search and selection environment. The outer limit of the domain is analogous to the outer rim of a neoclassical production possibility frontier.

\section{Interactive and Social Nature of Learning}

Learning is an interactive and social process in the sense that people learn by interacting with each other rather than in isolation. Learning involves internal and external interactions, and a creative tension between cooperation, competition and challenge. Just as individuals work in teams and in networks, firms also learn through networking and other group or collective learning strategies. Networks between 
firms seem to emerge to maximise information flows and knowledge exchange, not to minimise transaction costs. Firms use networks to access external technology, or to externalise some of their activities without losing control of their core competencies or intangible assets.

Interactive learning occurs at the level of a firm and of a national innovation system (see Lundvall ed., 1992; Nelson ed., 1993). While an innovative firm is a search, selection and learning organisation, a national innovation system is a learning system writ large; different in scale and complexity to that of a firm, but not radically different in purpose. A national system of innovation involves many points of domestic and international interaction between a country's technostructure and firms, and among firms. The rate of technical (and in fact cultural and social) change in a country is to a great extent driven by the extent to which a society is interacting with others, and by its openness to new and international ideas. It is important that learning requires contrast, challenge, and lateral and orthogonal thinking, and this implies that learning will be enhanced by a strong external focus, cultural diversity and competing paradigms. It is argued that the rate and effectiveness of learning is not determined by the scale of the learning effort but also by the extent to which it involves different sets of ideas and new challenges.

\section{Differentiated Nature of Learning}

Learning is differentiated by its domain, by the type and source of learning, and by such variables as the type of firm, the industry sector, and the scientific and technological base.

The type and sources of learning include, inter alia, R\&D, formally structured learning in a "classroom" setting, learning by doing, learning by using, from failure, and from interactions with external customers, suppliers, other firms and from research institutes. Firms allocate resources to create firm-specific competencies using the above learning processes, and they exploit constant feedback from improved knowledge and experience. 
Cimoli \& Dosi (1995) highlight how learning is differentiated by the type of firm, comparing, for example, Korean Chaebol with networks of small and medium-sized firms in Taiwan. Florida \& Kenney (1990) compare learning in small Italian fashion firms with that of Silicon Valley microelectronics firms. Pavitt (in Dodgson \& Rothwell eds., 1994) notes as distinguishing marks of learning activities in larger firms its specificity, cumulativeness over time, tacitness of knowledge built up through experience, and its highly differentiated nature. Information channels for large firms often need to address weaknesses in internal information flows, while smaller firms need to focus more on external information flows. This can be illustrated when the experience of the Dairy Board with the Alatal 821 innovation is contrasted with that of Vega with its lighthouse beacon. Learning in firms of all sizes is not a process of acquiring codified knowledge and buying technology "off a shelf" but rather depends on firms actively extending and applying their knowledge and competencies that have been built up cumulatively and path-dependently over time.

Innovations both in the case studies and in the Annex 1 Database of Innovations illustrate how the sources of learning differ according to industry sector. The Greenweld case shows how sawmilling firms more readily adopt new technology from adhesives suppliers than directly from an R\&D institute. While sheep farmers, for example, adopt new forage plants from research institutes, the pig and poultry sectors rely largely on feed suppliers and veterinarians as sources of new technology.

The source of learning will also differ according to the science and technology base and how it is changing. The pharmaceutical industry is increasingly relying on basic, university research to underpin its new product development. In recent years New Zealand's dairy and forest industries have invested substantially in strategic research to extend the knowledge base underpinning their industry strategies. New technologies such as biotechnology, advanced new materials, and information technology have been shown in studies to increase the dependence of technology on science and to enhance the importance of external networks for innovative success (Freeman, 1994, p. 470). 


\section{Implications for Theory}

It is important to elucidate how the core category variables and differentiated learning processes fit together, interrelate and become productive in the innovation process. The "learning" of existing knowledge by itself is not innovation. Innovation requires active creativity to generate new ideas, and the integrated management of a host of other variables. The thesis of differentiated technological learning being at the heart of innovation therefore needs to be placed in the wider and more systemic context of a model. This enables learning and the core category variables to be integrated with subsidiary (but still desirable) variables that impact on the technological innovation process. The model of technological innovation advanced in this thesis is illustrated in Figure 2 below:

Figure 2: A Model of Technological Innovation

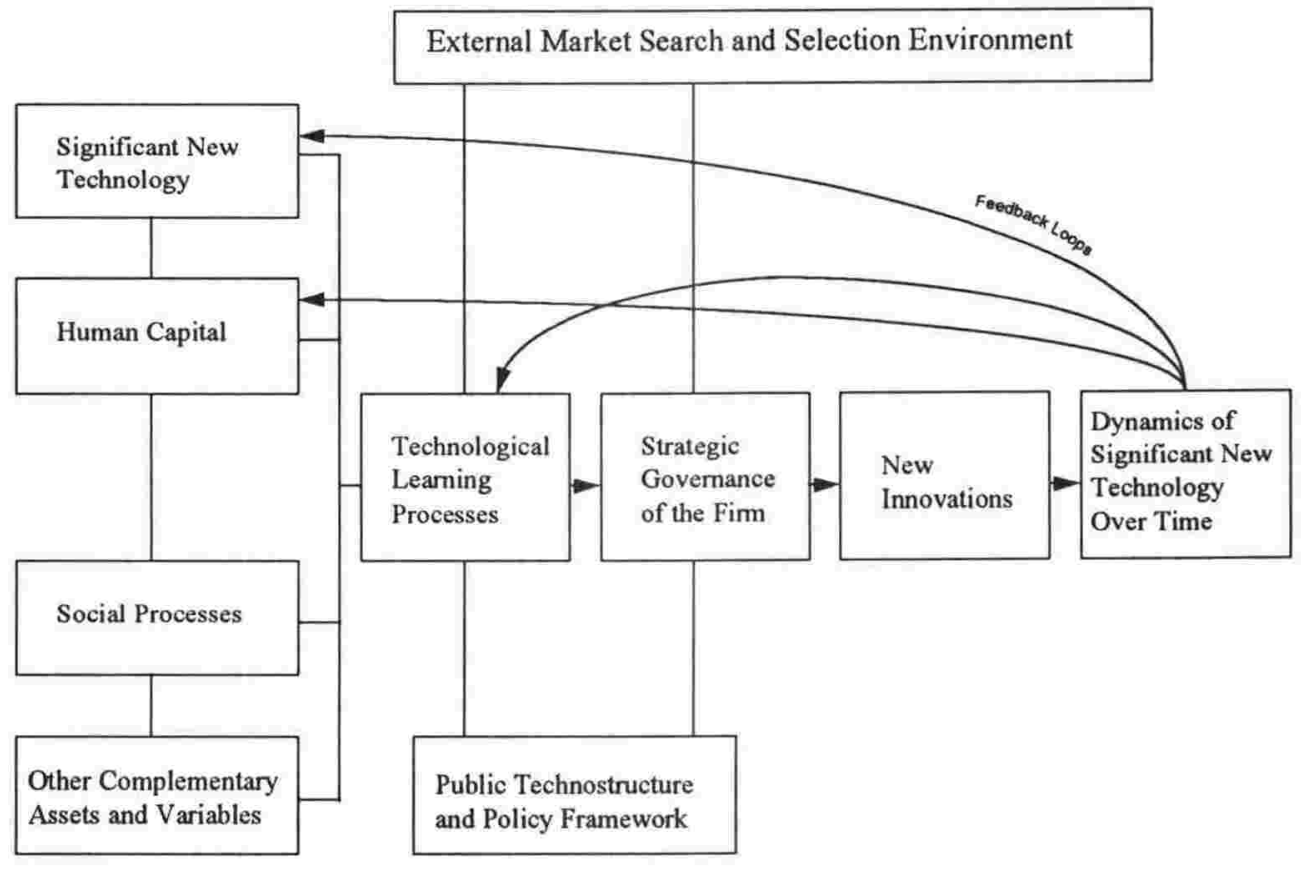

The model effectively argues that the core categories encompass the necessary conditions of technological innovation. These conditions are made productive through technological learning processes that exploit existing human capital and create new human capital, which in turn forms the basis for significant new 
technology. The learning processes are differentiated, interactive and social processes. They do not occur in isolation but are managed within the strategic governance of a firm. This strategic governance encompasses the firm's links with the wider economic and policy framework in an economy and the national system of innovation. It encompasses the firm's strategic leadership and the management of its external relationships and interactions.

Learning and innovation occurs along a technological possibility frontier. The world's technological possibility frontier is determined by humanity's total scientific and technological knowledge base, the outer limits of which set the bounds around which technological innovation can occur. A firm's technological possibility frontier depends on such factors as the national innovation system within an economy and a firm's market and technological paradigms, human capital and strategic governance. Inside its technological possibility frontier are a firm's existing and understood products, processes, services and competencies; the "known and understood", while outside lies the unknown realm of potential new technologies and new economic opportunities. Firms search their immediate external neighbourhood for new ideas and markets. They also undertake research to create new knowledge that shifts their technological possibility frontier outwards, or which illuminate new neighbourhoods of search. This interaction with the "neighbourhood" or external selection environment will, with a firm's own competencies, create the intellectual and technological diversity, new ideas and stimuli that determine the innovative possibilities of firms.

The frontiers of New Zealand firms are very differentiated, and as part of a small, open economy New Zealand firms rely heavily on international as well as domestic influences. Government policy helps shape the national system of innovation which encompasses research, search and learning institutions, and creates networks with the international body of knowledge and technology. A national innovation system has many nodes, networks and links between the public technostructure and firms, and has both a domestic and an international dimension (see Nelson ed., 1993). 
Because learning processes occur within domains, firms need direction and a purposeful focus for their search and learning strategies. Technology managers must therefore synthesise a host of variables within a strategic governance framework and achieve "strategic fit" between them and external market opportunities. The strategic governance of a firm relates specific innovative activities to the "big picture" of the firm's competitive strategy, and provides a set of "compass bearings" that allows interactive learning processes to be given a strategic focus. More subtly, strategic governance helps combine and reconcile the competing value systems associated with the competitive behaviour of firms and the more cooperative environment that fosters interactive learning. Because the process of embodiment of knowledge is dynamic, long-term and systems-based strategic governance is required to integrate multiple inputs, ideas and technologies into a systemic whole. Systems learning and strategic governance are therefore closely related, and are necessary conditions of much technological innovation.

Domestic and international customers are both sources of stimulus for technological innovation. Where domestic customers are at an international standard and are highly discriminating, and where the demand they create is a microcosm of the world market, then firms learning from interactions with these customers can create a competitive advantage internationally. Because firms learn from each other, clusters of related industries and firms in a domestic economy can be a key success factor in technological learning and competitive advantage (see Porter, 1990). However, globalisation of world trade and the exceptional importance of international markets and technologies to small, open economies means that countries such as New Zealand need to be increasingly outward-looking.

The initial output of research and other creative activity is disembodied information which in turn can be regarded as a form of human capital. However information, whether in the form of a scientific publication, a dataset, or an idea does not become a knowledge-based form of human capital until it is absorbed, interpreted and understood. Differentiated learning processes are the catalysts through which information is turned into a knowledge form of human capital. A key constraint to 
innovation in New Zealand occurs on the absorptive side in industry where, because of a lack of human capital, information is inadequately understood and applied. While $\mathrm{R} \& \mathrm{D}$ is only one form of learning, it not only creates new knowledge but also builds up a firm's human capital and web of interactions needed to assimilate and exploit existing knowledge from external sources (see Cohen \& Levinthal, 1989).

When information becomes knowledge it is still initially a disembodied form of human capital. This knowledge may be very specialised or may involve indivisibilities in learning and give rise to economies of scope and generic applications (see Dosi, 1988). Through technological innovation human capital then becomes productive when it is embodied in new products, processes or services. When human capital is embodied, the dynamics of significant new technology induce further learning processes and help shape the course of further human capital development and pathways of learning. Knowledge, human capital and complementary assets such as design, marketing and production technology inputs are therefore synthesised by social processes into new and advanced forms of human capital and significant new technology. Social processes are really the informal structures and people relationships that provide a framework for learning, and therefore for human capital creation, to occur. And underlying social processes are individuals whose creativity, commitment and motivations are key drivers, but whose abilities need to be harnessed through team-based and social processes to deliver innovative outcomes.

The outputs of the innovation process are new products and processes delivering new functional properties and performance characteristics. These products and processes produce more output with fixed inputs, include non-rival technology, create technical platforms for future innovation, and shift the technological possibility frontier outwards, thus making long-run economic growth possible. These products and processes embody sufficient asset specificity, embedded uniqueness, or other barriers to competitive entry to allow a firm to earn premiums and a stream of profits that can finance future innovation, which in turn can shift the technological possibility frontier further outwards. 
Because of non-rivalry, technical platform effects, the "leakiness" of intellectual property, and incomplete appropriability, significant new technology delivers social returns beyond those that can be privately captured. Investment in such technology may therefore be irrational from the point of view of the privately appropriable gains that can be captured in the short-term. However, the innovation leader often has a value system higher than his narrow material interests and will give expression to it in his behaviour and in his ability to articulate and communicate a vision. The attitudes, values and vision of an innovation leader will be permeated in an organisation and be perceived by others in an innovation team, who then subsume their individual interests into that of the wider group. This then makes teamwork and the "extra mile" demanded in innovation possible, since the team as a whole focuses to a significant extent on collective goals and values higher than themselves.

\section{Implications for Business Managers}

The implications of this thesis for business managers centre on the importance of technological innovation to creating competitive advantage. To create competitive advantage through technological innovation managers must address the firm's strategy, structure, and ownership, human capital-related assets, social processes, and technological learning strategies.

\section{Strategy, Structure and Ownership of the Firm}

Technological innovation is the key to creating a competitive advantage for a firm because it allows firms to earn premiums through new products, processes and services with improved functional properties and performance characteristics. Technological innovation must form part of a wider business strategy that aims to create and sustain competitive advantage in the market. Innovation does not finish with a product launch but requires ongoing servicing to sustain that product and the competitive edge that it embodies in the market. Firms must therefore strategically 
manage innovation as a core part of business strategy and as a continuous process over time.

Significant new technological innovations allow competitive advantage to be sustained over time because they draw on skills and technology that can only be built up over time, and because such innovations are difficult for competitors to imitate. Managers need to recognise that technological innovation is a cumulative investment that requires a long-term focus within a tightly defined market or set of technological competencies. For New Zealand firms this often involves competing in niche markets that are too small to attract competition from major overseas corporations, but where the technology is specialised and difficult for others to imitate. These markets often require customised tailoring of the technology to users and flexible production runs.

Successful commercialisation requires that firms must not only be able to create, exploit or extend ideas and technologies, but also embody them in new products, processes or services that are traded. Firms that are essentially R\&D laboratories are rarely successful in growing through technological innovation. While they can create knowledge they lack the complementary and downstream assets to fully embody it, and to prototype, trial and commercialise new innovations. Above all, they lack the ability to earn premiums and capture the commercial benefits of innovation through control over production, branding, marketing, distribution, and intellectual property protection.

Technological innovation requires strategic management that encompasses interactions between the firm and its external environment and the strategic fit between external opportunities and the in-house competencies of the firm. Technological innovation requires the strategic integration of internal and external knowledge, skills and competencies, typically involving cross-functional project management, and embedding design, R\&D, quality management and distribution and servicing considerations in the innovation process. 
Firms must have a long-term outlook grounded in a clear strategic vision and value system, and be willing to sacrifice short-term returns to achieve long-term gains. There must be a strong strategic fit between a firm or innovator's value system and motivations, the innovations aimed for, and organisational ownership and structure.

Innovative firms should have an institutional framework based around a longer term competitive strategy and the ability to vertically integrate so that it can innovate, manufacture, market, distribute and service, and allow it to capture the benefits of innovation. Private ownership of firms, or unlisted public businesses owned by shareholders with long term innovation-oriented goals and value systems, lends itself to success in innovation. Listed public businesses will typically be able to mobilise the capital needed for larger scale and more ambitious innovations, but their innovative performance will often be severely constrained by shareholder demands for annual dividends, and by the unwieldiness of many large-scale bureaucracies.

Innovative firms will in many cases be New Zealand-owned and controlled. Subsidiaries of overseas-owned firms in New Zealand will often be marketing and distribution agencies, or involved in adaptations to existing product lines. Rarely will overseas-owned businesses have a significant R\&D and innovative capacity located fully onshore in New Zealand. A New Zealand-owned firm that controls its long-term vision and strategy and locates its R\&D effort within New Zealand will be well positioned to vertically integrate, exercise control over its marketing and distribution, and create barriers to competitors eroding its innovation-based premiums. It will also tend to create positive externalities for the domestic economy in the form of knowledge and human capital creation that leads to benefits wider than the firm.

\section{Human Capital-Related Assets in the Firm}

The key asset base of a firm is its human capital. Skills and knowledge are needed for innovation within the firm, to search for, interpret and adopt external sources of ideas and new technology, and they are at the heart of a firm's competencies in technological learning and knowledge application. 
A firm needs staff at all levels with a high degree of scientific and technological competency. These competencies will include both generic skills and those more specialised to the firm's core business, and will encompass codified and tacit knowledge and the skills and know-how that comes from past experience in other firms, and in many cases, other industries and countries.

Firms need the ability to integrate multi-disciplinary skills within a strategic framework that focuses those skills on technological and commercial opportunities. Firms also need the strategic management that allows their competencies to be applied to long-term opportunities in conditions of uncertainty, and the business management competencies to ensure the fit between technological opportunity and economic and commercial reality.

A firm needs the ability to produce tangible samples of products or prototypes internally, and this implies not only in-house engineering and production and instrumentation equipment but a "technical toolbox" of such skills as objective measurement techniques and tooling technology. A firm's strengths in product innovation will be complemented by substantial investments in enhancing the production technology and total quality management needed to get per unit costs down and quality standards up.

Firms need to decide what skills and competencies must be maintained within the firm and what should be accessed externally. All firms make use of external sources of learning (see Kleinknecht \& Reijnen, 1992). Where a firm lacks a required internal skill or knowledge base it will depend heavily on external sources (Senker \& Faulkner, 1992). A firm should maintain internally a broad based and multidisciplinary skill base, but with strong core competencies clustered around its key technologies and markets. These core competencies will interact with and complement each other, and allow economies of scope to be created and exploited. Core competencies will include tacit and uncodified knowledge that is difficult for competitors to replicate and which therefore allows differentiation and the earning of premiums. A firm should also have the staff continuity and in-house learning 
processes that will allow core competencies to be communicated over time. Firms will maintain a tight focus within their technological and market paradigm and diversify only from the building block of that paradigm.

At the same time a firm will have strong "learning to learn" abilities, and be able to forecast and create competencies in new technologies that will be important in the future. Typically this will require external networking and interactions, and the ability to draw on external sources of ideas, technology and specialised skills that it would not be feasible to internalise. Firms should also be able to track and interpret changes in the external scientific, technological and market dynamics that are important to their business and be flexible enough to adapt to them.

A firm should recognise the long-term and cumulative nature of the development of human capital-related competencies, and that generic and more specialised technologies should be managed differently. Generic competencies in a firm and competencies related to homogeneous industries and to volume or commodity markets can be mobile through a range of different organisations. This mobility can be an effective means of facilitating the adoption of new technology. However, firms will also recognise that there are very specialised competencies needed in differentiated markets that should be centralised and allowed to cumulate and be retained in a firm over a long time-frame. Firms must also recognise the dependence of innovation on past R\&D and cumulative competencies which lay a technical platform for further innovation. They should recognise that innovation must be continuous, that one innovation will often give rise to new ones, and that innovations should be designed with the "flexible architecture" and "robust designs" that allow later redevelopments and downstream innovations.

\section{$\underline{\text { Social Processes within the Firm }}$}

To create competitive advantage, managers must ensure that the organisational structure, leadership, team-based project management and the people relationships are 
in place that will foster the social processes needed for effective technological innovation.

An innovative firm should have an organisational structure that is suited to the dynamic, adaptive, integrative and information-intensive nature of technological innovation. The firm should have a flat organisational structure with substantial devolution to cross-functional project teams that include the research, design, engineering and marketing functions, As far as possible, firms should be vertically integrated to enhance information flows through the marketing, distribution, production, design, R\&D and other links in a firm's value chain. These information flows should facilitate interactive learning by the firm from both external and internal sources.

Leadership is needed for the effective management of innovation. A firm must ensure that innovative projects are led by a top-level sponsor or product champion such as a chief executive or other senior figure. This innovation leader must be effective at lobbying for resources, managing external relationships, and protecting the project team from undue external interference. He will have the overarching responsibility, power, autonomy and financial resources to carry a project through to successful commercialisation.

The innovation leader's behaviour must set a standard for the team by focusing on higher order innovation goals. An innovation leader must understand his innermost nature, values and motivations and act in accord with them. Innovation leadership rests on reputation that both results from and perpetuates the trust needed in innovation. The innovation leader should have a reputation and mana that builds trust. This emboldens the commitment of others by countering the uncertainty and potential for personal loss that is otherwise associated with demanding innovation processes. Innovation leaders need a complete overview of the innovation project. Their commitment to the project will involve their own irreversible investment and personal risk, and their belief in it will build confidence and create enthusiasm in those around them. 
Teamwork in innovation is vital to facilitate the cross-functional integration of different skills, technologies and learning processes around a common innovation goal. Teams should be organised so that all the key sources of knowledge and expertise needed for the successful development, commercialisation, marketing and servicing of the innovation are represented on the team. The team members must be empowered to provide their specialised knowledge and expertise interactively throughout the innovation process. For example, it is unacceptable for a technologist to develop a product in isolation, only to find later from an engineer that it is too expensive to produce, or from a service technician that it is impossible to service in the field. This means that input from all key team members should be provided in parallel, so that interactive learning occurs in real-time and is integrated and woven together throughout the innovation process.

Teams need strong and unambiguous project management. Project teams should have discretionary resources or seed funds at the early stages of an innovation, and funds for trialing and problem solving at a more advanced stage. Teams need to be adaptive and flexible and have the ability to respond dynamically to the different challenges posed throughout the innovation process. While key strategic decisions in innovation must be made early, researchers and project teams need tactical discretion to change direction as circumstances require. They must not be too constrained by rigid contracts or immutable project plans.

Innovation teams should be made up of people who can work effectively together and complement each other. All the key players in the innovation should be involved early in the innovation process and continue their involvement all the way through, whether they be the team members within the firm, suppliers, customers, or key people involved in other firms or institutes. For example, customers and suppliers should provide key input into an innovation before specifications are locked in, and they should be involved in trialing at an advanced stage. Scientists and technologists involved in technical work early in the process should continue to be involved right through to trialing, fine-tuning, marketing and servicing in the field. 
Innovation demands respect and trust between all those involved in the innovation process. In respecting and trusting each other people involved in innovation will listen to and draw on the advice and perspectives of others. Communication must be completely open and timely throughout the innovation process. This in turn will foster a sense of ownership by people in an innovation process and its outcomes. Open communication and ownership must be present at all levels in an organisation. Top management ownership without support from less senior staff is as self-defeating as intrapreneurship within an organisation that founders due to the lack of top-level support.

\section{$\underline{\text { Technological Learning Strategies }}$}

Learning is critical to both technological innovation and to the ongoing renewal and upgrading that is needed to stay in business in the long term.

Accelerating the rate and effectiveness of learning requires managers to recognise that learning processes are not generic across all types of firms, industries or technologies, but are differentiated and need to be tailored accordingly. While R\&D is only one form of learning, in most cases firms should have a strong in-house R\&D capability. However, in many cases this R\&D capability will be more focused on allowing firms to search for, interpret and adopt external (including international) sources of ideas and technologies rather than on in-house product and process development per se. Managers must ensure that the necessary conditions of technological innovation relating to the dynamics of significant new technology, human capital and social processes are effectively marshalled, and that the type and form of learning occurs within a domain, rather than through, for example, "blue skies" research or random information collection.

To create a competitive advantage a firm must achieve a congruence between its existing core competencies and the ability to apply them interactively to external opportunities. A key element in this will be learning based on external interactions at both the domestic and international levels. Hakannsson (1989) and Porter (1990) 
argue that domestic market competition is a critical stimulus to innovation and business performance. However, for small open economies such as New Zealand the export and international markets are key sources of technological learning and market opportunity, and this is borne out in case studies such as the ASDi, Greenweld and Treotek.

A firm should therefore treat the international environment as a source of markets and above all of the world's stock of ideas, basic scientific knowledge and technologies that help enrich the firm's selection environment. The limits of the selection environment for the firm should be on the outer edge of the technological possibility frontier of best-practice firms competing in similar markets internationally. Firms must network internationally to access new ideas, markets and sources of technology and to exploit complementary skill-bases. A firm must aim at achieving a good understanding of the international knowledge and technology available in a field. This should not be restricted to a passive or desk-bound search for codified knowledge but should involve interaction and active learning from users, customers and suppliers.

These interactions and learning processes must be at several levels, with production engineers, designers and R\&D staff as well as marketers interacting with customers and suppliers and informing their efforts with an awareness of their needs. The interaction between firms, research institutes and the market should be based on a shared level of technical understanding, and this may require "educating the customers or the providers". Customer interaction can, for example, involve technically demanding lead users forcing a "ratcheting up" of the performance standards of the firm and its technology, and acting as prestigious "flagships" for the business. A firm needs the ability to verify to external parties its quality and performance standards by meeting or exceeding ISO and other objective quality standards.

A firm must aim to deliver what the customer wants, and in some cases anticipate future needs. This may involve anticipating a future customer need for a technology that is "on the shelf" but whose time is yet to come. This requires a focus on the fitness for purpose of a technology, and a tight strategic fit between the innovation 
and customer needs. This in turn normally means that an innovation must aim to do one quite narrow, specific and tangible thing, not aim at the grandiose "revolutionisation of a whole industry".

Firms need to exercise leverage over key parts of their external environment, for example by vertical integration, controlling their marketing and distribution, and avoiding distributors who are also marketing competing product lines. Firms need to capture the benefits of their innovation through embedding uniqueness or difficult to imitate technical features in them, by influencing technical and regulatory standards, staying ahead of the competition through continuous improvement and innovation, and through branding, intellectual property protection and other strategies.

A firm's ability to interpret and exploit external sources of stimulus, ideas and technologies is shaped by its in-house competencies and knowledge bases. However, an innovative firm should ensure that the evolution of its in-house competencies and attitudes will be driven by the long-term needs and opportunities of the external environment rather than by the defensive protection of its internal capabilities. While the technology base of an innovative firm should be at the core of its business strategy and be its key competitive weapon, the technology base must always be a means of fulfilling the overarching vision or mission of the firm, not its raison d'etre. An innovative firm must constantly expose its technology base to pressures to evolve. This may be through the recruitment of new technologists, often from outside the industry, links with sources of new ideas and stimulus, accessing new forms of human capital, and active networking.

Networks between firms encompass partnerships, joint ventures, and many other forms of shared or collective learning relationships. Japan's ability to catch up with and finally outstrip Western competitors in the post-World War II period resulted to a great extent from the emergence of interrelated networks in Japan, which far more efficiently use information flows than would be achievable through the competitive strategies of firms acting in isolation. These interrelated networks were complemented by horizontal information flows, interactions with external users, 
organisational and management innovations such as JT, concurrent engineering, long-term equity, and cooperation between government and industry.

Managers therefore need to develop learning strategies for the individual firm and also strategies that allow the firm to access external ideas and technology and to network with other businesses and institutes to exploit collective learning opportunities. In an economy such as New Zealand, this should have a strong international focus, but firms should also form part of domestic clusters to allow access to complementary skills, shared generic technology bases, and specialised production technology. These clusters will include public research institutes, universities and polytechnics that help stretch the frontiers around the firm, inject new ideas, and provide a stream of human capital.

\section{Implications for Policy Managers}

The importance of technological learning to a country's economic performance is fundamental, and Fagerberg (1995) argues that a country's long-run competitive advantage will be in areas where its rate of learning is higher than that of competing countries. Arising from the research in this thesis are the following more specific implications for policy managers:

\section{International Trade, Technological and Market Environment}

Innovative countries and firms should be outward-looking and international in focus. For countries, active engagement in international trade, a willingness to learn from other countries, and a technostructure linked into overseas sources of science and technology is critical.

Innovation in a country will be fostered by an outward-looking trade policy, primarily because it accelerates the rate of learning at the level of the firm. An outward-looking trade policy allows innovators to exploit international sources of science, technology 
and new ideas, expanding the selection environment or "neighbourhood of opportunity" from which they can draw ideas, and thereby exploit a wider choice of technological and market opportunities. The international economy also raises the sights and stretches the frontiers of innovative firms because they and their innovations are judged by the highest or best-practice world standards rather than by the standards of the domestic market.

A firm's interaction with international customers and sources of technology will be essential to the continuous enhancement of its performance. Because of the fundamental importance of externally-driven technological learning, it is argued that these international learning interactions are more important to firms than the vigorous domestic competition and the interactions within industry clusters highlighted by Porter (1990).

This does not imply a total reliance on international competition or a completely open trade policy. Open trade policies can hamper the emergence of start-up businesses which cannot initially compete against imported products from overseas competitors. The difficulties faced by start-up and emerging firms need to be addressed by a supportive domestic environment and targeted microeconomic interventions. These policies will deliver support in the form of intangible assets such as human capital, knowledge and advisory services, assistance in overseas marketing, supplemented by public agencies acting as "demand side" leading-edge purchasers of technology-based products. These policies will encourage the start-up and emergence of firms to the stage where they are generating the cashflow and have the products on the market that can form a basis for future growth and export performance.

In the recent Uruguay GATT round the TRIPS (Trade Related Intellectual Property) agreement aimed to tighten up intellectual property protection. The increasingly restrictive approach to intellectual property protection has significant implications for small, open trading economies in the future, and could imply a need for active government interventions to access overseas technology and intellectual property. 


\section{Domestic Economic, Policy and Cultural Environment}

Macroeconomic stability and conservative fiscal policies will increase stability and reduce the uncertainty in which firms operate. This will assist innovative firms that already face high technological uncertainty. Low real interest rates and high domestic savings rates will assist the venture financing of technology-based businesses, and a neutral or positive tax treatment for $R \& D$ and other innovative investments will also foster innovation. Macroeconomic stability should be complemented by microeconomic flexibility and workplace reform. Labour market flexibility should be a core part of this, but with a focus on the workforce being a resource to develop and make flexible, multi-skilled and productive rather than being a cost to minimise.

Small firms are to a great extent dependent for their learning on external sources of ideas and on links with other firms. Therefore, a country such as New Zealand with an industry structure dominated by small firms is exceptionally dependent on networks between firms, and links between firms and the public technostructure. These should be actively fostered.

Innovation will be encouraged by a cultural environment that fosters achievement, entrepreneurship and risk taking. This supportive environment may include businesslinked entrepreneurship programmes from school level on, sponsored awards and honours for innovators, and high prestige being accorded to technological innovators. Innovation will also be fostered by a high trust business environment and a low tolerance for fraud, misappropriation of funds, breach of tacit and unwritten codes of conduct, and other business behaviour that erodes the trusting relationships that are crucial for innovation.

\section{Public Technostructure}

The public technostructure of educational, research, property rights and technical institutions forms a systemic part of a country's national system of innovation. It therefore helps underpin a country's ability to learn and innovate, and helps provide or 
foster those intangible assets that are not created by the free workings of markets. Key contributions of the public technostructure will therefore be the intangible assets resulting from human capital creation and R\&D.

Human capital creation at all levels of an economy is a fundamental condition of technological innovation. Countries should invest heavily in education throughout all age groups and produce large numbers of science, engineering and technology graduates from universities and polytechnics. The education and training system should foster a spirit of enquiry and a critical questioning of incumbent ideas and ways of doing things. Education and training should be imbued in people as a lifetime habit, not treated as a one-off investment early in life. Human capital should be mobile between and among the public research and technological infrastructure and firms, and in the international and domestic economies. The quality, quantity and mobility of this human capital, and its location within strategic governance structures that can focus it and make it productive, will be recognised as of the highest importance to a country's economic performance.

Publicly-funded R\&D creates the "co-produced goods" of human capital and knowledge. Many studies suggest that the main economic benefits of more basic publicly-funded research result from the creation of skills, human capital and networks rather than from the creation of published scientific results (see Irvine \& Martin, 1980; Nelson \& Levin, 1986; Pavitt, 1991; Rosenberg \& Nelson, 1992; Senker \& Faulkner, 1992).

Publicly-funded R\&D needs to be undertaken within domains in which a country has, or can create a competitive advantage. Research institutes conducting this research should have an intimate knowledge of the industry serviced, commercial powers and structures, and the ability to present to industry comprehensive and integrated technology packages rather than "disembodied ideas". Links between researchers and industry should be interactive and exploit two-way learning processes. 
Publicly-funded R\&D should also link into and exploit R\&D and technological development undertaken overseas. Public investment in research and in technostructure is partly designed to buy entry into international networks that feed into, augment, and exercise a multiplier effect on domestic research and technological competencies. R\&D is therefore essential to reduce transaction costs at a country as well as a firm level, to reduce $R \& D$ redundancy, and to better exploit overseas sources of ideas and technologies. Overseas and domestic R\&D are complements and not substitutes, and the interaction between them is synergistic and involves economies of scope rather than being additive. As Coe \& Helpman (1993, p. 1) point out:

..own [domestic] R\&D enhances a country's benefits from foreign technical advances, and the better a country takes advantage of technological advances in the rest of the world the more productive it becomes.

The public R\&D effort also interacts synergistically with that of the private sector. Leyden \& Link (1991, p. 1680) argue that:

...governmental R\&D directly stimulates private R\&D. Moreover, governmental R\&D also stimulates sharing [of information], which in turn stimulates private R\&D.

Leyden et al (1989) argue that governmental R\&D not only stimulates private sector R\&D but also spurs industry $R \& D$ laboratories towards greater sharing of their innovation-related knowledge. Networking and porous boundaries between public research institutes and firms, and mobility of people between public research, educational and other institutes and the business sector, therefore needs to be strongly encouraged to enhance interactive learning and the diffusion of knowledge and human capital throughout the economy. 


\section{Further Research}

This thesis has argued that differentiated learning is at the heart of technological innovation. Further research could well develop a taxonomy of differentiated learning in the New Zealand economy, encompassing the type and source of learning, characteristics of industries including firm size and market structure, and the nature and dynamics of technology. This taxonomy could allow policy and business managers to better tailor their interventions, $R \& D$, search and learning strategies to the particular features of different firms and industry groups.

\section{Conclusion}

This chapter summarised the results of the thesis and gave expression to them in the form of a model of technological innovation. The chapter set out the implications of this thesis for business and for policy managers, and then made suggestions for further research. 


\section{ANNEX 1: DATABASE OF INNOVATIONS}

\section{Introduction}

The database of innovations from 1981-1993 was assembled by the author primarily by scanning a very comprehensive number of trade journals and other literature. The major sources are listed in Annex 1.1 of this Annex. The "raw database" recorded the name (descriptive title) of the innovation, the brand name (if applicable), a short description, and the reference citation. In most cases the raw database recorded basic information on the innovating organisation, when the innovation was launched on the market, and in some cases, information such as on patenting of the innovation. A more in-depth understanding of many of the innovations was obtained from the written literature on the innovations, and from other enquiries made directly to relevant firms and innovators.

The innovations for in-depth case study were selected from this database using the criteria set out in the Methodology chapter. The database was used only as a basis to select innovations for detailed case study and no attempt was made by the author to further classify or analyse the database. However, on her request, the database was made available to a masterate student in economics, Wilhelmina Eveleens. Acknowledgment of this assistance is recorded in Annex 1.2 attached. Wilhelmina classified the data on a sectoral basis and the results of her work are recorded in Tables $\mathrm{A} 1$ and $\mathrm{A} 2$ below.

\section{Classification of the Innovations}

The database of innovations was, as far as possible, classified using the NZSIC sectoral codes, covering both where the innovation was produced and the main sector of use. Difficulties in the classification of innovations between sectors are discussed in Eveleens (1995). The sectoral distribution of the innovations is set out in Table A1 below: 
Table A1: Sectoral Distribution of New Zealand Innovations 1981-1993

Sector (NZSIC)

\begin{tabular}{|c|c|c|c|c|}
\hline \multirow[t]{2}{*}{ 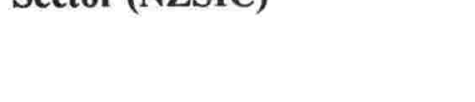 } & \multicolumn{2}{|c|}{ Production } & \multicolumn{2}{|c|}{ Usage } \\
\hline & Number & Percent & Number & Percent \\
\hline Agriculture and Hunting & 117 & 7.3 & 381 & 23.8 \\
\hline Forestry and Logging & 1 & - & 24 & 1.5 \\
\hline Fishing & 2 & - & 15 & 0.9 \\
\hline Mining and Quarrying & 1 & - & 8 & 0.5 \\
\hline Food, Beverage, Tobacco & 63 & 3.9 & 235 & 14.7 \\
\hline Textile, Apparel, Leather & 26 & 1.6 & 72 & 4.5 \\
\hline $\begin{array}{l}\text { Wood processing and } \\
\text { wood manufacturing }\end{array}$ & 13 & 0.8 & 45 & 2.8 \\
\hline $\begin{array}{l}\text { Manufacture of Paper } \\
\text { and Paper Products }\end{array}$ & 6 & 0.4 & 12 & 0.8 \\
\hline $\begin{array}{l}\text { Manufacture of Chemicals } \\
\text { and Chemical Products }\end{array}$ & 179 & 11.2 & 32 & 2.0 \\
\hline $\begin{array}{l}\text { Concrete, Clay, Glass, } \\
\text { Plaster, Masonry, Asbestos } \\
\text { and related Mineral Products }\end{array}$ & 14 & 0.9 & 4 & 0.3 \\
\hline Basic Metal Industries & 7 & 0.4 & 6 & 0.4 \\
\hline $\begin{array}{l}\text { Manufacture of Fabricated } \\
\text { Metal Products, Machinery } \\
\text { and Equipment }\end{array}$ & 1005 & 62.9 & 218 & 13.63 \\
\hline Electricity, Gas and Water & 0 & - & 12 & 0.8 \\
\hline Construction & 2 & 0.1 & 54 & 3.4 \\
\hline $\begin{array}{l}\text { Wholesale and Retail Trade, } \\
\text { Restaurants and Hotels }\end{array}$ & 0 & - & 32 & 2.0 \\
\hline $\begin{array}{l}\text { Transport, Storage and } \\
\text { Communications }\end{array}$ & 3 & 0.2 & 54 & 3.4 \\
\hline $\begin{array}{l}\text { Business and Financial } \\
\text { Services }\end{array}$ & 160 & 10 & 38 & 2.4 \\
\hline $\begin{array}{l}\text { Community, Social and } \\
\text { Personal Services }\end{array}$ & 0 & - & 166 & 10.4 \\
\hline No details of sector & 0 & - & 191 & 11.9 \\
\hline Total & 1599 & 100.0 & 1599 & 100.0 \\
\hline
\end{tabular}


A more detailed breakdown at the 4 digit NZSIC level is set out in Table A2 below.

Table A2: Innovations Produced and Used by 4-Digit Sectoral Category

SIC Code Description of Sector Production Usage

Agriculture, Forestry and Mining

1002 Other 150

$\begin{array}{llll}1110 & \text { General Agriculture } & 40 & 171\end{array}$

1111 Dairy Farming $\quad$ - $\quad 47$

1112 Sheep Farming $\quad 1 \quad 18$

$1114 \quad$ Mixed and Other Livestock Farming $\quad$ - $\quad 7$

$\begin{array}{llll}1115 & \text { Horticulture } & 16 & 29\end{array}$

$\begin{array}{llll}1116 & \text { Cropping } & 26 & 27\end{array}$

$\begin{array}{llll}1117 & \text { Fruit Growing } & 33 & 67\end{array}$

1119 n.e.c. $\quad-\quad 3$

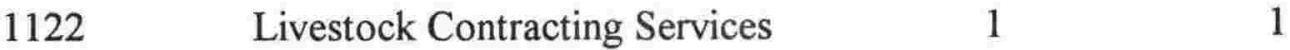

1123 Grain, Fodder and Pasture Cropping, $\quad$ - $\quad 10$

$1124 \quad$ Topdressing and Spraying

Contracting Services $\quad-\quad 1$

$\begin{array}{llll}1210 & \text { Forestry } & 1 & 13\end{array}$

1220 Logging and Other Timber Felling - 10

$1230 \quad$ Forestry and Logging Management and $\quad-\quad 1$

Consulting Services

Fishing

8

1322

Fish Farming

2

7

2100

Coal Mining

2 
2901 Extraction of Stone, Clay, Gravel, Sand etc.

Manufacturing

3000

3100

3111

3112

3113

3114

3115

3117

3121

3122

3131

3132

3133

3211

3212

3214

3215

3221
General Manufacturing

General Food Production

Slaughtering and Meat Processing

18

15

12

3

Fish and Shellfish Processing

Vegetable and Animal Oil and

Fat Processing

5

Bakery Products

Miscellaneous Food Products

Animal Feed

Spirit Beverage

Wine

Beer and Malt

Textiles, Fibre and Textile Processing

19

Made-up Textile Goods Except Clothing 4

Carpets and Rugs

3

Cordage, Rope and Twine

Clothing

Tanneries and Leather Finishing 
3311 Sawmills, Planning and Other

Wood Mills

Manufacture of Wooden and

Cane Containers

3319 Manufacture of Cork and

Wood Products nec

$3411 \quad$ Pulp, Paper and Paperboard

$3412 \quad$ Paper and Paperboard Containers

3419 Pulp, Paper and Paperboard Articles $\quad$ - 1

$3420 \quad$ Printing, Publishing and Allied Industries

3511 Basic Industrial Chemicals

Except Fertilisers $\quad 60$

Fertilisers and Pesticides

16

2

Synthetic Resins, Plastic Materials etc

Paints, Varnishes and Lacquers

Drugs and Medicines

Soap and Cleaning Preparations,

Perfumes, Cosmetics etc.

Chemical Products n.e.c.

Petroleum Refineries

$3540 \quad$ Miscellaneous Products of

Petroleum and Coal

Rubber Products n.e.c.

Plastic Products n.e.c. 


\begin{tabular}{|c|c|c|c|}
\hline 3692 & Cement, Lime and Plaster & 5 & 2 \\
\hline 3699 & Non-metallic Mineral Products n.e.c. & 2 & - \\
\hline 3710 & Iron and Steel Basic Industries & 6 & 4 \\
\hline 3720 & Non-Ferrous Metal Basic Industries & 1 & 2 \\
\hline 3812 & Furniture and Fixtures Primarily of Metal & 4 & - \\
\hline 3813 & Structural Metal Products & 9 & - \\
\hline 3814 & $\begin{array}{l}\text { Household and Kitchen Utensils, General } \\
\text { Hardware and Fabricated Metal Products }\end{array}$ & $\begin{array}{l}42 \\
\text { n.e.c. }\end{array}$ & 3 \\
\hline 3819 & $\begin{array}{l}\text { Wireworking, Nail and Fastener } \\
\text { Manufacturing etc. }\end{array}$ & 1 & - \\
\hline 3821 & $\begin{array}{l}\text { Manufacture and Reconditioning of } \\
\text { Engines and Turbines }\end{array}$ & 8 & 6 \\
\hline 3822 & Agricultural Machinery and Equipment & 112 & 2 \\
\hline 3823 & $\begin{array}{l}\text { Tool, Die and Jig Making and } \\
\text { Manufacture of Metal and } \\
\text { Woodworking Machinery }\end{array}$ & 4 & - \\
\hline 3825 & $\begin{array}{l}\text { Office, Computing and Accounting } \\
\text { Machinery }\end{array}$ & 38 & 7 \\
\hline 3826 & Industrial Machinery and Equipment & 227 & 10 \\
\hline 3831 & $\begin{array}{l}\text { Electrical Industrial Machinery } \\
\text { and Apparatus }\end{array}$ & 186 & 79 \\
\hline 3832 & $\begin{array}{l}\text { Radio, Television and Communication } \\
\text { Equipment and Apparatus }\end{array}$ & 95 & 21 \\
\hline 3833 & $\begin{array}{l}\text { Domestic Electrical Appliances } \\
\text { and Housewares }\end{array}$ & 1 & 12 \\
\hline 3839 & Electrical Apparatus and Supplies n.e.c. & 13 & 2 \\
\hline 3841 & Ship Building and Repair & 3 & 1 \\
\hline 3843 & Motor Vehicles & 2 & 12 \\
\hline 3845 & Aircraft & - & 14 \\
\hline
\end{tabular}


3851 Professional and Scientific, Measuring and Controlling Equipment 243

\section{Electricity, Gas and Water}

$\begin{array}{llll}4101 & \text { Electricity Generation and Distribution } & - & 7 \\ 4102 & \text { Gas Treatment and Distribution } & - & 4 \\ 4200 & \text { Water Works and Supply } & - & 2 \\ 5100 & \text { General Construction } & 1 & 41 \\ 5101 & \text { Buildings - Residential } & - & 3 \\ 5102 & \text { Buildings - Non-Residential } & 1 & 4 \\ 5200 & \text { Construction Other Than Buildings } & - & 4 \\ 5309 & \text { Painting and Paperhanging } & - & 12 \\ \text { Wholesale and Retail } & & 10 \\ 6000 & \text { General Wholesale and Retail } & - & 10 \\ 6122 & \text { Fresh Fruit and Vegetables } & - & \\ 6282 & \text { Fuel and Transport Vehicle } & & \\ & \text { Repair Garages } & & \\ & & & \end{array}$

\section{Transport, Storage and Communication}

$7100 \quad$ General Transport and Storage

$7111 \quad$ Railway Transport $\quad-\quad 2$

7113 Other Road Passenger Transport $\quad$ - 3

$7114 \quad$ Freight Transport by Road $\quad-\quad 1$ 


\section{Business and Financial Services}

$\begin{array}{llcr}8110 & \text { Banking } & - & 1 \\ 8131 & \text { Investment } & - & 1 \\ 8300 & \text { General Real Estate and Business Services } & - & 3 \\ 8322 & \begin{array}{l}\text { Accounting, Auditing and Bookkeeping } \\ \text { Services }\end{array} & - & 10 \\ 8323 & \text { Software Development etc } & 152 & 2 \\ 8324 & \begin{array}{l}\text { Engineering, Architectural and } \\ \text { Technical Services }\end{array} & & \\ & & & 21\end{array}$

\section{Community, Social and Personal Services}

9101 Central Government Administration and Defence

$9201 \quad$ Sanitary and Garbage Disposal Services $\quad-\quad 7$

$\begin{array}{llll}9310 & \text { Education Services } & - & 7\end{array}$

$9320 \quad$ Research and Scientific Institutes $\quad-\quad 26$

$9331 \quad$ Medical, Health Services $\quad-\quad 50$

$\begin{array}{llll}9420 & \text { Libraries, Museums etc } & - & 8\end{array}$

$9430 \quad$ Racing and Associated Services $\quad-\quad 2$

$9440 \quad$ Sport and Recreation (including professionals) $\quad-\quad 6$

$9450 \quad$ Amusement and Recreational Services $\quad-\quad 11$

9513 Services for the Repair of Cars and Bikes - 2 


\section{ANNEX 1.1: LITERATURE AND SOURCES TO IDENTIFY POPULATION OF INNOVATIONS}

The following are sources that were used by the author to identify and assemble the population of technological innovations for the study.

Specific Journals and Magazines etc.

Title

Agricultural Machinery Review

Commercial Grower

Apiarist, The

Commercial Horticulture

Apple and Pear Marketing Board

Computer Scene and Office

Annual Reports

Automation

Arable Farming

Computer World NZ

Australian and NZ Wine Industry

Computing Today

Journal

Connections

Automation and Control

Construction

Better Business

Contractor, The

Bits and Bytes

Dairy Board Annual Reports

Boating NZ

Dairying Today

BRANZ Annual Report

Dairyman

BRANZ Appraisal

Dairy Research Institute News

BRANZ Bulletin

Dairy Research Institute Report

Build (BRANZ journal)

Dairy Technology

Building Industry News

Deer Farmer, The

Building News

Demm Monthly

Catch

Demm Product News

Chemistry, Industry and Laboratory

Directory of Technology

Management

Electrical Industry

Chemistry in New Zealand

Energy Journal, The

Commercial Fishing

Energy Management News 
Energy Management Yearbook

Energy R\&D News

Exporter, The

Export News

Farm Equipment News

Fibre News

Fishing Industry Board Bulletin

Fishing Industry Board Newsletter

Fletcher Challenge News

Focus on Science

Food Industry News

Food Processing Product News

Food Technologist, The

Food Technology in NZ

Freshwater Catch

FRI Annual Research Report

FRI News

Gas News

Graphix

Growing Today

Heating and Ventilating Engineer, The

(later renamed IRHACE)

Horticulture in New Zealand

Horticulture News

Horticulture Today

Imprint

Industrial Business Magazine

Industrial Equipment News

International Business (NZ)

IPENZ Yearbook

IPENZ: Technical Group Proceedings

IPENZ: Transactions
Journal of the NZ Institute of

Mechanical Engineers

Kiwifood

Laboratory News

Live Lines

Logging Industries

Management

Manufacturer

Materials Handling and Logistics

Management

Meat Directory

Meat News

Mechanical Engineering Digest

Medical Equipment Digest

Metal

Milk Industry Bulletin

MIRINZ Annual Research Reports

Motor Industry News

National Business Review

New Electronics

NZ Agrichemicals Manual

NZ Beekeeper

NZ Cement and Concrete Information

Bulletins

NZ Coal

NZ Commercial Grower

NZ Computer Interface

NZ Computer Reviews

NZ Computer Scene

NZ Concrete Construction

NZ Concrete Industry Guide

NZ Dairy Exporter 
NZ Electrician

NZ Electronics Review

NZ Energy News

NZ Engineering

NZ Engineering News

NZ Engineering Review

NZ Export Yearbook

NZ Farmer

NZ Fertiliser Journal

NZ Forest Industries

NZ Forestry

NZ Fishing News

NZ Fruit and Produce Journal

NZ Gardener

NZ Hardware Journal

NZ Horticulture

NZ Interface and NZ Computer

Interface

NZ Journal of Agricultural Research

NZ Journal of Agriculture

NZ Journal of Computing

NZ Journal of Crop and Horticultural

Science

NZ Journal of Dairy Science and

Technology

NZ Journal of Environmental Health

NZ Journal of Forestry

NZ Journal of Forestry Science

NZ Journal of Medical Laboratory

Technology

NZ Journal of Technology

NZ Kiwifruit
NZ Manufacturer

NZ Meat Producer

NZ Meat Producers Board Annual

Report

NZ Meat Worker

NZ Medical Journal

NZ Mohair News

NZ Motor Industry News

NZ Pharmacy

NZ Poultry Industry Review

NZ Printer

NZ Professional Fisherman

NZ Timber Construction Review

NZ Timber Worker

NZ Tree Grower

NZ Veterinary Journal

Orchardist of NZ, The

Packaging

Plastics Industry Directory

Pork Industry Gazette

Pork Industry Newsletter

Poultry Forum

Printers News

Progressive Engineering

Scitech(MoRST publication)

Small Farmer, The

Soil and Health Journal

Southern Horticulture

Standards

Straight Furrow

Terra Nova

Town Milk 
Transearch

Transport News of NZ

Waste Observer

Water and Wastes in New Zealand

Wool Report

Works News

WRONZ Annual Report

WRONZ Communication

WRONZ Technical Papers

\section{Other Written Sources}

All University Research Reports

All Annual Reports and Research Reports of Research Associations Annual reports of companies DSIR Annual Reports MAF Annual Reports Ministry of Forestry Annual Reports Newspaper and magazine articles, miscellaneous unpublished reports etc.

Patent Office data

Plant Variety Rights Office data 
ANNEX 1.2: LETTER OF ACKNOWLEDGMENT 
Ministry of Research, Science and Technology

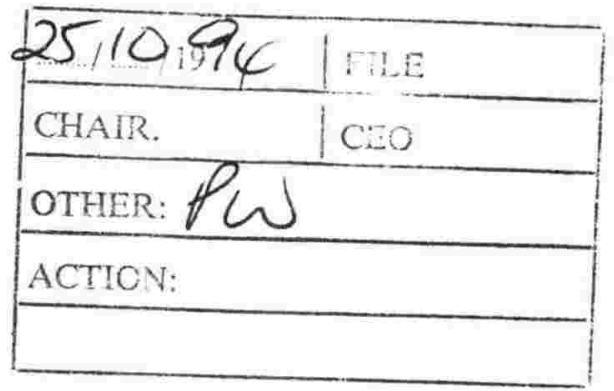

21 October, 1994

\section{Peter Winsley}

Foundation for Research, Science and Technology

PO Box 12-240

Wellington

\section{Dear Peter}

I acknowledge the receipt of the database of innovations, 1980-1992, which you have collated. I intend to further develop the database by classifying the innovations to the NZSIC categories, to feed into the analytical part of my thesis. I will cite your work as the source of the raw data in any publications produced. I appreciate your generosity in sharing this database.

Kind regards,

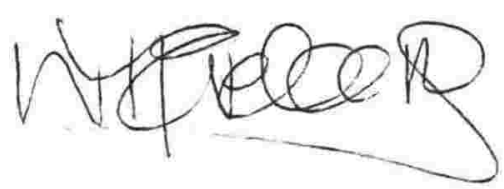

Wilhelmina Eveleens 


\section{ANNEX 2: SAMPLES OF DOCUMENTS RELATING TO CASE RESEARCH}

\section{Introduction}

This annex provides samples of documents used in the course of the case study research. The documents attached are as follows:

Annex 2.1. An outline format for the case research interviews. This format was given to each person interviewed before the interview.

Annex 2.2. Copy of confidentiality agreement.

Annex 2.3. List of people interviewed in the case studies. 


\section{ANNEX 2.1: FORMAT FOR CASE STUDY INTERVIEWS}

The key people associated with the innovation will be interviewed for around an hour. The interview results will be written up and circulated to the participants, who can then ask for any errors or misinterpretations to be corrected. Follow up interviews will be undertaken where necessary to amplify points or verify interpretations.

The interview format will be kept very open, allowing the information collection to be driven by the participants rather than by the interviewer. The aim is to avoid biases or preconceptions of the interviewer distorting the data collection.

The interviews will focus on the following broad areas:

1. The origins of the innovation (encompassing the initial idea, "trigger event" or stimulus, as well as the sources of the key technologies).

2. External influences (a very broad area encompassing market influences, changes in economic conditions or government policy, external joint ventures and networking etc).

3. The background, past experience, education etc. of the key players.

4. The motivations of the key players.

5. Dynamic processes over time, including the roles and interrelationships between the key players, and organisational behaviour.

It is stressed that the above 5 broad areas are not intended to be restrictive. They are rather intended as "prompts" and to provide a focus for the interview. The emphasis given to particular areas will obviously vary according to whether the participant is a technologist, marketer, business manager etc. 


\section{ANNEX 2.2: CONFIDENTIALITY AGREEMENT}

I,

(full name)

of

(address)

am a $\mathrm{PhD}$ candidate undertaking research forming part of the New Zealand Innovation Project within the Faculty of Commerce and Administration at Victoria University, Wellington.

In undertaking this research, I acknowledge that I may become privy to commercially sensitive or confidential information revealed by companies, Research Institutes or other parties.

In respect of such commercially sensitive or confidential information, I undertake:

(a) not to use such information for the purposes of any competitive business operation;

(b) not to use it in any way which could reasonably be expected to be detrimental to the business or other interests of the person or persons from whom it was received.

(c) to use such information only for the purposes of academic research.

Signed:

Date:

Witnessed:

Name:

Occupation:

Address: 


\section{ANNEX 2.3: LIST OF PEOPLE INTERVIEWED IN CASE STUDIES}

The following people were interviewed in the course of the case study research.

\section{ASDi Variable Speed Drive}

Keith Valentine, Vectron Technologies Ltd, Napier

Murray Porteous, PDL Electronics, Napier

Dr Simon Walton, PDL Electronics, Napier

Professor John Boys, Dept of Electrical and Electronic Engineering, Auckland

University, Auckland

\section{Kiwifruit Wine}

Dr David Heatherbell, Lincoln University, Lincoln

Norman Lodge, HortResearch Institute, Mt Albert Research Centre, Auckland

Warren Preston, Preston's Kiwifruit Winery, Tauranga

\section{Ruakura Milk Harvester}

Bill Thompson, InterAg Ltd, Hamilton

Dr Ken Jury, Dairying Research Corporation, Ruakura Agricultural Centre, Hamilton

Dr Murray Woolford, Dairying Research Corporation, Ruakura Agricultural Research Centre, Hamilton

Dr Robert Sherlock, Dairying Research Corporation, Ruakura Agricultural Centre, Hamilton

Graham Duirs, AgResearch Head Office, Hamilton 


\title{
FP4000 Intelligent Fire Alarm
}

Richard Cree, Vigilant Fire and Evacuation Systems, Christchurch

David Sharp, Vigilant Fire and Evacuation Systems, Christchurch

Mike Holdaway, Vigilant Fire and Evacuation Systems, Christchurch

\author{
Alatal 821 Milk Product \\ Dr Robin Fenwick, Protein Division, NZ Dairy Board, Wellington \\ Andrew Revfeim, Whey Products NZ Ltd, Wellington \\ Marsha Swartz, NZ Milk Products, Santa Rosa, California \\ Dr Chao Wu, NZ Milk Products, Santa Rosa, California \\ Neal Van Degrift, NZ Milk Products, Santa Rosa, California \\ Rob Boswell, Anchor Products, Hautapu \\ Julie O'Sullivan, NZDRI, Palmerston North \\ Kevin Oliver, Protein Division, NZ Dairy Board, Wellington
}

\section{Loin Boner}

Gordon Wickham, MIRINZ, Hamilton

Weng Ng, MIRINZ, Hamilton

Dr Doug Wright, retired director of MIRINZ, Hamilton

Alan Dean, Richmonds Ltd, Otaki

\section{Treotek Spinning Technology}

Dr Garth Carnaby, WRONZ, Lincoln

Jack Watt, WRONZ, Lincoln

Stuart Hammer, Alliance Textiles Ltd, Mosgiel

Alistair Coleman, Alliance Textiles Ltd, Timaru 


\title{
GS 2085 Apple Variety
}

\author{
Allan White, HortResearch, Havelock North Research Orchard, Havelock North \\ Dr John Field-Dodgson, NZ Apple and Pear Marketing Board, Hastings \\ Dr Geisla Ahlborn, NZ Apple and Pear Marketing Board, Hastings \\ David Cranwell, NZ Apple and Pear Marketing Board, Hastings
}

\section{XAB-17 Beacon}

John Rochfort, Vega Ltd, Porirua

Martyn Cook, Vega Ltd, Porirua (telephone interview only)

\section{Greenweld}

Dr Justin Williamson, NZ Forest Research Institute, Rotorua Jeremy Taylor, NZ Forest Research Institute, Rotorua

Dr John Butcher, NZ Forest Research Institute, Rotorua

Dr Russell Burton, NZ Forest Research Institute, Rotorua Jeff Parker, NZ Forest Research Institute, Rotorua

Dr Terry Lomax, Ministry of Research, Science and Technology, Wellington

\section{Dual Fuel Kit}

George Jones, Solid State Ltd, Lower Hutt

Harvey Poletti, Solid State Ltd, Lower Hutt

Harvey Reid, DieselGas Ltd, Lower Hutt 


\section{ANNEX 3: OPEN CODED VARIABLES BY BROAD AREA AND AXIAL CATEGORY}

The following lists open coded variables grouped for convenience within the broad areas and organised by axial categories. Annex 3.1 attached provides an example of the information recorded on an open coded card. Annex 3.2 attached provides an example of the information recorded on an axial coded card.

\section{Broad Area: Origins of Innovation}

\section{Axial Categories within Broad Area}

1. Evolutionary Origins

\section{Variables:}

Memes

Invention is irreversible

Imitation

Innovations draw on antecedent technology

Platform of knowledge

Technical platform

Technical platforms in relation to expandable/extendable innovation

Evolutionary adoption of radical new technologies but within same core business

R\&D based innovations depend on antecedent R\&D

Innovations as part of an on-going continuum

Product variants from robust designs

Invention is the "mother of necessity"

Transmission of tacit technology over extended time-frames

Additional benefits result from research subsequent to an innovation 
One innovation will spawn another or loosely related one

"Failed research" leads to success

Learning from failure

2. Overseas Influences

Variables:

Ideas coming from overseas

Japanese companies using NZ companies to commercialise their patents

International databases and external sources of technology

Involvement of international technical people

International links reducing $R \& D$ redundancy

Combination of NZ and overseas technology

3. Published Sources of Ideas and Technologies

Variables:

Published conference results

Importance of technical trade journals

Published scientific papers as a major stimulus to innovation

Publication of new ideas is underrated as technology transfer

Patents 


\section{Public Technostructure}

Variables:

Research institutes providing a secondary input into an industry-driven innovation

Intellectual freedom in DSIR and universities

Technology transfer seminars and promotions

University-based innovation

University research underpinning industry $R \& D$

Academics/scientists generating new ideas

University involvement

Public researchers aiming to be ahead of industry

Public research institutes often aren't doing research in areas relevant to companies

Public research institutes following rather than leading private sector innovation

Links with industry by Research Institutes

Public research institutes used to provide a very specialised technical input

Fundamental skills and knowledge from universities

Companies manufacturing inventions from public research institutes

University/industry joint projects

Long-term alliances with universities

Research institutes needing an intimate knowledge of industry

Supportive public infrastructure

Industry-sponsored, university-conducted innovation

Information exchanges between universities/institutes and companies

CRI involvement

Innovative output of graduate student-level research

Research institutes providing a key technical input of technology unavailable to the innovator

Innovations do come from "public good" research 
Companies leading institutes in innovation

Lack of sophisticated technostructure

5. Market/Customer Origins of Innovation

Customer contact or problem solving directly stimulates innovation

Business or commercial person spotting potential of technology

Ideas generated for research institutes by commercial clients

Development of an innovation to meet a very specific tender

Industry/marketing person isolating potential of a technology that was

otherwise seen as a failure

"Impossible" outside specification as stimulus to innovation

Innovation focused on real market problems/opportunities

\section{Formal Idea Generating Processes}

Variables:

Brain-storming sessions

Systematic method of scanning for external sources of technology

"Creative swiping"

Formal searching for external technology

Formal process of identifying opportunities

7. Other External Origins of Innovation

Variables:

Interaction with ideas generated by others, especially external ideas Recruitment of external personnel

Innovators often come from outside the commercialising company

Students finishing off or doing their degrees in companies 
Innovative companies spinning off from existing companies

Benefits of external critiques of innovation

Use of external technical consultants

\section{Cognition, and Informal Creative and Idea Generating Processes and}

$\underline{\text { Activities }}$

Variables:

Good ideas come from actively doing things, not sitting at a desk or "just thinking"

Dreaming

Luck favours a prepared mind

Pattern recognition ability

Free interchange of scientific ideas among scientists

Lateral thinking

Open and free exchange of ideas

Good ideas come from the factory floor

Flash of insight or understanding

Openness and exposure to new ideas is associated with rapid technological advances

Innovative ideas spin-off orthogonally from focused development

Divergent thinking

Serendipity

Intuitive thinking

Accident and chance events

"Shock of recognition"

Ability to recognise and see the significance of an unexpected result

"Kiwi ingenuity"

Time needed for in-depth, reflective thinking

Analytical convergent thinking

Making connections between unrelated things 
Key ideas of innovators stimulated by other people with different experiences

\section{Formal R\&D}

\section{Existence of structured R\&D}

Scale of R\&D needed to be competitive may be increasing

Some companies do strategic research

Companies supporting $\mathrm{PhD}$ research

Companies that are wholly or partly R\&D contract labs

World-class research on industry problems

$\mathrm{PhD}$ research can be of direct commercial benefit to companies

Importance of basic science input from outside the core innovation field

Understanding of the theoretical base or basic science underlying an innovation

Basic science

Basic research knowledge resulting from focused research

\section{Family Origins of Innovation}

\section{Variables:}

Innovative families

Technological interests and competencies transmitted from parent to child

Same family maintains an interest in the same technology over several generations

11. NZ's Specific Resource Endowments and Problems/Opportunities

\section{Variables:}

Dependence on biologically-based industries

Resource endowments 
High health status of $\mathrm{NZ}$ biological products

Non-uniformity of biological materials

Perishability

Weakness of a raw material may turn out to be an exploitable strength

Upgrading low value waste products

Extracting value from a waste product

Biological lag times

Shortage of raw materials or resources as a spur to innovation

Specific problems of unique NZ materials

Availability of raw materials

Changing or exploiting a weakness in an NZ product

Control over key raw materials

Adding value to $\mathrm{NZ}$ raw materials

Technical or functional characteristics of a product or raw material determines innovative potential

Demand for innovation driven by core industries

Many NZ innovations are inputs, ingredients or production equipment

Frustrating farm problems as a source of innovation

12. Nature of the Technology

Variables:

Electronics

Technology as a lifeline to a company

Technological paradigm shift

Objective measurement technology

Importance of computer software

Embedded software

Tacitness

Key scientists/engineers have an input into a wide range of innovations by others 
Availability of radical new technologies

Sensory science

Flexible production technology

Tracking and identification technology

New functional properties

Embedded uniqueness

Multiplier effects of systemic innovation

Inherent functional properties of a product allow differentiation

Advanced technologies involve specific problems which are themselves valuable learning experiences

Technology push

Strong commitment and "sunk costs" in existing incumbent technologies or skill-bases

Engine and automotive innovations loom large

Very good ideas and technologies tend to always be successfully commercialised in the end; inept implementation will delay but not stop them Innovations succeed in different uses

Embedded software as specific rather than generic technology

Specificity of innovation

Producer Boards moving from generic promotion to specific innovation

Production technology that is both an input and an output

Skills applied to quite different technologies

Specific innovation creates generic platform

Innovation often blends applied technology and basic understanding

Major "cross overs" of science from other fields

Move from products to complete systems

Enabling technology embedded in an existing product

Innovative technology is often new to New Zealand but not to the world

Technologies emerge from one part of a field, such as electronics, but are then adopted more widely

Innovations traverse industries

Opportunities exploited often differ from the original goal of the innovation 
Process innovation to produce a new product

Early stages of innovation are "thing oriented", later stages are people oriented

Systems with common features but with specific tailoring to particular clients

Versatility and adaptability of NZ technologists

Planting rates and biological lag-times allow future to be predicted

Nature of the technology has to be appropriate to its market

Intangibility of competencies and skills make them difficult to borrow against

Satisficing rather than optimising technology

Some types of academic science lend themselves to commercial interaction

Niche innovation

Generic technology applied to a totally different purpose

Generic technology created by focusing on real problems

Innovations that are one-off or design solutions to specific problems

13. Cost, Production, Labour or Technical Problems as Origin of Innovation

Variables:

Production manufacturing costs and reliability

Cost as a pressure for innovation

Cost reducing process innovation that also improves quality or functional performance

Innovation as a simplification of design

Need to simplify things in general, especially production

Innovation resulting from frustrating technical problems

Concentration on reducing costs of manufacture

Unreliability of labour

Innovation to deal with a bottleneck

Process quality to reduce waste and reworking

Increasing external pressure for safety, purity and QA

Systemic bottlenecks 
14. New Combinations, Competitions or Inter-Relationships Between Technology as Origins of Innovation

Variables:

Innovation results from new combinations of existing technology

Systemic innovation

Intertwining of hardware and software

Willingness to exploit new disciplines or complementary skillbases

Advanced technological development on technological frontiers requires complementary "lower tech" or supportive R\&D

Contribution from other innovations

Competing theories aimed at same goal

Multi-disciplinary research

Innovation as the putting together of new combinations

Hardware built around software to make software productive

Clusters of innovation in the same field

Clusters of innovation in the same field produced by quite different people

Convergent technologies

\section{Broad Area: Dynamic Processes}

\section{Axial Categories within Broad Area}

1. Capturing Benefits from Innovation

Variables:

Importance of early and attractive branding

Need to differentiate rather than be imitative

Identify the right market, not the obvious market

Competition in several markets using same core technology 
Differentiation by the difficulty of the technology or process

In differentiated, specialised niche markets skills should be retained in one place and allowed to cumulate

Passion about branding

Intellectual property protection

Pre-emptive patenting

Testing procedures as a "locking in" mechanism

Diversification

Intensively sales-engineered products

Strategy of moving away from commodities to added value

Economies of scope

Manner in which something is produced does itself capture premiums

Flexible production runs to earn premiums

Innovations marred by distributors with competing product lines

The "currency of technology"

Leverage created through distribution networks

History of innovation in a market sets regulatory standards

Many companies don't patent

Balance needs to be maintained between confidentiality and openness

Control over transport

Specifications developed around the product

Control over distribution

Process innovation may confer a new competitive edge on an existing product

Diversification

Trademarking

Good returns depend on embodied technology

Branding

Copyrights

Intellectual property as a major asset

Increasing returns to specialisation

Commercial confidentiality

Royalties from licensed technology are quite modest 
Sowing a minefield of patents

Too much differentiation can be a problem in the market

Patenting

Fast followers rather than the initial innovators often capture most of the benefits

Speed to the market

Specialised intellectual property management skills

Being first with a new innovation

Desire to have a differentiating feature

Importance of consolidating and channelling first sales of an innovation back into the business rather than into consumption

Overseas standards designed around NZ innovations

2. Time

Variables:

Industry is short-term in its view of R\&D

Time-frame for a prototype is much shorter than time-frame to commercialise Technology's time often comes in the future

Time-scales in relation to industry

Lack of time and money for research

Long term stable focus on a defined area

Scientists ability to meet rigid and tight commercial deadlines

Time

"White time"

Inherently long-term business

Long-term approach

2-4 years to develop an innovation is typical

Continuity

Fast response times for customers

Long-term financial struggle before success is achieved 
Product life cycles of 4-5 years

Some innovations overtaken by more advanced technology

Need to speed up the product development cycle

3. Organisational Structural Aspects of Innovation

Variables:

Teamwork: innovation as a team/group rather than individual phenomenon

"Rugby approach" to innovation

Concurrent engineering

Devolution to a taskforce

Workplace reform

Technological innovators should interact across disciplines and specialities and not be segmented

Management or social innovation as a key to success

Innovative teams of around 4-8 people

Project team for innovation

Cross-functional teams

Social architecture

Flat organisational structure

Innovation forces companies to change structure and workplace organisation

Absence of rigidly formal and hierarchal structures

Organisational structure

Devolution and decentralisation of technical servicing and QA functions

Flexible institutional arrangements for R\&D and technological innovation

Innovative company and business based around innovation

Backyard or garage level start-ups

"Footloose" companies

Research Institute limits to how far they can go with commercialisation 
4. Organisational Cultural Aspects of Innovation

Variables:

Company culture

An enabling culture

Belief that a company should make a positive contribution to society

Family atmosphere

Toleration of the "oddball"

Great attention to detail

Institutionalising attitudinal change, eg. for continuous improvement

United front of managers and workers needed for successful technological innovation

Organisational cohesion

Design culture

5. Formal Business Management Techniques and Skills

Variables:

Financial planning

Planning

Benchmarking

Cash flow management

Clear Go: No Go criteria

Written business plan or strategy

Absence of business plan analysis

Written mission statement

Cost benefit analysis

Systematising modus operandi of innovative companies

Vision statement

Good marketing 
Performance targets need to be specified

Need for focus early on

Key commercial decisions in an innovation being made early

Lack of rigorous market analysis and reliance on instinct

Innovation must be directed to an end purpose

Advanced processes to enhance innovative management in a company

"Imagineering"

Technology-based companies often lack basic administrative and commercial skills

Quality management

Importance of good record keeping

Importance of design

Innovation associated with strategic changes within companies

Quality control and practical operational problems

$\mathrm{NZ}$ companies need their own marketing and technical staff overseas

Product and process-specific marketing often required

Vigorous internal and external promotion of innovation

Science provider strategy a crucial variable

\section{Resourcing of Innovation}

\section{Variables:}

Availability of existing plant and competencies

Minimum critical mass of resources needed for innovation

Innovations funded out of turnover

Willingness to spend large sums of money

Discretionary funds available to, or within, research institutes

Reluctance to borrow

Bootlegging of internal resources

Banks not understanding the innovation process

Family money 
External R\&D funding

Redundancy money and superannuation

Flexibility in R\&D funding

Smallness and inability of NZ companies to support large-scale innovation

Availability of adequate financial and other resources

Large personal financial commitments

R\&D and innovation investment is pervasive and integral rather than separately budgeted and structured

Offshore R\&D money

Research Institute capitalisation

Ability for risk to be borne by a company or other risk pooling device rather than by an individual

Continuous process innovation

Motivation of getting volume up to justify R\&D levels

\section{Networking, Technical Alliances and Partnerships with Other Organisations}

\section{Variables:}

Long term strategic relationships with component suppliers

Technical partnerships between companies

Use of other companies or contractors

Technology-based companies often work together

Technical assistance through networking

Research institutes having a commercial partner

Solo innovators teaming up with a company to commercialise innovations

Joint public/private sector ventures resulting from science reforms

Research institutes and companies at similar technical levels

Research institutes need commercial partners to provide tooling, trialing, production technology etc.

Cooperative or collaborative technological links with other companies in the same group 
International collaboration

Company-specific contracts/relationships of Research Institutes

Close, long-term strategic relationships with customers

Licensed manufacture of innovations

International technical alliances

Close, interactive, and long-term relationships with suppliers

Need for companies to interact positively with other competing companies

Networking strategically externally

Networking and technical cooperation between non-competing NZ companies

Ecological cooperation

Ventures with larger companies to avoid being quashed

Solo innovators who get a large company to make the product

8. Key Roles in Innovation

Variables:

Product champion

People complementing each other

Business financier

Role of manager

Business innovator and Chief Executive tend to complement technical innovator and product champion

Top-level sponsor

Specialisation of roles rather than "jack of all trades" approach

Managers and innovators being more generalist and responsible for the whole process

Complementary skill-bases

Facilitator 
9. Relationships Between People in the Innovation Process

Variables:

Stress

Conflict

People back people

Complementary personalities

Personal inter-relationships

People in an innovative team getting on well together

Mutual respect

Friendship and personal relationships

Personal rapport

10. People Management in Innovation

Variables:

Leadership

Empowerment

Letting everybody have their say

Need to manage upwards as well as downwards

Key people must be involved early, preferably at inception

Creative people stifled or unrewarded

Mentoring and other means of fostering innovators

Management by walking around

Innovative people are difficult to manage

Product development is different to research and must be managed differently

Leading visibly from in front

Communication

Open communication with no hidden agendas

Secrecy from other key people 
Open exchange of information

Good communication between top management and the innovative team

Ability of scientists/technologists to communicate with workers

Willingness to listen to others

Staff stability

Worker "buy in" to an innovation at an early stage

Innovation causes frustration and anguish

Passion for the vision

One manager must have the overview

All key players are employers/managers rather than consultants

Leadership by example rather than decree

Empowerment of and communication with the staff

"Loose cannons" on deck have to be controlled

Organisational slack

New management

Focus on people's strengths to make their weaknesses irrelevant

Innovation is making ideas happen

Need for clear lines of decision making

Bureaucratic stifling of innovation

Balance between $R \& D$, production and applications must be maintained Key scientists and technologists must be involved all the way through Intrapreneurship

11. Asset Specificity

Variables:

Embedded uniqueness

Asset specificity as tool to capture benefits

Asset specificity (general)

Asset specificity of food ingredient formulas 
Specialised capital equipment to earn premiums through low marginal cost production

12. Dynamic Change and Adaptiveness and its Management in Innovation

Variables:

Organisational flexibility and adaptability

Innovations must have the flexibility to allow later extension or reinnovation Avoidance of "locking in" designs, software structure etc too early

Maintain core focus and avoid branching out into the wrong field

Key people doing the whole job, including $R \& D$, marketing, servicing etc

Interactive feedback from users/industry while R\&D is underway

Engineers and innovators interacting closely with customers

Flexibility

Uncertainty

As technology grows in complexity there is a need for companies to increasingly rely on external sources of expertise

Key innovators involved across the basic research to applied technology perspective

Innovators in existing companies spinning off and setting up their own companies

Companies adopting and transferring human capital rather than disembodied technology

The act of innovation itself builds up expertise, skills and human capital as spin-offs

Need to ensure "performance in peripheral matters"

"Do it once and do it right"

Innovation must be continuous

Reinnovation

Ability to recognise and avoid or withdraw from "blind alleys"

Internal competition between competing technologies 
Flexibility to change course and direction during the course of the R\&D

Most innovation costs and efforts are development rather than research

Enormous gulf between what works at prototype level and what can be successfully marketed

Innovations not "one off": Got to keep others on the go

\section{KISS}

Learning on the job and learning by doing

Movement of people as technology transfer

Follow-on products

13. The Effects, Consequences and Benefits of Innovation

Variables:

User satisfaction

Innovation as a "door opener" to new markets and new technologies

Unexpected technical and commercial benefits of an innovation

Money/profit is always the consequence or the spin-off, not the primary goal

Innovation as a catalyst for new plant investment

Technical success is more likely than commercial success

Innovation has to be adopted or supported by multiple players to be a success in an integrated industry

Success with applied product development can stimulate more basic scientific work

Success breeds further success

14. Cost Variables in Innovation

Variables:

Problem of cost of production

Development costs far exceed research costs 
Importance of getting product price down

Per unit costs drop dramatically over product life

Research institute cost control

Problem of lack of efficiency and QA in manufacturing

15. Science/Technology Push Versus Market Pull

Variables:

Technology-led developments failing or getting into difficulties

"Technology push" by scientists creates an innovative success

Science/technology push

Technology that is "too clever by half"

Innovations from an institute or university need additional commercial features

Identifying a customer need before a customer can articulate it

16. Prototyping and Trialing

\section{Variables:}

Trialing in industry

Input needed to overcome difficulties in getting the technology working in industry

Trialing as an integral part of research

Provision of technical servicing and back-up

Need for early testing, trialing and evaluation

Research scientists assisting in ongoing trialing and problem solving

In-house prototyping by providers

Technology that works in a lab having problems in an industrial or "real life" setting

Tradeoffs needed in innovation

In-house engineering and prototyping ability 
Trial and error

\section{Broad Area: Background/Past Experience of Key Players}

\section{Axial Categories within Broad Area}

\section{Past Experience}

\section{Variables:}

Research institute staff with private sector experience

Rich and diverse background experience

Innovators cover a range of tasks

Mobility between the university and research institute sectors

Academics with an industry background

Immigrants

Key people in an innovation from outside the industry

International experience

Innovators with a broad based academic background

Experience in overseas research institutes

Technical people mobile through an industry

Diverse work experience at a number of levels

Strong background in the field/industry

Innovators from Defence, Post Office and DSIR backgrounds

Innovations arising from recreational interests

People who leave school and innovate despite lack of advanced education

Long-serving staff

Fear of technology 
Trial and error

\section{Broad Area: Background/Past Experience of Key Players}

\section{Axial Categories within Broad Area}

\section{1. $\quad$ Past Experience}

Variables:

Research institute staff with private sector experience

Rich and diverse background experience

Innovators cover a range of tasks

Mobility between the university and research institute sectors

Academics with an industry background

Immigrants

Key people in an innovation from outside the industry

International experience

Innovators with a broad based academic background

Experience in overseas research institutes

Technical people mobile through an industry

Diverse work experience at a number of levels

Strong background in the field/industry

Innovators from Defence, Post Office and DSIR backgrounds

Innovations arising from recreational interests

People who leave school and innovate despite lack of advanced education

Long-serving staff

Fear of technology 


\section{Family Background}

Variables:

Family farming background

Family background

Innovators coming from several generation in same industry

Childhood hobbies and "tinkering"

\section{Formal Education and Training}

Variables:

Skill levels in companies

Skills in analytical techniques

Food science background

Multi-disciplinary scientific and technical skills of individuals

Formal technical training and technician-level qualifications

Multi-disciplinary staff complement

Commercial skills in research institutes

Technicians and instrument makers

Generic industry-wide technical training

Formal human capital creation

NZ engineers and innovators with very practical, versatile skills

Trained staff in companies adopting an innovation

Knowledge and experience

Large number of innovators at $\mathrm{BE}, \mathrm{BSc}$ level or lower 


\section{Broad Area: Motivations}

\section{Axial Categories within Broad Area}

\section{Nature and Characteristics of Innovators}

Variables:

\section{Gender}

Mature men needing a challenge

Age

Balance of age and experience

Self confidence

Risk takers

Lacking in preconceptions

Ignorant of how hard the innovation process will be

Success with first risk or first innovation led to much greater confidence later

"Blind faith"

Innovators go on to new innovations

People, not technologies, are innovators

Extraordinary scientific achievement of individuals

Innovators often wouldn't do it again, if they had their time over

Really great innovators tend to have several patents to their credit

Influence of younger people

Innovators are optimists

Visionary CEOs

Ability to sell ideas

Good social, political and networking skills

Passion for the vision

Innovators are special and unusual personalities

Single mindedness

The enterpreneurial personality 
Personal integrity

Dislike of authority

Curiosity

Discipline

Bright young technologist as a "transformer"

Strong drive to turn ideas into practice

Hard work over long hours

Personality

Determination

Innovators often demand tidiness, order, perfection, beauty in design, and optimality

Perseverance

Lack of patience

Self motivation and drive

Faith

Feeling of certainty about innovation

Prima donnas

Inspirational professors and supervisors

People behaving in accord with their nature

Initial loneliness of an innovator

Willingness to be different

Self-reliant personalities

High self-esteem

Craftsmanship and love of craft

Involvement of a "maniac"

Idiosyncrasy

Willingness to live on very little money

Charisma

Fanatical belief in a technology

Intelligence

Innovators have a strong desire to do what they feel is right 
2. How Innovators Lead and Motivate Others

Variables:

Patriarchal figures

Perceived expertise leads to confidence

Infallible persona

Caring attitude to staff

Culture, values, belief systems of founder pervades firm after his departure

Putting wellbeing of staff ahead of your own

All staff recognise the company $\mathrm{CEO}$ or owner

Vision about company's future

Innovation leader must be able to explain things clearly and communicate the vision

Knowledge that a patriarchal or charismatic figure will look after staff is a "glue that binds"

Sticking to an innovation because of the technical knowledge to know that things are going well

One person knows all parts of a project and has the overview

Belief that people, not structures drive innovation and performance

3. Motivations Relating to Inter-Relationships Between People and How People Perceive Each Other

\section{Variables:}

Clannishness

When trust has been well placed, tested and proven, then those who have trusted give a great deal back (loyalty, personal favours etc)

Reputation

Very explicit value system of key people

Sense of duty or ethic 
Love as an analogue of innovation

Loyalty and commitment resulting from observing innovators trying to create and build something bigger than their own material interests

Relationship between trust and risk

Trust

Cooperation

Social ethics

Respect for colleagues

Coexistence

Guile and opportunism

Personality conflicts

Good relationships in technological innovation minimise need for prescriptive contracts

4. Financial and Material Motivations for an Innovation

Variables:

Money

Lack of financial incentives for research institute scientists

Profitability

Reward systems for innovators

People forced by material circumstance to take a risk

The expense of particular types of academic research forces academics to go to industry for funding

Lack of funding forcing academics to earn research funding from industry

5. Non-Financial and Non-Material Motivations for an Innovation

Variables:

Non-monetary motivations 
Goal must be the innovation or the business, not money

Ownership and control of the business

Desire to help the industry or company

Innovations as "babies"

Innovation as a means of "passing on genes and achieving immortality"

Extremely strong emotional commitment to an innovation

"Innovation becomes my life"

Publication ethos as a demotivator for innovation

Altruism and public spiritedness

Belief in a technology or an innovation

Technological satisficing rather than optimising behaviour

Strong emotional commitment to innovation by other than the key innovator(s)

People emotionally attached to a specific technology or technical solution and ignoring other options

Sense and feeling of ownership by the innovators

Emotional involvement in an innovation but without control over the key variables

Scientific prestige and mana as a motivation

Intellectual freedom

Innovators like to control own business and not be controlled by bosses

Organisational culture

Academic and other intellectual leaders knowing when to "let go"

Interest in the subject or innovation as a motivator

Lifestyle variable

6. Motivations Relating to the Innovation Process Itself

\section{Variables:}

Journey more fun than arriving

Motivation from challenge of solving the problem 
Missionary zeal and feeling of "us against the world"

Drive to understand the science underpinning the technology

High degree of freedom to work on areas of greatest interest

Feeling of "ownership" by customers in the design and development of a new

product

Enthusiasm

Innovation induces a euphoric high

Teamwork itself as a motivation

Scientists love research - and they get paid as well

Innovators often see jobs as paid hobbies

People innovate because its interesting, not because its a rational investment

Having a go

Fun

Innovators enjoy the experience

Empowerment resulting from surviving crises

Too much success can stifle innovation

Success builds confidence

Sense of ownership of how (rather than why) innovations are to be developed

\section{Broad Area: External Influences}

\section{Axial Categories within Broad Area}

\section{Government Incentives and Specific Policy Interventions}

\section{Variables:}

DFC

Government subsidies

Public awards

Export Guarantee Office

Export tax incentives 
Inventions Development Authority

Business Development Boards

Flexible R\&D funding mechanisms such as PRCS

Public R\&D funding

TBG

Government as the main customer for innovation

Export incentives

Tradenz

\section{Industry Structure and Organisation}

\section{Variables:}

Industry structure

NZ has a good cross section of industry

Arrogance by large companies against smaller companies

Existence of a clear industry structure

Importance of trade shows

Producer Boards

Restriction in competition due to industry structure

Vertical integration from production to market as an innovation stimulus

Centralised coordination of $\mathrm{R} \& \mathrm{D}$

Pressures to benefit the whole industry, especially through generic technology

Industry Associations

Industry-wide awards

Industry associations giving a lead

Threat of withdrawal of Producer Board funding

Research Association involvement 


\section{Catastrophic Events}

Variables:

Catastrophic events

Accidents

1987 sharemarket crash

\section{Economic and Regulatory Reforms and Environment}

\section{Variables:}

Economic reforms in the 1980 s

Open trade policy

Farming crisis in the 1980s

Deregulation

Taxation

Employment Contracts Act

Establishment of CRIs with full commercial powers

CRI establishment means that individuals as well as institutes behave more commercially

Science reforms

Commercial structures, powers and incentives for CRIs

Dependence of a research institute on a company or industry surviving

Transfer of Q.A. and other technical servicing functions from government to industry

CRI establishment and science reforms leads to short termism

Import controls as a stimulus to innovation

Comfort from a protected market stifles innovation

Competition

Trade unions

External economic debate and criticism of an industry 
Economic bad times are a spur to innovation

\section{Regulatory and Legal Factors}

Variables:

Existence of regulatory standards

Barrier of overseas regulations

ISO 9000

Country by country differences in technical and regulatory standards

Liability issues

External standards drive specifications

Market access barriers to added value products

Overseas regulatory standards as a barrier to NZ innovation

Regulatory barriers can create opportunities

\section{Nature and Ownership of a Company}

\section{Variables}

Type of ownership of a business

Management buy-out

NZ ownership

Ownership structure

Family companies

Private companies

Innovative companies tend to be unlisted

Partnerships

Privatisation

Subsidiaries hide R\&D from the Head Office parent company

Non-public company forms of ownership

SMEs 
Ownership and control

\section{Customer and Market Influences}

\section{Variables}

Market-driven innovation

Customer and market influences

Customer-driven specifications

Local market is a microcosm of world market

Lead users

Response to health concerns

Health barriers to innovation

OOS stimulus to innovation

Innovation is intensely needs driven

Pressures to get onto the market before the competition

Desire for practical functionality in a commercial environment

Belief by customers in health properties of a food

Exceptionally high quality requirements force companies to "raise their act"

Defence innovations associated with shrinking defence budgets

Need for direct link with consumers, not just customers and distributors

Customers often not consumers

Interactive dialogue with customers

Existence of a discerning customer

Clear and explicit specification of a need

Customer-driven innovation

Use of market stepping stones

Niche market that allows multiple variants and type specifications

Customers, especially overseas customers, that signify to other customers the prestige and credibility of a product

Niche markets

Sensitivity and responsiveness towards market and business trends 
Sudden change in the market

Unexpected and non-traditional markets

Changing fashions

Specialist innovators have at least some customer contact

Consumers concerned with ethics/safety/purity/sustainability of production processes, as well as with the product consumed

Food health and safety

Lifestyle changes

Environmental concerns influence innovation

Comfort and wellbeing

8. Cultural Environment

Variables:

Kiwi "clobbering machine"

Cultural niche markets

Treaty of Waitangi issues

"Invented here" syndrome

Cultural affinities with some overseas markets

9. Geography and Location

Variables:

Closeness to Asia

Small towns

Location

Provincial cities

Isolation of many $\mathrm{NZ}$ industries increases eagerness to discuss and adopt new ideas

Geographic closeness of institutes or innovators and adopters of technology 
Geographic buffer to competition

\section{Overseas and International Influences}

\section{Variables:}

International trade fairs crucial launching platform for overseas sales

Innovations developed for offshore clients

Overseas sales establish credibility of an innovation in NZ

NZ's image overseas

International markets force a higher level of technological development and innovation than domestic markets

Overseas companies as first adopters of innovation

Company with a global presence

Adaptation to foreign tastes

Overseas visits, offices and secondments to do market research etc

Export market

International marketing

Importance of international scientific and technical conferences

LDCs providing niche markets

\section{External People and Ideas}

Variables:

Lack of external stimulus means people become clones of each other and innovation is stifled

External consultants can be disastrous

Good value from external consultants

Immigrants

External consultants without "ownership" can be dangerous

Technically literate external director 
Need for access to specialised external expertise and sources of help Exposure to new ideas from new people from outside 


\section{ANNEX 3.1: AN EXAMPLE OF THE INFORMATION RECORDED ON AN OPEN CODED CARD}

\section{Open Coded Variable: Trust}

Occurs

It occurs in a positive or negative sense in most cases, but especially strongly in the Ruakura Milk Harvester, Greenweld and DieselGas cases. Strong variable in secondary data sources (eg. Tait Electronics).

\section{Taxonomic Description}

A belief in how others behave that cannot be objectively verified or contracted for. An assumption about how things will be in conditions of uncertainty, based on observed behaviour.

\section{Comment}

Technological innovation is a process subject to uncertainty. It depends on behaviour which is difficult to contract for and is subject to measureability problems and problems of opportunism. Trust therefore emerges to address these problems of uncertainty and lack of measureability, and to allow business to be transacted and innovation to occur. 


\title{
ANNEX 3.2: AN EXAMPLE OF THE INFORMATION RECORDED ON AN AXIAL CODED CARD
}

\author{
Axial Category: Evolutionary Origins
}

\section{Causal Conditions}

Key causal condition is that "things come from somewhere". Also, the concepts of the genotype and phenotype, punctuated equilibrium, selection environments, irreversibility and cumulativeness, technical platform effects, non-rival goods, pathdependency and trajectories. Causal conditions include the struggle to survive, or at least to get better, and also how agents/firms etc. impact on and shape their environment.

\section{Properties}

Properties include the concepts of change and serendipity, cumulativeness, and sometimes suboptimality (due to "Mathew Effect" etc.). Properties include time, the tacit transmission of ideas and technologies through time, and the embodied as well as disembodied properties of technology (see for example robust, evolutionary designs). Properties of evolutionary-related variables include the tendencies for improvement due to selection pressures and "survival of the fittest".

\section{Context}

Bounded by the past but also by the limits of a company's resources, skills, in-house competencies and the limits of the selection environment. But it can be radically changed by basic scientific breakthroughs and punctuated equilibrium-type effects. Variables exist in an interdependent context. Innovations exist in relation to other innovations and are not divisible. Relationship between extent of technical platform and non-rival effects and the embodiment/disembodiment of technology. 
Innovations interact with each other, spawn new ones, and compete against each other, including in "idea space". The engine of change and dynamics of how things respond to and interact with external stimuli. The outcome of this is "more from less".

\section{Links and Relationships within Categories}

All variables are linked by the role of time, the effects of the past, interaction with the external environment, and above all by the concept of something (eg. a "meme") that flows like an immortal river through a series of mortal vessels. Also, innovations and different variables interact with each other.

Tentative Links with Existing Theory, Other Knowledge and Data

Very strong links to evolutionary economics and to a lesser extent neo-Schumpeterian perspectives. Links with the ideas implicit in new growth theory, though these links are not let explicit in new growth literature. 


\section{ANNEX 4: CORE CATEGORY VARIABLES}

\section{Introduction}

This annex sets out the core categories developed through axial and selective coding and lists the variables encompassed within each core category. In some cases, one variable encompasses or merges several closely related variables generated through open coding. Annex 4.1 attached provides an example of the information resulting from selective coding that is recorded on a core category card.

\section{Core Category: Dynamics of Significant New Technology}

\section{Brief Description}

The nature of significant new technology, defined as technology that embodies new functional properties or technical characteristics that deliver improved quality, performance or "fitness for purpose" which is objectively measurable, and the dynamics of that technology over time.

\section{$\underline{\text { Variables }}$}

Invention is irreversible

Memes

Innovations draw on antecedent technology

Technical platforms

Invention as the "mother of necessity"

Transmission of tacit technology over time

Additional benefits subsequent to an innovation

One innovation gives rise to another or related one

International databases and external sources of technology

International links reducing $R \& D$ redundancy 
Published scientific papers

Extremely demanding outside specifications as stimulus to innovation

Recruitment of external personnel

\section{Formal R\&D}

Basic science (including that resulting from focused or applied research)

Technological interests and competencies transmitted from parent to child

Specific problems of New Zealand materials

Technological paradigm shift

Tacitness

Availability of radical new technologies

New functional properties

Embedded uniqueness

Multiplier effects of systemic innovation

Inherent functional properties of a product allow differentiation

Strong commitment and sunk costs in existing incumbent technologies or skill-bases

Advanced technologies involve specific problems which are themselves valuable learning experiences

Very good ideas/technologies tend to be successfully commercialised eventually; inept implementation will delay but not stop them

Specificity of innovation

Specific innovation creates generic platforms

Intangibility of competencies and skills makes them difficult to borrow against

Clusters of innovation

Economies of scope

History of innovation sets regulatory standards

Asset specificity

Uncertainty

Satisficing rather than optimising technology

Innovation as "new combinations"

Technical or functional characteristics of a product determines innovative potential 


\section{Core Category: Human Capital}

\section{Brief Description}

The intangible assets of peoples' skills, experience and education, ideas, information and knowledge, including their creation.

\section{$\underline{\text { Variables }}$}

Overseas ideas, technologies and stimulus

Overseas databases

Failed research leads to success

Learning from failure

International collaboration

Overseas technical people

Publication of ideas and results

Technical journals

Patents

Public technostructure

Public research institutes

Links with industry and university research

Alliances by companies with universities and research institutes

Information exchange between universities/institutes and companies

Innovative output of graduate student level research

Companies leading institutes in innovation

Market/customer origins of innovation

Customer contact or problem solving stimulates innovation

Innovation is focused on real problems/opportunities

Innovation to meet a very specific tender

Formal idea generating processes

Brainstorming sessions 
Systematic scanning for external sources of technology

"Creative swiping"

Formal searching for opportunities

Recruitment of external people

Interaction with ideas generated by others

Students doing research in companies

Companies spinning off from existing companies

External critique of innovation

Free exchange of scientific ideas

Openness and exposure to new ideas

Flash of insight

Lateral thinking

Dreams

Luck favours a prepared mind

Good ideas come from doing things

Pattern recognition

Divergent thinking

Serendipity

Intuition

Recognition

Reflective thinking

Analytical convergent thinking

Making unexpected connections

Accidents

Orthogonal thinking

Key ideas often stimulated by people with quite different experience

Ideas spin-off orthogonally from focused development

Ideas from factory floor

Formal R\&D

Companies doing strategic research

Companies as R\&D labs

Companies supporting $\mathrm{PhD}$ research 
Companies doing world-class research

Basic science input from outside core innovation field

Family origins of innovation

Human capital transmitted through families

Tacit technology

"Nature of technology" variables

Access to specialised external people

External people and ideas

\section{Core Category: Social Processes}

\section{Brief Description}

The informal relationships and interactions between people, grounded in their perceptions of and feelings towards each other, and the voluntary, informal "implicit contracts", shared values and beliefs that drive behaviour among people.

\section{$\underline{\text { Variables }}$}

Brainstorming sessions

Interaction with ideas generated by others, especially external ideas

Free exchange of ideas among scientists

Key ideas of innovators stimulated by other people with different experiences

Teamwork; innovation as a team/group rather than individual phenomenon

"Rugby approach" to innovation

Company culture

An enabling culture

Belief that a company should make a positive contribution to society

Family atmosphere

Toleration of the "oddball"

Organisational cohesion 
Ecological cooperation

People complementing each other

Conflict

People back people

Complementary personalities

Personal interrelationships

People in an innovation team getting on well together

Mutual respect

Friendship or personal relationships

Personal rapport

Leadership

Empowerment

Letting people have their say

Need to manage upwards as well as downwards

Mentoring and other means of fostering innovators

Innovative people are difficult to manage

Leading visibly from in front

Communication

Ability of scientists and technologists to communicate with workers

Willingness to listen to others

Worker "buy in" to an innovation at an early stage

One manager must have the overview

Leadership by example rather than decree

"Loose cannons on deck" must be controlled

Focus on peoples' strengths to make their weaknesses irrelevant

Key scientists and technologists must be involved all the way through

Success breeds further success

Perceived expertise leads to confidence

Culture, values, belief systems of founder pervades firms after his departure All staff recognise the company $\mathrm{CEO}$ or owner

Innovation leader must be able to explain things clearly and communicate the vision 
Knowledge that a patriarchal or charismatic figure will look after staff is a "glue that binds"

\section{Clannishness}

\section{Trust}

\section{Reputation}

Duty and ethics

Very explicit value system of key people

Good relationships in technological innovation minimise need for prescriptive contracts

Persanality sonflicts

Cooperation

Respect for colleagues

Relationship between trust and risk

Social ethics

Loyalty and commitment resulting from observing innovators trying to build and create something bigger than their material interests

Teamwork itself as a motivation 


\section{ANNEX 4.1: AN EXAMPLE OF THE INFORMATION RECORDED ON A CORE CATEGORY CARD}

\section{Core Category: Dynamics of Significant New Technology}

\section{Brief Description}

The nature of significant new technology, defined as technology that embodies new functional properties or technical characteristics that deliver improved quality, performance or "fitness for purpose" which is objectively measurable, and the dynamics of technology over time.

Key Variables/Categories of Variables Making up the Core Category

Invention is irreversible/Memes/Innovations draw on antecedent technology/Technical platforms/Inventions as the "mother of necessity"/Transmission of tacit technology over time/Additional benefits subsequent to an innovation/One innovation gives rise to another or related one/International databases and external sources of technology/ International links reducing $\mathrm{R} \& \mathrm{D}$ redundancy/Published scientific papers/Extremely demanding outside specifications as stimulus to innovation/Recruitment of external personnel/Formal R\&D/Basic science (including that resulting from focused or applied research)/Technological interests and competencies transmitted from parent to child/Specific problems of New Zealand materials/Technological paradigm shift/Tacitness/Availability of radical new technologies/New functional properties/Embedded uniqueness/Multiplier effects of systemic innovation/Inherent functional properties of a product allow differentiation/Strong commitment and sunk costs in existing incumbent technologies or skill-bases/Advanced technologies involve specific problems which are themselves valuable learning experiences/Very good ideas/technologies tend to be successfully commercialised eventually; inept implementation will delay but not stop them/Specificity of innovation/Specific innovation creates generic platforms/Intangibility of competencies and skills makes 
them difficult to borrow against/Clusters of innovation/Economies of scope/History of innovation sets regulatory standards/Asset specificity/Uncertainty/Satisficing rather than optimising technology/Innovation as "new combinations"/Technical or functional characteristics of a product determines innovative potential

\section{Observations/Descriptions/Discussion of Data within Core Category}

The core category encompasses several different sub-categories of variables. One type of sub-category (eg. non-rival attributes, asset specificity, path-dependency) is made up of variables that are major drivers of other variables or sub-categories of variables. Other sub-categories of variables are essentially to do with how significant new technology is an expression or manifestation of other variables (eg. how significant new technology is the outcome of pattern recognition ability). Another sub-category of variables relates to the behavioural dynamics of technology over time.

Observations/Descriptions/Discussion of Nature of Data/Relationships between Core Category and Other Variables

This core category combines the nature of significant new technology with variables relating to evolutionary perspectives, and the dynamic behaviour of technology over time. It is closely associated with the origins of innovation variables, such as cognitive processes, with human capital creation, and with formal R\&D. It is partly the end product of other variables and exists in relation to them. It is especially associated with the Nature of Innovators category [an interim core category later absorbed into Social Processes], in the sense that without human creativity, cognitive processes etc. significant new technology would not be created.

It is a core category and driver in the sense that significant new technology causes things to happen - eg. by its non-rivalry, technical platform, path-dependency and technological trajectory effects. 


\section{ANNEX 5: VARIABLES RELATING TO TECHNOLOGICAL LEARNING}

This annex lists variables relating to learning processes in innovation, illustrating how differentiated learning processes provide a unifying thread across core categories. It includes both learning-related variables that are integral to core categories, and also variables from other axial categories that are linked or associated with core categories.

The learning-related variables are organised by the core category they are part of or are associated with. Where they do not easily fall within a core category they are listed under the category "Other Learning-Related Variables".

\section{Dynamics of Significant New Technology Core Category}

Innovations draw on antecedent technology

Failed research leads to success

Availability of radical new technologies

Advanced technologies involve specific problems which are themselves valuable learning experiences

Innovation often blends applied technology and basic understanding

Major "cross overs" of science from other fields

Learning from failure

Avoidance of "locking in" designs, software structure etc. too early

As technology grows in complexity there is a need for companies to increasingly rely on external sources of expertise

Success with applied product development can stimulate more basic scientific work 


\section{Human Capital Core Category}

Fundamental skills and knowledge from universities

Recruitment of external personnel

Serendipity

Intuitive thinking

Same family maintains an interest in the same technology over several generations

Technological interests and competencies transmitted from parent to child

"Shock of recognition"

Ability to recognise and see the significance of an unexpected result

"Kiwi ingenuity"

Luck favours a prepared mind

Good ideas come from actively doing things, not sitting as a desk or "just thinking" Flash of insight or understanding

Openness and exposure to new ideas is associated with rapid technological advances

Innovative ideas spin-off orthogonally from focused development

Divergent thinking

Pattern recognition ability

Lateral thinking

Innovators often come from outside the commercialising company

Students finishing off or doing their degrees in companies

Innovative companies spinning off from existing companies

Key scientists/engineers have an input into a wide range of innovations by others

The act of innovation itself builds up expertise, skills and human capital as spin-offs

Movement of people as technology transfer

Research institute staff with private sector experience

Rich and diverse background experience

Mobility between the university and research institute sectors

Academics with an industry background

Innovators with a broad-based academic background

Experience in overseas research institutes 
Long-serving staff

\section{Social Processes Core Category}

Customer contact or problem-solving directly stimulates innovation

Industry/marketing person isolating potential of a technology that was otherwise seen as a failure

Key ideas of innovators stimulated by other people with different experiences

Good ideas come from the factory floor

Brain storming sessions

Free exchange of scientific ideas among scientists

Open and free exchange of ideas

Ideas generated for research institutes by company clients

Key ideas of innovators stimulated by other people with different experiences

Teamwork: innovation as a team/group rather than individual phenomenon

"Rugby approach" to innovation

Concurrent engineering

Cross-functional teams

Social architecture

Flat organisational structure

Innovation forces companies to change structure and workplace organisation

Personal interrelationships

People in an innovative team getting on well together

Mutual respect

Friendship and personal relationships

Personal rapport

Key people must be involved early, preferably at inception

Communication

Open communication with no hidden agendas

Open exchange of information

Good communication between top management and the innovative team 
Ability of scientists/technologists to communicate with workers

Willingness to listen to others

Key people doing the whole job, including $R \& D$, marketing, servicing etc

Interactive feedback from users/industry while $R \& D$ is underway

Engineers and innovators interacting closely with customers

\section{Other Learning-Related Variables}

\section{Ideas coming from overseas}

Imitation

International databases and external sources of technology

Involvement of international technical people

International links reducing $\mathrm{R} \& \mathrm{D}$ redundancy

Published conference results

Importance of technical trade journals

Published scientific papers as a major stimulus to innovation

Publication of new ideas is underrated as technology transfer

\section{Patents}

Research institutes providing a secondary input into an industry-driven innovation

Intellectual freedom in DSIR and universities

Technology transfer seminars and promotions

University-based innovation

University research underpinning industry R\&D

Academics/scientists generating new ideas

Public research institutes used to provide a very specialised technical input

University/industry joint projects

Long-term alliances with universities

Research institutes needing an intimate knowledge of industry

Supportive public infrastructure

Industry-sponsored, university-conducted research

Information exchanges between universities/institutes and companies 
Research institutes providing a key technical input of technology unavailable to the innovator

Innovations do come from "public good" research

Development of an innovation to meet a very specific tender

Impossible outside specification as stimulus to innovation

Systematic method of scanning for external sources of technology

Creative swiping

Formal searching for external technology

Formal process of identifying opportunities

Interaction with ideas identified by others, especially external ideas

Benefits of external critiques of innovation

Use of external technical consultants

Analytical convergent thinking

Making connections between unrelated things

Accident and chance events

Time needed for in-depth, reflective thinking

Existence of structured R\&D

Some companies do strategic research

Companies supporting $\mathrm{PhD}$ research

Companies that are wholly or partly R\&D contract labs

World-class research on industry problems

$\mathrm{PhD}$ research can be of direct commercial benefit to companies

Importance of basic science input from outside the core innovation field

Understanding of the theoretical base or basic science underlying an innovation

Basic research knowledge resulting from focused research

Frustrating farm problems as a source of innovation

Innovation resulting from frustrating technical problems

Innovation to deal with a bottleneck

Increasing external pressure for safety, purity and QA

Technological innovators should interact across disciplines and specialities and not be segmented

Need for focus early on 
Innovation must be directed to an end purpose

Long term strategic relationships with component suppliers

Technical partnerships between companies

Technology-based companies often work together

Technical assistance through networking

Research institutes having a commercial partner

Cooperative or collaborative technological links with other companies in the same group

International collaboration

Close, interactive and long-term relationships with suppliers

Need for companies to interact positively with other competing companies

Networking strategically externally

Networking and technical cooperation between non-competing NZ companies

Ability to recognise and avoid or withdraw from "blind alleys"

Learning on the job and learning by doing

Technical people mobile through an industry

Key people in an innovation from outside an industry

Strong background in the field/industry

Innovators from Defence, Post Office and DSIR backgrounds

Innovations arising from recreational interests

Family background

Childhood hobbies and "tinkering" 


\section{BIBLIOGRAPHY}

Abramowitz, M. 1956: 'Resource and Output Trends in the United States since 1870', American Economic Review, Vol. 46, Papers and Proceedings, pp. 5-23.

Acar, W.; Melcher, A.J. 1989: 'The Implementation of Innovative Strategies', International Journal of Technology Management, Vol. 4, No. 6, pp. 631-651.

Ackerman, C. ; Harrop, J. 1985: 'The management of technological innovation in the machine tool industry: a cross-national regional survey of Britain and Switzerland', R\&D Management, Vol. 15, No. 3, pp. 207-218.

Acs, Z.T.; Audretsch, D. B. 1988: 'Innovation in Large and Small Firms: An Empirical Analysis', American Economic Review, Vol. 78, No. 4, pp. 678-690.

Added Value 1991: 'New boning automation at the cutting edge of technology', Added Value, October, Issue 4, pp. 1-3.

Added Value 1990: 'Equipment export to Russia is a milestone for MIRINZ Development Engineers', Added Value, February, Issue 2, pp. 1-3.

Ahlbrandt, R.S.; Blair, A.R. 1986: 'What it takes for Large Organisations to Be Innovative', Research Management, Vol. XX1X, No. 2, pp. 34-37.

Akin, G.; Hopelain, D. 1986: 'Finding the Culture of Productivity', Organisational Dynamics, Winter, pp. 19-32.

Allen, T.J. 1977: Managing the flow of technology. Cambridge, MA., MIT Press.

Allen, T.J.; Cohen, S.I. 1969: 'Information flow in research and development laboratories', Administrative Science Quarterly, Vol. 14, pp. 12-19. 
Amabile, T.M. 1983: The Social Psychology of Creativity. New York, SpringerVerlag.

Amendola, G.; Dosi, G.; Papagni, E. 1993: 'The dynamics of international competitiveness', Weltwirtschaftliches Archiv, Vol. 129, pp. 451-471.

Amendola, M.; Gaffard, J.L. 1988: The Innovation Choice: An Economic Analysis of the Dynamics of Technology. Oxford, Basil Blackwell.

Amesse, F.; Desranleau, C. 1991: 'The Individual Inventor and the Role of Entrepreneurship: A Survey of the Canadian Evidence', Research Policy, Vol. 2, No. 1, pp. 13-27.

Arrow, K.J. 1962a: 'Economic Welfare and the Allocation of Resources for Inventions.' In: Nelson, R.R. (ed.) 1962: The Rate and Direction of Inventive Activity. New York, Princeton University Press. pp. 609-625.

Arrow, K.J. 1962b: 'The Economic Implications of Learning by Doing', Review of Economic Studies, Vol. 29, No. 80, pp. 155-173.

Arrow, K.J. 1971: Essays in the Theory of Risk-Bearing. Chicago, Markham.

Arrow, K.J. 1984: The Economics of Information. Collected Papers, Vol. 4. Oxford, Blackwell.

Arthur, W. B. 1989: 'Competing Technologies, Increasing Returns and Lock-In by Historical Events', Economic Journal, Vol. 99, March, pp. 116-131.

Atkinson, J.D. 1976: DSIR'S First Fifty Years. Wellington, DSIR. 
Authier, J.F. 1990: 'Mechanical dressing developments.' In: Proceedings of the 26th Meat Industry Research Conference, Hamilton, MIRINZ. pp. 225-231.

Automation and Control 1982: 'About Wormald Vigilant: In the Beginning', Automation and Control, May, pp. 17-21.

Automation and Control 1983: 'The Microdrive - a third generation AC motor speed controller', Automation and Control, September, pp. 31-34.

Automation and Control 1985: 'PDL Electronics, guardian of the production line', Automation and Control, August, pp. 33-43.

Automation and Control 1986a: 'AC motors under variable speed control', Automation and Control, October, pp. 52-54.

Automation and Control 1986b. 'Advanced transistor drives', Automation and Control, April, pp. 21-24.

Automation and Control 1989a: 'AU/PDL Intelligent drive enters the market', Automation and Control, January, pp. 26-28.

Automation and Control 1989b: 'Commercial loin-boner', Automation and Control, December 1989/January 1990, p. 3.

Automation and Control 1989c: 'Key MIRINZ focus on automated sheep boning', Automation and Control, August, p. 13.

Automation and Control 1989d. 'PDL People', Automation and Control, February, p. 8.

Automation and Control 1990: 'PDL appointments', Automation and Control, February, p. 8. 
Automation and Control 1991a: 'Intelligent AC drives (1) The technology', Automation and Control, August, pp. 18-22.

Automation and Control 1991b: 'Intelligent AC drives (2) Marketing/Application', Automation and Control, September, pp. 16-21.

Automation and Control 1991c: 'Microdrive-3 - PDL takes the next step', Automation and Control, May, pp. 7-8.

Automation and Control 1992a: 'Horse sense', Automation and Control, February, p. 15.

Automation and Control 1992b: 'PDL wins award', Automation and Control, July, p. 4.

Automation and Control 1993a: 'Measuring the future - machine vision and automation', Automation and Control, June, pp. 18-20.

Automation and Control 1993b: 'Sealed environment sets new PDL Udi drive apart', Automation and Control, February, pp. 18-19.

Automation and Control 1994: 'Overseas demand drives ongoing development at PDL', Automation and Control, September, pp. 8-10.

Ayres, R.U.; 1992: CIM: 'A Challenge to Technology Management', International Journal of Technology Management, Vol. 7, Nos. 1, 2, 3, pp. 17-40.

Baker, N. R.; Green, S.G.; Bean, A.S. 1986: 'Why R\&D projects succeed or fail', Research Management, Vol. XXIV, No. 6, pp. 29-34. 
Barber, B. 1983: The Logic and Limits of Trust. New Brunswick, N.J. Rutgers University Press.

Barclay, I. 1992a: 'The new product development process: past evidence and future practical application', R\&D Management, Vol. 22, No. 3, pp. 255-264.

Barclay, I. 1992b: 'The new product development process: Improving the process of new product development', R\&D Management, Vol. 22, No. 4, pp. 307-318.

Barnett, W.P. 1990: 'The Organisational Ecology of a Technological System', Administrative Science Quarterly, Vol. 35, No. 1, pp. 31-60.

Barras, R. 1990: 'Interactive innovation in financial and business services: The vanguard of the service revolution', Research Policy, Vol. 19, No. 3, pp. 215-237.

Bartel, A.P.; Lichtenberg, F.R. 1990: 'The Age of Technology and its Impact on Employee Wages', Economics of Innovation and New Technology, Vol. 1 (Specimen Issue), pp. 1-16.

Basalla, G. 1988: The Evolution of Technology. Cambridge, Cambridge University Press.

Batten, D.; Casti, J.; Johansson, B. (eds.) 1987: Economic Evolution and Structural Adjustment. Berlin, Springer-Verlag.

Bedford, J. 1994: 'Reducing impact of air on milkline', Dairy Exporter, April, p. 93.

Betz, F. 1987: Managing Technology: Competing through New Ventures, Innovation and Corporate Research. Englewood Cliffs, New Jersey, Prentice Hall.

Bijker, W.E.; Hughes, T.P.; Pinch, T.J. (eds.) 1987: The Social Construction of Technological Systems. Cambridge, MA., MIT Press. 
Bijker, W.E.; Law, J. (eds.) 1992: Shaping Technology/Building Society: Studies in Sociotechnical Change. Cambridge, MA., MIT Press.

Birt, C. 1983: 'Making kiwifruit wine for the world', Food Technology in New Zealand, March, pp. 10-13.

Blakstad, M. 1979: The Risk Business. London, The Design Council.

Blandy, R.; Dawkins, P.; Gannicott, K.; Kain, P.; Kasper, W.; Kriegler, R. 1985: Structured Chaos: The Process of Productivity Advance. Melbourne, Oxford University Press.

Boddy, D.; Buchanan, D. A. 1986. Managing New Technology. Oxford, Basil Blackwell.

Boisot, M.H. 1995: Information Space. A Framework of learning in organisations, institutions and culture. London, Routledge.

Bollard, A.; Harper. D. 1987: Research and Development in New Zealand: A Public Policy Framework. Wellington, NZIER.

Bowie, R.; Bollard, A. 1987: The Diffusion of Microelectronics through New Zealand Mamufacturing. Wellington, NZIER.

Bowonder, B.; Miyake, T. 1992: 'A model of corporate innovation management: some recent high tech innovations in Japan', R\&D Management, Vol. 22, No. 4, pp. 319-336.

Bowonder, B.; Miyake, T. 1993: 'Japanese innovations in advanced technologies: an analysis of functional integration', International Journal of Technology Management, Vol. 8, Nos. 1/2, pp. 135-156. 
Boys, J. 1988: 'Intelligent AC Drive- What it is and how it works', Automation and Control, January, pp. 19-23.

Braverman, H. 1974: Labor and monopoly capital. New York, Monthly Review Press.

Bray, M.; Perry, M. 1994: Innovation and the market: Lessons and experiences from the DSIR. Wellington, NZ Institute of Social Research and Development.

Brocklesby, J. 1984: 'Technological Change and the Labour Process - Towards an Analysis of Computerisation in the New Zealand Trading Banks', New Zealand Journal of Industrial Relations, Vol. 9, No. 3, pp. 195-210.

Bromily, P.; Cummings, L.L. 1992: Transaction costs in organisations with trust. Working Paper No. 28, Strategic Management Research Center, University of Minnesota, Minneapolis.

Brown, S.L.; Eisenhardt, K.M. 1995: 'Product Development: Past Research, Present Findings, and Future Directions', Academy of Management Review, Vol. 20, No. 2, pp. 343-378.

Brown, W.B. 1981: Smoothing the Process of Organisational Innovation. Working Paper No 6, Department of Management Studies, Auckland University.

Bryman, A. (ed.) 1988: Doing Research in Organisations. London, Routledge.

Burgelman, R.A.; Sayles, L.R. 1986: Inside Corporate Innovation: Strategy, Structure and Managerial Skills. New York, The Free Press. 
Burkhardt, M.E.; Brass, D.J. 1990: 'Changing Patterns or Patterns of Change: The Effects of a Change in Technology on Social Network Structure and Power', Administrative Science Quarterly, Vol. 35, No. 1, pp. 104-127.

Burns, D. J.W. 1981: 'Juices, Nectars and Enzymes from Kiwifruit.' In: Robertson, G. (ed.) 1981. Proceedings of a Seminar on the Processing of Kiwifruit and other Subtropicals. Palmerston North, Department of Food Technology, Massey University. pp. 35-43.

Bush, V. 1945: Science: The Endless Frontier. Washington DC, United States Office of Scientific Research and Development.

Business Outlook 1992: 'Vega's a leading light', Business Outlook, June, p. 14.

Butler, J.K.; Cantrell, R.S. 1984: 'A behavioural decision theory approach to modeling dyadic trust in superiors and subordinates', Psychological Reports, Vol. 55, pp. 19-28.

Cainarca, G.C.; Colombo, M.G. Mariotti S. 1989: 'An evolutionary pattern of innovation diffusion. The case of flexible automation', Research Policy, Vol. 18, No. 2, pp. 59-86.

Callaghan, F.R. (ed.) 1957: Science in New Zealand. Wellington, A.H. and A.W. Reed.

Campbell, C. 1982: Industry Planning, Industry Policy and Technical Change. Unpublished $\mathrm{PhD}$ thesis in economics. Wellington, VUW.

Campbell, G. 1993: 'Bright Light, big future', Listener, 4 September, pp. 26-27.

Campbell, P. 1983: 'Project headed for world markets', Kapiti-Mana News, March, p. 3. 
Carnaby, G.A. 1994: The Role of Technology in 100 years of New Zealand Wool. Lincoln, WRONZ.

Carson, M. 1994: 'Innovation in NZFRI Research', NZFRI Research Directions, September, p. 3.

Cassell, C.; Symon, G. (eds.) 1994: Qualitative Methods in Organisational Research. A Practical Guide. London, Sage Publications.

Cesaratto, S.; Mangano, S.; Sirilli, G. 1991: 'The Innovative Behaviour of Italian Firms: A Survey on Technological Innovation and R\&D', Scientometrics, Vol. 21, No. 1, pp. 115-141.

Chakrabarti, A.K. 1974: 'The role of champion in product innovation', California Management Review, Vol. 17, No. 2, pp. 58-62.

Chakrabarti, A.K.; Hauschildt, J. 1989: 'The Division of Labour in Innovation Management', R\&D Management, Vol. 19, No. 2, pp. 161-171.

Chakrabarti, A.K.; Souder, W.E. 1984: 'Critical Factors in Technological Innovation and Their Policy Implications', Technovation, Vol. 2, No. 4, pp. 255-275.

Chidamber, S.R.; Kon, H.B. 1994: 'A research retrospective of innovation inception and success: the technology push, demand pull question', International Journal of Technology Management, Vol. 9, No. 1, pp. 94-112.

Child, J.; Bate, P., eds. 1987: Organisation of Innovation: East-West Perspectives. Berlin, Walter de Gruyter. 
Cimoli, M.; Dosi, G. 1995: 'Technological paradigms, patterns of learning and development: an introductory roadmap', Journal of Evolutionary Economics, Vol. 5, No. 3, pp. 243-268.

Clark, J.; McLoughlin, I.; Rose, H.; King, R. 1988: The Process of Technological Change. Cambridge, Cambridge University Press.

Clark, K.B.; Fujimoto, T. 1991: Product Development Performance. Boston, Harvard Business School Press.

Clark, N.; Juma, C. 1987: Long-Run Economics: An Evolutionary Approach to Economic Growth. London, Pinter Publishers.

Clark, P. 1987: Anglo-American Innovation. Berlin, Walter de Gruyter.

Cleland, P. 1993: Dairy Production and Processing: Research Strategy for the Public Good Science Fund. Wellington, Foundation for Research, Science and Technology.

Coase, R. 1937: 'The Nature of the Firm', Economica, Vol. 4, pp. 386-405.

Coe, D.T.; Helpman, E. 1993: International R\&D Spillovers. Working Paper of the International Monetary Fund.

Cohen, W.M.; Levinthal, D.A. 1989: 'Innovation and Learning: The Two Faces of R\&D', The Economic Journal, Vol. 99, September, pp. 569-595.

Cohen, W.M.; Levinthal, D.A. 1990: 'Absorptive Capacity: A New Perspective on Learning and Innovation', Administrative Science Quarterly, Vol. 35, No. 1, pp. 128152. 
Cohn, S.F. 1980: 'Characteristics of Technically Progressive Firms', Omega, Vol. 8, No. 4 , pp. $441-450$.

Cohn, S. F. 1981: 'Adopting innovations in a technology push industry', Research Management, Vol. XXIV, No. 5, pp. 26-31.

Construction 1986: 'Field logger reduces corrosion', Construction, November, p. 17.

Conway, H.A.; McGuinness, N.W. 1986: 'Idea Generation in Technology-Based Firms', Journal of Product Innovation Management, Vol. 4, No. 3, pp. 276-291.

Coover, H.W. 1986: 'Programmed innovation - strategy for success', Research Management, Vol. XXIX, No. 6, pp. 12-17.

Couchman, P.K. 1984: Government and Technological Change: The Social Implications of Science and Technology Policy. Unpublished MPP research paper. Wellington, VUW.

Couchman, P.K. 1987: 'The Paradoxical Nature of Technological Change: A Sociological Perspective.' In: Technology and Society: New Directions in Social Research. Proceedings of a symposium jointly sponsored by the DSIR and the SSRFC. Wellington, SSRFC.

Couchman, P.K. 1989: 'Opening Black Boxes: The Social Dimensions of Science and Technology and their Relevance to the Current Policy Debate', NZ Science Review, Vol. 46, Nos. 1-3, pp. 49-54.

Couchman, P.K.; Fitzgerald, G.; Warren, J. 1988: Technological change and social policy: A Directions Paper. Wellington, DSIR. 
Cowan, R; Foray, D. 1995: 'Quandries in the economics of dual technologies and spillovers from military to civilian research and development', Research Policy, Vol. 24 , No. 6 , pp. $851-868$.

Crawford, C.M. 1980: 'Defining the Charter for Product Innovation,' Sloan Management Review, Fall, pp. 3-12.

Crawford, C.M.1987: New Products Management. Homewood, Illinois, Irwin.

Cremer, J. 1993: 'Corporate Culture and Shared Knowledge', Industrial and Corporate Change, Vol. 2, No. 3, pp. 351-386.

Crocombe, G.T.; Enright, M.J.; Porter, M.E. 1991: Upgrading New Zealand's Competitive Advantage. Auckland, Oxford University Press.

Cullwick, T.D.C.; Kan, M. 1983: Technologically Innovative Firms in New Zealand. Research Paper No. 19. Wellington, Department of Business Administration, VUW.

Cullwick, T.D.C.; Thirkell, P.C. 1977: An Analysis of Factors Associated with the Adoption and Diffusion of Numerically Controlled Machine Tools in New Zealand Engineering Firms. Research Paper No. 12. Wellington, Department of Business Administration, VUW.

Dairy Exporter 1992: 'Attention to milking machines can keep mastitis in check', Dairy Exporter, January, pp. 8-9.

Dairy Exporter 1993a: 'North Island expansions lift whey processing up to $70 \%$ ', Dairy Exporter, June, p. 73.

Dairy Exporter 1993b: 'People in motion linking R\&D centres', Dairy Exporter, August, p. 79. 
Dairy Exporter 1993c: 'Research linkages vital', Dairy Exporter, November, p. 54.

Dairy Exporter 1994a: 'First Global R\&D Review', Dairy Exporter, March, pp. 9293.

Dairy Exporter 1994b. 'Hydrolysed milk proteins cater to athletes, infants, invalids,' Dairy Exporter, May, p. 82.

Dairyman 1990: 'Ruakura Milking System now available commercially', Dairyman, December, p. 9.

Dairy Technology 1989: 'Whey protein plant becomes a major income earner', Dairy Technology, June, p. 1.

Dasgupta, P.; Stoneman, P. (eds.) 1987: Economic Policy and Technological Performance. Cambridge, Cambridge University Press.

David, P. 1985: 'Clio and the economics of QWERTY', American Economic Review, Vol. 75, No. 2, pp. 332-337.

David, P. 1992: "Heroes, Herds and Hysteresis in Technological History: Thomas Edison and 'The Battle of the Systems' Reconsidered", Industrial and Corporate Change, Vol. 1, No. 1, pp. 129-180.

Davies, A. 1986: Industrial Relations and New Technology. London, Croom Helm.

Davis, D.D. (ed.) 1986: Managing Technological Innovation. San Francisco, JosseyBass.

Dean, R.C. 1974: 'The Temporal mismatch - Innovations pace versus management's time horizon', Research Management, Vol. XV11, No. 3, pp. 12-15. 
Dearden, J.; Ickes, B.W.; Samuelson, L. 1990: 'To Innovate or Not to Innovate: Incentives and Innovation in Hierarchies', American Economic Review, Vol. 80, No. 5, pp. 1105-1124.

Debresson, C. 1989: 'Breeding Innovation Clusters: A Source of Dynamic Development', World Development, Vol. 17, No. 1, pp. 1-16.

DeGregori, T.R. 1985: A Theory of Technology. Amers, Iowa State University Press.

Demm 1991: 'Unique experience for exporter', Demm, October, p. 12.

Dempster, P. 1994: Empirical estimates of external returns to business expenditure on R\&D: an introduction to the literature. Working Paper No 91. Canberra, Bureau of Industry Economics.

Denison, E. 1967: Why Growth Rates Differ. Washington, Brookings Institution.

Dertouzos, M.L.; Lester, R.K.; Solow, R.M. 1989: Made in America. Regaining the Productive Edge. Cambridge, MA., MIT Press.

Dodgson, M. (ed.) 1989: Technology Strategy and the Firm. Management and Public Policy. Longman, Harlow.

Dodgson, M. 1990: Technical Learning, Technology Strategy and Competitive Pressures. DRC Discussion Paper No. 77. Brighton, SPRU, University of Sussex.

Dodgson, M. 1991: The Management of Technological Learning: Lessons from a Biotechnology Company. Berlin, De Gruyter.

Dodgson, M. 1993: 'Learning, trust, and technological collaboration', Human Relations, Vol. 46, No. 1, pp. 77-95. 
Dodgson, M.; Rothwell, R. (eds.) 1994: The Handbook of Industrial Innovation. Aldershot, Edward Elgar.

Doessel, D.P. 1987: 'Innovation and Health Expenditure: Some Empirical Results for a Diagnostic Technology', Prometheus, Vol. 5, No. 1, pp. 46-61.

Dominion 1994: 'Joe Pope: the art of making haste slowly', Dominion, 26 August, p. 15.

Dordick, H.S. 1987: Information Technology and Economic Growth in New Zealand. Wellington, Victoria University Press.

Dore, R. 1983: The Social Sources of the Will to Innovate. London, Technical Change Centre.

Dosi, G. 1982: 'Technological Paradigms and Technological Trajectories: a Suggested Interpretation of the Determinants and Directions of Technical Change', Research Policy, Vol. 11, No. 3, pp. 147-162.

Dosi, G. 1984: Technical Change and Industrial Transformation. London, MacMillan Press.

Dosi, G. 1988: 'Sources, Procedures and Microeconomic Effects of Innovation', Journal of Economic Literature, Vol. XXV1, pp. 1120-1171.

Dosi, G.; Freeman, C.; Fabiani, S. 1994: 'The Process of Economic Development: Introducing some Stylized Facts and Theories on Technologies, Firms and Institutions', International Journal of Technology Management, Vol. 3, No. 1, pp. $1-45$.

Dosi, G.; Freeman, C.; Nelson, R.; Silverberg, G.; Soete, L. 1988: Technical Change and Economic Theory. London, Pinter. 
Dosi, G.; Pavitt, K.; Soete, L. 1990: The Economics of Technical Change and International Trade. New York, Harvester Wheatsheaf.

DSIR, 1985: Anmual Report for Year ended 31 March 1985. Wellington, DSIR.

Dwyer, L; Mellor, R. 1990: 'Product Innovation Activities in Australian Manufacturing Industry', Prometheus, Vol. 8, No. 1, pp. 129-148.

Easterby-Smith, M.; Thorpe, R.; Lowe, A. 1991: Management Research: An Introduction. London, Sage.

Ehrensaft, P.; Armstrong, W. 1978: 'Dominion Capitalism: A First Statement', A.N.Z.J.S., Vol. 14, No. 2, pp. 352-362.

Elam, M. 1993: Innovation as the craft of combination. Linkoping, Linkoping University.

Electrical Industry 1988: 'Intelligent control', Electrical Industry, December, p. 32.

Electrical Industry 1989a: 'Coveted NEDA Award goes to PDL Electronics Ltd.' Electrical Industry, September, p. 37.

Electrical Industry 1989b: 'Electrotech '89', Electrical Industry, August, p. 21.

Electrical Industry 1989c: 'Versatile data logger', Electrical Industry, September, p. 36.

Electrical Industry 1990: 'Research fund produces early results', Electrical Industry, December, p. 45. 
Electrical Industry 1991: 'Niche for crystal driver', Electrical Industry, November, p. 18.

Eveleens, W.M. 1995: Data Measurement Issues in Studying the Relationship between Technological Change and Productivity Growth in New Zealand. Unpublished Master of Commerce thesis in Economics. Auckland, University of Auckland.

Export News 1992a: 'Breakthrough at Alliance', Export News, 9 April, p. 6.

Export News 1992b: 'PDL a world leader', Export News, 9 April, p. 12.

Export News 1992c: 'The bright promise of wool', Export News, 9 April, p. 6.

Export News 1992d: 'World beater for Hamilton firm', Export News, 13 February, p. 10 .

Export News 1993a: 'Apple \& Pear Board takes top award', Export News, 18 October, p. 1.

Export News 1993b: 'Mixed news for apple industry', Export News, 10 June, p. 1.

Export News 1994a: 'New phase in forestry boom' Export News, 21 March, pp. 5-8.

Export News 1994b: 'PDL Electronics sees potential,' Export News, 27 June, p. 13.

Fagerberg, J. 1995: 'User-producer interaction, learning and comparative advantage', Cambridge Journal of Economics, Vol. 19, pp. 243-256.

Farm Equipment News 1990: 'State-of-art milker put in at Paeroa', Farm Equipment News, September, p. 1. 
Ferguson, A.R.; Yee, M.L.; 1983: 'Kiwifruit.' In: Wratt, G.S.; Smith, H.C. (eds.) Plant Breeding in New Zealand. Wellington, Butterworths. pp. 111-116.

Fisher, E. 1985: 'Kiwifruit wine leads export field', Food Technology in New Zealand, July, p. 41.

Florida, R.; Kenney, M. 1990: The Breakthrough Illusion. New York, Basic Books.

Food and Beverage Exporters Council. 1993. 'FBEC members scoop annual food awards', News from the New Zealand Food and Beverage Exporters' Council, October/November, pp. 1-2.

Food Industry News 1992: 'New speed drive out', Food Industry News, March, p. 16.

Food Industry News 1993a: 'MIRINZ secures a major research contract', Food Industry News, July, p. 15.

Food Industry News 1993b: 'Natural Venison Stock takes premier award', Food Industry News, October, pp. 1-2.

Food Industry News 1994: 'Production of Alatal 821 triples this year', Food Industry News, August, p. 12.

Food Technology in New Zealand 1984: 'New Takapau works uses NZ designed system', Food Technology in New Zealand, August, p. 3.

Food Technology in New Zealand 1993: 'Venison scoops food awards', Food Technology in New Zealand, October, p. 3. 
Foray, D. 1991: 'The Secrets of Industry are in the Air: Industrial Cooperation and the Organisational Dynamics of the Innovative Firm', Research Policy, Vol. 20, No. 5, pp. 393-405.

Foray, D.; Freeman, C. (ed.) 1993: Technology and the Wealth of Nations: The Dynamics of Constructed Advantage. London, Pinter Publishers.

Forestry Report 1994: 'Greenweld commercialised', Forestry Report, September, p. 4.

Forrest, J.E. 1991: 'Models of the process of technological innovation', Technology Analysis and Strategic Management, Vol. 3, No. 4, pp. 439-453.

Foundation for Research, Science and Technology 1991: Research Report 1990/91. Wellington, Foundation for Research, Science and Technology.

Frankel, E.G. 1990: Management of Technological Change. Dordrecht, Kluwer Academic Publishers.

Frankl, V.E. 1975: The Unconscious God. New York, Simon and Schuster.

Fransman, M. 1993: 'Information, Knowledge, Vision and Theories of the Firm', Industrial and Corporate Change, Vol. 3, No. 3, pp. 713-757.

Frater, P.; Stuart, G.; Rose, D.; Andrews, G. 1995: The New Zealand Innovation Environment. Wellington, BERL.

Freedman, G. 1988: The Pursuit of Innovation: Managing the People and Processes that Turn New Ideas into Profits. New York, AMACOM.

Freeman, C. 1974: The Economics of Industrial Innovation. 1st ed. Harmondsworth, Penguin. 
Freeman, C. 1982: The Economics of Industrial Innovation. 2nd ed. Cambridge, MA., MIT Press.

Freeman, C. (ed.) 1990: The Economics of Innovation. Aldershot, Edward Elgar.

Freeman, C. 1994: 'Critical Survey; The economics of technical change', Cambridge Journal of Economics, Vol. 18, pp. 463-514.

Freeman, C.; Lundvall, B.A. (ed.) 1988: Small Countries Facing the Technological Revolution. London, Pinter Publishers.

Freeman, C.; Soete, L. (eds.) 1990: New Explorations in the Economics of Technical Change. London, Pinter Publishers.

Fruit and Produce Journal 1981: 'DSIR finding new products from kiwifruit', Fruit and Produce Journal, July-August, pp. 7-8.

Frumau, C.C. F.1992: 'Choices in R\&D and business portfolio in the electronics industry: What the bibliometric data show', Research Policy, Vol. 21, No. 2, pp. 97 124.

Gambardella, A. 1992: 'Competitive advantages from in-house scientific research: The US pharmaceutical industry in the 1980s'. Research Policy, Vol. 21, No. 5, pp. 391-408.

Gardiner, J. 1994: 'Solar-powered navigation beacon wins ECNZ award', Dominion, 28 September, p. 13.

Garnsey, E.; Wright, S.M. 1990: 'Technical Innovation and Organisational Opportunity', International Journal of Technology Management, Vol. 5, No. 3, pp. 267-291. 
Georghiou, L.; Metcalfe, J.S.; Gibbons, M.; Ray, T.; Evans, J. 1986: Post-Innovation Performance. Technological Development and Competition. Basingstoke, MacMillan Press.

Gibbons, M. Johnston, R. 1974: 'The role of science in technological innovation', Research Policy, Vol. 3, No. 3, pp. 220-242.

Gibbons, M.; Limoges, C.; Nowotny, H.; Schwartzman, S.; Scott, P.; Trow, M. 1994: The New Production of Knowledge. London, Sage Publications.

Gilbertson, Dai.; Gilbertson, Deb. 1995: Innovation and Management. Case Studies. Vol. 2. Palmerston North, Dunmore Press.

Gilbertson, D.W.; Gilbertson, D.K.; Andrews, B. 1994: Barriers and Gateways to Innovation in New Zealand. Australia-New Zealand Institute of Management.

Gilbertson, D.; Knight, R.M. 1992: Innovation and Management in New Zealand: A Casebook. Palmerston North, Dunmore Press.

Glaser, B.; Strauss, A.L. 1967: The Discovery of Grounded Theory Strategies for Qualitative Research. New York, Aldine Publishing.

Gobeli, D.H.; Brown, D.J. 1987: 'Analysing Product Innovations', Research Management, Vol. XXX, No. 4, pp. 25-31.

Gobeli, D.H.; Brown, D.J. 1993: 'Improving the Process of Product Innovation', Research Technology Management, Vol. 36, No. 2, pp. 38-44.

Gobeli, D.H.; Rudelius, W. 1985: 'Managing Innovation: Lessons from the CardiacPacing Industry', Sloan Management Review, Summer, pp. 29-43. 
Goldhar, J.D. 1986: 'In the Factory of the Future Innovation is Productivity', Research Management, Vol. XX1X, No. 2, pp. 26-33.

Graham, A.K.; Senge, P.M. 1980: 'A Long-Wave Hypothesis of Innovation', Technological Forecasting and Social Change, Vol. 17, No. 4, pp. 283-311.

Granstrand, O. 1982: Technology, Management and Markets. London, Frances Pinter.

Greson, C. 1984: 'Designing Organisations to Innovate and Implement: Using Two Dilemmas to Create a Solution', Columbia Journal of World Business, Winter, pp. 63-67.

Griliches, Z. 1973: 'Research Expenditures and Growth Accounting.' In: Williams, B.R. (ed.) 1973: Science and Technology and Economic Growth. London, MacMillan.

Groenewegen, P. 1992: “Stimulating 'Hot Technologies': Interorganisational networks in Dutch ceramic research", R\&D Management, Vol. 22, No. 4, pp. 291292.

Grossman, G.M.; Helpman, E. 1991a: Innovation and Growth in the Global Economy. Cambridge, MA,, MIT Press.

Grossman, G.; Helpman, E. 1991b: 'Quality Ladders in the Theory of Growth', Review of Economic Studies, Vol. 58, pp. 43-61.

Gruber, W.H.; Marquis, D.G. (eds.) 1969: Factors in the Transfer of Technology. Cambridge, MA., MIT Press.

Hage, J.; Aiken, M. 1970: Social Change in Complex Organisations. New York, Random House. 
Hagedoorn, J. 1989: The Dynamic Analysis of Innovation and Diffusion: A Study in Process Control. London, Pinter Publishers.

Hakansson, H. 1989: Corporate Technological Behaviour - Cooperation and Networks. London, Routledge.

Hamilton, R. 1991: The Nature of Innovation in the NZ Dairy Industry. Unpublished project submitted in partial fulfilment of MBS Studies. Christchurch, University of Canterbury.

Harman, R. 1978: Direction. New Zealand Innovation and Achievement. Wellington, Sheffield Associates Southern Ltd.

Harper, D.; Campbell-Hunt, C. 1992: Islands of Excellence. Wellington, NZIER.

Haustein, H-D.; Maier, H. 1980: 'Basic Improvement and Pseudo-Innovations and Their Impact on Efficiency', Technological Forecasting and Social Change, Vol. 16, No. 3, pp. 243-265.

Hayek, F.A. 1975: The Pretence of Knowledge. Nobel Memorial Lecture, 11 December 1974. Stockholm, Les Prix Nobel en 1974, Stockholm, 1975.

Hayek, F.A. 1978: New Studies in Philosophy, Politics, Economics and the History of Ideas. London, Routledge and Kegan Paul.

Heatherbell, D.A.; Struebi, P.; Eisenbruch, R.; Withy, L.M. 1980: 'A New Fruit Wine from Kiwifruit: A Wine of Unusual Composition and Riesling Sylvaner Character', American Journal of Enology and Viticulture, Vol. 31, No. 2, pp. 114-121.

Hill, C.W.L. 1990: 'Cooperation, opportunism, and the invisible hand: Implications for transaction cost theory', Academy of Management Review, Vol. 15, pp. 500-513. 
Hill, R. 1983: From hot metal to cold type: labour process theory and new technology in the newspaper industry. Unpublished $\mathrm{PhD}$ thesis, Christchurch, University of Canterbury.

Hill, R.; Gidlow, B. 1988: From hot metal to cold type: negotiating technological change in the New Zealand newspaper industry. Wellington, DSIR.

Hirsch, F. 1978: Social Limits to Growth. Cambridge, MA., Harvard University Press.

Hodgson, G.M. 1988: Economics and Institutions: A Manifesto for a Modern Institutional Economics. Cambridge, Polity Press.

Hodgson, G.M.; Screpanti, E. (eds.) 1991: Rethinking Economics: Markets, Technology and Economic Evolution. Aldershot, Edward Elgar.

HortResearch 1994: 'Industry Benefits', HortResearch Annual Report for 1993/94, p. 6. Palmerston North, HortResearch.

HortTalk 1994: 'New Pipfruit Cultivars', HortTalk, November/December, p. 3.

Horwitch, M. (ed.) 1986: Technology in the Modern Corporation. New York, Pergamon Press.

Hosmer, L.T. 1995: 'Trust: The Connecting Link between Organisational Theory and Philosophical Ethics', Academy of Management Review, Vol. 20, No. 2. pp. 379403.

Howells, J. 1995a: 'A socio-cognitive approach to innovation', Research Policy, Vol. 24, No. 6, pp. 883-894. 
Howells, J. 1995b: Rethinking the Market-Technology Relationship for Innovation. Department of Management Studies, Brunel University. Paper submitted to workshop: New Perspectives on Technology, Organisation and Innovation. 14/15 September 1995.

Hubner, H. (ed.) 1986: The Art and Science of Innovation Management: An International Perspective. Amsterdam, Elsevier.

Hussey, D. 1992: Agricultural Marketing Regulation. Reality versus doctrine. A Report Prepared for the New Zealand Business Roundtable by ACIL. Auckland, Business Roundtable.

Illinois Institute of Technology 1968: Technology in Retrospect and Critical Events in Science (TRACES). Report for the National Science Foundation. Chicago, Illinois Institute of Technology.

Industrial Equipment News 1989a: 'Napier company is at the forefront of world technology', Industrial Equipment News, October, p. 7.

Industrial Equipment News 1989b: 'PDL claims trophy for third time', Industrial Equipment News, November, p. 1.

Industrial Equipment News 1989c: 'Quieter pumps', Industrial Equipment News, February, p. 10.

Industrial Equipment News 1990: 'Napier firm wows Europeans at Hannover trade fair', Industrial Equipment News, August, p. 3.

Industrial Equipment News 1991a: 'Strong bonds develop between university and electronics company', Industrial Equipment News, April, p. 7. 
Industrial Equipment News 1991b: 'Ten PDL drives now high in Andes of Chile', Industrial Equipment News, October, p. 7.

Inkson, J.; Cammock, P. 1984: 'Labour Process Theory and the Chain System in the New Zealand Meatworks', New Zealand Journal of Industrial Relations, Vol. 9, No. 3, pp. 149-160.

Inkson, K.; Henshall, B.; Marsh, N.; Ellis, G. 1986: Theory K: The Key to Excellence in New Zealand Management. Auckland, David Bateman.

IRHACE 1990: 'Company plays vital role in continuous modernisation', IRHACE Journal, February-March, p. 31.

Irvine, J.; Martin, B. 1980: 'The economic effects of big science: the case of radioastronomy.' In: Proceedings of the International Colloquium on Economic Effects of Space and Other Advanced Technologies. Strasbourg, 28-30 April 1980, ESA SP-151.

Isenson, R.S. 1969: 'Project Hindsight: An Empirical Study of the Sources of Ideas Utilised in Operational Weapons Systems.' In: Gruber, W.H.; Marquis, D.G. (eds.) 1969: Factors in the Transfer of Technology. Cambridge, MA., MIT Press. pp. 155176.

Iya, S.; Akhilesh, K.B. 1992: 'Technology as perceived by R\&D team leaders: an analysis', R\&D Management, Vol. 22, No. 3, pp. 265-276.

Jelinek, M.; Schoonhoven, C.B. 1990: The Innovation Marathon. Lessons from High Technology Firms. Oxford, Basil Blackwell.

Jewkes, J.; Sawers, D.; Stillerman, R. 1969: The Sources of Invention. 2nd ed. London, MacMillan. 
Johanson, J.; Mattsson, L-G. 1987: 'Interorganisational Relations in Industrial Systems: A Network Approach Compared with the Transaction-Cost Approach', International Studies of Management and Organisation, Vol. XV11, No. 1, pp. 34-48.

Johne, A.; Snelson, P. 1988: 'Auditing Product Innovation Activities in Manufacturing Firms', R\&D Management, Vol. 18, No. 3, pp. 227-233.

Johne, F.A. 1985: Industrial Product Innovation: Organisation and Management. Beckenham, Croom Helm.

Johnston, R. 1991: Technology Strategy in New Zealand Industry. MoRST Report No. 12. Wellington, MoRST.

Kash, D.E. 1989: Perpetual Innovation. New York, Basic Books.

King, P. 1987: 'DSIR toasts inventors of kiwifruit wine', The Orchardist, August, p. 219.

Kirk, J.; Miller, M.L. 1986: Reliability and validity in qualitative research. London, Sage Publications.

Kirkpatrick, K. 1993: 'Selling dairy products as food ingredients', Dairy Exporter, February, p. 48.

Klein, J.T. 1990: 'Innovation and Change in Organisational Relationships: Interdisciplinary Contexts', R\&D Management, Vol. 20, No. 2, pp. 97-102.

Kleinknecht, A.; Reijnen, J.O.N. 1992: 'Why do Firms Cooperate on R\&D? An Empirical Study', Research Policy, Vol. 21, No. 4, pp. 347-360. 
Kline, S.J. 1985: 'Innovation is not a linear process', Research Management, Vol. 28, No. 4 , pp. $36-45$.

Knight, R.M. 1987: 'Corporate innovation and entrepreneurship: A Canadian Study', Journal of Product Innovation Management, Vol. 4, No. 4, pp. 284-297.

Knight, R.M. 1989: 'Technological innovation in Canada: a comparison of independent entrepreneurs and corporate innovators', International Journal of Technology Management, Vol. 4, No. 3, pp. 273-281.

Labes, J. 1994: The Strategic Focus of WRONZ 1993/94. Lincoln, WRONZ.

Labes, N. 1993: New Product Development. Unpublished academic project.

Lamberton, D. M. 1986: 'Information, Economic Analysis and Public Policy', Prometheus, Vol. 4, No. 1, pp. 174-186.

Lamberton, D.M. 1992: 'Information, Exploratory Behaviour and the Design of Organisations', Human Systems Management, Vol. 11, No. 2, pp. 61-65.

Landau, R. (ed.) 1984: The Nature of Technological Knowledge. Are Models of Scientific Change Relevant? Dordrecht, D. Reidel Publishing Company.

Landau, R.; Rosenberg, N. (eds.) 1986: The Positive Sum Strategy: Harnessing Technology for Economic Growth. Washington DC, National Academy Press.

Langlois, R.N. 1992: 'Transaction-cost Economics in Real Time', Industrial and Corporate Change, Vol. 1, No. 1, pp. 99-127.

Langlois, R.N.; Robertson, P.L. 1992: 'Networks and innovation in a modular system: Lessons from the microcomputer and stereo component industries', Research Policy, Vol. 21, No. 4, pp. 297-313. 
Langrish, J.; Gibbons, M.; Evans, W.G.; Jevons, F.R. 1972: Wealth from Knowledge. Studies of Innovation in Industry. London, MacMillan Press.

Larsson, S. 1993: 'New dimensions in organising industrial networks', International Journal of Technology Management, Vol. 8, Nos. 1/2, pp. 39-58.

Layder, D. 1993: New Strategies in Social Research. Cambridge, Polity Press.

Leary, G. 1992: 'Success and failure in commercialising chemistry research', Chemistry in New Zealand, Vol. 56, No. 2, pp. 22-27.

Leyden, D.P.; Link, A.N. 1991: 'Why are governmental R\&D and private R\&D complements?', Applied Economics, Vol. 23, No. 10, pp. 1673-1681.

Leyden, D.P.; Link, A.N.; Bozeman, B. 1989; 'The effects of governmental financing on firms' R\&D activities: a theoretical and empirical investigation', Technovation, Vol. 9, pp. 561-575.

Little, J.S. 1948: A Century of Fires and Fire Brigades in Dunedin. 1848-1948. Dunedin, Dunedin Metropolitan Fire Board.

Loasby, B.J. 1991: Equilibrium and evolution. An exploration of connecting principles in economics. Manchester, Manchester University Press.

Lodge, N. 1981: 'Kiwifruit: Two novel processed products', Food Technology in New Zealand, July, pp. 35-43.

Lodge, N.; Nguyen, T.; Hogg-Stec, M.; Stanton, D. 1986: 'Production of kiwifruit wine using a deionisation technique', New Zealand Journal of Technology, Vol. 2, No. 4 , pp. 225-230. 
Lucas, R.E. 1988: 'On the mechanics of economic development', Journal of Monetary Economics, Vol. 22, No. 1, pp. 3-42.

Lucas, R.E. 1990: 'Why Doesn't Capital Flow from Rich to Poor Countries?', $A E A$ Papers and Proceedings, Vol. 80, No. 2, pp. 92-96.

Lundstedt, S.B.; Colgrazier, E.W.(eds.) 1982: Managing Innovation. New York, Pergamon Press.

Lundstedt, S.B.; Moss, T.H. (eds.) 1989: Managing Innovation and Change. Dordrecht, Kluwer Academic Publishers.

Lundvall, B. (ed.) 1992: National Systems of Innovation. Towards a Theory of Innovation and Interactive Learning. London, Pinter Publishers.

MacAlister, P. 1994: 'New technique tipped to be a money-spinner', Evening Post, 14 June, p. 14.

Macdonald, S. 1989: 'Human Qualities Necessary for Invention: Independent Inventors and the Stimulus of Adversity', Prometheus, Vol. 7, No. 2, pp. 333-348.

Macdonald, S; Lamberton, D.; Manderville, T. (eds.) 1983: The Trouble with Technology. London, Pinter Publishers.

MacKenzie, D. 1990: Inventing Accuracy. Cambridge, MA., MIT Press.

MacKenzie, D.; Wajcman, J. (eds.) 1985: The Social Shaping of Technology. Philadelphia, Open University Press.

MacLeod, R. (ed.) 1986: Technology and the Human Prospect. London, Frances Pinter. 
Maideque, M.A. 1980: 'Entrepreneurs, Champions, and Technological Innovation', Sloan Management Review, Winter, pp. 59-76.

Maideque, M.A.; Zirger, B.J. 1985: 'The new product learning cycle', Research Policy, Vol. 14, No. 6, pp. 299-313.

Malerba, F. 1992: 'Learning by Firms and Incremental Technical Change', Economic Journal, Vol. 102, July, pp. 845-859.

Malerba, F.; Orsenigo, L. 1993: 'Technological Regimes and Firm Behaviour', Industrial and Corporate Change, Vol. 2, No. 1, pp. 45-71.

Malerba, F.; Orsenigo, L. 1996: 'The Dynamics and Evolution of Industries', Industrial and Corporate Change, Vol. 5, No. 1, pp. 51-87.

Mansfield, E. 1981: 'How Economists see R\&D', Harvard Business Review, Vol. 59, No. 6, pp. 98-106.

Mansfield, R.S.; Busse, T.V. 1981: The Psychology of Creativity and Discovery. Chicago, Nelson-Hall.

Mansfield, E.; Rapoport, J.; Romeo, A.; Wagner, S.; Beardsley, G. 1977: 'Social and private rates of return from industrial innovations', Quarterly Journal of Economics, Vol. 91, No. 2, pp. 221-240.

Manufacturer 1984: 'PDL goes into high-tech', Manufacturer, April, p. 8.

Manufacturer 1991: 'Corrosion datalogger future assured', Manufacturer, October, p. 21 . 
Marceau, J. 1995: 'Policies for Growth: Strategies for Industrial Development in the 1990s and Beyond.' Paper presented to the seminar Industrial Policies for Australia's Future, 13 September. Melbourne, Victoria University of Technology.

March, J.D.; Simon, H.A. 1958: Organisations. New York, Wiley.

Marchetti, C. 1980: 'Society as a Learning System: Discovery, Invention and Innovation Cycles Revisited', Technological Forecasting and Social Change, Vol. 18 , No. 4 , pp. $267-282$.

Marquis, D.G.; Myers, S. 1969: Successful Industrial Innovations. Washington, National Science Foundation.

Marryatt, H.W. 1988: Fire. A Century of Automatic Sprinkler Protection in Australia and New Zealand 1886-1986. Melbourne, Australia Fire Protection Association.

Marsh, N. 1993: The All Star Company. People, Performance, Profit. Auckland, Random House.

Maruta, Y. 1980: 'The Management of Innovation in Japan - The Tetsuri Way', Research Management, Vol. XX111, No. 1, pp. 39-41.

Marx, K. 1959: Das Capital. Vol. 111. Moscow, Foreign Languages Publishing House.

Marx, K.; Engels, F. 1963. The Communist Manifesto of Karl Marx and Friedrich Engels. Ryazanoff, P. (ed.). New York, Russell and Russell.

Matla, S. 1994: 'Vega Industries shows the light to US Coast Guard', Export News, 17 October, p. 11. 
May, T. 1993: Social Research. Issues, Methods and Process. Philadelphia, Open University Press.

McCulloch, D.G. 1980: Technology and Innovation in New Zealand Manufacturing Industry: The Role of Government. PEL Report No. 686. Lower Hutt, Physics and Engineering Laboratory, DSIR.

McEldowney, L. 1992: 'Functional foods no fad in Japan', Dairy Exporter, April, p. 62 .

McGourty, J.; Tarshis, L. A.; Dominick, P. 1996: 'Managing Innovation: Lessons from World Class Organisations', International Journal of Technology Management, Vol. 11, Nos. 3/4, pp. 354-368.

McGuinness, N.W; Conway, H.A. 1989: 'Managing the Search for New Product Concepts: A Strategic Approach', R\&D Management, Vol. 19, No. 4, pp. 297-308.

McKelvey, M. 1991: 'How do National Systems of Innovation Differ? A Critical Analysis of Porter, Freeman, Lundvall and Nelson.' In: Hodgson and Screpanti (eds.) 1991: Rethinking Economics: Markets, Technology and Economic Evolution. Aldershot, Edward Elgar. pp. 117-137.

McKenzie, D.W. 1983: 'Apples.' In: Wratt, G.S.; Smith, H.C. (eds.)1983: Plant Breeding in New Zealand. Wellington, Butterworths. pp. 83-90.

McLauchlan, G. 1982: McMeekan. A Biography. Auckland, Hodder and Stoughton.

McLean, G. 1981: Spinning Yarns. A Centennial History of Alliance Textiles and its Predecessors 1881-1981. Dunedin, Alliance Textiles.

McLean, G. 1992: New Zealand Tragedies. Fires and Firefighting. Wellington, Grantham House. 
Mensch, G. 1979: Stalemate in Technology. Innovations Overcome the Depression. Cambridge, MA., Ballinger Press.

Michalos, A. 1990: 'The impact of trust on business, international security, and the quality of life', Journal of Business Ethics, Vol. 9, No. 7, pp. 619-638.

Ministry of Agriculture and Fisheries 1982: Agricultural Research in Progress 1981/82. Wellington, MAF.

Ministry of Agriculture and Fisheries 1987a: Agricultural Research in Progress 1986/87. Wellington, MAF.

Ministry of Agriculture and Fisheries 1987b: Anmual Report for the Year ended 31 March 1987. Wellington, MAF.

MIRINZ 1985: Anmual Research Report 1984/85. Hamilton, MIRINZ.

MIRINZ 1987: Annual Research Report 1986/87. Hamilton, MIRINZ.

MIRINZ 1990: Annual Research Report 1989/90. Hamilton, MIRINZ.

MIRINZ 1991: Annual Research Report 1990/91. Hamilton, MIRINZ.

MIRINZ 1992: Annual Research Report 1991/92. Hamilton, MIRINZ.

Mitchell, W. 1992: 'Are More Good Things Better, or Will Technical and Market Capabilities Conflict When a Firm Expands?', Industrial and Corporate Change, Vol. 1, No. 2, pp. 327-346.

Mitchell, W.C. 1964: What Veblen Taught: Selected Writings of Thorstein Veblen. New York, A.M. Kelley. 
Mokyr, J. 1990: The Lever of Riches. Technological Creativity and Economic Progress. New York, Oxford University Press.

Mokyr, J. 1991: 'Evolutionary Biology, Technological Change and Economic History', Bulletin of Economic Research, Vol. 43, No. 2, pp. 128-149.

Mole, V.; Elliot, D. 1987: Enterprising Innovation: An Alternative Approach. London, Frances Pinter.

Morison, K. 1993: 'Measurement and the Dairy Industry - A Special Report', Automation and Control, April, pp. 10-16.

Morris, R.A. 1970. 'The development of inventions by the DSIR', NZ Electronics Review, August, pp. 21-23.

Mort, J. 1994: 'Science, technology and innovation: an evolutionary perspective,' International Journal of Technology Management, Vol. 9, No. 1, pp. 30-42.

Mountfort, M. 1988: 'Separate Milk Transport on line for next season', Dairy Exporter, June, pp. 10-13.

Mowery, D. C. 1992: 'The US National Innovation System: Origins and Prospects for Change', Research Policy, Vol. 21, No. 2, pp. 125-144.

Mowery, D.C.; Rosenberg, N. 1979: 'The Influence of Market Demand upon Innovation: A Critical Review of Some Recent Empirical Studies', Research Policy, Vol. 8, No. 2, pp. 220-242.

Mowery, D.C.; Rosenberg, N. 1989: Technology and the pursuit of economic growth. Cambridge, Cambridge University Press. 
Mulroney, B. G. 1994: 'Create an organisational learning laboratory', Research Technology Management, Vol. 37, No. 2, pp. 12-13.

Mumford, M.D.; Gustafson, S.B. 1988: 'Creativity Syndrome: Integration, Application, and Innovation', Psychological Bulletin, Vol. 103, No. 1, pp. 27-43.

Myers, S.; Marquis, D.G. 1969: Successful Industrial Innovation. Washington DC, National Science Foundation.

Namatame, A. 1989: 'Dynamic comparison of R\&D innovation process structures', International Journal of Technology Management, Vol. 4, No. 3, pp. 305-315.

Napolitano, G. 1991: 'Industrial Research and Sources of Innovation: A CrossIndustry Analysis of Italian Manufacturing Firms', Research Policy, Vol. 20, No. 2, pp. 171-178.

National Business Review 1990: 'Meat Marketer takes top prize', National Business Review, 18 October, p. 3.

Nelson, R.R. (ed.) 1962: The Rate and Direction of Inventive Activity. A Report of the National Bureau of Economic Research. New York, Princeton University Press.

Nelson, R.R. 1987: Understanding Technical Change as an Evolutionary Process. Amsterdam, North-Holland.

Nelson, R.R. 1992: 'National Innovation Systems: A Retrospect on a Study', Industrial and Corporate Change, Vol. 1, No. 2, pp. 347-374.

Nelson, R.R. (ed.) 1993: National Systems of Innovation: A Comparative Study. Oxford, Oxford University Press. 
Nelson, R.; Levin, R. 1986: The Influence of Science, University Research and Technical Societies on Industrial R\&D and Technical Advance. Policy Discussion Paper Series No. 3, Yale University. New Haven, Yale University.

Nelson, R.R.; Winter, S.G. 1974: 'Neoclassical vs Evolutionary Theories of Economic Growth: Critique and Prospectus', Economic Journal, Vol. 84, December, pp. 886-905.

Nelson, R.R.; Winter, S.G. 1977: 'In Search of a Useful Theory of Innovation', Research Policy, Vol. 6, No.1, pp. 36-76.

Nelson, R.R.; Winter, S.G. 1982: An Evolutionary Theory of Economic Change. Cambridge, MA., Belknap Press of Harvard University Press.

New Electronics 1983: 'IEA drive wins NEDA Award for second time', New Electronics, August, pp. 1-5.

New Electronics 1984: 'Weighing in for the NEDA Award,' New Electronics, August, pp. $1 \& 5$.

New Electronics 1987a: 'Canterbury University - key player in commercial developments', New Electronics, October, p. 27.

New Electronics 1987b: 'City's electronics firms surviving, some thriving', New Electronics, October, pp. 18-19.

New Electronics 1987c: 'David Byers takes an early retirement', New Electronics, July, p. 22.

New Electronics 1987d: 'One hundred years of engineering', New Electronics, July, p. 21 . 
New Electronics 1987e: "Wormald Vigilant "future exciting", New Electronics, October, p. 26.

New Electronics 1988a. 'Controls company benefits from tough times', New Electronics, April, pp. 25-27.

New Electronics 1988b: 'Milking equipment, robots, image processing, and computers', New Electronics, September, p. 26.

New Electronics 1988c: 'Older buildings not forgotten', New Electronics, March, p. 19.

New Electronics 1988d: 'Solid State - money not the main motivation', New Electronics, February, p. 17.

New Electronics 1989a. 'Export thrust for speed drives', New Electronics, December, pp. 33-34.

New Electronics 1989b: 'Milk harvester prototypes on stream for new season', New Electronics, July, p. 30.

New Electronics 1989c: 'NEDA award for PDL', New Electronics, November, p. 4

New Electronics 1990a: 'Many uses for data loggers', New Electronics, May, pp. 4647.

New Electronics 1990b: 'PDL Electronics Ltd cracks European market', New Electronics, November, p. 7.

New Electronics 1991: 'Key export order', New Electronics, September, p. 15. 
New Zealand Communications Advisory Council 1985: Towards a More Conducive Climate for the Electronics Industry in New Zealand. Wellington, NZ Communications Advisory Council.

New Zealand Dairy Board 1983: Anmual Report for Year ended May 1983. Wellington, NZ Dairy Board.

New Zealand Dairy Board 1984: Anmual Report for Year ended May 1984. Wellington, NZ Dairy Board.

New Zealand Dairy Board 1985: Anmual Report for Year ended May 1985. Wellington, NZ Dairy Board.

New Zealand Dairy Board 1986: Anmual Report for Year ended May 1986. Wellington, NZ Dairy Board.

New Zealand Dairy Board 1987: Annual Report for Year ended May 1987. Wellington, NZ Dairy Board.

New Zealand Dairy Board 1988: Anmual Report for Year ended May 1988. Wellington, NZ Dairy Board.

New Zealand Meat Producer 1990: 'New Formula for funding', New Zealand Meat Producer, First Quarter, p. 7.

New Zealand Meat Producer 1991: 'Getting more mechanical', New Zealand Meat Producer, Third Quarter, p. 13.

New Zealand Wool Board 1993: Annual Report 1993. Wellington, New Zealand Wool Board. 
Ng, W. 1992: 'Advantages of machine boning of lamb.' In: Proceedings of the 27th Meat Industry Research Conference, Hamilton, MIRINZ. pp. 322-326.

Noiton, D.; Currie, A.; Shelbourne, T. 1994: 'Genetic diversity for apple breeding', Orchardist, July, pp. 36-39.

Nordmark, B. 1993: 'Recent developments in meat industry engineering', Food Technology in New Zealand, April, pp. 17-19.

NZ Electronics Review 1980: 'Wormald Vigilant Ltd. From fire alarms to microprocessors', NZ Electronics Review, p. 57.

NZ Electronics Review 1981: 'Industrial Electronics and Automation Ltd', NZ Electronics Review, p. 24.

NZ Electronics Review 1983a: 'NEDA Award 1983', NZ Electronics Review, p. 11.

NZ Electronics Review 1983b: 'Wormald Vigilant: Ultra-high security - SHU', NZ Electronics Review, p. 38.

NZ Engineering News 1988: 'New series of AC drives released', NZ Engineering News, December, p. 16.

NZ Engineering News 1989a: 'Intelligent controllers', NZ Engineering News, November, p. 18.

NZ Engineering News 1989b: "NZ firm 'switched on' at Hanover", NZ Engineering News, August, p. 6.

NZ Engineering News 1993: 'Minister inspects electronics unit', NZ Engineering News, September, p. 15. 
NZ Forest Industries 1988: 'Data logger prevents engine damage and informs on vehicle use', NZ Forest Industries, June, p. 11.

NZFRI 1992: 'Green finger-jointing process has benefits for timber industry', What's New in Forest Research No. 218. Rotorua, NZFRI.

NZFRI 1993a: Greenweld: Advanced adhesive system for finger-jointing green timber. Rotorua, NZFRI.

NZFRI 1993b: Science Report 1992/93. Rotorua, NZFRI.

NZFRI 1994a: 'NZFRI/BRE Link', NZFRI Research Directions, September, p. 6.

NZFRI 1994b: 'Robert Franich', NZFRI Research Directions, September, p. 8.

NZFRI 1994c: Science Report 1993/94. Rotorua, NZFRI.

NZ Science Monthly 1993: 'Mariners' Microlight', NZ Science Monthly, October, p. 5.

O'Hare, M. 1988: Innovate: How to Gain and Sustain Competitive Advantage. Oxford, Basil Blackwell.

Oliver, K. 1994: 'Nutritional opportunities for protein products', Dairy Exporter, December, p. 42.

Orchardist 1989: 'Top sport combines best pear qualities', Orchardist, May, p. 8; p. 12.

Orchardist 1991a: 'Apple breeding now at faster tempo', Orchardist, July, p. 40.

Orchardist 1991b: 'New pear wins wide support', Orchardist, May, p. 29. 
Orchardist 1992a: 'Stronger link to Board has assisted FIPIA', Orchardist, June, p. 31.

Orchardist 1992b: 'The secrets of good breeding', Orchardist, July, pp. 33-34.

Orchardist 1993a: 'Apples hard to move in depressed European market', Orchardist, August, p. 9.

Orchardist 1993b: 'Foundations for export success laid in '70s', Orchardist, December, pp. 28-29.

Orchardist 1993c: 'Hard-nosed approach on new varieties', Orchardist, December, p. 38.

Orchardist 1993d: 'Same skills apply in dairy and pipfruit research', Orchardist, December, p. 39.

Orchardist 1993e: 'Tough year presents opportunities', Orchardist, October, pp. 10-12.

Otago Daily Times 1994: 'Alliance Knitting Yarns', Otago Daily Times, 16 December, pp. 26-27.

Panzar, J.C.; Willig, R.D. 1981: 'Economies of Scope', American Economic Association Papers and Proceedings, Vol. 71, No. 2, pp. 268-272.

Papahristodoulou, C. 1987: Inventions, Innovations and Economic Growth in Sweden: An Appraisal of the Schumpeterian Theory. Uppsala, Uppsala University.

Parker, J. 1994: 'Greenweld in Australia', NZ FRI Research Directions, March, pp. 4-5. 
Parker, J.E.S. 1978: The Economics of Innovation. New York, Longman.

Pavitt, K. (ed.) 1980: Technical Innovation and British Economic Performance. Science Policy Research Unit, Sussex University. London, MacMillan.

Pavitt, K. 1984: 'Sectoral patterns of technical change: Towards a taxonomy and a theory, Research Policy, Vol. 13, No. 6, pp. 343-373.

Pavitt, K. 1986: 'Technology, Innovation and Strategic Management.' In: McGee, J.; Thomas, H. (eds.) 1986: Strategic Management Research: A European Perspective. New York, Wiley.

Pavitt, K. 1991: 'What Makes Basic Research Economically Useful?', Research Policy, Vol. 20, No. 2, pp. 109-119.

Pennings, J.M.; Buitendam, A. (eds.) 1987: New Technology as Organisational Innovation. The Development and Diffusion of Microelectronics. Cambridge, MA., Ballinger.

Penrose, E. 1959: The Theory of the Growth of the Firm. Oxford, Basil Blackwell.

Peters, T.J.; Waterman, R.H. 1982: In Search of Excellence: Lessons from America's best-run companies. New York, Harper and Row.

Pinchot 111, G. 1987: 'Innovation through Intrapreneuring', Research Management, Vol. XXX, No. 2, pp. 14-19.

Polanyi, M. 1958: Personal Knowledge: Towards a Post-Critical Philosophy. London, Routledge and Kegan Paul.

Polanyi, M. 1967: The Tacit Dimension. London, Routledge and Kegan Paul. 
Porteous, M. 1985: 'The choice and application of AC variable speed drives', Automation and Control, August, pp. 41-43.

Porter, M. 1990: The Competitive Advantage of Nations. London, Macmillan.

Postrel, S.; Rumelt, R.P. 1992: 'Incentives, Routines and Self-Command', Industrial and Corporate Change, Vol. 1, No. 3, pp. 397-425.

Prahalad, C. K. 1993: 'The Role of Core Competencies in the Corporation', Research Technology Management, Vol. 36, No. 6, pp. 40-47.

Progressive Engineering 1990: 'New, Prestigious Designmark Award for Wormald Vigilant', Progressive Engineering, Vol. 8, No. 1, p. 33.

Quinn, J. B. 1985: 'Managing innovation: controlled chaos', Harvard Business Review, May-June, pp. 73-84.

Raymond, L.; Julien, P.; Carriere, J.; Lachance, R. 1996: 'Managing Technological Change in Manufacturing Smes: A Multiple Case Analysis'. International Journal of Technology Management, Vol. 11, Nos. 3/4, pp. 270-285.

Reade, D. 1992a: 'Export gains likely from timber invention', Export News, 14 July, p. 1.

Reade, D. 1992b: 'Finger-jointer has huge export potential', Export News, 10 September, p. 12.

Reid, H.M.; Jones, G.L.; Lister, T.A. 1994: 'Dual Fuel Kits for less sophisticated markets.' Unpublished paper.

Rhodes, E.; Wield, D. (ed.) 1985: Implementing New Technologies. Oxford, Basil Blackwell. 
Richardson, P.R. 1985: 'Managing Research and Development for Results', Journal of Product Innovation Management, Vol. 2, No. 2, pp. 75-87.

Rickards, T. 1985: Stimulating Innovation: A Systems Approach. New York, St Martin's Press.

Riley, B. 1995: Kiwi Ingenuity. A Book of New Zealand Ideas and Inventions. Auckland, AIT Press.

Robbins, S.P.; Waters-Marsh, T.; Cacioppe, R.; Millet, B. 1994: Organisational Behaviour. Concepts, Controversies and Applications. Australia and New Zealand. Sydney, Prentice-Hall.

Roberts, E.B. (ed.) 1987: Generating Technological Innovation. New York, Oxford University Press.

Roberts, E.B. 1988: 'Managing Invention and Innovation', Research-Technology Management, Vol. 31, No. 1, pp. 11-29.

Robertson, G. (ed.) 1981: Proceedings of a Seminar on the Processing of Kiwifruit and other Subtropicals. Palmerston North, Department of Food Technology, Massey University.

Romer, P.M. 1986: 'Increasing Returns and Long Run Growth', Journal of Political Economy, Vol. 94, No. 5, pp. 1002-1037.

Romer, P.M. 1987: 'Growth Based on Increasing Returns Due to Specialisation', American Economic Association Papers and Proceedings, Vol. 77, No. 2, pp. 56-62.

Romer, P.M 1989a: Human Capital and Growth: Theory and Evidence. NBER Working Paper No. 3173. Cambridge, MA., NBER. 
Romer, P.M 1989b: What Determines the Rate of Growth and Technical Change? World Bank Working Paper No. WPS 279. Washington DC, The World Bank.

Romer, P.M. 1990: 'Endogenous Technological Change', Journal of Political Economy, Vol. 98, No. 5, Pt. 2, pp. 70-102.

Romer, P.M. 1993: 'Implementing a National Technology Strategy with SelfOrganising Industry Investment Boards', Brookings Papers on Economic Activity, Microeconomics 2, pp. 345-399.

Ronen, J. (ed.). 1983: Entrepreneurship. Lexington, MA., Lexington Books.

Roobeek, A.J.M. 1990: Beyond the Technology Race: An Analysis of Technology Policy in Seven Industrial Countries. Amsterdam, Elsevier Press.

Rosenberg, N. 1976: Perspectives on Technology. Cambridge, Cambridge University Press.

Rosenberg, N. 1982: Inside the black box. Technology and economics. Cambridge, Press Syndicate of the University of Cambridge.

Rosenberg, N. 1992: 'Economic Experiments', Industrial and Corporate Change, Vol. 1, No. 1, pp. 181-203.

Rosenberg, N. 1994: Exploring the black box. Technology, economics and history. Cambridge, Cambridge University Press.

Rosenberg, N.; Nelson, R. 1992: American Universities and Technical Advance in Industry. Centre for Economic Policy Research, Stanford University. 
Rosenbloom, R.S.; Burgelman, R.A. (eds.) 1989: Research on Technological Innovation, Management and Public Policy. New York, Free Press.

Rothberg, R.R. (ed.) 1981: Corporate Strategy and Product Innovation. New York, Free Press.

Rothwell, R. 1991: 'External networking and innovation in small and medium-sized manufacturing firms in Europe', Technovation, Vol. 11, No. 2, pp. 93-111.

Rothwell, R. 1992: 'Successful industrial innovation: critical factors for the 1990s', R\&D Management, Vol. 22, No. 3, pp. 221-240.

Rothwell, R.; Bessant, J. 1987: Innovation: Adaptation and Growth. An International Perspective. Amsterdam, Elsevier Press.

Rothwell, R.; Freeman, C.; Horsley, A.; Jervis, V.T. P.; Robertson, A.B.; Townsend, J. 1974: 'Sappho updated', Research Policy, Vol. 3, No. 5, pp. 258-291.

Rothwell, R.; Gardiner, P. 1988: 'Re-Innovation and Robust Designs: Producer and User Benefits', Journal of Marketing Management, Vol. 3, No. 3, pp. 372-387.

Rothwell, R.; Gardiner, P. 1989: 'The Strategic Management of Re-Innovation', R\&D Management, Vol. 19, No. 2, pp. 147-160.

Rothwell, R.; Whiston, T.G. 1990: 'Design, Innovation and Corporate Integration', R\&D Management, Vol. 20, No. 3, pp. 193-201.

Rothwell, R.; Zegveld, W. 1985: Reindustrialization and Technology. Harlow, Essex, Longman.

Roy, R.; Wield, D. (ed.) 1986: Product Design and Technological Innovation. Milton Keynes, Open University Press. 
Sabel,C.F. 1993: 'Studied trust: building new forms of cooperation in a volatile economy.' In: Foray, D.; Freeman, C. (eds.) 1993: Technology and the Wealth of Nations: The Dynamics of Constructed Advantage. London, Pinter Publishers.

Sagoo, B. 1994: The Qualifications and Experience of New Zealand's Key Decision Makers. MoRST Report No 27. Wellington, MoRST.

Sahal, D. 1981: Patterns of Technological Innovation. Reading, MA., AddisonWesley.

Sahal, D. 1983: 'Invention, Innovation, and Economic Evolution', Technological Forecasting and Social Change, Vol. 23, No. 3, pp. 213-235.

Sahal, D. 1985: 'Technological guideposts and innovation avenues', Research Policy, Vol. 14, No. 2, pp. 61-82.

Sako, M. 1992: Contracts, Prices and Trust: How the Japanese Manage Their Subcontracting Relationships. Oxford, Oxford University Press.

Sankar, Y. 1991: Management of Technological Change. New York, John Wiley and Sons.

Saviotti, P.P.; Metcalfe, J.S. (eds.) 1991: Evolutionary Theories of Economic and Technological Change. Reading, Harwood Academic Publishers.

Scherer, F.M. 1982: 'Demand-Pull and Technological Invention: Schmookler Revisited', Journal of Industrial Economics, Vol. 30, No. 3, pp. 225-237.

Scherer, F.M. 1984: Innovation and Growth: Schumpeterian Perspectives. Cambridge, MA., MIT Press. 
Scherer, F.M.; Perlman, M. (ed.) 1992: Entrepreneurship, Technological Innovation and Economic Growth: Studies in the Schumpterian Tradition. Ann Arbor, University of Michigan Press.

Schmookler, J. 1966: Invention and Economic Growth. Cambridge, Harvard University Press.

Schumpeter, J.A. 1942: Capitalism, Socialism and Democracy. New York, Harper Row.

Scobie, G.M.; Jacobsen, V. 1994: The Returns to Investment by WRONZ in R\&D for the New Zealand Wool Industry. A Report Prepared for the Wool Research Organisation of New Zealand. Hamilton, SER.

Scotchmer, S. 1991: 'Standing on the Shoulders of Giants: Cumulative Research and the Patent Law', Journal of Economic Perspectives, Vol. 5, No. 1, pp. 29-41.

Senge, P. 1990: The Fifth Discipline. The Art and Practice of the Learning Organisation. London, Century Press.

Senker, J.; Faulkner, W. 1992: 'Industrial Use of Public Sector Research in Advanced Technologies: A Comparison of Biotechnology and Ceramics', R\&D Management, Vol. 22, No. 2, pp. 157-175.

Shane, S.A. 1990: Why do some societies invent more than others? Working Paper Series $8 / 90$. Wellington, VUW.

Shapin, S. 1994: A Social History of Truth: Civility and Science in SeventeenthCentury England. Chicago, University of Chicago Press.

Shaw, B. 1985: 'The Role of the Interaction between the User and the Manufacturer in Medical Equipment Innovation', R\&D Management, Vol. 15, No. 4, pp. 283-292. 
Silberston, A. (ed.) 1989: Technology and Economic Progress. Basingstoke, MacMillan Press.

Silverberg, G. 1987: 'Technical Progress, Capital Accumulation and Effective Demand: A Self-Organisation Model.' In: Batten, D.; Casti, J.; Johansson, B. (eds.) 1987: Economic Evolution and Structural Adjustment. Berlin, Springer-Verlag.

Silverberg, G.; Dosi, G.; Orsenigo, L. 1988: 'Innovation, Diversity and Diffusion: A Self-Organisation Model', The Economic Journal, Vol. 98, No. 2, pp. 1032-1053.

Simonton, D.K. 1988: Scientific Genius: A psychology of science. Cambridge, Cambridge University Press.

Slade, P.L. 1994: Technological change in the New Zealand sawmilling industry. Unpublished thesis presented in partial fulfilment of a $\mathrm{PhD}$. Palmerston North, Massey University.

Slaughter, S. 1993: 'Innovation and learning during implementation: a comparison of user and manufacturer innovations', Research Policy, Vol. 22, No. 1, pp. 81-96.

Smith, J.J.; McKeon, J.E.; Hoy, K.L.; Boysen, R.L.; Schecter, L. 1984: 'Lessons from 10 Case Studies in Innovation - 2', Research Management, Vol. 27, No. 6, pp. 12-17.

Smith, J.J.; McKeon, J.E.; Hoy, K.L.; Boysen, R.L. Shechter, L., Roberts, K.B 1984: 'Lessons from 10 Case Studies in Innovation - 1', Research Management, Vol. 27, No. 5, pp. 23-27.

Solow, R.M. 1957: 'Technical Change and the Aggregate Production Function', Review of Economics and Statistics, Vol. XXX1X, August, pp. 312-320. 
SPRU 1972: Success and Failure in Industrial Innovation. London, Centre for the Study of Industrial Innovation.

Starbuck, W.H. 1996: 'Unlearning ineffective or obsolete technologies', International Journal of Technology Management, Vol. 11, Nos. 7/8, pp. 725-737.

Steele, L.W. 1989: Managing Technology: The Strategic View. New York, McGraw-Hill.

Stern, B.T. (ed.) 1982: Information and Innovation. Amsterdam, North-Holland.

Stevenson, P. 1992: 'The Royal Gala story', Orchardist, March, pp. 22-28.

Stewart, A. 1991: 'A Prospectus on the Anthropology of Entrepreneurship', Entrepreneurship, Theory and Practice, Winter, pp. 71-91.

Stiglitz, J.E. 1987a: 'Learning to learn, localised learning and technological progress.' In: Dasgupta, P.; Stoneman, P. 1987 (eds.): Economic Policy and Technological Performance. Cambridge, Cambridge University Press. pp. 125-153.

Stiglitz, J.E. 1987b: 'Technological Change, Sunk Costs, and Competition', Brookings Papers on Economic Activity, Vol. 3, pp. 883-937.

Stiglitz, J.E. 1994: 'Economic Growth Revisited.' Industrial and Corporate Change, Vol. 3, No. 1, pp. 65-110.

Strauss, A.; Corbin, J. 1990: Basics of Qualitative Research. Sage Publications, London.

Stuart, G.F. 1980: Technology and Innovation in the New Zealand Manufacturing Industry. Empirical Studies. Resource Paper No. 1. Lower Hutt, Physics and Engineering Laboratory, DSIR. 
Stuart, G.F.; McCulloch, D.G. 1980: Technology and Innovation in the New Zealand Manufacturing Industry: A Discussion Paper. Lower Hutt, Physics and Engineering Laboratory, DSIR.

Swan, P.L. (ed.) 1992: New Technology and the Firm. London, Routledge.

Tait, A.M. 1989: Electronics Engineers as Entrepreneurs. Keynote Address to National Electronics Conference, Wellington, 19 September.

Takeuchi, H.; Nonaka, I. 1986: 'The new product development game', Harvard Business Review, January-February, pp. 137-145.

Talking Fruit and Trees 1991: 'Think Pink and Bite', Talking Fruit and Trees, Autumn, Issue No. 2, p. 1.

Tapon, F. 1989: 'A Transaction Costs Analysis of Innovations in the Organisation of Pharmaceutical R\&D', Journal of Economic Behaviour and Organisation, Vol. 12, No. 2, pp. 197-213.

Tassey, G. 1991: 'The functions of technology infrastructure in a competitive economy', Research Policy, Vol. 20, No. 4, pp. 345-361.

Taylor, F. 1947: Scientific Management. New York, Harper and Brothers.

Teece, D.J. 1986: 'Profiting from technological innovation: Implications for integration, collaboration, licensing and public policy', Research Policy, Vol. 15, No. 6, pp. 285-305.

Teece, D.J. 1988: 'Technological Change and the Nature of the Firm.' In: Dosi, G.; Freeman, C.; Nelson, R.; Silverberg, G.; Soete, L. (eds.) 1988: Technical Change and Economic Theory. London, Pinter. pp. 256-281. 
Teece, D.J. 1993: 'The Dynamics of Industrial Capitalism: Perspectives on Alfred Chandler's Scale and Scope', Journal of Economic Literature, Vol. XXXI, No. 1, pp. 199-225.

Telarc 1989: Technical information relating to Wormald Vigilant application for a Design Mark for the FP4000. Auckland, Telarc.

Thomson, R. 1993: Learning and Technical Change. London, Macmillan.

Tushman, M.L.; Moore, W.L. (eds.) 1988: Readings in the Management of Innovation. 2nd ed. Cambridge, MA., Ballinger.

Twiss, B. 1980: Managing Technological Innovation. 1st ed. London, Longman.

Twiss, B. 1992: Managing Technological Innovation. 4th ed. London, Pitman.

Twiss, B.; Goodridge, M. 1989: Managing Technology for Competitive Advantage. London, Pitman.

Udwadia, F.E. 1990: 'Creativity and Innovation in Organisations: Two Models and Managerial Implications', Technological Forecasting and Social Change, Vol. 38, No. 1, pp. 65-80.

Underwood, G.W. 1971: Practical Fire Precautions. Barry, South Wales, Gower Press.

Utterback, J.M.; Abernathy, W. J. 1975: 'A Dynamic Model of Process and Product Innovation' Omega, Vol. 3, No. 6, pp. 639-655. 
Utterback, J.M.; Meyer, M.; Roberts, E.; Reitberger, G. 1988: 'Technology and industrial innovation in Sweden: A Study of Technology based Firms formed between 1965 and 1980', Research Policy, Vol. 17, No. 1, pp. 115-26.

Utterback, J. M.; Suarez, F.F. 1993: 'Innovation, competition and industry structure', Research Policy, Vol. 22, No. 1, pp. 1-22.

Van den ven, A.H. 1986: 'Central problems in the management of innovation', Management Science, Vol. 32, No. 5, pp. 590-607.

Van den ven, A.H.; Angle, H.L.; Poole, M.S. (eds.) 1989: Research on the Management of Innovation: The Minnesota Studies. New York, Harper and Row.

Veblen, T. 1921: The Engineers and the Price System. New York, Viking.

Vega Industries 1993: 'Vega XAB-17 Landfall Beacon.' Submission to 1993 ECNZ/Rutherford Awards. Wellington, Vega Industries.

Verspagen, B. 1992: 'Endogenous Innovation in Neo-Classical Growth Models: A Survey', Journal of Macro-Economics, Vol. 14, No. 4, pp. 631-662.

Vitkovskij, V.L. 1972: 'The prospects of cultivating cranberries, blueberries, cornelian cherries and other non-popular species', Works on Applied Botany, Genetics and Selection, Vol. 46, No. 2, pp. 225-275.

Von Hippel, E. 1982: 'Appropriability of innovation benefit as a predictor of the source of innovation', Research Policy, Vol. 11, No. 2, pp. 95-115.

Von Hippel, E. 1986: 'Lead Users: A Source of Novel Product Concepts', Management Science, Vol. 32, No. 7, pp. 791-805. 
Von Hippel, E. 1988: The Sources of Innovation. New York, Oxford University Press.

Wakasugi, R. 1992: 'Why are Japanese firms so innovative in engineering technology?', Technology Policy, Vol. 21, No. 1, pp. 1-12.

Walker, P. 1993: A Review of the Hydrolysis Research and Development Programme 1984-1991. Wellington, Protein Division, NZ Dairy Board.

Wallace, A. 1970: Culture and Personality. New York, Random House.

Wallace, D.; Hughes, J. 1995: Style Book: A Guide for New Zealand Writers and Editors. Wellington, GP Publications.

Wallmark, J.T.; McQueen, D.H. 1991: 'One Hundred Major Swedish technical innovations 1945-1980', Research Policy, Vol. 20, No. 4, pp. 325-344.

Watson, J. 1984: Crisis and change: Economic Crisis and Technological Change between the World Wars, with special reference to Christchurch 1926-1936. Unpublished PhD thesis in History. Christchurch, University of Canterbury.

Weeds, B. 1993: 'Dairy Board operational structure', Dairy Exporter, June, pp. 7071.

Wheeler, C. 1988: 'NZ electronics better bet than US hydraulics in sawmill', Automation and Control, July, pp. 17-18.

White M.; Braczyk, H.J., Ghobanian, A.; Niebuhr, J. 1988: Small Firms' Innovation: Why Regions Differ. London, Policy Studies Institute. 
Wickham, G. 1990: 'Developments in mechanical boning and cutting.' In: Proceedings of the 26th Meat Industry Research Conference. Hamilton, MIRINZ. pp. 232-237.

Wickham, G. 1992: 'An overview of boning machinery developments.' In: Proceedings of the 27th Meat Industry Research Conference. Hamilton, MIRINZ pp. 317-321.

Williamson, O.E. 1975: Markets and Hierarchies: Analysis and Anti-Trust Implications. New York, Free Press.

Williamson, O.E. 1985: The Economic Institutions of Capitalism. New York, Free Press.

Wilton, J. 1994: 'The variety dilemma', The Orchardist, December, pp. 17-19.

Winsley, P.H. 1991: A Technology Policy Framework for New Zealand. Wellington, Foundation for Research, Science and Technology.

Withy, L.M.; Lodge, N. 1982: 'Kiwifruit wine: production and evaluation', American Journal of Enology and Viticulture, Vol. 33, No. 4, pp. 191-193.

Wolcott, H.F. 1990: Writing up Qualitative Research. Qualitative Research Methods Vol. 20. London, Sage Publications.

Woolford, M.W.; Phillips, D.S.M.; Copeman, P.J.A. 1982: 'New Concepts in Milking Management and Milking Machines.' In: Proceedings of the Ruakura Farmers' Conference, Hamilton. pp. 97-101. 
Woolford, M.W.; Sherlock, R.A. 1985: A Method and Means for the Machine Milking of Animals. Patent Provision Specification. Lower Hutt, Patents Office.

Woolford, M.W.; Sherlock, R.A. 1987: 'Milking Machine Developments: The Next Advance.' In: Proceedings of the Ruakura Farmers' Conference, Hamilton. pp. 57-61.

Wool Report 1991: 'Fine fabrics from carpet wools.' Wool Report, December, p. 15.

Wool Report 1993: 'Ferry a first for Treotek order', Wool Report, September, p. 14.

Wozniak, G.D. 1987: 'Human Capital, Information, and the Early Adoption of New Technology', Journal of Human Resources, Vol. 22, No. 1, pp. 101-112.

Wratt, G.S.; Smith, H.C. (eds.) 1983: Plant Breeding in New Zealand. Wellington, Butterworths.

Wright, D.E. 1990: 'Who pays for research? - the effects on MIRINZ.' In: Proceedings of the 26th Meat Industry Research Conference. Hamilton, MIRINZ. pp. 179-182.

WRONZ 1986: WRONZ Anmual Report 1985/86. Lincoln, WRONZ.

WRONZ 1987: WRONZ Anmual Report 1986/87. Lincoln, WRONZ.

WRONZ 1991: WRONZ Anmual Report 1990/91. Lincoln, WRONZ.

WRONZ 1993: WRONZ Anmual Report 1992/93. Lincoln, WRONZ.

Yin, R.K. 1989: Case Study Research: Design and Methods. Applied Social Research Methods Series 5. Beverly Hills, CA, Sage Publications. 
Zand, D.E. 1972: 'Trust and managerial problem solving', Administrative Science Quarterly, Vol. 17, No. 2, pp. 229-239.

Zirger, B.J.; Maidique, M. 1990: ‘A model of new product development: An empirical test', Management Science, Vol. 36, No. 7, pp. 867-883.

Zukovskij, P.M. 1950: Cultivated plants and their wild relatives. Abridged translation by P.S. Hudson of a publication of the Ministry of Higher Education. USSR State Publishing House, Soviet Science, Moscow. Commonwealth Agricultural Bureaux. 